\title{
Determinants of energy and substrate metabolism
}

Citation for published version (APA):

Schrauwen, P. (1998). Determinants of energy and substrate metabolism. [Doctoral Thesis, Maastricht University]. Shaker Publishing. https://doi.org/10.26481/dis.19981112ps

Document status and date:

Published: 01/01/1998

DOI:

10.26481/dis.19981112ps

Document Version:

Publisher's PDF, also known as Version of record

\section{Please check the document version of this publication:}

- A submitted manuscript is the version of the article upon submission and before peer-review. There can be important differences between the submitted version and the official published version of record.

People interested in the research are advised to contact the author for the final version of the publication, or visit the DOI to the publisher's website.

- The final author version and the galley proof are versions of the publication after peer review.

- The final published version features the final layout of the paper including the volume, issue and page numbers.

Link to publication

\footnotetext{
General rights rights.

- You may freely distribute the URL identifying the publication in the public portal. please follow below link for the End User Agreement:

www.umlib.nl/taverne-license

Take down policy

If you believe that this document breaches copyright please contact us at:

repository@maastrichtuniversity.nl

providing details and we will investigate your claim.
}

Copyright and moral rights for the publications made accessible in the public portal are retained by the authors and/or other copyright owners and it is a condition of accessing publications that users recognise and abide by the legal requirements associated with these

- Users may download and print one copy of any publication from the public portal for the purpose of private study or research.

- You may not further distribute the material or use it for any profit-making activity or commercial gain

If the publication is distributed under the terms of Article $25 \mathrm{fa}$ of the Dutch Copyright Act, indicated by the "Taverne" license above, 
DETERMINANTS OF ENERGY AND SUBSTRATE METABOLISM 
Determinants of energy and substrate metabolism/ Patrick Schrauwen Proefschrift Maastricht - Met lit. opg. Met samenvatting in het Nederlands

Vormgeving: Patrick Schrauwen

Omslagidee: Patrick Schrauwen

Omslagrealisatie: Lars Borghouts

Copyright Shaker 1998

Alle rechten voorbehouden. Niels van deze uitgave matg worden verveelvoudigd, opgeslagen in een geautomatiseerd gegevensbestand, of openbaar gemaakt, in enige vorm, zonder schriftelijke toestemming van de uitgever.

ISBN 90-423-0051-5

Shaker Publishing B.V.

St. Maartenslaan 26

6221 AX Maastricht

tel.: 043-3500424

fax.: 043-3255090

http://www.shaker.nl

Printing of this thesis was financially supported by the Dr. Ir. J.H. van der Laar Foundation and by Novartis Nutrition Ltd., Bern, Switzerland 


\title{
DETERMINANTS OF ENERGY AND SUBSTRATE METABOLISM
}

\author{
PROEFSCHRIFT
}

ter verkrijging van de graad van doctor aan de Universiteit Maastricht, op gezag van de Rector Magnificus, Prof. dr. A.C. Nieuwenhuijzen Kruseman, volgens het besluit van het College van Decanen, in het openbaar te verdedigen op donderdag 12 november 1998 om 16.00 uur

door

\section{Patrick Schrauwen}

geboren te Hoogerheide op 4 april 1971 


\section{Promotores:}

Prof. dr. K.R. Westerterp (Katholieke Universiteit Leuven)

Prof. dr. ir. W.H.M. Saris

\section{Co-promotor:}

Dr. W.D. van Marken Lichtenbelt

\section{Beoordelingscommissie:}

Prof. dr. T.W.A. de Bruin (voorzitter)

Prof. dr. J.P. Flatl (University of Massachusetts, USA)

Prof. dr. J.P.M. Geraedts

Prof. dr. D. Halliday

Prof. dr. G.J. wan der Vusse 


\section{Contents}

Chapter 1 Introduction

Chapter 2 Energy balance in a respiration chamber: individual adjustment of energy intake to energy expenditure

Chapter 3 Changes in fat oxidation in response to a high-fat diet

Chapter 4 Role of glycogen-lowering exercise in the change of fat oxidation in response to a high-fat diet

Chapter 5 Fat balance in obese subjects: role of glycogen stores

Chapter 6 Validation of the $[1,2-13 \mathrm{C}]$-acetate recovery factor for correction of $\left[\mathrm{U}-{ }^{13} \mathrm{C}\right]$-palmitate oxidation rates

Chapter 7 The effect of high-fat diet on plasma-derived fatty acid oxidation

Chapter 8 Effect of diet composition on leptin concentration in lean subjects

Chapter 9 The role of uncoupling proteins in energy ballance

Chapter 10 Skeletal muscle UCP3 expression is a determinant of energy expenditure in Pima Indians

Chapter 11 Skeletal muscle UCP2 and UCP3 expression in trained and untrained male subjects

Chapter 12 General discussion

Summary

Samenvatting

Dankwoord

Abbreviations

Curriculum vitae 



\section{Chapter 1}

\section{Introduction}

Obesity is becoming a major health problem in affluent societies. The incidence of obesity is increasing rapidly. For example, in the United States the age-adjusted prevalence of a body mass index (BMI) $>30$ increased between 1960 and 1994 from $13 \%$ to $23 \%$ for people over 20 years of age. The overall prevalence of a BMI $>25$ was found to be $55 \%$ (16). This rapid increase in the prevalence of obesity is often ascribed to the changing lifestyle in westernized societies. In the last twenty years many food products came available which are cheap, palatable and high in fat content and dietary fat intake has increased rapidly. Dietary fat, however, is also the most energy dense macronutrient, with about $38 \mathrm{~kJ} / \mathrm{g}$, whereas carbohydrate and protein only provide about $17 \mathrm{~kJ} / \mathrm{g}$. Therefore, an increase in dietary fat intake can easily promote an increase in energy intake and thus result in overconsumption. Furthermore, a diminished capacity to oxidize fats when compared to carbohydrate and protein has been suggested (5), which would enhance the effect of high-fat diets on the prevalence of obesity.

Together with the increase in dietary fat intake (and thus energy intake) a decrease in physical activity is observed in westernized societies. Occupational work has been automated and this is not compensated by an increase in physical activity during leisure time. Therefore, energy expenditure will be lower and thus a positive energy balance is likely to occur, even when energy intake does not change.

Although these environmental factors promote the development of obesity, there is still large individual variability in the effect of environmental factors on the development of obesity, i.e. some individuals are more susceptible to become obese than others. Indeed, adoption and twin studies show the impact of the interaction between environmental and genetic factors on body composition (37). In the remainder of this introduction some envirommental and genetic determinants, which can play a role in the development of obesity, are discussed.

\section{The effect of dietary fat on fat oxidation: a two compartment model}

Weight maintenance requires that, on the long term, energy intake is equal to energy expenditure. This also requires a close match between intake and oxidation for the separate nutrients. Important work on this concept is done by Flatt $(13,12,14)$. He describes the features of body weight maintenance with a two compartment model (Figure 1.1). The small reservoir is representative for the carbohydrate stores in the human body, which can vary between 200 and 800 gram glycogen. The large reservoir represents the capacity of the human body to store fat, which is huge when 
compared to the glycogen stores. The relative size of the two reservoirs determines the composition of the fuel being oxidized. Expansion of one reservoir will lead to an increased influx from this reservoir and a greater contribution to the fuel mix oxidized. Addition of a fixed quantity (carbohydrates) to the small reservoir will lead to an increase in the contribution of carbohydrates to the fuel mix oxidized (rise in respiratory quotient (RQ)), whereas addition of an iso-energetic quantity (fat) to the large reservoir will only result in minor changes in the fuel mix oxidized. With this model, the effect of diet composition and physical activity on substrate metabolism can be predicted. Addition of fat to the diet, will not stimulate fat oxidation and, on the long-tern, fat mass will be expanded. When diet composition is iso-energetically switched from low-fat to high-fat, the model predicts that an expansion of the large reservoir (fat stores) or a decrease in the small reservoir (glycogen stores) is required to allow an increase in fat oxidation. Because it is unlikely that glycogen stores will voluntary be maintained in a lower range, an expansion of fat mass will occur when high fat diets are consumed. Thus the model gives a possible explanation for the suggested link between dietary fat and obesity observed in the western society. Physical activity might prevent the development of obesity when high-fat diets are consumed, by lowering glycogen stores.

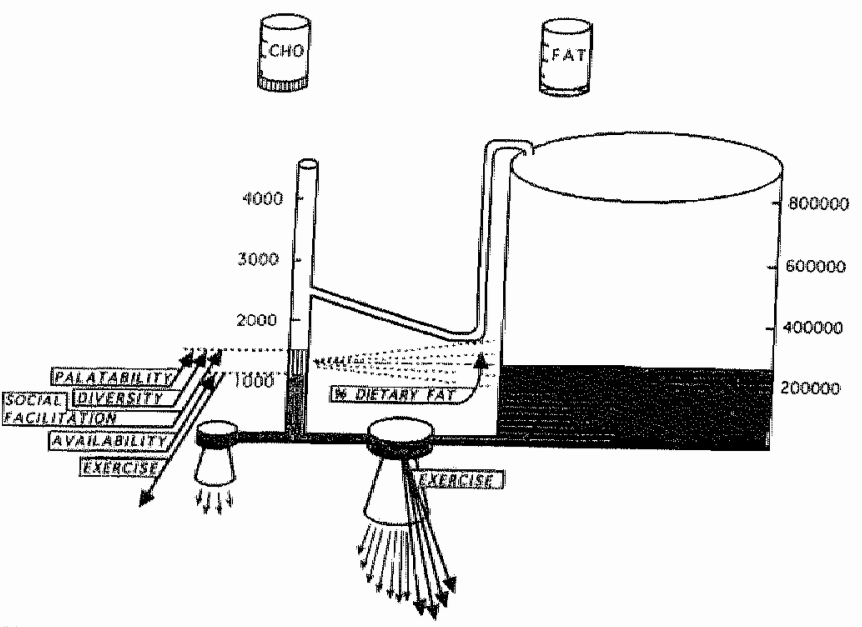

Figure 1.1 Two-compartment model.

\section{The effect of dietary fat intake on fat oxidation: a short literature review}

Numerous studies have examined the effect of diet composition on substrate oxidation. Two approaches have been used: the effect of fat supplements in excess of energy requirements, or the effect of iso-energetic high-and low-fat diets, given in
energy balance.

The effect of fat stapplements on fat oxidation

Flatt et al. (15) investigated the effect of dietary fat on postprandial substrate utilization and nutrient balance in 7 young men, 1 hour before and 9 hour after the ingestion of three different breakfasts. Subjects were given low-fat breakfast (11 en\% 
fat), a low-fat breakfast with a 50 gram long-chain triglyceride supplement or a lowfat breakfast with a 40 gram medium-chain triglyceride supplement. As predicted by his model, substrate oxidation was not influenced by the surplus fat and a positive fat balance was reached. Simillar results were obtained by Bennett et al. (4). Adding 50 gram of fat to a standard breakfast did not increase fat oxidation during a $18 \mathrm{~h}$ period following the breakfast and therefore it was concluded that all surplus fat was stored. Schutz et al. (32) studied the effect of a dietary surplus fat on substrate oxidation in a respiration chamber over $60 \mathrm{~h}$ intervals. In the first $24 \mathrm{~h}$ subjects consumed a mixed diet (35 en\% fat) and were in energy balance and fat balance. Adding $106 \mathrm{~g}$ of fat to the diet on the next day did not change energy expenditure or substrate oxidation, leading to the conclusion that the total surplus fat was stored. Fat balance and energy balance were closely correlated. The effect of one week fat-overfeeding on $24 \mathrm{~h}$ substrate oxidation was studied by Dalloso et al. (11). They found that the fat overfeeding had no effect on fat oxidation and the surplus fat (50\% of normal energy intake) was stored. To study the influence of diet composition on the regulation of body weight, Thomas et all. (38) fed 11 lean and 10 obese ad libitum with low-fat and high-fat diets for 1 week. On day 7 on each diet, 24 h substrate oxidation was measured using a respiration chamber. Voluntary energy intake was higher on the high-fat diet compared to the low-fat diet. On day 7 on the low-fat diet, carbohydrate intake was positively related to carbohydrate oxidation, indicating that carbohydrate intake stimulated its own oxidation, and carbohydrate balance was reached. After 7 days on the high-fat diet, fat intake was related to fat oxidation, but only in the lean subjects. Furthermore, even the lean subjects were not able to stimulate fat oxidation to an extent sufficient to match fat intake, and a positive fat balance was reached.

These studies clearly show that, both on the short as well as on the long term, fat intake does not stimulate its own oxidation, when dietary fat is given in excess of energy requirements.

\section{The effect of iso-energetic high-and low-fat diets on fat oxidation}

Another approach to study the effect of diet composition on substrate metabolism is the comparison of iso-energetic high- and low-fat diets with energy contents equal to the individuals' energy requirements. Abott et al. (1) studied the acute effect of such high $(65 \mathrm{en} \%$ fat) and low-fat diets ( $20 \mathrm{en} \%$ fat) on $24 \mathrm{~h}$ substrate oxidation in Pima Indians. On the high-fat diet, $24 \mathrm{~h} \mathrm{RQ}$ was similar to food quotient (FQ) whereas on the low-fat diet RQ was significantly less than FQ. McNeill et al. (26) studied the long-term effects ( 6 days) of diet composition on fasting RQ in 11 healthy women. Fasting RQ was lower after a diet with normal composition (41 en $\%$ fat) compared to a high-carbohydrate diet ( $31 \mathrm{en} \%$ fat) and the difference in RQ was similar to the difference in FQ between the diets. Similarly, Hurni et al (22) studied the long-term (7 days) effects of low-fat ( $4 \mathrm{en} \%$ fat) and mixed-fat ( $37 \mathrm{en} \%$ fat) diets on substrate metabolism in lean subjects. Twenty-four hour RQ was lower on the low-fat diet compared to the high-fat diet. Hill et al (21) studied lean subjects after 3 and 7 days on high-fat ( $60 \mathrm{en} \%)$ and low-fat (20 en\%) diets. On day 3, RQ was shifted in the direction of FQ on both diets, and no further changes in RQ between day 3 and day 7 were observed. 
Several studies were performed to study the effect of diet composition on substrate metabolism in groups with different susceptibility to obesity. Lean et al. (23) studied the acute effect of iso-energetic low-fat ( $3 \mathrm{en} \%$ fat) and high-fat (40 en\%) diets on $24 \mathrm{~h}$ substrate oxidation in lean, obese and post-obese women. The lean and obese women responded to the high-fat diet by increasing fat oxidation, whereas in the post-obese women the increase in fat oxidation in response to the high-fat diet was blunted. This might indicate a diminished capacity for fat oxidation in pre- or postobese subjects. Similar results were obtained by Astrup et al. (2). They studied whether subjects with a predisposition to obesity (post-obese) respond differently to changes in dietary composition compared to controls. Subjects consumed a low-fat (20 en\% fat) or high-fat ( $50 \mathrm{en} \%$ fat) for 3 days at home and subsequently for $24 \mathrm{~h}$ in a respiration chamber. In the lean subjects the high-fat diet stimulated fat oxidation and substrate balance was reached. However, the post-obese subjects were not able to stimulate their fat oxidation sufficiently to match fat intake. Verboeket-van de Venne et al. (39) studied the effect of 3 days low-fat (10 en\% fat), medium-fat ( 30 en\% fat) or high-fat ( $50 \mathrm{en} \%$ fat) diets on $24 \mathrm{~h}$ substrate oxidation in restrained and unrestrained eaters. On the low-fat and medium-fat diets RQ was lower than FQ, whereas on the high-fat diet RQ was equal to FQ. However, the restrained eaters, who are considered to have higher susceptibility to become obese, responded with a smaller increase in fat oxidation on the high-fat diet than the unrestrained eaters.

Table 1 Food quotient (FQ) and respiratory quotient (RQ) in iso-energetic high- and low-fat diets

\begin{tabular}{|c|c|c|c|c|c|c|}
\hline study & subjects & $\%$ fat & $\begin{array}{c}\text { duration } \\
\text { (days) }\end{array}$ & $\mathrm{FQ}$ & $\mathrm{RQ}$ & $\mathrm{RQ}$ minus $\mathrm{FQ}$ \\
\hline \multirow[t]{2}{*}{ Mcneil et al., 1988} & \multirow[t]{2}{*}{ lean/obese } & 31 & 6 & 0.88 & $0.85 \pm 0.03$ & -0.03 \\
\hline & & 41 & 6 & 0.85 & $0.82 \pm 0.03$ & -0.03 \\
\hline \multirow[t]{2}{*}{ Abbot et al., 1990} & \multirow[t]{2}{*}{ Pima Indians } & 20 & 1 & 0.91 & $0.88 \pm 0.01$ & -0.03 \\
\hline & & 42 & 1 & 0.83 & $0.84 \pm 0.01$ & 0.01 \\
\hline \multirow[t]{2}{*}{ Hurni et al., 1982} & \multirow[t]{2}{*}{ lean } & 4 & 7 & 0.95 & $0.88 \pm 0.01$ & -0.07 \\
\hline & & 37 & 7 & 0.85 & $0.80 \pm 0.01$ & -0.05 \\
\hline \multirow[t]{2}{*}{ Hiil et al., 1991} & \multirow[t]{2}{*}{ lean } & 20 & 7 & 0.92 & $0.86 \pm 0.01$ & -0.06 \\
\hline & & 60 & 7 & 0.77 & $0.75 \pm 0.01$ & -0.02 \\
\hline \multirow[t]{6}{*}{ Lean et all., 1988} & \multirow[t]{2}{*}{ leam } & 3 & 1 & 0.96 & $0.87 \pm 0.01$ & -0.09 \\
\hline & & 40 & 1 & 0.85 & $0.82 \pm 0.01$ & -0.03 \\
\hline & \multirow[t]{2}{*}{ obese } & 3 & 1 & 0.96 & $0.87 \pm 0.01$ & -0.09 \\
\hline & & 40 & 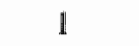 & 0.85 & $0.82 \pm 0.01$ & -0.03 \\
\hline & \multirow[t]{2}{*}{ postobese } & 3 & 1 & 0.96 & $0.89 \pm 0.01$ & -0.07 \\
\hline & & 40 & 1 & 0.85 & $0.85 \pm 0.01$ & 0.00 \\
\hline \multirow{4}{*}{ Verboeket et all, 1994} & unrestrained & 10 & 3 & 0.94 & $0.90 \pm 0.01$ & -0.04 \\
\hline & \multirow{3}{*}{ restrained } & 50 & 3 & 0.82 & $0.82 \pm 0.00$ & 0.00 \\
\hline & & 10 & 3 & 0.94 & $0.91 \pm 0.00$ & -0.03 \\
\hline & & 50 & 3 & 0.82 & $0.83 \pm 0.00$ & 0.01 \\
\hline
\end{tabular}


The results from these studies (Table 1.1) all indicate that iso-energetic high- and lowfat diets influence substrate oxidation, with RQ shifting in the direction of FQ. Furthermore the results suggest that a diminished fat oxidation capacity might be a predictor for the development of obesity.

\section{Genetic determinants of obesity}

High-fat, energy-dense diets and physical activity are considered as the most important environmental factors being involved in the increase in the prevalence of obesity. However, there is substantial interaction between environmental and genetic determinants, as was shown by Ravussin et al (31). They studied two populations with similar genetic background (Pima Indians) living in different environments. The Pima Indians who live in Mexico have a traditional lifestyle, with high levels of physical activity and carbohydrate rich diets. The mean body mass index of these Mexican Pima Indians is 7-10 units below the mean BMI of the Pima Indians living in the United States, who have a westernized lifestyle. Within the population of the American Pimas a high resting RQ was shown to be a predictor of future weight gain and RQ was shown to be a familial trait (44). These results indicate that the mean body composition of a population is determined by environmental factors and that genetic determinants account for the variability in body composition between individuals. Estimates of the heritability of body composition suggest that 40 to 70 percent of the variation in body composition is heritable(36). In animals, several single-gene mutations have been shown to be associated with obesity, but in humans such single-gene mutations do not explain the high prevalence of obesity. In recent years, the discovery of two previously unknown genes, the ob-gene, encoding for the adipositas hormone leptin, and the UCP2 and UCP3 genes, encoding for uncoupling proteins, renewed the interest for the genetic determinants of obesity. Leptin is thought to be involved in the regulation of food intake and to be a negative feedback hormone, controlling the size of the fat mass. Uncoupling proteins on the other hand, dissipate energy as heat and might thus be involved in the regulation of energy expenditure. Both genes thus may be involved in the development of obesity. Here we will discuss some aspects of leptin and UCPs and their involvement in obesity.

\section{Leptin}

The ob-gene was discovered in 1994 by Zhang et al. (43). The ob-gene encodes for the ob-protein, called leptin after the Greek leptos which means thin. Leptin is secreted by the adipose tissue and has, after interplay with its receptors, an effect on food intake and energy expenditure. A mutation in the ob gene of the ob/ob mice is responsible for the absence of leptin, the product of the ob-gene, resulting in obesity in these mice. Administration of recombinant leptin to the ob/ob mice results in a decrease in food intake, increase in energy expenditure and a loss of body weight $(20,29)$. In another obesity prone strain of mice, $\mathrm{db} / \mathrm{db}$ mice, leptin is overexpressed and administration of leptin does not result in change in body weight. It was shown that these mice thave a mutation in the gene encoding for the leptin receptor, resulting in an ineffective receptor for the ob-protein (9). In humans, so far only three families 
have been identified which have functional mutations in the gene encoding for leptin or the leptin receptor. In two severely obese children, a homozygous mutation in the leptin gene resulted in extreme low leptin levels (27). Similarly, in three obese members of a Turkish family a homozygous missense mutation was associated with low leptin levels (35). Finally, a homozygous mutation in the human leptin receptor gene resulted in early-onset morbid obesity and no pubertal development (10). Although these mutations indicate that leptin, and its receptor may play a role in human obesity it is not likely that single-gene mutations will explain a substantial part of the prevallence of obesity. Therefore research has focused mainly on the normal physiological regulation of leptin concentrations. Increasing evidence suggests that leptin exerts its effect through the hypothalamus. The synthesis of hypothalamic neuropeptide Y (NPY), a potent stimulator of food intake, is inhibited by leptin (34). Evidence is also accumulating for an effect of leptin on lipid metabolism. In cell cultures, leptin directly inhibits intracellular lipid concentrations by reducing fattyacid and triglyceride synthesis and increases lipid oxidation (33), possibly by an inhibiting effect of leptin on acetyl-coA carboxylase activity (3). Recently, Wang et al. (41) showed that hyperlipidemia and hyperglycemia resulted in increased leptin expression in white adipose tissue and, interestingly, also in skeletal muscle. This finding might unveil an important link between increased nutrient availability and leptin expression. However, most of the variability in leptin expression is explained by the size of the adipose tissue stores. In obese humans, leptin levels are elevated in close relation to the body fat mass, eliminating a causal role for (low) leptin levels on obesity. However, interesting is the finding that in Pima Indians low leptin levels predispose to future weight gain (30).

\section{Uncoupling proteins}

In brown adipose tissue (BAT) an uncoupling protein, UCP1, is responsible for the thermogenic effect of this tissue (28). Uncoupling proteins increase inner mitochondrial membrane conductance and uncouple oxygen consumption from ATP production, thereby dissipating energy as heat. However, brown adipose tissue is limited in adult humans, and therefore the role of uncoupling proteins in human obesity has long been controversial (24). In 1997 Fleury et al. (17) and Gimeno et al. (18) cloned a homologue of UCP1, called UCP2. Interestingly, UCP2 has a wide tissue distribution and is most abundant in white adipose tissue and skeletal muscle. UCP2 was found to have uncoupling activity and might therefore play a role in regulation of energy expenditure in humans. Later, Boss et al. (7) identified a homologue of UCP2, called UCP3. In contrast to UCP2, UCP3 is only present in BAT and skeletal muscle, and was also shown to have uncoupling activity. Both UCP2 and UCP3 genes are located on chromosome 11q13, a region which was linked to sleeping metabolic rate (8) and weakly to obesity (40) in humans. No mutations, resulting in absence or inactive UCPs have been reported yet. Some support for a role of these UCPs in obesity comes from functional studies. In rodents, it was shown that UCP2 and UCP 3 are regulated by thyroid hormone (19), fasting (6) and glucocorticoids (19), UCP2 (17) and UCP3 (25), due to an effect of FFA on UCP2 and UCP3 expression
(42). Therefore UCPS might play a role in diet-induced obesity, and high expression 
of UCPs would be beneficial in preventing obesity. In humans, until now, the data on the expression of these novel uncoupling proteins in humans is limited.

\section{Outline of the thesis}

Some of the conflicting results in studies on the effect of diet composition on subsequent substrate oxidation is accounted for by methodological problems. An important prerequisite to demonstrate the effect of dietary fat on subsequent substrate oxidation is energy balance. It has repeatedly been shown that fat balance and energy balance are closely related. A surplus of dietary energy will completely be stored as fat, whereas an energy deficit is compensated for by an increase in fat oxidation. In chapter 2 we tested a study protocol in which energy intake is individually adjusted to energy expenditure to reach energy ballance while subjects stay in a respiration chamber.

Previous studies on the effect of diet composition on substrate oxidation studied either short-term ( $\leq 1$ day) or long-term ( 2 days - 1 week) effects. Suggestions have been made that predisposed and/or obese subjects have a diminished capacity to increase fat oxidation when consuming a high-fat diet. However, no data is available on the time course of changes in fat oxidation in response to a change in dietary fat content in lean subjects. A diminished capacity to increase fat oxidation to fat intake on a high fat diet in predisposed or obese subjects can only be unevokely be proven at a point in time when the adjustment of fat oxidation to fat intake is complete in normal-weight subjects. Measurement of substrate oxidation on other time points might lead to erroneous conclusions. In chapter 3 , the study protocol as described in chapter 2 is used to study the time course of changes in fat oxidation in response to a change in dietary fat content, when lean subjects were fed in energy balance.

According to the two compartment model of Flatt, fat oxidation can be raised in response to a higher dietary fat content by expansion of the fat mass (long term) or by reducing glycogen stores (short term). In chapter 4 we investigated the role of the glycogen stores in the change of fat oxidation in response to a high-fat diet. Exercise was used as a means to reduce glycogen stores and substrate oxidation was measured for 24 hour using a respiration chamber. Because suggestions have been made that obese subjects have diminished fat oxidation this study was repeated in obese subjects, as is described in chapter 5 .

Using a respiration chamber to measure substrate oxidation provides information on whole body processes but does not provide detailed information on the underlying metabolic processes. Processes that might be involved in determining the change in fat oxidation in response to a high-fat diet include FFA availability, lypolysis, plasmaand muscle substrate oxidation. To examine the source of the fatty acid oxidized and the effect of diet composition on the latter, other techniques than indirect calorimetry are required. Infusion of labeled fatty acids in the blood and measurement of the label in breath $\mathrm{CO}_{2}$, can provide information about the oxidation of plasma fatty acids. In this way, whole-body fat oxidation can be divided into plasma-derived fat oxidation, 
VLDL and intramuscular triglyceride oxidation. In chapter 7 we examined whether the increase in whole-body fat oxidation on a high-fat diet can be explained by an increase in plasma-derived fat oxidation. Furthermore, we examined the effect of glycogen stores on $24 \mathrm{~h}$ substrate oxidation (respiration chamber) and plasma-derived fat oxidation. For a correct measurement of plasma-derived fat oxidation using labeled fatty acids, a correction for loss of label in the TCA cycle has to be applied, which can be achieved by determining the acetate correction factor. So far the information about this correction factor is limited. Therefore, we studied this correction factor in detail and determined the correct way to apply the factor for correction of plasma-derived fat oxidation (chapter 6).

In chapters 8 through 11 , the effect of the products of some previously unknown genes on energy and substrate metabolism is examined. The first, leptin, is thought to be a satiety signal, regulating food intake and the size of the fat mass. In chapter 8 we examined whether a high-fat diet, independent of changes in body fat mass, had an effect on leptin levels in humans. Uncoupling proteins, primarily have an effect on energy expenditure, by uncoupling oxygen consumption from ATP production and thus dissipating energy as heat. In chapter 9 the role of uncoupling proteins in human obesity is reviewed. In chapter 10 we investigated the relationship between UCP2 and $U C P 3$ expression in skeletal muscle and obesity/energy metabolism in nondiabetic Pima Indians, a racial group with known genetic predisposition to obesity. In chapter 11 the effect of endurance training on UCP2 and UCP3 expression in lean subjects is examined.

\section{References}

1. Abbott. W. G., Howard, B. V., Ruotolo, G, and Ravussin, E. Energy expenditure in humans: effects of dietary fat and carbohydrate. An J Physiol. 258: E347-351, 1990.

2. Astrup, A., Buemann, B., Christensen, N. J., and Toubro, S. Failure to increase lipid oxidation in response to increasing dietary fat content in formerly obese women. Am $J$ Pliysiol. 266: F592-599, 1994.

3. Bai, $Y$, Zhang, S., Kim, K. S., Lee, J. K., and Kim, K. H. Obese gene expression alters the ability of 30A5 preadipocytes to respond to lipogenic hormones. J Biol Chem. 271: 13939 . $13942,1996$.

4. Bennett, C., Reed, G. W., Peters, J. C., Abumrad, N. N., Sun, M., and Hill, J. O. Short-term effects of dietary-fat ingestion on energy expenditure and nutrient balance. Am I Clin Nutr.
$55: 107,-1077,1992$.

5. Blaak, E. E., Baak, M. A. v., Kemerink, G. J., Pakbiers, M. T. W., Heidendal, G. A. K., and Saris, W. H. M. B-Adrenergic stimulation of energy expenditure and forearm skeletal muscle
metabolism in lean and obese men. Am J Physiol. 267: E306-E315, 1994 .

6. Boss, O., Samec, S., Kithne, F., Bijlenga. P., Assimacopoulos-Jeannet, F., Seydoux, J., Giacobino, J.P., and Muzzin, P. Uncoupling protein-3 expression in rodent skeletal muscle 273: $5-8,1998$.

7. Boss, O., Samec, S., Paoloni-Giacobino, A., Rossier, C., Dulloo, A., Seydoux, J., Muzzin, P., and Giacobino, J. P. Uncoupling protein-3: a new member of the mitochondrial carrier
family with tissue-specific expression. FEBS let. $408: 39-42,1997$. 
8. Bouchard, C., Pérusse, L., Chagnon, Y. C., Warden, $G_{n}$ and Ricquier, D. Linkage between markers in the vicinity of the uncoupling protein 2 gene and resting metabolic rate in humans. Hum Mol Genet. 6: 1887-1889, 1997.

9. Chua, S. C., Cliung, W. K., Wu-Peng, X. S., Zhang, Y., Liu, S. M., Tartaglia, L., and Leibel, R. L. Phenotypes of mouse diabetes and rat faty due to mutations in the OB (leptin) receptor. Science. 271: 994-996, 1996.

10. Clément, K., Vaisse, C., Lahlou, N., Cabrol, S, Pelloux, V., Cassuto, D., Gourmelen, M., Dina, C., Chambaz, J., Lacorte., J. M. A mutation in the human leptin receptor gene causes obesity and pituitary dysfunction. Nature. 392: 398-401, 1998 .

11. Dallosso, H. M., and James, W. P. Whole-bady calorimetry studies in adult men. 1. The effect of fat over-feeding on 24 h energy expenditure. Br J Nutr. 52: 49-64, 1984.

12. Flatt, J. P. Dietary fat, carbohydrate balance, and weight maintenance: effects of exercise. Am J Clin Nutr. 45: 296-306, 1987.

13. Flat, J. P. The difference in the storage capacities for carbohydrate and for fat, and its implications in the regulation of body weight. Am N Y Acad Sci. 499: 104-23, 1987.

14. Flatt, J. P. Importance of nutrient balance in body weight regulation. Diabetes Metab Rev. 4 : $571-81,1988$.

15. Flatt, J. P., Ravussin, E., Acheson, K. J., and Jequier, E. Effects of dietary fat on postprandial substrate oxidation and on carbohydrate and fat balances. $J$ Clin Invest. 76: 1019-24, 1985.

16. Flegal, K. M., Carroll, M. D., Kuczmarski, R. J., and Johnson, C. L. Owerweight and obesity in the United States: prevallence and trends, 1960-1994. Int J Obesity. 22: 39-47. 1998.

17. Fleury, C., Neverova, M., Collins, S., Raimbault, S., Champigny, O., Levi-Meyrueis, C., Bouillaud, F., Seldin, M. F., Surwit, R. S., Ricquier, D. Uncoupling protein-2: a novel gene linked to obesity and hyperinsulinemia. Nature Genetics. 15:269-273, 1997.

18. Gimeno, R. E., Dembski, M., Weng, X., Deng, N., Shyjan, A. W., Gimeno, C. J., Iris, F., Ellis, S. J., Woolf, E. A., and Tartaglia, L. A. Cloning and characterization of an uncoupling protein homolog: a potential molecular mediator of human thermogenesis. Diabetes. 46 : 900-906, 1997.

19. Gong, D.-W., He, Y.. Karas, M., and Reitman, M. Uncoupling protein-3 is a mediator of thermogenesis regulated by thyroid hormone, B3-adrenergic agonists, and leptin. I Biol Chem. 272: 24129-24132, 1997.

20. Halaas, J. L., Gajiwala, K. S., Maffei, M., Cohen, S. L., Chait, B. T., Rabinowitz, D., Lullone, R. L., Burley. S. K., and Friedman, J. M. Weight-reducing effects of the plasma protein encoded by the obese gene. Science. 269: 543-546, 1995.

21. Hill, J. O., Peters, J. C., Reed, G. W., Schlundt, D. G., Sharp, T., and Greene, H. L. Nutricnt balance in humans: effects of diet composition. Am J Clin Nutr, 54: 10 17, 1991.

22. Hurni, M., Burnand, B., Pittet, P., and Jequier, E. Metabolic effects of a mixed and a highcarbohydrate low-fat diet in man, measured over $24 \mathrm{~h}$ in a respiration chamber. $B r J$ Natr. 47: $33-43,1982$.

23. Lean, M. E., and James, W. P. Metabolic effects of isoenergetic nutrient exchange over 24 hours in relation to obesity in women. Im J Obes. 12: 15-27, 1988.

24. Lean, M. E., James, W. P., Jennings, G., and Trayhurn, P. Brown adipose tissue uncoupling protein content in human infants, children and adults. Clin Sci. 71:291-297, 1986.

25. Matsuda, J., Hosoda, K. Itoh, H., Son, C., Doi, K., Tanaka, T., Fukunaga, Y., Inoue, G.,

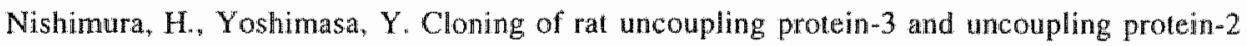
CDNAs: their gene expression in rats fed high-fat diet. FEBS lett. 418: 200-204, 1997. 
26. McNeill, G., Bruce, A. C., Ralph, A., and James, W. P. Inter-individual differences in fasting nutrient oxidation and the influence of diet composition. Im J Obesity. 12: 455-63, 1988.

27. Montague, C. T., Faroogi, I. S., Whitehead, J. P., Soos, M. A., Rau. H., Wareham, N. J., Sewter, C. P., Digby, J. E., Mohammed, S. N., Hurst, J. A. Congentinal leptin deficiency is associated with severe early-onset obesity in humans. Nature. 387: 903-908, 1997.

28. Nicholis, $D$, Bernson, $V$, and Heaton, $G$. The identification of the component in the inner membrane tesponsible for regulating energy dissipation. Effectors of thermogenesis. Basel, Birkhauser Verlag. 89-93, 1978

29. Pelleymounter, M. A., Cullen, M. J., Baker, M. B., Hecht, R., Winters, D., Boone, T., and Collins, F. Effects of the obese gene product on body weight regulation in $a b / o b$ mice. Science. 269: 540-543, 1995.

30. Ravussin, E., Pratley, R. E., Maffei, M., Wang, H., Friedman, J. M., Bennett, P. H., and Bogardus, C. Relatively low plasma leptin concentrations precede weight gain in Pima lndians. Nature Medicine. 3: 238-240, 1997.

31. Rawussin, E., Valencia, M. E., Esparza., J., Bennett, P. H., and Schuld, L. O. Effects of a traditional lifestyle on obesity in Pima Indians. Diabetes Care. 17: 1067-1074, 1994.

32. Schutz, Y., Flatt, I. P., and Jequier, E. Failure of dietary fat intake to promote fat oxidation: a factor favoring the development of obesity. Am I Clin Nutr. 50:307-14, 1989.

33. Shimabukuro, M., Koyama, K., Chen, G., and al., e. Direct antidiabetic effect of leptin through triglyceride depletion of tissues. Proc Natl Acad Sci. 94: 4637-4641, 1997.

34. Stephens, T. W., Basinski, M., Bristow, P. K., Bue-Valleskey, J, M., Burgett, S. G., Craft, L., Hale, J. Hoffmann, J., Hsiung. H. M., Kriauciunas, A. The role of neuropeptide $Y$ in the antiobesity action of the obese gene product. Nature. 377; 530-532, 1995.

35. Strobel, A., Issad, T., Camoin, L., Ozata ${ }^{*}$ M., and Strosberg, A. D. A leptin missense mutation associated with hypogonadism and morbid obesity. Nature Gexetics. 18: 213-215, 1998.

36. Stunkard, A. J., Harris, J. R., Pedersen, N. L., and McClearn, G. E. The body-mass index of twins who have been reared apart. $N$ Engl J Med. 322: 1483-7, 1990.

37. Stunkard, A. J., Sorensen, T. I. A., Hanis, C., Teasdale, T. W., Chakraborty, R., Schull, W. J., and Schulsinger, F. An adoption study of human obesity. $N$ Engl J Med. 314: 193-198. 1986.

38. Thomas, C. D., Peters, J. C., Reed, G. W., Abumrad, N. N., Sun, M., and Hill, J. O. Nutrient batance and energy expenditure during ad libitum feeding of high-fat and highcarbohydrate diets in humans. Am J Clin Nutr. 55: 934.942, 1992.

39. Verboeket-van de Venne, W. P. H. G., Westerterp, K. R., and ten Hoor, F. Substrate utilizution in man: effects of dietary fat and carbohydrate. Metabolism. 43: 152-156, 1994.

40. Walder, K., Norman, R. A., Hanson, R. L., Schrauwen, P., Neverova, M., Jenkinson, C. P., Easlick, J., Warden, C. H., Pecqueur, C., Raimbatult, S., Ricquier, D., Harper, M., Silver, K., Shuldiner, A.R., Solanes, G., Lowell, B. B., Chung, W. K., Leibel, R. L., Pratley, R., Ravussin, E. Association between uncoupling protein polymorphisms (UCP2 UCP3) and energy metabolism/obesity in Pima Indians. Hum Molecular Genetics. 7: 1431-1435, 1998.

41. Wang, J., Rong, L., Hawkins, M., Barzilai, N., and Rossetti, L. A nutrient-sensing pathway regulates leptin gene expression in muscle and fat. Nature. 393:684-688, 1998.

42. Weigle, D. S., Selfridge, L. E., Schwartz, M. W., Seeley, R. J., Cummings, D. E., Havel, P. J., Kuijper, J. L., and BertrandelRio, HI. Elevated free fatty acids induce uncoupling protein 3 expression in muscle. A potential explanation for the effect of fasting. Diabetes. 47: 298- 
43. Zhang, Y., Proenca, R., Maffei, M., Barone, M., Leopold, L., and Friedman, J. M. Posinional cloning of the mouse obese gene and its human homoloque. Nature. $372: 425-432,1994$.

44. Zurlo, F., Lillioja, S., Esposito, D. P. A., Nyomba, B. L., Raz, I., Saad, M. F., Swinburn, B. A., Knowler, W. C., Bogardus, C., and Ravussin, E. Low ratio of fal to carbohydrate oxidation as predictor of weight gain: study of 24-h RQ. Am J Physiol. 259: E650-E657, 1990. 


\title{
Energy balance in a respiration chamber: individual adjustment of energy intake to energy expenditure
}

\author{
Patrick Schrauwen, Wouter D van Marken Lichtenbelt and Klaas R Westerterp
}

Department of Human Biology, Maastricht University, Maastricht, The Netherlands

International Journal of Obesity, 21 (9): 769-774, 1997.

\begin{abstract}
In studies on substrate utilization, a state of energy balance is often required. Energy requirements are based on measured or calculated sleeping metabolic rate (SMR) or basal metabolic rate (BMR). A study was performed to compare this protocol with adjustment of energy intake (EI) to 24 hour energy expenditure (24hEE).

In part one, eight subjects spent one night and the subsequent 3 days in a respiration chamber. On day 1 EI was set at 1.5*SMR. On day 2 and 3 EI was set at 24 hE of day 1 . In part two of the study, an activity protocol was provided while staying in the chamber. Twelve subjects spent one night and the subsequent 2 days in the respiration chamber. On day 1 EI was set at $1.55^{*} \mathrm{SMR}$ and on day 2 EI was set at 24 h EE of day 1.

Sleeping metabolic rate, diet induced themogenesis, physical activity index and $24 \mathrm{~h}$ energy expenditure were measured using a respiration chamber.

Subjects: Eight healthy normal-weight females (age: $22 \pm 3$, BMI: $20.9 \pm 1.8$ ) in part one and twelve healthy normal-weight males and females (age: $26 \pm 2$, BMI: $21.4 \pm$ 0.5 ) in part two of the study.

Physical activity index $(\mathrm{PAI}=24 \mathrm{~h} \mathrm{EE} / \mathrm{SMR})$ on day 1 (part 1) was $1.55 \pm 0.04$, close to the predicted value of 1.5 , but between-subject variation was large (range: 1.39 1.68). Absolute deviation from energy balance reduced significantly from $1.35 \pm 0.30$ $\mathrm{MJ} /$ day on day 1 to $0.51 \pm 0.21$ and $0.31 \pm 0.10 \mathrm{MJ} /$ day on day 2 and 3 respectively $(\mathrm{p}<0.05)$. The latter can be considered as energy balance. With the activity protocol (part 2) absolute deviation from energy balance reduced significantly from $0.93 \pm$ $0.20 \mathrm{MJ} /$ day on day 1 to $0.27 \pm 0.11 \mathrm{MJ} /$ day on day $2(\mathrm{p}<0.05)$.

In conclusion, a 3-day stay in the chamber allows adjustment of energy intake to energy expenditure, in this way achieving energy balance. When prescribing an activity protocol the same results can be obtained within 2 days.
\end{abstract}




\section{Introduction}

Respiration chambers are an elegant tool for measuring whole body energy and substrate metabolism. They have frequently been used for studying the effect of treatments like exercise and diet composition on substrate utilization. "To provide conclusive results for substrate utilization a state of energy balance is necessary. A positive or negative energy balance has, on the short term, only a minor influence on energy expenditure. The only component of energy expenditure directly depending on energy intake is diet induced thermogenesis (DIT), which accounts for approximately $10 \%$ of daily energy expenditure. However, the effect of a positive or negative energy balance on substrate utilization is enormous. It has been shown that, for both protein and carbohydrate, oxidation is rapidly adjusted to intake (2). Fat oxidation, on the other hand is determined by the difference between energy expenditure and carbohydrate and protein oxidation. So under- or overfeeding is accompanied by increased and decreased fat oxidation respectively. Different attempts have been made to feed subjects at energy balance in a respiration chamber. Often energy requirements while staying in a respiration chamber have been based on the measured energy intake on a "weight maintenance diet" $(10,8)$ or a fixed percentage (normally $80 \%$ ) of this energy intake $(16,1,27)$, or ad libitum access to food modules after consumption of a fixed amount of food $(13,21)$. Also equations which predict twenty four hour energy expenditure (24h EE) have been used, based on anthropometric measurements $(2,22)$ or the relation between lean body mass and $24 \mathrm{~h} \mathrm{EE}(3,4,5)$. Furthermore, resting metabolic rate (RMR) or basal metabolic rate (BMR), both predicted (23), and measured $(14,12,26)$ multiplied by an activity factor has been used to determine energy requirements. However, these approaches often have resulted in negative or positive energy balances.

In weight stable subjects, body weight shows only a small age related increase. In such a situation, the difference between energy intake and expenditure is less than $0.2 \%$ (24). The difference between energy expenditure and energy intake would therefore be about $20-40 \mathrm{~kJ} / \mathrm{day}$. However, in studies on energy metabolism one has to deal with the accuracy of the methods used. Using a respiration chamber, energy expenditure can be measured with an accuracy of about $2 \%$ (11). Calculated energy intake, using food composition tables, has also an accuracy of about $2 \%$ (15). Together, the accuracy with which energy balance can be measured is within $4 \%$. Thus, assuming a subject to be in energy balance requires an difference between energy intake and expenditure of less than $4 \%$.

It has frequently been shown, that $24 \mathrm{~h} \mathrm{EE}$, as measured in a respiration chamber, is reproducible $(9,6,17,26)$. Therefore this $24 \mathrm{~h}$ EE can be used to estimate energy requirements. In part one of this study we used a 3-day protocol to measure energy requirements on day 1 and individually adjusted energy intake to energy expenditure on day 2 and 3 . In part two of this study we examined whether the results could be improved when subjects were given an activity protocol during their stay in the
respiration chamber. 


\section{Methods}

Subjecrs

Eight female volunteers participated in part one of the study. In part two of the study six female and six male volunteers participated. Subject characteristics for both part one and part two of the study are shown in table 2.1. All subjects were healthy and non-obese. The study was approved by the Ethical Committee of the Maastricht University and all subjects gave their written informed consent.

Table 2.1 Subjects characteristics

\begin{tabular}{lccccc}
\hline Subject & $\mathrm{n}$ & $\begin{array}{c}\text { Age } \\
\mathrm{y}\end{array}$ & $\begin{array}{c}\text { Height } \\
\mathrm{m}\end{array}$ & $\begin{array}{c}\text { Weight } \\
\mathrm{kg}\end{array}$ & $\begin{array}{c}\mathrm{BMI} \\
\mathrm{kg} / \mathrm{m}^{2}\end{array}$ \\
\hline part 1 & 8 & $21.5 \pm 1.1$ & $1.72 \pm 0.02$ & $61.8 \pm 2.0$ & $20.9 \pm 0.6$ \\
part 2 & 12 & $25.8 \pm 1.7$ & $1.77 \pm 0.03$ & $67.0 \pm 2.4$ & $21.4 \pm 0.5$ \\
\hline
\end{tabular}

Values are mean \pm s.e.m.

\section{Experimental design}

Part one

Subjects came to the laboratory on the evening of day 0 (20:00) and entered the respiration chamber for a three and a half day stay. Thus, on the morning of day 4 they left the respiration chamber at 8:00 am.

\section{Part two}

Subjects came to the laboratory on the evening of day $0(20: 00)$ and entered the respiration chamber for a five and a half day stay, as part of an experiment on long term substrate utilization. Thus, on the morning of day 6 they left the respiration chamber at 8:00 am. Here only data from day I and 2, where subjects consumed a low fat diet, is presented.

\section{Energy requirements and activity protocol}

\section{Part one}

Energy requirement on day 1 in the respiration chamber was set at 1.5 times sleeping metabolic rate (SMR) as measured during the first night. On day 2 and $3,24 \mathrm{~h} \mathrm{EE}$ of day 1 was used to individually adjust energy intake to energy expenditure.

In the respiration chamber, no activity protocol was provided.

\section{Part two}

Energy requirement on day 1 in the respiration chamber was set at 1.55 times SMR as measured during the first night. On day $2,24 \mathrm{~h} \mathrm{EE}$ of day 1 was used to individually adjust energy intake to energy expenditure. In the respiration chamber subjects followed an activity protocol consisting of fixed times for breakfast, lunch and dinner, sedentary activities and bench stepping exercise. The bench stepping exercise was performed for 30 minutes with intervals of 5 minutes exercise alternated with 5 minutes rest, at a rate of 60 steps per minute with a bench height of $33 \mathrm{~cm}$, and was repeated three times a day. Thus, subjects exercised for 45 minutes per day, at a relatively low-to-medium intensity. 
In both studies, no sleeping or other exercise than bench stepping in part two, was allowed at daytime during the stay in the respiration chamber. Spontaneous physical activity of the subjects was monitored by means of a radar system based on the Doppler principle.

\section{Diets}

All food was consumed as breakfast, lunch, dinner and 2 or more snacks per day. Diets consisted of $65 \%$ of energy as carbohydrate, $20 \%$ of energy as fat and $15 \%$ of energy as protein. Metabolizable energy intake and macronutrient composition of the diets were calculated using the Dutch food composition table (19). In the table metabolizable energy is calculated by multiplying the amount of protein, fat and carbohydrate with the Atwater factors (7).

\section{Indirect calorimetry and physical activity}

Oxygen consumption and carbon dioxide production was measured in a whole-room indirect calorimeter, which was described previously (18). The respiration chamber is a $14 \mathrm{~m}^{3}$ room furnished with a bed, chair, television, radio, telephone, intercom, wash bowl and toilet. The room is ventilated with fresh air at a rate of $70-80 \mathrm{l} / \mathrm{min}$. The ventilation rate was measured with a dry gas meter (Schlumberger, type G6, The Netherlands). The concentration of oxygen and carbon dioxide was measured using a paramagnetic $\mathrm{O}_{2}$ analyzer (Hartmann \& Braun, type Magnos G6, Germany) and an infrared $\mathrm{CO}_{2}$ analyzer (Hartmann \& Braun, type Uras $3 \mathrm{G}$, Germany). Ingoing air was analyzed every 15 minutes and outgoing air once every 5 minutes. The gas sample to be measured was selected by a computer that also stored and processed the data. Energy expenditure was calculated from $\mathrm{O}_{2}$ consumption and $\mathrm{CO}_{2}$ production according to the method of Weir (25).

24h EE was calculated from $8.00 \mathrm{~h}$ am to $8.00 \mathrm{~h}$ am. SMR was defined as the lowest mean energy expenditure during three subsequent hours between $0.00 \mathrm{~h}$ am and $8.00 \mathrm{~h}$ am. For calculation of the DIT, $24 \mathrm{~h} \mathrm{EE}$ was plotted against radar output over 30 minute intervals. Residuals of this relationship were plotted in time and area under curve was estimated as reported previously (20). DIT was calculated over a $24 \mathrm{~h}$ period and was defined as the area under curve divided by energy intake times $100 \%$, so DIT is presented as percentage of energy intake.

\section{Statistical analysis}

A one way analysis of repeated measures (ANOVA) was used to test differences in measured variables between days. Coefficient of variation was defined as standard deviation divided by the mean value multiplied by 100 . All data are presented as mean \pm s.e.m. and $\mathrm{p}<0.05$ was considered as statistical significant.

\section{Calculations}

Energy balance was determined as calculated energy intake minus measured energy expenditure. Furthermore (theoretical) energy balance was calculated assuming energy intake $=1.5 * B M R_{h \& b}$ and energy intake $=1.6 * B M R_{h \& b}$, where $B M R_{h \& b}$ is predicted BMR by the Harris and Benedict formulla for women: 
$\mathrm{BMR}_{\text {h⿱乛龰b }}(\mathrm{MJ} /$ day $)=2.74+0.774 \mathrm{H}+0.040 \mathrm{BM}-0.020 \mathrm{~A}$,

where $H$ is height in meters, BM is body mass in $\mathrm{kg}$ and $\mathrm{A}$ is age in years. This predicted energy balance was compared with real energy balance measured on day 1 (part one).

\section{Results}

Part I

$24 \mathrm{~h} E \mathrm{EE}$ was not significantly different between any of the days spent in the respiration chamber (table $2.2 \mathrm{a}$ ). Within-subject coefficient of variation was $3.7 \pm 1.0$ $\%$. Between-subjects coefficient of variation was $8.8,12.0$, and $7.1 \%$ for day 1,2 and 3 respectively. SMR was not significantly different between day 1,2 and 3 (table 2.2a). Within-subject coefficient of variation was $2.2 \pm 0.5 \%$. Between-subject coefficient of variation was $5.8,5.5$ and $5.4 \%$ for day 1,2 and 3 respectively.

Table 2.2a Energy expenditure, sleeping metabolic rate (SMR), physical activity (PAI), and diet induced thermogenesis (DIT) as measured in the respiration chamber

\begin{tabular}{ccccc}
\hline day & $\begin{array}{c}\text { Energy expenditure } \\
\text { MJ/day }\end{array}$ & $\begin{array}{c}\text { SMR } \\
\text { MJ/day }\end{array}$ & PAI\# & $\begin{array}{c}\text { DIT } \\
\text { \% of energy intake }\end{array}$ \\
\hline 1 & $9.56 \pm 0.30$ & $6.18 \pm 0.13$ & $1.55 \pm 0.04$ & $10.3 \pm 1.6$ \\
2 & $9.84 \pm 0.42$ & $6.19 \pm 0.12$ & $1.59 \pm 0.05$ & $10.2 \pm 0.9$ \\
3 & $9.36 \pm 0.23$ & $6.03 \pm 0.11$ & $1.55 \pm 0.04$ & $11.5 \pm 1.3$ \\
$\mathrm{CV} \%$ & $3.7 \pm 1.0$ & $2.2 \pm 0.5$ & $3.6 \pm 0.9$ & $20.7 \pm 5.0$ \\
\hline
\end{tabular}

Values are mean \pm s.e.m. $(n=8)$

\# physical activity index: $24 \mathrm{~h}$ energy expenditure/sleeping metabolic rate

There was no significant difference in physical activity index ( $\mathrm{PAI}=24 \mathrm{~h} \mathrm{EE} / \mathrm{SMR})$ between measurement days. Within-subject coefficient of variation was $3.6 \pm 0.9 \%$. Between subjects coefficient of variation was $6.5,9.2$ and $6.8 \%$ for day 1,2 and 3 respectively.

DIT was not significant different between any of the days spent in the respiration chamber. Within-subject coefficient of variation was $20.7 \pm 5.0 \%$ and between subject coefficient of variation was $44.0,25.0$ and $32.1 \%$ for day 1,2 and 3 respectively.

Absolute deviation from energy balance on day 1, when energy requirements were fixed at $1.5 * \mathrm{SMR}$, was $1.35 \pm 0.30$ (range $0.26-2.32$ ) $\mathrm{MJ} /$ day. Using the Harris and Benedict formula, we calculated BMR, which was not significantly different from measured SMR. Estimating energy requirements using this BMR, multiplied with an activity factor of 1.5 would have resulted in an absolute deviation from energy balance of $0.81 \pm 0.24$ (range $0.22-2.29$ ) $\mathrm{MJ} /$ day. For an activity factor of 1.6 this figure would have been $0.71 \pm 0.27$ (range 0.12-1.97) $\mathrm{MJ} /$ day. Minimal average absolute deviation from energy balance was reached with an activity factor of 1.58 : 
$0.67 \pm 0.27$ (range $0.02-1.84$ ) MJ/day. Using SMR yields even worse figures: With an activity factor of 1.73 a minimal absolute deviation from energy balance is reached of $0.86 \pm 0.17$ (range 0.01-1.65) $\mathrm{MJ} / \mathrm{day}$.

When energy intake was individually adjusted to real energy requirements on day 2 , absolute deviation from energy balance reduced significantly from $1.35 \pm 0.30$ (range $0.26-2.32$ ) $\mathrm{MJ} /$ day on day 1 to $0.51 \pm 0.21$ (range $0.05-1.68$ ) $\mathrm{MJ} /$ day on day 2 and $0.31 \pm 0.10$ (range $0.06-0.75$ ) MJ/day on day 3 (figure $2.1, p<0.05$ ). In the latter difference between energy intake and expenditure is within $4 \%$.

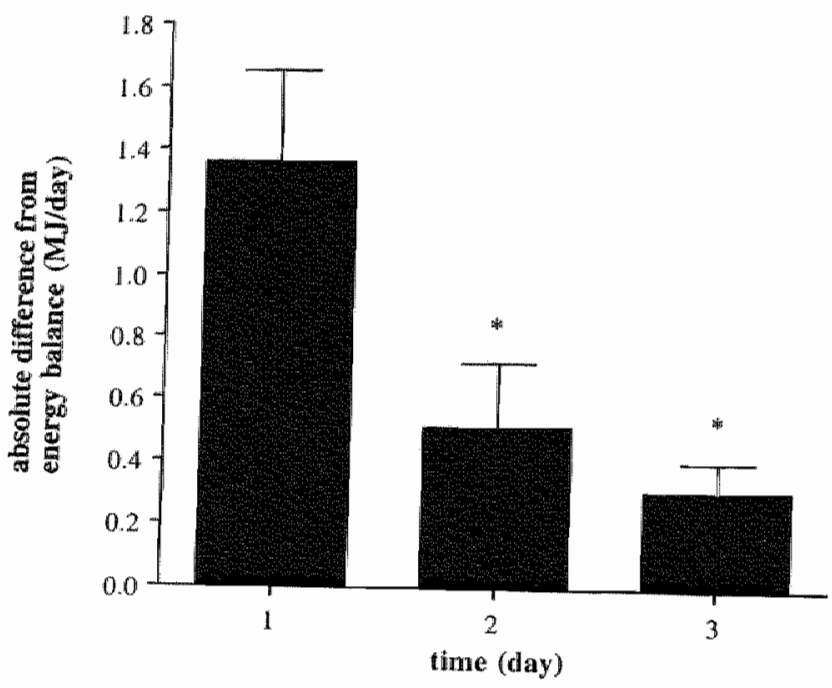

Figure 2.1 Absolute deviation from energy balance (MJ/d) as measured in a respiration chamber for day 1,2 and $3(n=8$, mean \pm s.e.m.).

$*=p<0.05$ compared to day 1

Part 2

$24 \mathrm{~h} \mathrm{EE}$ was not significantly different between day 1 and 2 (table $2.2 \mathrm{~b}$ ). Withinsubject coefficient of variation was $1.7 \pm 0.5 \%$. Between-subjects coefficient of variation was 11.6 and $13.3 \%$ for day 1 and 2 respectively. SMR was not significantly different between day 1 and 2 (table $2.2 \mathrm{~b}$ ). Within-subject coefficient of variation was $2.0 \pm 0.4 \%$. Between-subject coefficient of variation was 14.6 and $13.1 \%$ for day
1 and 2 respectively.

There was no significant difference in PAI between measurement days. Withinsubject coefficient of variation was $2.6 \pm 0.4 \%$. Between subjects coefficient of
variation was 7.2 and $5.8 \%$ for day 1 and 2 respectively.

DIT was not significant different between any of the days spent in the respiration chamber. Within-subject coefficient of variation was $24.6 \pm 5.7 \%$ and between subject coefficient of variation was 31.1 and $22.4 \%$ for day 1 and 2 respectively. 
Table 2.2b Energy expenditure, sleeping metabolic rate (SMR), physical activity index (PAI), and diet induced thermogenesis (DIT) as measured in the respiration chamber

\begin{tabular}{ccccc}
\hline day & $\begin{array}{c}\text { Energy expenditure } \\
\text { MJ/day }\end{array}$ & $\begin{array}{c}\text { SMR } \\
\text { MJ/day }\end{array}$ & PAI\# & $\begin{array}{c}\text { DIT } \\
\text { \% of energy intake }\end{array}$ \\
\hline 1 & $10.01 \pm 0.34$ & $6.30 \pm 0.27$ & $1.60 \pm 0.03$ & $11.9 \pm 1.1$ \\
2 & $10.08 \pm 0.39$ & $6.31 \pm 0.24$ & $1.60 \pm 0.03$ & $10.2 \pm 0.7$ \\
CV\% & $1.7 \pm 0.5$ & $2.0 \pm 0.4$ & $2.6 \pm 0.4$ & $24.6 \pm 5.7$ \\
\hline
\end{tabular}

Values are mean \pm s.e.m. $(n=12)$

\# physical activity index: $24 \mathrm{~h}$ energy expenditure/sleeping metabolic rate

Absolute deviation from energy balance on day 1, when energy requirements were determined using $1.55^{*} \mathrm{SMR}$, was $0.93 \pm 0.20$ (range 0.02-2.27) $\mathrm{MJ} / \mathrm{day}$. When energy intake was individually adjusted to real energy requirements on day 2 , absolute deviation from energy balance reduced to $0.27 \pm 0.11$ (range 0.01-1.40) $\mathrm{MJ} /$ day on day 2 (figure $2.2, \mathrm{p}<0.05$ ). In the latter difference between energy intake and expenditure is within $4 \%$.

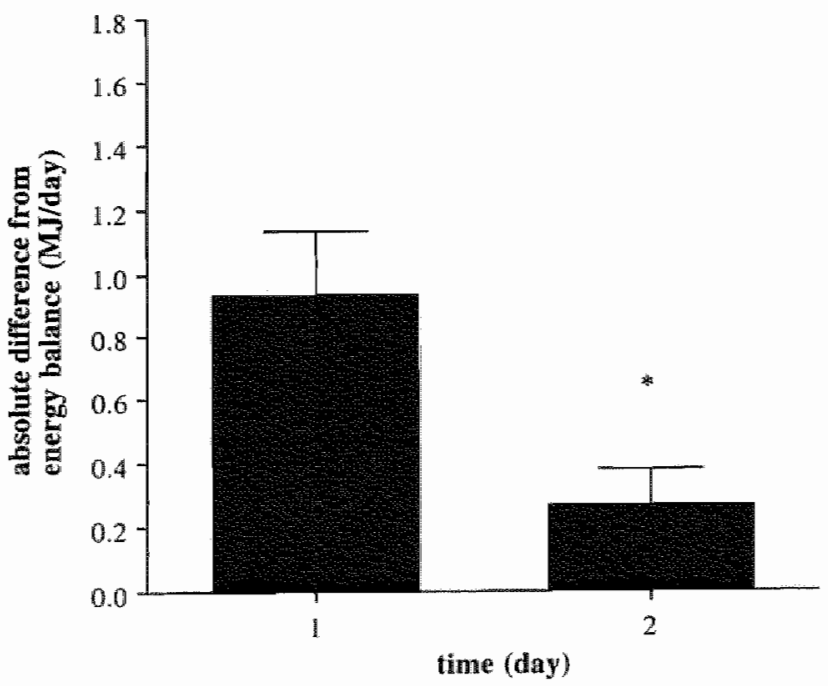

Figure 2.2 Absolute deviation from energy balance ( $\mathrm{MJ} / \mathrm{d})$ as measured in a respiration chamber for day 1 , and 2 , while subjects followed an activity protocol $(n=12$, mean \pm s.e.m.). $*=p<0.05$ compared to day 1

\section{Discussion}

This study shows that subjects can be fed in energy balance when energy intake is individually adjusted to energy expenditure. The small within subject coefficient of variation of energy expenditure makes such an adjustment possible. In our study absolute deviation from energy balance reduced from $1.3 \mathrm{MJ}$ on day 1 to $0.3 \mathrm{MJ}$ on day 3 . When prescribing an activity protocol energy balance can be further improved. 
Many efforts have been made to feed subjects in energy balance. Especially in studies regarding substrate oxidation, a state of energy balance is necessary. Both carbohydrate and protein oxidation is rapidly adjusted to intake (2). Fat oxidation is primarily determined by the gap between energy expenditure and carbohydrate and protein oxidation. In this way, a negative energy balance will lead to an increase in fat oxidation. It can be calculated that a negative energy balance of $1.3 \mathrm{MJ}$, as we found on day 1 of part 1 of this study, would result in a stimulation of fat oxidation by $35 \mathrm{gram} /$ day. When an average fat oxidation of about $100-150 \mathrm{~g} /$ day is considered the impact of such a negative energy balance can easily be seen. The same considerations can be made when a positive energy balance occurs. Therefore the importance of feeding subjects in energy balance is apparent.

In literature, different approaches to estimate energy requirements have been used. In most of these approaches, RMR or SMR is measured or estimated and multiplied with an activity factor $(14,12,23,26)$. However, in such a case an average activity factor for the group under study is assumed. There is, as we show in this study, a large between subject variation in physical activity level when staying in a respiration chamber. From our results it can be seen that using this approach a minimal absolute deviation from energy balance of approximately $0.7 \mathrm{MJ} /$ day can be obtained. However, when energy intake is individually adjusted to energy expenditure, account is taken for the between subject variation in physical activity level inside the chamber. This results in better absolute deviation of energy balance, with differences between energy intake and expenditure of less than $4 \%$. In part 1 of this study no activity protocol was provided while staying in the respiration chamber. Therefore individual adjustment of energy intake to expenditure should even be better when within subject variation in energy expenditure is reduced by means of an activity protocol. In part 2 of this study we found that energy balance improved from $0.93 \pm 0.20$ (range 0.02-2.27) $\mathrm{MJ} /$ day on day 1 to $0.27 \pm 0.11$ (range $0.03-1.40$ ) $\mathrm{MJ} /$ day on day 2 when subjects were restricted to an activity protocol. Therefore, from the results, the best approach to feed subjects in energy balance in a respiration seems to be an individual adjustment of energy intake to expenditure in combination with an activity protocol. Another approach to correct for the variability in energy expenditure is shown by Roy and Lovejoy (H. Roy \& J. Lovejoy - unpublished data). They determine freeliving energy expenditure, using activity monitoring and adjust the activity protocol while in the respiration chamber so that energy expenditure is closely related to freeliving energy expenditure. In this way, as in part two of the current study, the impact of variation in spontaneous activity on $24 \mathrm{~h} \mathrm{EE}$ is minimized. The approach resulted in near neutral energy balance $(0.33 \pm 0.08 \mathrm{MJ} /$ day, mean \pm s.e.m). This, and our study demonstrate the importance of individually adjusting energy intake or expenditure while staying in a respiration chamber.

The present study shows that $24 \mathrm{~h}$ EE, SMR and PAI are highly reproducible. The variation coefficients of $3.7,2.2$ and $3.6 \%$ are comparable with those found by others
$(17,22,26)$. 
In conclusion, the present study shows that individually adjusting energy intake to energy requirements results in perfect energy balance. Prescribing an activity protocol while staying in the respiration chamber allows a further improvement of the ballance between energy intake and expenditure.

\section{References}

1. Abbott, W. G., Howard, B. V., Ruotolo, G., and Ravussin, E. Energy expenditure in humans: effects of dietary fat and carbohydrate. Am $J$ Physiol. 258: E347-351, 1990.

2. Abbott, W. G. H., Howard, B. V., Christin, L. Freymond, D., Lillioja, S., Boyce, V. L., Anderson, T. E., Bogardus, C., and Ravussin, E. Short-term energy balance: relationship with protein, carbohydrate, and fat balances. Am J Physiol. 255: E332-337, 1988.

3. Astrup, A., Buemann, B., Christensen, N. J., and Madsen, J. 24-hour energy expenditure and sympathetic activity in postobese women consuming a high-carbohydrate diet. Am $J$ Physiol. E282-E288, 1992.

4. Astrup, A., Buemann, B., Christensen, N. J., Madsen, J., Gluud, C., Bennett, P., and Svenstrup, $B$. The contribution of body composition, substrates, and hormones to the variability in energy expenditure and substrate utilization in premenopatusal women. $J$ Clin Endocrinol Metab. 74: 279-286, 1992.

5. Astrup, A., Buemann, B., Christensen, N. J., and Toubro, S. Failure to increase lipid oxidation in response to increasing dietary fat content in formerly obese women. Am $J$ Physiol. 266: E592-599, 1994.

6. Astrup, A., Thorbek, G., Lind, J., and Isaksson, B. Prediction of 24-h energy expenditure and its components from physical characterestics and body composition in norma-weight humans. Aw J Clin Nutr. 52: 777-783, 1990.

7. Atwater, W. O. Principles of nutrition and nutritive values of food. United States Famers ${ }^{r}$ Bulletin. 142: 1910.

8. Benmett, C., Reed, G. W., Peters, J. C., Abumrad, N. N., Sun, M., and Hill, J. O. Short-term effects of dietary-fat ingestion on energy expenditure and nutrient balance. Am $J$ Clin Nutr. 55: $1071-1077,1992$.

9. Boer, J. d., Es, A. J. v., Vogt, J. E., Raaij, J. M. w., and Hautvast, J. G. Reproducibility of $24 \mathrm{~h}$ energy expenditure measurements using a human whole body indirect calorimeter. $\mathrm{Br} . J$ Nutr. 57: 201-209, 1987

10. Dallosso, H. M., and James, W. P. Whole-body calorimetry studies in adult men. 1. The effect of fat over-feeding on 24 h energy expenditure. Br J Nutr. 52: 49-64, 1984.

11. Dauncey, M. J. Metabolic effects of altering the 24 th energy intake in man using direct and indirect calorimetry. $\mathrm{Br} J$ Nutr. 43: 257-269, 1980.

12. Hill, J. O., Peters, J. C., Reed, G. W., Schlundt, D. G., Sharp, T., and Greene, H. L. Nutrient balance in humans: effects of diel composition. Am J Clin Nurr. 54: 10-17. 1991.

13. Hurni, M., Burnand, B., Pittet, P., and Jequier, E. Metabolic effects of a mixed and a highcarbohydrate low-fat diet in man, measured over 24 h in a respiration chamber. Br $J$ Natr. 47: $33-43,1982$.

14. McNeill, G., Bruce, A. C., Ralph, A., and James, W. P. Inter-individual differences in fasting nutrient oxidation and the influence of diet composition. In $/$ Obesity, 12:455-63, 1988. 
15. Norgan, N. G., and Durnin, J. V. G. A. The effect of 6 weeks of overfeeding on the body weight, body composition, and energy metabolism of young men. Am J Clin Nutr. 33: 978$988,1.980$.

16. Ravussin, E., Lillioja, S., Anderson, T. E., Christin, L., and Bogardus, C. Determinants of 24hour energy expenditure in man. Methods and results using a respiratory chamber. $J$ Clin Invest, 78: 1568-1578, 1986.

17. Rumpler, W. V., Seale, J. L., Conway, J. M., and Moe, P. W. Repeatability of 24-h energy expenditure measurements in humans by indirect calorimetry. Am $f$ Clin Nutr. 51: 147-152, 1990.

18. Schoffelen, P. F. M., Saris, W. H. M. Westerterp K. R., and ten Hoor, F. Evalution of an automatic indirect calorimeter for measurement of energy balance in man. Human Energy Metabolism: Physical Activity and Energy Expenditure Measurements in Epidemiological Research Based Upon Direct and Indirect Calorimerry. Wageningen, Euro-Nut. 51-54, 1984.

19. Stichting-Nederlands-Voedingsstoffenbestand. NEVO Tabel. Den Haag, Voorlichtingsbureau woor de voeding, 1993

20. Tataranni, P. A., Larson, D. E., Snitker, S., and Ravussin, E. Thermic effect of food in humans: methods and results from use of a respiratory chamber. Am J Clin Nutr. 61: 1013$1019,1995$.

21. Thomas, C. D., Peters, J. C., Reed, G. W., Abumrad, N. N. Sun, M., and Hill, J. O. Nutrient balance and energy expenditure during ad libitum feeding of high-fat and highcarbohydrate diets in humans. Am J Clin Natr. 55: 934-942, 1992.

22. Toubro, S. Christensen, N. J., and Astrup, A. Reproducibility of 24-h energy expenditure, substrate utilization and spontaneous physical activity in obesity measured in a respiration chamber. Int J Obesity. 19:544-549, 1995.

23. Verboeket-van de Venne, W. P. H. G., Westerterp, K. R., and ten Hoor, F. Substrate utilization in man: effects of dietary fat and carbohydrate. Metabolism. 43: 152-156, 1994.

24. Weigle, D. S. Appetite and the regulation of body composition. FASEB $\pi .8: 302-310$, 1994.

25. Weir J. B. d. V. New methods for calculating metabolic ratte with speciall reference to protein metabolism. I Physiol. 109: 1-9, 1949 .

26. White, M. D., Bouchard, G., Buemann, B., Alméras, N., Després, J.-P., Bouchard, C., and Tremblay, A. Reproducibility of 24-h energy expenditure and macronutrient oxidation rates in an indirect calorimeter. $J$ Appl Physiol. 80: 133-139, 1996.

27. Zurlo, F., Lillioja, S., Esposito, D. P. A., Nyomba, B. L., Raz, I., Saad, M. F., Swinburn, B. A., Knowler, W. C., Bogardus, $C$, and Ravussin, E. Low ratio of fat to carbohydrate oxidation as predictor of weight gain: study of 24-h RQ. Am I Physiol. 259: E650-E657, 1990. 


\title{
Changes in fat oxidation in response to a high-fat diet
}

Patrick Schrauwen, Wouter D van Marken Lichtenbelt, Wim H M Saris, and Klaas R Westerterp

Department of Human Biology, Maastricht University, Maastricht, The Netherlands

American Journal of Clinical Nutrition, 66: 276-282, 1997.

\begin{abstract}
Intervention studies have shown that the adaptation of fat oxidation to fat intake, when changing the dietary fat content, is not abrupt. This study was conducted to measure the time course of adaptation of oxidation rates to increases in the fat content of the diet, when feeding subjects at energy balance. Twelve healthy, nonobese males and females (age: $26 \pm 2$, BMI: $21.4 \pm 0.5$, habitual fat intake: $29 \pm 1 \mathrm{E} \%$ ) consumed a low-fat diet for 6 days (day 1-6) followed by a high-fat diet for 7 days (day 7-13). Days 5-9 and day 13 were spent in a respiration chamber. After adjusting energy intake to $24 \mathrm{~h}$ energy expenditure on day 5 , subjects were in energy balance (range -0.15 to $+0.23 \mathrm{~kJ} /$ day) on days $6-9$ and day 13 . Fat balance was zero on day 6 but became positive after changing to the high-fat diet $(1.06 \pm 0.15,0.75 \pm 0.15$ and $0.55 \pm 0.14 \mathrm{MJ} /$ day for days 7,8 and 9 respectively, $\mathrm{p}<0.05$ ), reaching a new balance on day 13, 7 days afterwards. In conclusion: in case of energy balance, lean subjects are capable of adjusting fat oxidation to fat intake within 7 days, when dietary fat content is increased.
\end{abstract}




\section{Introduction}

Weight maintenance requires that, on the long term, energy intake matches energy expenditure. Apart from energy balance, this also requires oxidation rate to be equal to intake for separate nutrients. For both protein and carbohydrate it has been shown that the rate of oxidation is well adjusted to intake $(1,2)$. The body's storage capacity for fat is 100 -fold the storage capacity for carbohydrate. Therefore fat stores are considered to be the main energy stores for the human being and maintaining zero fat balance has little priority. Indeed, it has been shown that fat balance is poorly regulated and positive or negative energy balances (= energy intake minus energy expenditure) are accommodated by gains or losses of fat $(27,7)$. These principles are postulated in the two compartment model of Flatt (13). This model states that, when the dietary fat content increases, fat oxidation can be raised by two mechanisms: 1) glycogen concentration can be maintained in a lower range, leading to lower glucose and insulin concentrations between meals, and hence higher fatty acid concentrations and higher rates of fat oxidation and/or 2) expansion of the adipose tissue mass which leads to enhanced fatty acid oxidation.

In our western society with a surplus of food available, it is unlikely that the body would compensate the lower carbohydrate content of a high-fat diet by attuning at low glycogen concentrations. It is more likely that food intake will be increased. As a result high-fat diets will lead to a positive energy balance, and therefore in gains of fat mass. Indeed, it has been shown that voluntary energy intake is higher on high-fat diets $(20,9)$ and that high-fat diets are fattening $(22,23,18)$. So, ad libitum consumption of a high-fat diet will lead to expansion of the body's fat stores, which will increase fat oxidation (5) until a new equilibrium is reached between fat intake and fat oxidation.

However when energy intake is fixed, rapid shifts in substrate oxidation have been demonstrated (15). In Hill's experiment subjects were studied for 7 days on a diet with an food quotient (FQ) of 0.770 and for 7 days on a diet with an FQ of 0.917 . Twenty four hour respiratory quotient (24h RQ) was determined three and seven days after the start of each diet using a respiration chamber. Twenty four hour RQ shifted in the direction of FQ on both diets. However, even after seven days no complete adjustment was observed. In the respiration chamber subjects were fed in energy balance. However, as suggested by the authors, they might have been in a negative energy balance on days outside the respiration chamber. To our knowledge no studies have been reported which measured both acute (within days) and long term (up to one week) adaptation of substrate oxidation to alterations in diet composition.

The fat content of the diet may be of special relevance in the treatment/occurrence of obesity. It has been suggested that in people with obesity adaptation to a high-fat diet is diminished $(31,4)$. However, before studying overweight subjects, it is important to know how long adaptation to an increase in dietary fat content takes in normal-weight subjects. We therefore measured substrate oxidation on a habitual (low-fat) diet and subsequently the adaptation to a high-fat diet during 7 days, while 
feeding subjects in energy balance. We hypothesized that complete adaptation to the changed fat content of the diet can occur within a few days.

\section{Methods}

Subjects

The characteristics of the 12 volunteers ( 6 men, 6 women) participating in this study are shown in table 3.1. All subjects were healthy and had a habitual diet which could be considered as low-fat (mean \pm s.e.m.: energy intake: $9.0 \pm 0.7 \mathrm{MJ}$, of which $29 \pm$ $1 \%, 54 \pm 2 \%$ and $16 \pm 1 \%$ provided as fat, carbohydrates and proteins respectively, as determined with a 3 day food-intake record). Subjects were non-obese and did not have a family history of obesity. The study was approved by the Ethical Conmittee of the University of Limburg and all subjects gave their written informed consent.

Table 3.1 Subjects characteristics measured at the end of the experimental period

\begin{tabular}{lcccccc}
\hline Subject & $\mathrm{n}$ & $\begin{array}{c}\text { Age } \\
\mathrm{y}\end{array}$ & $\begin{array}{c}\text { Height } \\
\mathrm{m}\end{array}$ & $\begin{array}{c}\text { Weight } \\
\mathrm{kg}\end{array}$ & $\begin{array}{c}\text { Body fat } \\
\%\end{array}$ & $\begin{array}{c}\text { BMI } \\
\mathrm{kg} / \mathrm{m}^{2}\end{array}$ \\
\hline total & 12 & $25.8 \pm 1.7$ & $1.77 \pm 0.03$ & $67.0 \pm 2.4$ & $19.1 \pm 1.8$ & $21.4 \pm 0.5$ \\
males & 6 & $28.5 \pm 3.0$ & $1.83 \pm 0.03$ & $72.0 \pm 3.4$ & $15.1 \pm 1.3$ & $21.4 \pm 0.7$ \\
females & 6 & $23.0 \pm 1.0$ & $1.71 \pm 0.03$ & $62.0 \pm 1.9$ & $23.1 \pm 2.4$ & $21.3 \pm 0.8$ \\
\hline
\end{tabular}

Values are mean \pm s.e.m.

\section{Experimental design}

Subjects consumed a low-fat diet for 6 days, followed by a high-fat diet for 7 days. On days 1 till 4 , subjects were instructed to consume a low-fat diet and to fill in a food intake record. On day 5 and 6 subjects were fed a low-fat diet in the respiration chamber. On day 7 till 13 subjects consumed a high-fat diet. On days 10 till 12 this high-fat diet was given to the subjects for consumption at home to guarantee diet composition did not change. Subjects entered the respiration chamber on the evenings of day 4 and 12 , and left the chamber on the morning (8:00 am) of day 10 and 14 .

\section{Diets}

All food was consumed as breakfast, lunch, dinner and 2 or more snacks per day. Diet composition of experimental diets is given in table 3.2. All snacks had a fixed macronutrient composition. Metabolizable energy intake and macronutrient composition of the diets were calculated using the Dutch food composition table (29). In the table metabolizable energy is calculated by multiplying the amount of protein, fat and carbohydrate with the Atwater factors (6) (16.74, 37.66 and 16.74 $\mathrm{kJ} / \mathrm{g}$ for carbohydrate, fat and protein respectively). It has been shown that the metabolizable energy of a diet decreases when the fiber content of the diet increases (21). Therefore the diets were composed such that the fiber content was comparable ( $1.41 \pm 0.04$ vs. $1.13 \pm 0.06 \mathrm{~g} / \mathrm{MJ}$ for low and high-fat diets respectively). 
Table 3.2 Composition of experimental diets

\begin{tabular}{lcc} 
& low-fat diet & high-fat diet \\
\hline Protein (\% of total energy) & 15 & 15 \\
Carbohydrate (\% of total energy) & 55 & 25 \\
Fat (\% of total energy) & 30 & 60 \\
Food Quotient & 0.878 & 0.798 \\
\hline
\end{tabular}

On days 1 till 4 and days 10 till 12 , the days spent at home, subjects were free to eat as much as they wanted. On day 5 , the first day in the respiration chamber, subjects were given an amount of energy equal to 1.5 times 24 hour sleeping metabolic rate (24hSMR), as measured during the night. On days 6 till 10 and day 13 the amount of energy given was equal to the amount of energy expended on day 5. In this way, energy intake could be individually adjusted to energy expenditure, assuming no major changes in energy expenditure during the experiment.

\section{Body composition}

Subjects weighed themselves every morning during their stay in the respiration chamber, after voiding and before eating and drinking. Measurements were done on a digital balance (Seca delta, model 707) accurate to $0.1 \mathrm{~kg}$. On the morning of day 14 whole body density was determined by underwater weighing in the fasted state, directly after subjects left the respiration chamber. Body weight was measured with a digital balance accurate to $0.01 \mathrm{~kg}$ (Sauter, type E1200). Lung volume was measured simultaneously with the helium dilution technique using a spirometer (Volugraph 2000 , Mijnhardt). Percent body fat was calculated using the equations of Siri (28). Fat-free mass (FFM) in $\mathrm{kg}$ was calculated by subtracting fat mass from total body mass.

\section{Indirect calorimetry and physical activity}

Oxygen consumption and carbon dioxide production was measured in a whole-room indirect calorimeter, which was described previously (25). The respiration chamber is a $14 \mathrm{~m}^{3}$ room furnished with a bed, chair, television, radio, telephone, intercom, wash bowl and toilet. The room is ventilated with fresh air at a rate of $70-801 / \mathrm{min}$. The ventilation rate was measured with a dry gas meter (Schlumberger, type G6, The Netherlands). The concentration of oxygen and carbon dioxide was measured using a paramagnetic $\mathrm{O}_{2}$ analyzer (Hartmann \& Braun, type Magnos G6, Germany) and an infrared $\mathrm{CO}_{2}$ analyzer (Hartmann \& Braun, type Uras $3 \mathrm{G}$, Germany). Ingoing air was analyzed every 15 minutes and outgoing air once every 5 minutes. The gas sample to be measured was selected by a computer that also stored and processed the data. Energy expenditure was calculated from $\mathrm{O}_{2}$ consumption and $\mathrm{CO}_{2}$ production according to the method of Weir (32).

In the respiration chamber subjects followed an activity protocol consisting of fixed times for breakfast, lunch and dinner, sedentary activities and bench stepping exercise. The bench stepping exercise was performed for 30 minutes at intervals of 5 minutes exercise alternated with 5 minutes rest, at a rate of 60 steps per minute with a bench height of $33 \mathrm{~cm}$, and was repeated three times a day. Thus, subjects exercised for 45 minutes per day, at a relative low-to-medium intensily. At daytime, no sleeping 
or other exercise was allowed during the stay in the respiration chamber. Spontaneous physical activity of the subjects was monitored by means of a radar system based on the Doppler principle.

\section{Urinary nitrogen excretion}

During the stay in the respiration chamber $24 \mathrm{~h}$ urine was collected from $8.00 \mathrm{~h}$ am to $8.00 \mathrm{~h}$ am. Subjects had to empty the bladder at $8.00 \mathrm{~h}$ am so urine produced during the night could be included with the urine sample of the previous day. Samples were collected in containers with $10 \mathrm{ml} \mathrm{H}_{2} \mathrm{SO}_{4}$ to prevent nitrogen loss through evaporation; volume and nitrogen concentration were measured, the latter using a nitrogen analyzer (Heraeus, type CHN-O-Rapid).

\section{4 energy expenditure and substrate oxidation}

$24 \mathrm{~h}$ Energy expenditure (24h EE) and $24 \mathrm{~h}$ RQ were calculated from $8.00 \mathrm{~h}$ am to $8.00 \mathrm{~h}$ am. Sleeping metabolic rate (SMR) was defined as the lowest mean energy expenditure during three subsequent hours measured between $0.00 \mathrm{~h}$ am and $8.00 \mathrm{~h}$ am. For calculation of the thermic effect of food (TEF) energy expenditure from $8.30 \mathrm{~h}$ am to $23.30 \mathrm{~h} \mathrm{pm}$ was plotted against radar output over $30 \mathrm{~min}$ intervals. The intercept of the regression line at lowest radar output (offset) represents the energy expenditure in the inactive state: SMR and thermic effect of food. TEF was determined by subtracting SMR from energy expenditure in the inactive state.

Carbohydrate, fat and protein oxidation were calculated using $\mathrm{O}_{2}$ consumption, $\mathrm{CO}_{2}-$ production and urinary nitrogen losses with the equations of Brouwer $(10)$.

Protein oxidation $(\mathrm{g} / \mathrm{d})=6.25 * \mathrm{~N}$

Fat oxidation $(\mathrm{g} / \mathrm{d})=1.718 * \mathrm{VO}_{2}-1.718 * \mathrm{VCO}_{2}-0.315 * \mathrm{P}$

Carbohydrate oxidation $(\mathrm{g} / \mathrm{d})=4.17 * \mathrm{VCO}_{2}-2.965 * \mathrm{VO}_{2}-0.390 * \mathrm{P}$

where $\quad \mathrm{N}$ is the total nitrogen excreted in urine ( $\mathrm{g} / \mathrm{day}$ )

$\mathrm{VO}_{2}$ is the oxygen consumption (l/day)

$\mathrm{VCO}_{2}$ is the carbon dioxide production (V/day)

$\mathrm{P}$ is protein oxidation (g/day)

\section{Blood analysis:}

$10 \mathrm{ml}$ of venous blood was sampled on the morning of days 4, 10 and 14 after an overnight fast. Blood was collected in tubes containing EDTA to prevent clotting and immediately centrifuged at $3000 \mathrm{rpm}$ for 10 minutes. Plasma was frozen in liquid nitrogen and stored at $-80^{\circ} \mathrm{C}$ until further analysis. Plasma substrates were determined using the hexokinase method (LaRoche, Basel, Switzerland) for glucose, the Wako NEFA C testkit (Wako chemicals, Neuss, Germany) for free fatty acids, the glycerolkinase-lipase method (Boehringer, Mannheim) for glycerol and triglycerides and the ultra sensitive human insulin ria kit (linco research, St. Charles, U.S.A.).

\section{Statistical analysis}

All data are presented as mean \pm S.E.M. Equality of RQ and FQ, as well as energy intake and energy expenditure was determined by calculating the $95 \%$ confidence intervals for $\mathrm{RQ}$ minus $F Q$ and energy intake minus energy expenditure. To test if the 
decline in RQ observed between day 3 and 9 was statistically significant, individual slopes were calculated and tested using the non-parametric t-test (Wilcoxon). A repeated measures one way analysis of variance (ANOVA) was used to detect differences in any parameters between days. When significant differences were found, a Tukey post-hoc test was used to determine the exact location of this difference. Gender differences in any parameter were analyzed using repeated measures two factor ANOVA.

\section{Results}

On days 1 to 4 subjects were instructed to consume a low-fat diet and to fill in a food intake record. This resulted in an energy intake of $8.4 \pm 0.7 \mathrm{MJ}$, of which $25 \pm 2 \%, 57$ $\pm 2 \%$ and $16 \pm 1 \%$ were provided as fat, carbohydrate and protein respectively and a food quotient of $0.890 \pm 0.004$.

There was a significant difference in body weight between days $(\mathrm{P}<0.05)$. Post-hoc testing revealed that body weight showed a slight but significant decline with $0.6 \pm$ $0.2 \mathrm{~kg}$ between day 5 and day 13 (table 3.3). No significant differences in bady weight between days 5 to 9 were observed.

Table 3.3 Sleeping metabolic rate (SMR), physical activity index (PAI) and body weight as measured in the respiration chamber

\begin{tabular}{ccccc}
\hline diet & day & $\begin{array}{c}\text { SMR } \\
\mathrm{KJ} / \mathrm{min}\end{array}$ & PAI\# & $\begin{array}{c}\text { Body weight } \\
\mathrm{kg}\end{array}$ \\
\hline low fat & day 5 & $4.373 \pm 0.185$ & $1.60 \pm 0.03 *$ & $67.5 \pm 2.5 *$ \\
low fat & day 6 & $4.379 \pm 0.165$ & $1.60 \pm 0.03 *$ & $67.2 \pm 2.6$ \\
high fat & day 7 & $4.369 \pm 0.169$ & $1.60 \pm 0.03 *$ & $67.4 \pm 2.5$ \\
high fat & clay 8 & $4.386 \pm 0.161$ & $1.57 \pm 0.03$ & $67.5 \pm 2.5 *$ \\
high fat & day 9 & $4.460 \pm 0.179$ & $1.59 \pm 0.04$ & $67.3 \pm 2.5$ \\
high fat & day 13 & $4.389 \pm 0.180$ & $1.55 \pm 0.02$ & $66.9 \pm 2.4$ \\
\hline Values are mean \pm s.e.m. $(\mathrm{n}=12)$ &
\end{tabular}

\# physical activity index: 24 h energy expenditure/sleeping metabolic rate

* $p<0.05$ compared to day 13

There were no significant differences in sleeping metabolic rate between days (table 3.3). There was a significant difference in physical activity index (PAI=ADMR/SMR) between days $(\mathrm{p}<0.05)$. Post-hoc testing revealed that PAI was somewhat lower during day 13 compared to day 5, 6 and 7 (table 3.3). No significant differences in PAI between days 5 to 9 were observed. The somewhat lower PAI on day 13 can be explained by a diminished energy expenditure for physical activity on this day, because subjects reported to feel bored and spent their time watching television.

On day 5 (first day in the respiration chamber) average PAI was 1.60. Because $24 \mathrm{~h}$ energy requirement was estimated using $1.5 * \mathrm{SMR}$, a significantly negative energy balance was found. After individual adjusting of energy intake to energy requirement, 
energy balance was not significantly different from zero on days 6-9 and 13 (table 3.4).

Table 3.4 Twenty-four hour energy intakes, expenditure and balances

\begin{tabular}{ccccc}
\hline test & day & $\begin{array}{c}\text { Intake } \\
\text { MJ/ day }\end{array}$ & $\begin{array}{c}\text { Expenditure } \\
\text { MJ/ day }\end{array}$ & \multicolumn{1}{c}{$\begin{array}{c}\text { Balance } \\
\text { MJ/ day }\end{array}$} \\
\hline low fat & day 5 & $9.109 \pm 0.383$ & $10.012 \pm 0.336$ & $-0.903 \pm 0.212 *$ \\
low fat & day 6 & $9.980 \pm 0.325$ & $10.083 \pm 0.386$ & $-0.103 \pm 0.132$ \\
high fat & day 7 & $9.988 \pm 0.327$ & $10.025 \pm 0.370$ & $-0.037 \pm 0.131$ \\
high fat & day 8 & $9.982 \pm 0.317$ & $9.914 \pm 0.363$ & $0.068 \pm 0.116$ \\
high fat & day 9 & $9.990 \pm 0.317$ & $10.140 \pm 0.405$ & $-0.150 \pm 0.176$ \\
high fat & day 13 & $9.976 \pm 0.319$ & $9.750 \pm 0.396$ & $0.226 \pm 0.134$ \\
\hline
\end{tabular}

Values are mean \pm s.e.m. $(\mathrm{n}=12)$

* significantly different from zero balance $(\mathrm{p}<0.05)$

24h RQ and FQ are presented in figure 3.1. On day 5 and 6, RQ and FQ were not significantly different. Between days 7 and $1324 \mathrm{~h} R Q$ declined significantly $(p<0.005)$, resulting in an equality of RQ and FQ on day 13. Sleeping RQ also declined significantly between days 7 and $13(0.823 \pm 0.009$ vs. $0.798 \pm 0.008$, $\mathrm{p}<0.005$ ).

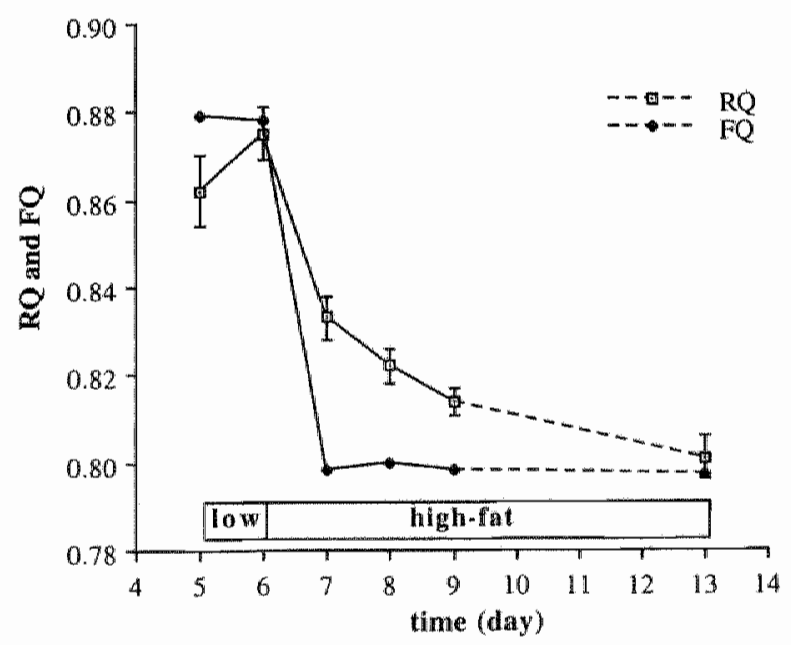

Figure 3.1 Twenty-four hour respiratory quotient and $24-h$ food quotiens as measured in the respiration chamber for days $5-9$ and $13(n=12$, mean \pm s.e.m. $)$.

Protein balance was not significantly different from zero during the measurement days (figure 3.2). Carbohydrate oxidation was significantly different between days $(p<0.001)$. Post-hoc testing revealed that carbohydrate oxidation was not significantly different between days 5 and 6 . However, carbohydrate oxidation declined significantly between day 6 and 13 . This resulted in a significantly negative carbohydrate balance on days 7,8 and 9 . On day 5 and 6 , as well as on day 13 
carbohydrate balance was not significantly different from zero (figure 3.2). Fat oxidation was significantly different between days $(p<0.001)$. Post-hoc testing revealed that fat oxidation was not significantly different between day 5 and 6 . However fat oxidation increased significantly between day 6 and 13. Fat balance was significantly negative on day 5 , whereas on days 7,8 and 9 a positive fat balance was reached. On day 6 as well as on day 13 fat balance was not significantly different from zero (figure 3.2).

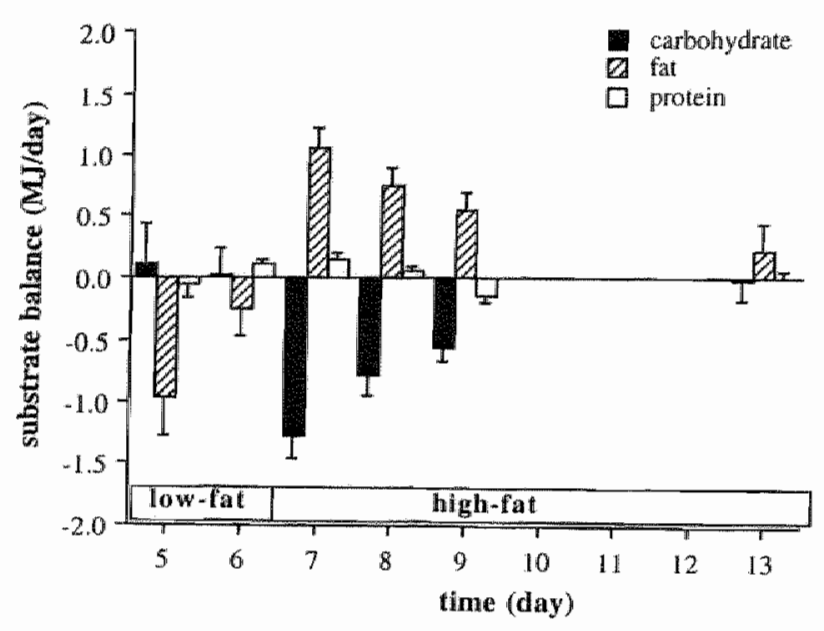

Figure 3.2 Substrate balances for days 5-9 and 13 as measured in the respiration chamber $(\mathrm{n}=12$, mean \pm s.e.m. $)$.

When we individually adjusted energy and substrate balance for the baseline day (day 6) carbohydrate balance was significantly negative for days 7,8 and $9(-1.2 \pm$ $0.1,-0.8 \pm 0.1$ and $-0.6 \pm 0.2 \mathrm{MJ} / \mathrm{day}$ respectively), whereas on day 13 carbohydrate balance was not significantly different from zero $(-0.0 \pm 0.2 \mathrm{MJ} /$ day $)$. Fat balance was significantly positive on days 7,8 and $9(1.3 \pm 0.1,1.0 \pm 0.1$ and $0.8 \pm 0.2 \mathrm{MJ} /$ day respectively) and was not significantly different from zero on day $13(0.5 \pm 0.2$ $\mathrm{MJ} / \mathrm{day})$. On all days subjects were in protein balance $(0.0 \pm 0.0,-0.0 \pm 0.0,0.2 \pm 0.1$ and $0.1 \pm 0.0 \mathrm{MJ} /$ day for days $7,8,9$ and 13 respectively) and energy balance $(0.1 \pm$ $0.1,0.2 \pm 0.1,-0.0 \pm 0.1$ and $0.3 \pm 0.1 \mathrm{MJ} /$ day for days $7,8,9$ and 13 respectively).

\section{Blood parameters}

There were no significant differences in glycerol, glucose insulin and FFA concentrations between days 4,10 and 14 . On day 10 and 14 triglyceride concentration was significantly lower compared to day $4(\mathrm{p}<0.005)$. 


\section{Gender differences}

This study was performed in both men and women. Some gender differences were observed. As expected, women had significantly lower body weight $(p<0.05)$, greater body fat percentage $(p<0.05)$ and less fat-free mass $(p<0.001)$. No differences in body mass index and fat mass were observed between men and women.

RQ was significantly higher for women on day 13 compared to men $(0.816$ vs. 0.786 , $\mathrm{p}<0.001$ ). Also, RQ declined significantly more between day 9 and 13 for men compared to women $(\mathrm{p}<0.005)$. There were, no significant differences between men and women in (decline in) RQ between day 5 and 9.

Carbohydrate oxidation as percentage of energy expenditure was significantly lower for men compared to women on day $13(p<0.001)$. This resulted in a significant difference in carbohydrate balance $(p<0.001)$, with men being in a positive carbohydrate balance and women in a negative balance. Fat oxidation as percentage of energy expenditure on day 13 was significantly higher for men compared to women $(p<0.05)$. The male subject were in negative fat balance and the female subjects in a positive fat balance, the difference being significant $(p<0.01)$. No differences in substrate oxidation or any other parameters (except for some blood parameters, see below) measured during the stay in the respiration chamber were observed between men and women.

Free fatty acid concentration was significantly higher for women on day 10 compared to men $(p<0.05$, table 3.5 ). Glycerol concentration significantly increased between day 4 and day 10 in women, whereas no change was seen in men $(p<0.05$, table 3.5). In women, insulin concentration was significantly lower on days 10 and 14 compared to day $4(p<0.05)$. No other differences in blood parameters on any days were found.

Table 3.5 Blood parameters measured before, during and after high-fat cliet

\begin{tabular}{ccccccc}
\hline day & sex & $\begin{array}{c}\text { glucose } \\
\text { mmol/L }\end{array}$ & $\begin{array}{c}\text { triglycerides } \\
\mu \text { mol/L }\end{array}$ & $\begin{array}{c}\text { FFA } \\
\mu \text { mol/L }\end{array}$ & $\begin{array}{c}\text { glycerol } \\
\mu \mathrm{mol} / \mathrm{L}\end{array}$ & $\begin{array}{c}\text { insulin } \\
\mu \mathrm{U} / \mathrm{mL}\end{array}$ \\
\hline 4 & female & $4.73 \pm 0.23$ & $908 \pm 217$ & $289 \pm 54$ & $54 \pm 5$ & $12.03 \pm 2.35$ \\
10 & female & $4.57 \pm 0.06$ & $666 \pm 91$ & $386 \pm 36^{*}$ & $86 \pm 12 ¥$ & $8.16 \pm 0.74 ¥$ \\
14 & fernale & $4.72 \pm 0.10$ & $703 \pm 100$ & $352 \pm 31$ & $73 \pm 11$ & $8.12 \pm 1.09 ¥$ \\
4 & male & $5.13 \pm 0.34$ & $721 \pm 93$ & $253 \pm 35$ & $61 \pm 8$ & $6.58 \pm 1.84$ \\
10 & male & $4.80 \pm 0.10$ & $421 \pm 40 \%$ & $248 \pm 26$ & $59 \pm 5$ & $8.05 \pm 1.06$ \\
14 & male & $4.86 \pm 0.10$ & $482 \pm 40$ & $263 \pm 45$ & $64 \pm 6$ & $7.08 \pm 0.61$ \\
\hline
\end{tabular}

Values are mean \pm s.e.m. Female $(n=6)$ and male $(n=6)$

* $\mathrm{p}<0.05$ compared to men

$p<0.05$ compared to day 4

\section{Discussion}

The results of the present study demonstrate that, in situations where energy balance is reached, substrate oxidation can be adjusted to substrate intake. After seven days on a high-fat diet fat oxidation was, on average, equal to fat intake. However some 
gender differences were found. The adjustment of fat oxidation occurred without any change in energy expenditure or body weight during the days in the respiration chamber.

High-fat diets often are considered to be fattening $(22,9)$. It has been suggested that, together with raising energy intake, high-fat diets result in a lower energy expenditure $(3,19)$. In our study we did not find any difference in 24 h energy expenditure between low and high-fat diets except for the last day. On day 13 energy expenditure was significantly lower than on any other day spent in the respiration chamber. It is possible that this was a diet-effect, because 7 days after the start of the high-fat diet (day 13), subjects were in substrate balance, and could be considered as completely adapted to the high-fat diet. However, it is more likely that most subjects became bored and therefore were more sedentary on their last day in the respiration chamber. This was indeed indicated by a lower physical activity index. If any difference in energy expenditure between low and high-fat diets would have occurred it was expected to occur in the thermic effect of food. It has been reported that carbohydrate-rich diets result in a greater thermic effect of food compared to diets with a high-fat content. We estimated thermic effect of food (TEF) as reported by Schutz et all. (26) and found no difference in TEF between high-, and low-fat diets (data not shown). Our results, therefore are in agreement with the studies of Roust et al. (24) and Hill et al. (15) and a recent study of Stubbs et al. (30) performed under free-living circumstances. Furthermore, no changes in body weight were seen in the first three days on the high-fat diet. If anything, body weight declined slightly on the high-fat diet (day 13). The decrease in body weight might be due to decreased glycogen concentrations. Thus, the present study does not support other studies like Prewitt et al. (23) which show that consumption of high-fat diets is more fattening than consumption of iso-energetic low-fat diets.

This study demonstrated that the body has a great capacity to adjust substrate oxidation to substrate intake on the long term (up to one week) for carbohydrate and fat. Earlier studies could not demonstrate such an adaptation to a high-fat diet, probably because their subjects were not in energy balance. In contrast to other studies, in this experiment subjects were permanently in the chamber during the dietary switch and the subsequent days. During the stay in the respiration chamber $24 \mathrm{~h}$ energy expenditure was virtually constant in the subjects. By prescribing activities throughout the day we could limit daily fluctuations in energy expended in physical activity. This made it possible to adjust energy intake to energy expenditure after the first measurement day. With this protocol we were able to measure substrate oxidation with subjects being in energy balance. The results show that human subjects have a capacity to adjust RQ to FQ in 7 days. Theoretically, the adaptation period under conditions of energy balance might be somewhat longer, because our data on body weight suggest that subjects were in a negative energy balance on the three days spent at home, which may have accelerated adaptation to the high fat diet.

Fat oxidation gradually increased in this study. These results can be interpreted as an adaptation to a high fat intake. The consequence of an iso-energetic exchange of fat 
for carbohydrate is that the results can also be interpreted as being an adaptation to a low carbohydrate intake. However, the capacity of carbohydrate oxidation to adjust to carbohydrate intake has been shown to be rapid (1). Therefore, if the increase in fat oxidation was solely a consequence of the decrease in carbohydrate oxidation a more rapid adaptation would have been expected. In regulating substrate oxidation, the effect of glycogen content should be considered. According to Flatt's model (13) fat oxidation can be raised on high-fat diets by maintaining glycogen concentrations in a lower range. In our study we found a positive fat balance and a negative carbohydrate balance on days 7 till 9 . The negative carbohydrate balance (on average $-142 \mathrm{~g}$ between day 5 and 9) must have resulted in reduction of the glycogen stores, which was however not detectable in body weight. It therefore seems that glycogen content of the body decreased till a new concentration was reached in which fat oxidation was sufficiently elevated to become in equilibrium with the elevated fat intake. However, it is also possible that fat oxidation was elevated because of increased enzymatic capacity for fat oxidation which occurred because of the exposure to the high-fat diet. Further studies are necessary to investigate the role of glycogen content in the regulation of fat oxidation in a situation of energy balance.

It was assumed that changes in carbohydrate balance are reflected in changes in glycogen content. The fact that sleeping RQ was also affected by the high-fat diet indicates that changes in body's nutrient stores occurred. However, a part of the negative carbohydrate balance can be accounted for by enhanced gluconeogenesis from amino acid, lactate or glycerol. We did not find any difference in urinary nitrogen excretion. It is therefore unlikely that protein breakdown was enhanced to make amino acids available for gluconeogenesis. Klein et al. (17) showed that restriction of dietary carbohydrate is responsible for the metabolic responses to shortterm fasting, such as enhanced lipolysis and gluconeogenesis. Carlson et al. (11) recently found that FFA reesterification together with lipolysis, is increased during fasting, in this way making FFA available for oxidation and maximize glycerol release for gluconeogenesis. In our study we did not measure any endogenous lipid kinetics. Therefore we can not determine whether glycerol was released in favor of gluconeogenesis.

On the fourth day after the start of the high-fat diet (day 10) marked differences in plasma substrate concentrations were observed between men and women. Fasting FFA and glycerol concentrations were elevated in women compared to day 4 , whereas in men no change in FFA and glycerol concentrations was seen. Also a lower fasting insulin concentration was found on day 10 compared to day 4 in women but not in men. Those differences between men and women occurred without any accompanying differences in substrate oxidation or balances on days 5-9. It therefore seems that the elevation of fat oxidation was reached by different mechanisms in men and women. Jensen (16) recently showed that normal weight women had greater suppression of FFA flux after consumption of a mixed meal than age-matched men, despite their greater percent body fat, suggesting increased insulin sensitivity of adipose tissue lipolysis in women compared to men. In our study, the 
lower insulin as well as the elevated FFA and glycerol concentration in women on day 10 compared to day 4 suggest that lipolysis was increased to make FFA available for oxidation and glycerol available for gluconeogenesis. How fat oxidation is increased in men is not yet clear.

On the eighth day after the start of the high-fat diet (day 14) the differences in blood parameters between men and women disappeared. However on this day significant differences in substrate oxidation between men and women occurred. Women had higher carbohydrate oxidation (in \% of energy expenditure) and lower fat oxidation (in \% of energy expenditure) than men. It is possible that women, despite their assumed increase in lipolysis, were not able to further increase fat oxidation. However, we did not control for activity on days 10 to 13 (the days they spent at home) and also food intake on those days was ad libitum. It is therefore also possible that women were in a positive energy balance and in this way partly repleted their gllycogen stores. Further studies have to be conducted to examine possible gender differences in long term adaptation to high-fat diets.

We demonstrated that normal-weight persons were able to reach substrate balance on a high-fat diet after one week. However on the short term substrate balances could not be maintained. We can not conclude from these results whether obese or obese susceptible people would have the same capacity to maintain body weight on highfat diets. Ample evidence exists that (pre-,post-) obese people have a diminished fat oxidation capacity $(33,4,8,12)$. It is also possible that in obese (susceptible) persons the time course of adjusting fat oxidation to increased fat intake is delayed $(14,31)$. This will result in amounts of fat storage and glycogen mobilization, which are greater in obese (susceptible) people. Therefore obesity might result from cumulative positive fat balances due to day to day fluctuations in fat intake as will occur in affluent societies, where food is always available ("party effect").

In conclusion, our results demonstrate that, in case of energy balance, lean subjects are capable of adjusting fat oxidation to fat intake within 7 days, when dietary fat content is increased.

\section{References}

1. Abbott, W. G. H., Howard, B. V., Christin, L., Freymond, D., Lillioja, S., Boyce, V. L. Anderson, T. E., Bogardus, $C$, and Ravussin, E. Short-term energy balance: relationship with protein, carbohydrate, and fat balances. Am J Physiol. 255: E332-337. 1988.

2. Acheson, K. J., Schutz, Y., Bessard, T., Anantharaman, K., Flatt, J. P., and Jequier, E. Glycogen storage capacity and de novo lipogenesis during massive carbohydrate overfeeding in man. Am J Clin Nutr. 48: 240-7, 1988.

3. Acheson, K. J., Schutz, Y., Bessard, T., Ravussin, E., Jequier, E., and Flatt, J. P. Nutritional influences on lipogenesis and thermogenesis after a carbohydrate meal. Am J Physiol. 246:
E62-E70, 1984.

4. Astrup, A., Buemann, B., Christensen, N. J., and Toubro, S. Failure to increase lipid oxidation in response to increasing dietary fat content in formerly obese women. Am J
Physiol. 266: E592-599, 1994. 
5. Astrup, A., Buemann, B., Westem, P., Toubro, S., Raben, A., and Christensen, N. J. Obesity as an adaptation to a high-fat diet: evidence from a cross-sectional study. Am J Clin Nutr. 59: $350-5,1994$.

6. Atwater, W. O. Principles of nutrition and nutritive values of food. United States Farmers Bulletin. 142: 1910 .

7. Bennett, C., Reed, G. W., Peters, J. C., Abumrad, N. N., Sun, M. and Hill, J. O. Shlort-term effects of dietary-fat ingestion on energy expenditure and nutrient balance. Am J Clin Nutr. 55: 1071-1077, 1992.

8. Blaak, E. E., Baak, M. A. v., Kemerink, G. J., Pakbiers, M. T. W., Heidendal, G. A. K., and Saris, W. H. M. B-Adrenergic stimulation of energy expenditure and forearm skeletal muscle metabolism in lean and obese men. Am J Physiol. 267: E306-E315, 1994.

9. Blundell, J. E., Burley, V. J., Cotton, J. R., and Lawton, C. L. Dietary fat and the control of energy intake: evaluating the effects of fat on meal size and postmeal satiety. Am $J$ Clin Nutr. 57: 772S-777S, 1993.

10. Brouwer, E. On simple formulae for calculating the heat expenditure and the quantities of carbohydrate and fat oxidized in metabolism of men and animals, from gaseous exchange (oxygen intake and carbonic acid output) and urine-n. Acta Physiol Pharmacol Neerlandica. 6: 795-802, 1957.

11. Carlson, M. G., Snead, W. L., and Campbell, P. J. Fuel and energy metabolism in fasting humans. Am J Clin Nutr. 60: 29-36, 1994.

12. Colberg, S. R., Simoneau, J.-A., Thaete, F. L., and Kelley, D. E. Skeletal muscle utilization of free fatty acids in women with visceral obesity. $J$ Clin Inwest. 95: 1846-1853, 1995.

13. Flatt, J. P. Dietary fat, carbohydrate balance, and weight maintenance: effects of exercise. Am J Clim Nutr. 45: 296-306, 1987.

14. Flatt, J. P. Importance of nutrient balance in body weight regulation. Diabetes Metab Rev. 4: $571-81,1988$.

15. Hill, J. O., Peters, J. C., Reed, G. W., Schlundt, D. G., Sharp, T., and Greene, H. L. Nutrient balance in humans: effects of diet composition. Am J Clin Nutr. 54: 10-17, 1991.

16. Jensen, M. D. Gender differences in regional fatty acid metabolism before and after meal ingestion. J Clin lwest. 96: 2297-2303, 1995.

17. Klein, S, and Wolfe, R. R. Carbohydrate restriction regulates the adaptive response to fasting. Am J Physiol. 262: E631-E636. 1992.

18. Klesges, R. C., Klesges, L. M., Haddock, C. K., and Eck, L. H. A longitudinal analysis of the impact of dietary intake and physical activity on weight change in adults. Am $J$ Clin Nutr. 55: $818-22,1992$.

19. Lean, M. E., and James, W. P. Metabolic effects of isoenergetic nutrient exchange over 24 hours in relation to obesity in women. Int $J$ Obes. 12: 15-27, 1988.

20. Lissner, L., Levitsky, D. A., Strupp, B. J., Kalkwarf, H. J, and Roe, D. A. Dietary fat and the regulation of energy intake in human subjects. Am J Clin. Nutr. 46: 886m892, 1987.

21. Miles, $C$. W. The metabolizable energy of diets differing in dietary fat and fiber measured in humans. INutr. 122: 306-11, 1992.

22. Miller, W. C., Lindeman, A. K., Wallace, J., and Niederpruem, M. Diet composition, energy intake, and exercise in relation to body fat in men and women. Am $J$ Clin Nurr. 52: 426-30, 1990. 
23. Prewitt, T. E., Schmeisser, D., Bowen, P. E., Aye, P., Dolecek, T. A., Langenberg. P., Cole, T., and Brace, $L$. Changes in body weight, body composition, and energy intake in women fed high- and low-fat diets. Am If Clin Nutr. 54: 304-10, 1991.

24. Roust, L. R., Hammel, K. D., and Jensen, M. D. Effects of isoenergetic, low fat diets on energy metabolism in lean and obese women. Am J Clin Nutr. 60: 470-475, 1994.

25. Schoffelen, P. F. M., Saris, W. H. M. Westerterp, K. R., and ten Hoor, F. Evalution of an automatic indirect calorimeter for measurement of energy balance in man. Human Energy Metabolism: Physical Activity and Energy Expenditure Measurements in Epidemiological Research Based Upon Direct and Indirect Calorimetry. Wageningen, Euro-Nut. 51-54, 1984.

26. Schutz, $Y .$, Bessard, $T$., and Jequier, E. Diet-induced thermogenesis measured over a whole day in obese and nonobese women. Am $J$ Clin Nutr. 40: 542-552, 1984.

27. Schutz, Y, Flatt, J. P., and Jequier, E. Failure of dietary fat intake to promote fat oxidation: a factor favoring the development of obesity. Am I Clin Nutr. 50: 307-14, 1989.

28. Siri, W. E. The gross composition of the body. Adv Biol Med Physiol. 4: 239-280, 1956.

29. Stichting-Nederlands-Voedingsstoffenbestand. NEVO Tabel. Den Haag, Voorlichtingsbureau voor de voeding, 1993.

30. Stubbs, R. J., Ritz, P., Coward, W. A., and Prentice, A. M. Covert manipulation of the ratio of dietary fat to carbohydrate and energy density: Effect on food intake and energy balance in free-liwing men eating ad libitum. Am J Clin Nutr. 62: 330-337, 1995.

31. Thomas, C. D., Peters, J. C., Reed, G. W., Abumrad, N. N., Sun, M., and Hill, I. O. Nutrient balance and energy expenditure during ad libitum feeding of high-fat and highcarbohydrate diets in humans. Am J Clin Nutr. 55: 934.942, 1992.

32. Weir, $\mathfrak{J}$ B. d. V. New methods for calculating metabolic rate with special reference to protein metabolism. J Physiol. 109: 1-9, 1949.

33. Zurlo, F., Lillioja, S., Esposito, D. P. A., Nyomba, B. L., Raz, I., Saad, M. F., Swinburn, B. A., Knowler, W. C., Bogardus, C., and Ravussim, E. Low ratio of fat to carbohydrate oxidation as predictor of weight gain: study of 24-h RQ. Am J Physiol. 259." E650-E657, 1990. 


\title{
Role of glycogen-lowering exercise in the change of fat oxidation in response to a high-fat diet
}

Patrick Schrauwen, Wouter D van Marken Lichtenbelt, Wim H M Saris, and Klaas R Westerterp

Department of Human Biology, Maastricht University, Maastricht, The Netherlands American Journal of Physiology, 273: E623-E629, 1997.

\begin{abstract}
One of the candidate factors for determining the increase of fat oxidation after a switch from a reduced-fat diet to a high-fat diet is the size of the glycogen storage. Therefore, we studied the effect of low glycogen stores on fat oxidation after a switch from a reduced-fat diet to a high-fat diet. Twelve healthy, non-obese males and females (age: $22 \pm 1$, BMT: $21.0 \pm 0.7, \mathrm{~W}_{\max }: 254 \pm 11 \mathrm{~W}$ att) consumed a reduced-fat diet $(30 / 55 / 15 \%$ of energy from fat, carbohydrate and protein respectively) three times at home for 3 days (day 1-3). On two occasions subjects came to the laboratory on day 3 at 15.00 to perform an exhaustive glycogen lowering exercise (EX), where after they went into the respiration chamber for a $36 \mathrm{~h}$ stay. On one occasion, subjects directly entered the respiration chamber at 18:00 for a $36 \mathrm{~h}$ stay. In the respiration chamber they were given either a high-fat diet (HF, 60/25/15\% of energy from fat, carbohydrate and protein respectively) or a reduced-fat diet (RF). In both cases they were fed at energy balance. All diets were consumed as breakfast, lunch "dinner and two or more snacks per day. On the HF treatment, fat oxidation was below fat intake, indicating the slow change of oxidation to intake on a high-fat diet. After the HF+EX treatment, however, fat oxidation matched fat intake. In conclusion: lean subjects are capable of rapidly adjusting fat oxidation to fat intake when glycogen stores are lowered by exhaustive exercise.
\end{abstract}




\section{Introduction}

The incidence of obesity is still increasing in affluent societies. Both increased fat content of the diet and decreased physical activity have been proposed to explain this phenomenon (4). Therefore, much attention has been paid to energy and substrate metabolism in obesity. It was found that weight maintenance requires, apart from energy balance, balances of the separate macro nutrients. For protein and carbohydrate such balances are maintained within narrow ranges. Fat balance is more depending on energy balance (1). Important work in this field is done by Flatt, who has postulated a two compartment model (8). This model states that, in response to an increase in dietary fat content, fat oxidation can be increased by two mechanisms: 1) Glycogen stores can be maintained in a lower range, leading to lower glucose and insulin concentrations between meals, and hence higher fatty acid concentrations and higher rates of fat oxidation and/or 2) expansion of the adipose tissue mass which leads to enhanced fat oxidation.

In humans, it has been shown that fat intake does not promote its own oxidation (26). In a previous study, we showed that, when dietary fat content is increased, lean subjects are capable of adjusting fat oxidation to fat intake within 7 days (25). In this study, subjects spent 2 days on a reduced fat diet ( 30 en\% as fat) and subsequently 3 days on a high-fat diet ( $60 \mathrm{en} \%$ as fat) in the respiration chamber. After seven days on the high-fat diet subjects spent another day in the respiration chamber. Fat oxidation gradually increased on the high-fat diet and equaled fat intake 7 days after the dietary switch. During the first days on the high fat diet negative carbohydrate balances were found (on average $-142 \mathrm{~g}$ ). We therefore suggested that declining glycogen stores might be responsible for the gradual increase in fat oxidation. However, other mechanisms such as increased enzymatic capacity for fat oxidation might be responsible for the increase in fat oxidation.

In this study we investigated the role of glycogen stores in the change of fat oxidation in response to a high-fat diet. Glycogen was lowered by means of exercise bouts, and substrate oxidation was measured using a respiration chamber. We hypothesized that the change in fat oxidation in response to an increased fat intake can be accelerated when glycogen stores are low.

\section{Methods}

\section{Subjects}

The characteristics of the 12 volunteers ( 6 men, 6 women) participating in this study are shown in table 4.1. All subjects were healthy, untrained (not active in any sport, no training history) and non-obese. Subjects' habitual energy intake was $11.0 \pm 0.7$ $\mathrm{MJ} / \mathrm{day}$, with $34 \pm 1 \%, 52 \pm 2 \%$ and $13 \pm 1 \%$ of energy from fat, carbohydrate and protein, respectively. The study was approved by the Ethical Committee of the Maastricht University and subjects gave their written informed consent. 
Table 4.1 Subjects characteristics

\begin{tabular}{lcccccc}
\hline Subject & $\begin{array}{c}\text { Age } \\
\mathrm{y}\end{array}$ & $\begin{array}{c}\text { Weight } \\
\mathrm{kg}\end{array}$ & $\begin{array}{c}\text { Percent fat } \\
\%\end{array}$ & $\begin{array}{c}\mathrm{BMI} \\
\mathrm{kg} / \mathrm{m}^{2}\end{array}$ & $\begin{array}{c}\text { Wmax } \\
\text { watt }\end{array}$ & $\begin{array}{c}\text { Wmax/kg ffm } \\
\text { watt }\end{array}$ \\
\hline total & $21.5 \pm 0.7$ & $66.7 \pm 2.2$ & $19 \pm 3$ & $21.0 \pm 0.7$ & $254 \pm 11$ & $4.71 \pm 0.14$ \\
males & $20.8 \pm 1.1$ & $68.0 \pm 3.2$ & $11 \pm 3 \#$ & $19.8 \pm 0.4$ & $279 \pm 20 *$ & $4.66 \pm 0.19$ \\
females & $22.2 \pm 1.0$ & $65.5 \pm 2.9$ & $27 \pm 1$ & $22.2 \pm 1.1$ & $229 \pm 11$ & $4.77 \pm 0.16$ \\
\hline
\end{tabular}

Values are mean \pm s.e.m.

* $\mathrm{p}<0.05$ compared to females

\# $\mathrm{p}<0.001$ compared to females

\section{Experimental design}

The experimental design is depicted in figure 4.1. Each subject followed three different treatments. Treatments were separated by at least one week and conducted in random order. Each treatment consisted of a 36-hour stay in the respiration chamber. Prior to all three treatments, subjects were given a reduced-fat diet for consumption at home for three days (day 1-3). On two occasions subjects came to the laboratory on day three at 15.00 to perform an exhaustive glycogen lowering exercise (EX), and to then enter the respiration chamber at 18:00 for a 36h stay. In the respiration chamber they were given either a high-fat diet (HF+EX) or a reduced-fat diet $(\mathrm{RF}+\mathrm{EX})$. The reduced fat diet contained 30 energy $\%$ fat, as is often recommended in the prevention of obesity (4). On the third occasion no glycogen lowering exercise was performed, but subjects directly entered the respiration chamber at 18:00 for a $36 \mathrm{~h}$ stay, where they were given a high-fat diet (HF). On the morning of day 5, subjects left the respiration chamber at 8:00 am.

\section{Maximal power output}

One week before the experimental treatment each subject performed an incremental exhaustive exercise test on an electronically braked cycle ergometer (Lode Excalibur, Groningen, The Netherlands) to determine maximal heart rate and maximal power output $\left(\mathrm{W}_{\max }\right)$. Exercise was performed until voluntary exhaustion or until the subject could no longer maintain a pedal rate of more than $60 \mathrm{rpm}$. Female subjects started at 50 Watt and male subjects at 75 Watt for 5 minutes. Thereafter, work load was increased by 50 Wat every 2.5 minute. When subjects were approaching exhaustion, as indicated by heart rate and subjective scoring, the increment was reduced to 25 Watt. In practice, this meant that the last 1 to 3 load increments were 25 Watt. Heart rate was registered continuously using a Polar Sport tester (Kempele, Finland). In each individual $\mathrm{W}_{\max }$ was calculated from:

$$
\mathrm{W}_{\max }=\mathrm{W}_{\text {out }}+(\mathrm{t} / 150) * \partial \mathrm{W}
$$

in which $W_{\text {out }}$ is the highest workload completed by the subject, $t$ is the time (in seconds) performed on the last workload and $\partial \mathrm{W}$ is the final uncompleted load increment (15). 


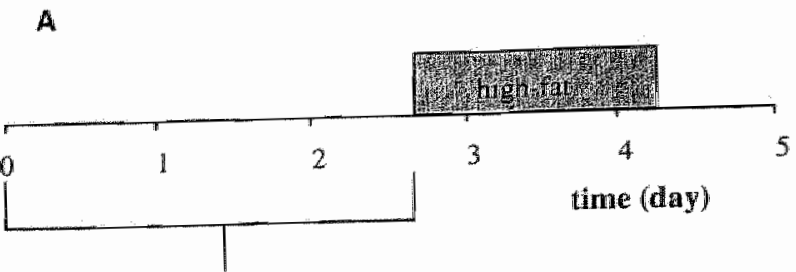

reduced-fat diet

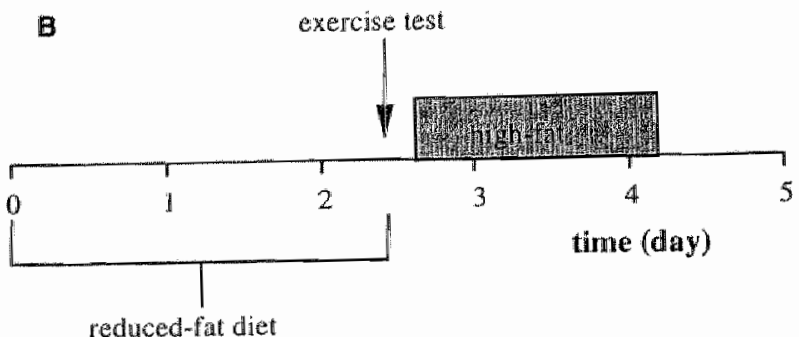

C

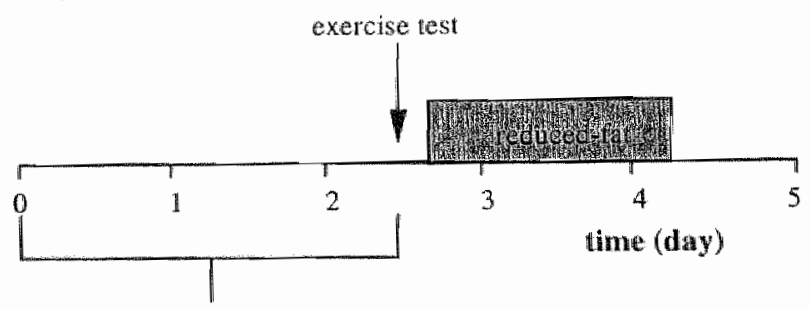

reduced-fat dien $=36 h$ stay in respiration chamber

Figure 4.1 Experimental design of the 3 different treatments. A: high-fat diet (HF) treat ment; $B: H F$ plus exercise $(H F+E X)$ treatment; $C$ : reduced-fat diet $+\mathbb{E X}$ $(\mathrm{RF}+\mathrm{EX})$ treatment. Time measured in days.

Glycogen lowering exercise

After fasting for two hours, the subjects came to the lab at 15:00 to perform a glycogen lowering exercise test. After a warming up at $50 \%$ of their maximal power output $\left(W_{\max }\right)$ for 5 minutes, subjects cycled two minutes on $90 \%$ of $\mathrm{Wmax}$ followed by two minutes on $50 \%$ of $\mathrm{W}_{\max }$. This was repeated until subjects were no longer able to perform the high intensity exercise. The maximal intensity was then lowered 
to $80 \%$ of $\mathrm{W}_{\max }$. Again, when this intensity could no longer be maintained, the maximal intensity was decreased to $70 \%$ of $W_{\max }$. The test was ended after exhaustion. Subjects were allowed to consume water during exercise. During the exercise heart rate was measured continuously with a polar sport tester. Energy expended during the exercise was calculated by assuming a mechanical efficiency of $20 \%$ (11).

\section{Diets}

Prior to the experiment subjects filled in a three day food intake record, to estimate habitual diet composition. Metabolizable energy intake and macronutrient composition of the diet was calculated using the Dutch food composition table (28). In the table metabolizable energy is calculated by multiplying the amount of protein, fat and carbohydrate with the Atwater factors $(16.74,37.66$ and $16.74 \mathrm{~kJ} / \mathrm{g}$ for carbohydrate, fat and protein, respectively) (19). The amount of protein, fat and carbohydrate was multiplied by $0.909,0.948$ and 0.953 respectively to correct for digestibility of macronutrients. All experimental diets were consumed as breakfast, lunch, dinner and 2 or more snacks per day. The composition of experimental diets is given in table 4.2. All snacks had the same macronutrient composition as the experimental diet.

Table 4.2 Composition of experimental diets

\begin{tabular}{lcc}
\hline & reduced-fat diet & high-fat diet \\
\hline Protein (\% of total energy) & 15 & 15 \\
Carbohydrate (\% of total energy) & 55 & 25 \\
Fat (\% of total energy) & 30 & 60 \\
Food Quotient & 0.88 & 0.80 \\
\hline
\end{tabular}

On days 1 and 2 and the first part of day 3 , a reduced-fat diet for consumption at home was provided. Subjects were given a fixed amount of food (based on their food intake record) and ad libitum access to snacks. On the evening of day 3, subjects consumed their dinner and evening snack (either low- or high-fat) in the respiration chamber. In the HF treatment energy intake for dinner and evening snack was fixed at $35 \%$ and $15 \%$ of estimated daily energy expenditure $(1.7 *$ BMR based on the Harris and Benedict equations; for women: $\mathrm{BMR}=2.74+0.774 * \mathrm{H}+0.040^{*} \mathrm{BM}$ $0.020^{*} \mathrm{~A}$ and for men: $\mathrm{BMR}=0.28+2.093^{*} \mathrm{H}+0.058^{*} \mathrm{BM}-0.028^{*} \mathrm{~A}$, in which $B M R$ is in $M J / d a y, H$ is height in $\mathrm{m}, \mathrm{BM}$ is body mass in $\mathrm{kg}$, and $\mathrm{A}$ is age in years) (12). In the RF+EX and HF+EX treatments, the evening snack had an energy content equall to energy expended during the exercise test. On day 4 , subjects were given an amount of energy equal to 1.55 times sleeping metabolic rate (SMR), as measured during the preceding night. In a previous study it was shown that with a comparable activity protocol used in the chamber a physical activity index of 1.58 was reached (20). 


\section{Body composition}

Subjects weighed themselves in the respiration chamber on the morning of day 4 and 5 , without clothing, after voiding and before eating and drinking. Measurements were done on a digital balance (Seca delta, model 707) with an accuracy of $0.1 \mathrm{~kg}$.

Whole body density was determined by underwater weighing in the morning in the fasted state. Body weight was measured with a digital balance with an accuracy of $0.01 \mathrm{~kg}$ (Sauter, type E1200). Lung volume was measured simultaneously with the helium dilution technique using a spirometer (Volugraph 2000, Mijnhardt). Percent body fat was calculated using the equations of Siri (27). Fat-free mass (FFM) in $\mathrm{kg}$ was calculated by subtracting fat mass from total body mass.

\section{Indirect calorimetry and physical activity}

Oxygen consumption and carbon dioxide production were measured in a wholeroom indirect calorimeter (24). The respiration chamber is a $14 \mathrm{~m}^{3}$ room furnished with a bed, chair, television, radio, telephone, intercom, wash bowl and toilet. The room is ventilated with fresh air at a rate of $70-80 \mathrm{l} / \mathrm{min}$. The ventilation rate is measured with a dry gas meter (Schlumberger, type G6, The Netherlands). The concentrations of oxygen and carbon dioxide are measured using a paramagnetic $\mathrm{O}_{2}$ analyzer (Hartmann \& Braun, type Magnos G6, Germany) and an infrared $\mathrm{CO}_{2}$ analyzer (Hartmann \& Braun, type Uras $3 \mathrm{G}$, Germany). Ingoing air is analyzed every 15 minutes and outgoing air once every 5 minutes. The gas sample to be measured is selected by a computer that also stores and processes the data. Energy expenditure is calculated from $\mathrm{O}_{2}$ consumption and $\mathrm{CO}_{2}$ production according to the method of Weir (32).

In the respiration chamber subjects followed an activity protocol consisting of fixed times for breakfast, lunch and dinner, sedentary activities and bench stepping exercise. The bench stepping exercise was performed for 30 minutes at intervals of 5 minutes exercise alternated with 5 minutes rest, at a rate of 60 steps per minute with a bench height of $33 \mathrm{~cm}$, and was repeated three times a day. Thus, subjects exercised for 45 minutes per day, at a relative low-to-medium intensity. At daytime, no sleeping or other exercise was allowed during the stay in the respiration chamber. All physical activity of the subjects was monitored by means of a radar system based on the Doppler principle.

\section{Urinary nitrogen excretion}

During the stay in the respiration chamber urine was collected in two batches, one from $20.00 \mathrm{pm}$ to 8.00 am and the second over the subsequent $24 \mathrm{~h}$ interval. Subjects were requested to empty the bladder at $8.00 \mathrm{am}$. The urine produced was included in the urine sample of the previous batch. Samples were collected in containers with 10 $\mathrm{ml.} \mathrm{H}_{2} \mathrm{SO}_{4}$ to prevent nitrogen loss through evaporation; volume and nitrogen concentration were measured, the latter using a nitrogen analyzer (Heraeus, type
CHN-Rapid). 


\section{4 energy expenditure and substrate oxidation}

Subjects stayed in the respiration chamber for 36 hours. Data from 20.00 pm on day 3 to 8.00 am on day 4 are presented to study short term effects of treatments. For calculating balances, $24 \mathrm{~h}$ energy expenditure ( $24 \mathrm{~h} \mathrm{EE}$ ) and $24 \mathrm{~h}$ respiratory quotient (24h RQ) were measured from $8.00 \mathrm{~h}$ am on day 4 to $8.00 \mathrm{~h}$ am on day 5 . Sleeping metabolic rate (SMR) was defined as the lowest mean energy expenditure during three subsequent hours measured between $0.00 \mathrm{~h}$ am and $8.00 \mathrm{~h}$ am with a minimal activity level as indicated by the radar system.

Carbohydrate, fat and protein oxidation were calculated using $\mathrm{O}_{2}$ consumption, $\mathrm{CO}_{2}$ production and urinary nitrogen losses with the equations of Brouwer (5).

Protein oxidation $(\mathrm{g} / \mathrm{d})=6.25 * \mathrm{~N}$

Fat oxidation $(\mathrm{g} / \mathrm{d})=1.718^{*} \mathrm{VO}_{2}-1.718 * \mathrm{VCO}_{2}-0.315 * \mathrm{P}$

Carbohydrate oxidation $(\mathrm{g} / \mathrm{d})=4.17 * \mathrm{VCO}_{2}-2.965 * \mathrm{VO}_{2}-0.390 * \mathrm{P}$

where $\quad \mathrm{N}$ is the total nitrogen excreted in urine ( $\mathrm{g} /$ day)

$\mathrm{VO}_{2}$ is the oxygen consumption ( $1 /$ day)

$\mathrm{VCO}_{2}$ is the carbon dioxide production (l/day)

$P$ is protein oxidation $(\mathrm{g} / \mathrm{day})$

\section{Statistical analysis}

All data are presented as mean \pm S.E.M. Equality of RQ and food quotient (FQ), energy intake and energy expenditure as well as substrate intake and substrate oxidation was determined by calculating the $95 \%$ confidence intervals for differences. A non-parametric Wilcoxon test, using a Bonferonni correction, was used to detect any differences in measured parameters between treatments.

\section{Results}

Time till exhaustion during the exercise test was not significantly different between the RF+EX and HF+EX treatment: $71 \pm 4$ and $69 \pm 4$ min, respectively. Also, no difference in energy expended during the exercise tests was found: $3.4 \pm 0.8$ and 3.5 $\pm 0.3 \mathrm{MJ}$ for $\mathrm{RF}+\mathrm{EX}$ and HF+EX treatments, respectively.

Body weight, as measured in the respiration chamber, was not significantly different between any of the treatments (table 4.3).

Table 4.3 Sleeping metabolic rate (SMR), physical activity index (PAI), and body weight as measured in the respiration chamber (mean \pm s.e.m.)

\begin{tabular}{llccc}
\hline treatment & $\begin{array}{c}\text { SMR night 1 } \\
\mathrm{kJ} / \mathrm{min}\end{array}$ & $\begin{array}{c}\text { SMR night 2 } \\
\mathrm{kJ} / \mathrm{min}\end{array}$ & PAI \# & $\begin{array}{c}\text { body weight } \\
\mathrm{kg}\end{array}$ \\
\hline $\mathrm{RF}+\mathrm{EX}$ & $4.52 \pm 0.14^{*}$ & $4.42 \pm 0.15$ & $1.60 \pm 0.02$ & $66.8 \pm 2.3$ \\
$\mathrm{HF}$ & $4.32 \pm 0.14$ & $4.42 \pm 0.15$ & $1.57 \pm 0.03$ & $66.6 \pm 2.3$ \\
$\mathrm{HF}+\mathrm{EX}$ & $4.52 \pm 0.17 \$$ & $4.44 \pm 0.15$ & $1.59 \pm 0.02$ & $66.7 \pm 2.3$ \\
\hline
\end{tabular}

\# physical activity index: 24 h energy expenditure/ $24 \mathrm{~h}$ sleeping metabolic rate

* $\mathrm{p}<0.05$ compared to HF

$\$ \mathrm{p}=0.056$ compared to $\mathrm{HF}$ 
Sleeping metabolic rate measured during the first night was significantly increased in the $\mathrm{RF}+\mathrm{EX}$ treatment compared to the HF treatment $(\mathrm{p}<0.05)$. In the HF+EX treatment sleeping metabolic rate tended to be increased compared to the HF treatment $(p=0.06)$. However, sleeping metabolic rate measured during the second night was not significantly different between any of the treatments (table 4.3). Twenty-four hour energy expenditure (table 4.4) and physical activity index ( $=24 \mathrm{~h}$ EE/SMR, table 4.3) were not significant different between treatments.

Table 4.4 Energy intake, energy expenditure and energy balance (MJ/day) as measured in the respiration chamber $(8: 00-8: 00)$ on three different treatments

\begin{tabular}{lccc}
\hline treatment & Intake & Expenditure & Balance \\
& $\mathrm{MJ}$ & $\mathrm{MJ}$ & $\mathrm{MJ}$ \\
\hline $\mathrm{RF}+\mathrm{EX}$ & $10.02 \pm 0.38$ & $10.19 \pm 0.38$ & $-0.17 \pm 0.19$ \\
$\mathrm{HF}$ & $10.00 \pm 0.37$ & $9.99 \pm 0.32$ & $+0.00 \pm 0.21$ \\
$\mathrm{HF}+\mathrm{EX}$ & $10.04 \pm 0.37$ & $10.17 \pm 0.38$ & $-0.13 \pm 0.16$ \\
\hline
\end{tabular}

Values are mean \pm s.e.m.

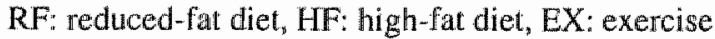

On the evening following the exercise test subjects were given an amount of energy to compensate for the energy expended during the exercise bout. Therefore, of course, a positive energy balance was measured during the first 12 hour in the chamber. However, this positive energy balance was not significantly different

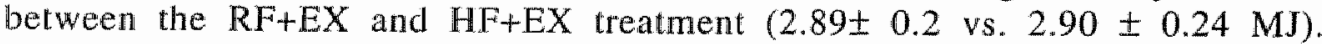
Respiratory quotient (RQ) during the first 12 hours in the respiration chamber was $0.843 \pm 0.014,0.846 \pm 0.023$ and $0.803 \pm 0.015$ for the RF+EX, HF and HF+EX treatments respectively. The $\mathrm{RQ}$ in the $\mathrm{HF}+\mathrm{EX}$ was significantly lower compared to the RF+EX and HF treatment $(p<0.01)$. In the HF treatment all energy of the positive energy balance $(1.71 \pm 0.19 \mathrm{MJ})$ was stored as fat. In the RF+EX treatment a positive carbohydrate balance of $136.6 \pm 22.5 \mathrm{~g}$ and a positive fat balance of $9.7 \pm 9.4 \mathrm{~g}$ was reached, while in the $\mathrm{HF}+\mathrm{EX}$ treatment those figures were $+48.7 \pm 21.8$ and $+49.3 \pm$ $26.6 \mathrm{~g}$ for carbohydrate and fat respectively. Thus, glycogen was more repleted in the $\mathrm{RF}+\mathrm{EX}$ treatment compared to the $\mathrm{HF}+\mathrm{EX}$ treatment and, as a result, differences in glycogen store were obtained.

In all three tests, 24 h energy balance (day 4 ) was not significantly different from zero. Twenty four hour RQ was significantly different between all treatments $(\mathrm{P}<0.05) . R Q$ was lowest in the HF+EX treatment, and highest in the RF+EX treatment (figure 4.2). Respiratory quotient was significantly different from food quotient (FQ) in the $\mathrm{HF}$ and $\mathrm{RF}+\mathrm{EX}$ treatment $(\mathrm{p}<0.05)$. In the $\mathrm{HF}+\mathrm{EX}$ treatment $\mathrm{RQ}$ and $\mathrm{FQ}$ were not significantly different (figure 4.2).

Twenty-four hour protein oxidation was not significantly different among treatments (table 4.5 ). In the RF+EX treatment protein intake was significantly higher compared to the $\mathrm{HF}$ and $\mathrm{HF}+\mathrm{EX}$ treatments $(84 \mathrm{vs} .78 \mathrm{~g} / \mathrm{day}$, table $4.5, \mathrm{p}<0.05$ ) resulting in a significantly positive protein balance in the RF+EX treatment (figure 4.3, $\mathrm{p}<0.05$ ). 


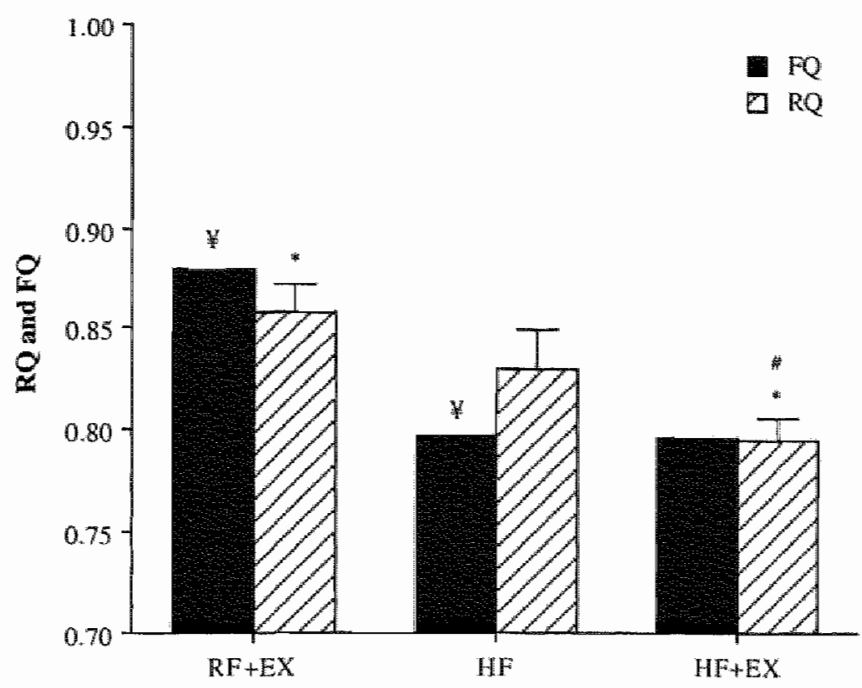

Figure 4.2 Twenty-four hour respiratory quotients (RQ) and food quotients (FQ) as measured in respiration chamber for day 4 (mean \pm s.e.m.). Significant difference $(\mathrm{p}<0.05)$ vs. *HF; \#RF+EX; $\mathrm{ZRQ}$.

Twenty fou hour carbohydrate oxidation was significantly different among all treatments, being highest in the RF+EX treatment and lowest in the HF+EX treatment ( $<<0.01$, table 4.5 ), resulting in positive carbohydrate balance in the $R F+E X$ treatment and negative carbohydrate balance in the HF treatment (figure 4.3).

Table 4.5 Carbohydrate, fat and protein intake and oxidation (g/day) as measured in the respiration chamber (8:00-8:00) on the three different treatments

\begin{tabular}{|c|c|c|c|c|c|c|}
\hline \multirow[t]{2}{*}{ treatment } & \multicolumn{2}{|c|}{$\mathrm{CHO}$} & \multicolumn{2}{|c|}{ Falt } & \multicolumn{2}{|c|}{ Protein } \\
\hline & intake & oxidation & intake & oxidation & intake & oxidation \\
\hline $\mathrm{RF}+\mathrm{EX}$ & $334 \pm 13 *$ & $283 \pm 13$ & 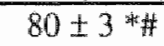 & $101 \pm 6 *$ * & $85 \pm 3 *$ & $67 \pm 4$ \\
\hline HF & $160 \pm 6$ & $219 \pm 10 \#$ & $160 \pm 6$ & $124 \pm 8 \#$ & $76 \pm 5$ & $68 \pm 3$ \\
\hline $\mathrm{HF}+\mathrm{EX}$ & $159 \pm 6$ & $\rrbracket 49 \pm 6$ & $161 \pm 6$ & $156 \pm 9$ & $77 \pm 4$ & $75 \pm 4$ \\
\hline
\end{tabular}

\footnotetext{
Values are mean \pm s.e.m.

RF: reduced-fat diet, $\mathrm{HF}$ : high-fat diet, EX: exercise

p $<0.05$ compared to $\mathrm{HF}$

\# $\mathrm{p}<0.05$ compared to $\mathrm{HF}+\mathrm{EX}$
}

Twenty four hour fat oxidation was significantly different among all treatments, being lowest in the RF+EX treatment and highest in the HF+EX treatment $(\mathrm{p}<0.05$, table 4.5), resulting in negative fat balance in the RF+EX treatment, positive fat balance in the HF treatment and zero fat balance in the HF+EX treatment (figure 4.3). 


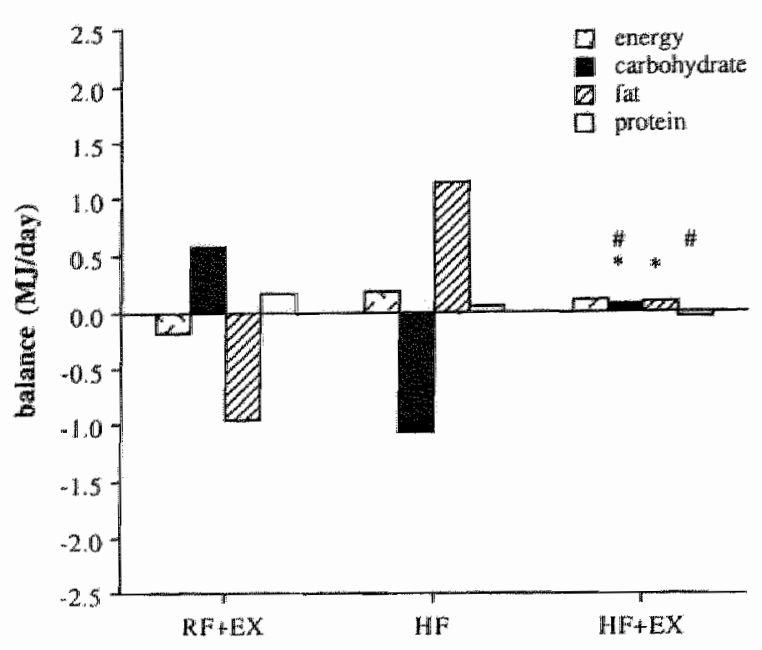

Figure 4.3 Twenty-four hour energy and substrate balances for day 4 as measured in respiration chamber (mean \pm s.e.m.). Significant difference ( $\mathrm{p}<0.05$ by Wilcoxon signed-rank test) vs. *HF; \#RF+EX.

\section{Discussion}

The results of the present study demonstrate that, after a switch from a reduced-fat diet to a high-fat diet under conditions of energy balance, fat oxidation can be increased rapidly to levels that match fat intake, when glycogen stores are lowered by exhaustive exercise. After glycogen lowering exercise in combination with a high-fat diet, fat oxidation was equal to fat intake, whereas on the high-fat diet without glycogen lowering exercise, fat oxidation was not increased sufficiently to match fat intake. After glycogen lowering exercise in combination with the reduced-fat diet, glycogen was partly repleted and the increase in fat oxidation was less marked, providing another indication of the important role of glycogen content in the regulation of fat oxidation.

Flatt (8) has proposed a model in which he states that, on a high-fat diet, fat oxidation can be increased by two mechanisms. Firstly, fat oxidation can be raised by maintaining glycogen stores in a lower range. Secondly, expansion of the fat mass will lead to increase in fat oxidation (2). In our experiment subjects were fed at energy balance and therefore expansion of the fat mass was negligible. We found that, on the high-fat diet fat oxidation was increased sufficiently to equal fat intake, when glycogen stores were low. Therefore, our data are in agreement with the model of Flatt, and demonstrate the importance of glycogen stores in increasing fat oxidation on a high-fat diet. Both in the RF+EX as in the HF+EX treatments, gllycogen was lowered by means of exercise. During the first 12 hours in the chamber, carbohydrate balance was more positive during the RF+EX treatment compared to the HF+EX treatment $(+137 \mathrm{~g}$ vs. $+49 \mathrm{~g})$. Considering the size of the positive carbohydrate balance and the prior exercise regime, most likely this positive carbohydrate balance is stored as glycogen. Therefore glycogen was more repleted in 
the RF+EX treatment. The difference in fat oxidation between the RF+EX and $\mathrm{HF}+\mathrm{EX}$ treatment can thus be explained by differences in both glycogen stores and exogenous carbohydrate availability. However, the higher fat oxidation in the $\mathrm{HF}+\mathrm{EX}$ treatment compared to the HF treatment (same exogenous carbohydrate availability) indicates the important role glycogen stores play in the regulation of fat oxidation.

In this study, we assumed that subjects on the reduced-fat diet (which was almost similar to their habitual diet) would have been in substrate balance. This would mean that the glycogen lowering exercise increased fat oxidation by $21 \mathrm{~g}$ on the reducedfat diet, whereas on the high-fat diet fat oxidation was increased by $32 \mathrm{~g}$, the difference most likely due to lower glycogen stores in the HF+EX treatment compared to the $\mathrm{RF}+\mathrm{EX}$ treatment.

Using indirect calorimetry for the assessment of substrate oxidation requires some precaution. The assumptions involved in using indirect calorimetry to determine substrate utilization have been reviewed by Livesey and Elia (17). They concluded that the accuracy of indirect calorimetry for assessing substrate oxidation is at best within $5 \%$ of the true value. Stubbs et al. (29) reported an accuracy of $\pm 20 \mathrm{~g} / \mathrm{day}$ and $9.5 \mathrm{~g} /$ day for $24 \mathrm{~h}$ carbohydrate and fat oxidation respectively as measured in a respiration chamber. Thus, changes in substrate oxidation of $64 \mathrm{~g} /$ day and $23 \mathrm{~g} / \mathrm{day}$ for carbohydrate and fat oxidation respectively (table 4.5 ) reported in the present study are well detectable.

In our study we lowered the glycogen stores by means of exercise. It is well known that during exercise at high intensities the major substrate for oxidation is carbohydrate. It has repeatedly been shown in our laboratory by Kuipers et al (16) and Wagenmakers et al. (31) and in other laboratories $(18,13,33,6)$ that glycogen stores in muscle are significantly decreased both in male and female subjects after exhaustive exercise protocols. The energy expended in both exercise tests was the same, so it can be assumed that glycogen was lowered to the same level. To prevent increases in fat oxidation due to an exercise-induced negative energy balance on the exercise day, energy intake on the first evening in the chamber was based on the energy expended during exercise. This resulted in a positive energy balance which was of the same magnitude in the HF+EX and RF+EX treatment. However, there was a difference in carbohydrate balance. Thus the protocol used must have resulted in differences in glycogen repletion and therefore differences in fat oxidation between the HF+EX and RF+EX treatment.

It is possible that the exercise bout itself resulted in other (hormonal) adaptations which accelerated fat oxidation. Bielinski et al. (3) found in their study that 2.5 hours after cessation of exercise FFA, glycerol and glucagon concentrations returned to their control values. This indicates that the (hormonal) disturbances induced by exercise are not long lasting. In our study the elevation in fat oxidation on the $\mathrm{HF}+\mathrm{EX}$ treatment was long-lasting. Respiratory quotient during sleep, for example, was not significantly different between the first and second night in the respiration 
chamber both in the RF+EX and HF+EX treatment (data not shown). If the elevation in fat oxidation was an exercise effect other than glycogen lowering, it would be expected that fat oxidation would have returned to lower levels after 36 hours. We therefore conclude that the increase in fat oxidation was long-lasting and cannot be explained by the exercise itself, but can be explained by low glycogen stores.

The mechanism by which low glycogen levels may lead to increased fat oxidation is not clear. Randle et al. (21) introduced the "glucose-fatty acid cycle" in 1963 to describe the interaction between fat and carbohydrate oxidation. They suggested that an increased availability of FFA leads to an increased fat oxidation. In our study the glycogen lowering exercise, especially in combination with the high-fat diet, might have resulted in lower insulin levels, and thus less inhibition of lipolysis (7), in turn leading to increased FFA availability and, according to the "glucose-fatty acid cycle", increased fat oxidation. However, a recent study in rats showed that glycogen depletion per se does not result in increased FFA uptake and oxidation, but increased blood glucose utilization, even at high FFA levels (30). In our experiment fat oxidation was highest when total carbohydrate availability was low. It therefore seems that carbohydrate oxidation takes priority over fat oxidation and that total carbohydrate availability regulates fat oxidation, for example through the conversion of acetyl-coA into malonyl-coA, which is an important inhibitor of carnitine palmitoyltransferase (CPT), necessary for FFA uptake and thus oxidation (22). This might explain why fat oxidation does not match fat intake on the short-term as long as endogenous carbohydrate availability is high. Further studies are necessary to elicit the exact mechanism behind the increase in fat oxidation when glycogen levels are decreased.

Recently, Fleury et al. (10) reported the discovery of a gene that codes for the uncoupling protein-2 (UCP2), which might have a role in diabetes and obesity. UCP2, which is expressed in a number of adult human tissues, might be involved in the regulation of energy balance by influencing energy expenditure and thermogenesis. On a high-fat diet UCP2 mRNA levels were significantly increased and raised levels of FFA may very well activate UCP2 in white adipocytes. Future work must reveal whether this finding is important for the interpretation of our results.

This experiment was performed in healthy, non-obese subjects. It has to be examined whether the same results can be found in obese subjects. Obesity often has been linked to a high fat intake and therefore much attention has been focused on decreasing the percentage of energy intake derived from fat (14). Due to the high energy density of high-fat foods this strategy may lead to decreased energy intake and in this way be effective in the treatment of obesity. Another factor that might explain the increased prevalence of obesity in westerm societies is a low level of physical activity $(9,23)$. Our results show that acute exercise (accompanied by decreasing glycogen concentration) is an effective method to handle a high fat intake. The same level of physical activity in combination with a reduced-fat diet resulted in a negative fat balance. Therefore, regular physical activity can be an effective strategy in the prevention of obesity. Apart from training effects which 
might stimulate fat oxidation, regular physical activity can prevent obesity by causing glycogen stores to be maintained in a lower range (9).

In conclusion, our results demonstrate that, after switching from a reduced-fat diet to a high-fat diet, lean subjects are capable of adjusting fat oxidation to fat intake when glycogen stores are lowered by exhaustive exercise.

\section{References}

1. Abbott, W. G. H., Howard, B. V., Christin, L., Freymond, D., Lillioja, S., Boyce, V. L., Anderson, T. E., Bogardus, C., and Ravussin, E. Short-term energy balance: relationship with protein, carbohydrate, and fat balances. Am J Physiol. 255: E332-337, 1988.

2. Astrup, A., Buemann, B., Western, P., Toubro, S., Raben, A., and Christensen, N. J. Obesity as an adaptation to a high-fat diet: evidence from a cross-sectional study. Am J Clin Nurr. 59: 350-5, 1994.

3. Bielinski, R., Schutz, Y., and Jéquier, E. Energy metabolism during the postexercise recovery in man. Am J Clin Nutr. 42: 69-82, 1985.

4. Bouchard, C. Can obesity be prevented? Nutr Rev. 54: S125-S130, 1996.

5. Brouwer, E. On simple formulae for calculating the heat expenditure and the quantities of carbohydrate and fat oxidized in metabolism of men and animals, from gaseous exchange (oxygen intake and carbonic acid output) and urine-n. Acta Physiol Pharmacol Neerlandica. 6: 795-802, 1957.

6. Burke, L. M., Collier, G. R., Davis, P. G., Fricker, P. A., Sanigorski, A. J., and Hargreaves, M. Muscle glycogen storage after prolonged exercise: Effect of the frequency of carbohydrate feedings. Am J Clin Nutr. 64: 115-119, 1996.

7. Campbell, P. J., Carlson, M. G., Hill, J. O., and Nurjhan, N. Regulation of free fatty acid metabolism by insulin in humans: role of lipolysis and reesterification. Am J Physiol. 263: E1063-E1069, 1992.

8. Flatt, J. P. The difference in the storage capacities for carbohydrate and for fat, and its implications in the regulation of body weight. Ann NY Acad Sci. 499: 104-23, 1987.

9. Flatt, J. P. Glycogen levels and obesity. Int J Obes. 20: S1-S11, 1996.

10. Fleury, C., Neverova, M., Collins, S., Raimbault, S., Champigny, O., Levi-Meyrueis, C., Bouillaud, F., Seldin, M. F., Surwit, R. S., Ricquier, D. Uncoupling protein-2: a novel gene linked to obesity and hyperinsulinemia. Nature Genetics. 15: 269-273, 1997.

11. Gaesser, G. A., and Brooks, G. A. Muscular efficiency during steady-state exercise: effects of speed and work rate. J Appl Physiol. 38: $1132-1139,1975$.

12. Harris, J. A., and benedict, F. G. A biometric study of basal metabolism in man. Washington. Carnegie Institution of Washington, 1919.

13. Ivy。 I. L., Frishberg, B. A., Farrell, S. W., Miller, W. J., and Sherman, W. M. Effects of elevated and exercise-reduced muscle glycogen levels on insulin sensitivity. $J$ Appl Physiol. 59: $154-9,1985$.

14. Klesges, R. C., Klesges, L. M., Haddock, C. K., and Eck, L. H. A longitudinal analysis of the impact of dietary intake and physical activity on weight change in adults. Am $J$ Clin Nutr. 55: 818-22, 1992.

15. Kuipers, H., Keizer, H. A., Brouns, F., and Saris, W. H. M. Carbohydrate feeding and glycogen synthesis during exercise in man. Pflugers Arch. 410: 652-656, 1987. 
16. Kuipers, H., Saris, W. H. M., Brouns, F, Keizer, H. A., and ten Bosch, C. Glycogen synthesis during exercise and rest with carbohydrate feeding in males and females. Int J Sports Med. 10: $\$ 63+567,1989$.

17. Livesey, G, and Elia, M. Estimation of energy expenditure, net carbohydrate utilization and net fat oxidation and synthesis by indirect calorimetry: ewaluation of errors with special reference to the detailled composition of fuels. Am J Clin Nutr. 47:608-628, 1988.

18. MacDougall, J. D., Ward, G. R., Sale, D. G, and Sutton, J. R. Muscle glycogen repletion after high-intensity intermittent exercise. J. Appl. Physiol. 42: 129-132, 1977.

19. Miles, C. W. The metabolizable energy of diets differing in dietary fat and fiber measured in humans. I Nutr. 122: 306-11, 1992.

20. Pannemans, D. L. E., Bouten, C. V. C., and Westerterp, K. R. 24 h energy expenditure during a standardized activity protocol in young and elderly men. Eur $J$ Clin Nutr. 49: 49-56, 1995.

21. Randle, P. J., Garland, P. B., Halles, C. N., and Newsholme, E. A. The glucose-fatty acid cycle: Its role in insulin sensitivity and the metabolic disturbances of diabetes mellitus. Lancet. i: $785-789,1963$.

22. Saha, A. K., Kurowski, T. G., and Ruderman, N. B. A malonyl-coA fuel-sensing mechanism in muscle: effects of insulin, glucose, and denervation. Am J Physiol. 269: E283-E289, 1995

23. Saris, W. H. M. Physical inactivity and metabolic factors as predictors of weight gain. Nutr Rev. 54: S110-S115, 1996.

24. Schoffelen, P. F. M., Saris, W. H. M., Westerterp, K. R., and ten Hoor, F. Evalution of an automatic indirect calorimeter for measurement of energy balance in man. Human Energy Metabolism: Physical Activity and Energy Expenditure Measurements in Epidemiological Research Based Upon Direct and Indirect Calorimetry. Wageningen, Euro-Nut. 51-54, 1984

25. Schratwen, P., Marken Lichtenbelt, W. D. v., Saris, W. H. M., and Westerterp, K. R. Changes in fat oxidation in response to a high-fat diet. Am $J$ Clin Nutr: 66:276-282, 1997.

26. Schutz, Y., Flatt, J. P., and Jequier, E. Failure of dietary fat intake to promote fat oxidation: a factor favoring the development of obesity. Am J Clin Nutr. 50: 307-14, 1989.

27. Siri, W. E. The gross composition of the body. Adv Biol Med Physiol. 4: 239-280, 1956.

28. Stichting-Nederlands-Voedingsstoffenbestand. NEVO Tabel. Den Haag, Voorlichtingsburesu voor de voeding, 1993.

29. Stubbs, R. J., Murgatroyd, P. R., Goldberg, G. R, and Prentice, A. M. Carbohydrate balance and the regulation of day-to-day food intake in humans. Am J Clin Nutr. 57: 897-903, 1993.

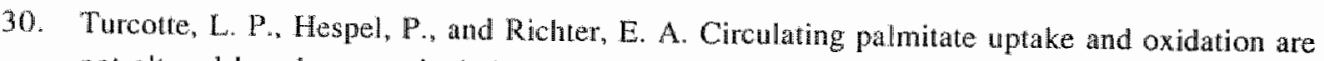
not altered by glycogen depletion in contracting skeletal muscle. $/$ Appl Physiol. 78: 1266$1272,1995$.

31. Wagenmakers, A. J. M., Beckers, E. J, Brouns, F., Kuipers, H., Soeters, P., Vusse, v. d. G. J., and Saris, W. H. M. Carbohydrate supplemenation, glycogen depletion, and amino acid metabolism during exercise. Am I Physiol. 260: E883-E890, 1991.

32. Weir, J. B. d. V. New methods for calculating metabolic rate with special reference to protein metabolism. J Physiol. 109: 1-9, 1949.

33. Zawadski, K. M., Yaspelkis, B. B., and Ivy, J. L. Carbohydrate-protein complex increases the rat of muscle glycogen storage after exercise. J. Appl. Physiol. 72: 1854-1859, 1992. 


\title{
Chapter 5
}

\section{Fat balance in obese subjects: role of glycogen stores}

Patrick Schrauwen, Wouter D van Marken Lichtenbelt, Wim H M Saris, and Klaas R Westerterp

Department of Human Biology, Maastricht University, Maastricht, The Netherlands

American Journal of Physiology, 274: E1027-E1033, 1998.

\begin{abstract}
In a previous study we showed that lean subjects are capable of rapidly adjusting fat oxidation to fat intake on a high-fat diet when glycogen stores were lowered by exhaustive exercise. However, it has been proposed that obese subjects have an impaired fat oxidation. Therefore, we studied the effect of low glycogen stores on fat oxidation after a switch from a reduced-fat diet to a high-fat diet in obese subjects. Ten healthy, obese males and females (age: $26 \pm 2$, BMI: $31.8 \pm 1.4, \mathrm{~W}_{\max }: 228 \pm 14$ Watt) consumed a reduced-fat diet $(30 / 55 / 15 \%$ of energy from fat, carbohydrate and protein respectively) at home for 3 days on four occasions (day 1-3). On two occasions subjects came to the laboratory on day 3 at 15.00 to perform an exhaustive glycogen lowering exercise test $(\mathrm{EX})$, whereafter they went into a respiration chamber for a $36 \mathrm{~h}$ stay. On the other two occasions, subjects directly entered the respiration chamber at 18:00 for a $36 \mathrm{~h}$ stay. In the respiration chamber they were fed, in energy balance, either a high-fat diet (HF, $60 / 25 / 15 \%$ of energy from fat, carbohydrate and protein respectively) or a reduced-fat diet (RF). All diets were consumed as breakfast, lunch, dinner and two or more snacks per day. Twenty-four hour respiratory quotient was $0.91 \pm 0.01,0.89 \pm 0.01,0.84 \pm 0.01$ and $0.81 \pm 0.01$ in the RF, RF+EX, HF and HF+EX treatment respectively. On the HF treatment, fat oxidation was below fat intake, indicating the slow change of oxidation to intake on a high-fat diet. After the HF + EX treatment, however, fat oxidation matched fat intake. In conclusion: obese subjects are capable of rapidly adjusting fat oxidation to fat intake when glycogen stores are lowered by exhaustive exercise.
\end{abstract}




\section{Introduction}

The high and still increasing prevalence of obesity in affluent societies is known to produce major health hazards. Apart from environmental factors it is now commonly accepted that obesity is also under the influence of genetic factors. However, the impact of environmental factors in the prevalence of obesity has been illustrated by Ravussin et al. (17). They studied two populations with similar genetic background (Pima Indians) living in different environments (Mexico and Arizona). The Mexican Pima Indians have a BMI which is 7-10 units lower than the Arizona Pima Indians, a difference which might be explained by the higher fat intake and lower spontaneous physical activity observed in the Arizona Pima Indians. Other studies also suggest an association between obesity and a high fat intake $(15,11)$. In humans, it has been shown that fat intake does not promote its own oxidation (21). Furthermore, in (pre-) obese subjects an impaired ability to oxidize fat has been shown $(27,24,3,6)$. Flatt (7) postulated a two compartment model, in which it is stated that fat oxidation can be increased to match fat intake by 1) maintaining glycogen stores in a lower range or 2) expansion of the adipose tissue mass. In a previous study we showed that lean subjects were capable of rapidly (within 24 hours) adjusting fat oxidation to fat intake, when glycogen stores were lowered by exhaustive exercise, whereas no complete adjustment of fat oxidation to fat intake occurred without glycogen lowering exercise (20). However, obesity has been described as an (mys)adaptation to a high fat diet (1). This might suggest that (pre-)obese subjects are not capable of rapidly adjusting fat oxidation to a high-fat intake by maintaining glycogen stores in a lower range. Another possibility however is that they have less fluctuations in their amount of glycogen stored, possibly due to low levels of physical activity. Therefore, we investigated whether obese subjects are capable of rapidly increasing fat oxidation on a high fat diet when glycogen stores are lowered by exhaustive exercise. We hypothesized that, compared to the lean subject in our previous study, the obese subjects are less capable of rapidly adjusting fat oxidation to fat intake on a high-fat diet when glycogen stores are lowered by exhaustive exercise.

\section{Methods \\ Subjects}

The characteristics of the 10 volunteers ( 4 men, 6 women) participating in this study are shown in table 5.1. All subjects were healthy, untrained (not active in any sport, no training history) and obese. No gender differences in the measured parameters of interest were observed and therefore data of males and females is pooled. Subjects" habitual energy intake was $9.5 \pm 0.6 \mathrm{MJ} /$ day, with $30.3 \pm 1.9 \%, 51.4 \pm 2.2 \%, 15.2 \pm$ 0.8 and $3.1 \pm 1.1 \%$ of energy from fat, carbohydrate, protein and alcohol, respectively. The study was approved by the Ethical Committee of the Maastricht University and subjects gave their written informed consent. 
Table 5.1 Subjects characteristics

\begin{tabular}{lcccccc}
\hline Subject & $\begin{array}{c}\text { Age } \\
\mathrm{y}\end{array}$ & $\begin{array}{c}\text { Weight } \\
\mathrm{kg}\end{array}$ & $\begin{array}{c}\text { Body fat } \\
\%\end{array}$ & $\begin{array}{c}\text { BMI } \\
\mathrm{kg} / \mathrm{m}^{2}\end{array}$ & $\begin{array}{c}\text { Wmax } \\
\text { watt }\end{array}$ & $\begin{array}{c}\text { Wmax/kg ffm } \\
\text { watt }\end{array}$ \\
\hline total & $25.9 \pm 1.8$ & $98.3 \pm 6.0$ & $38 \pm 3$ & $31.8 \pm 1.4$ & $228 \pm 14$ & $3.83 \pm 0.20$ \\
males & $29.8 \pm 3.6$ & $112.9 \pm 12.1^{*}$ & $34 \pm 5$ & $32.4 \pm 3.4$ & $259 \pm 30$ & $3.60 \pm 0.49$ \\
females & $23.3 \pm 1.2$ & $88.6 \pm 1.4$ & $41 \pm 3$ & $31.3 \pm 1.0$ & $208 \pm 9$ & $3.99 \pm 0.08$ \\
\hline
\end{tabular}

Values are mean \pm s.e.m.

* $p<0.05$ compared to females

\section{Experimental design}

Each subject followed four different treatments. Treatments were separated by at least one week and conducted in random order. Each treatment consisted of a 36-hour stay in a respiration chamber. To ensure a similar dietary macro nutrient composition prior to all four treatments, food intake was controlled for three days prior to the treatments. Subjects were given a reduced-fat diet for consumption at home for day 1 3. On two occasions subjects came to the laboratory on day three at 15.00 to perform an exhaustive glycogen lowering exercise test (EX), and then entered the respiration chamber at 18:00 for a 36h stay. In the respiration chamber they were given either a high-fat diet $(\mathrm{HF}+\mathrm{EX}, 60$ energy\% fat) or a reduced-fat diet (RF+EX). The reduced fat diet contained 30 energy $\%$ fat, as is often recommended in the prevention of obesity (4). On the other two occasions no glycogen lowering exercise was performed, but subjects directly entered the respiration chamber at 18:00 for a $36 \mathrm{~h}$ stay, where they were given either a high-fat diet (HF) or a reduced-fat diet (RF). On the morning of day 5 , subjects left the respiration chamber at 8:00 am.

\section{Maximal power output}

One week before the experiments each subject performed an incremental exhaustive exercise test on an electronically braked cycle ergometer (Lode Excalibur, Groningen, The Netherlands) to determine maximal heart rate and maximal power output ( $W_{\max }$ ). Exercise was performed until voluntary exhaustion or until the subject could no longer maintain a pedal rate of more than $60 \mathrm{rpm}$. Subjects started cycling at 75 Watt for 5 minutes. Thereafter, work load was increased by 50 Watt every 2.5 minute. When subjects were approaching exhaustion, as indicated by heart rate and subjective scoring, the increment was reduced to 25 Watt. In practice, this meant that the last 1 to 3 load increments were 25 Watt. Heart rate was registered continuously using a Polar Sport tester (Kempele, Finland). In each individual $\mathrm{W}_{\max }$ was calculated from:

$$
\mathrm{W}_{\text {max }}=\mathrm{W}_{\text {out }}+(\mathrm{t} / 150) * \partial \mathrm{W}
$$

in which $W_{\text {out }}$ is the highest workload completed by the subject, $t$ is the time (in seconds) performed on the last workload and $\partial W$ is the final uncompleted load increment (12). 


\section{Glycogen lowering exercise}

During the EX experiments the subjects came to the lab at 15:00, after fasting for two hours, to perform a glycogen lowering exercise test. It has repeatedly been shown in our laboratory by Kuipers et al (13) and Wagenmakers et al. (25) that glycogen stores in muscle are significantly decreased both in male and female subjects after this exercise test. After a warming up at $50 \%$ of their maximal power output ( $\mathrm{W}_{\max }$ ) for 5 minutes, subjects cycled two minutes on $80 \%$ of $W_{\max }$ followed by two minutes on $50 \%$ of $\mathrm{W}_{\max }$. This was repeated until subjects were no longer able to perform the high intensity exercise. The maximal intensity was then lowered to $70 \%$ of $\mathrm{W}_{\max }$. The test was ended after exhaustion, i.e. when subjects could no longer maintain a pedal rate of more than $60 \mathrm{rpm}$. Subjects were allowed to consume water during exercise. During the exercise, heart rate was measured continuously with a polar sport tester. Energy expended during the exercise was calculated by assuming a mechanical efficiency of $20 \%$ (9).

\section{Diets}

Prior to the experiment subjects filled in a three day food intake record, to estimate habitual diet composition. Metabolizable energy intake and macro nutrient composition of the diet was calculated using the Dutch food composition table (23). In the table metabolizable energy is calculated by multiplying the amount of protein, fat and carbohydrate with the Atwater factors (16.74, 37.66 and $16.74 \mathrm{~kJ} / \mathrm{g}$ for carbohydrate, fat and protein, respectively) (14). The amount of protein, fat and carbohydrate was multiplied by $0.909,0.948$ and 0.953 respectively to correct for digestibility of macro nutrients. All experimental diets were consumed as breakfast, lunch, dinner and 2 or more snacks per day. The composition of experimental diets is given in table 5.2. All snacks had the same macro nutrient composition as the experimental diet. Food quotient (FQ) was defined as the ratio of $\mathrm{CO}_{2}$ produced to oxygen consumed during the oxidation of a representative sample of the diet consumed (8).

Table 5.2 Composition of experimental diets

\begin{tabular}{lcc}
\hline & reduced-fat diet & high-fat diet \\
\hline Protein (\% of total energy) & 15 & 15 \\
Carbohydrate (\% of total energy) & 55 & 25 \\
Fat (\% of total energy) & 30 & 60 \\
Food Quotient & 0.88 & 0.80 \\
\hline
\end{tabular}

On days 1 and 2 and the first part of day 3 , a reduced-fat diet for consumption at home was provided. Subjects were given a fixed amount of food (based on their food intake record) and ad libitum access to snacks. On the evening of day 3, subjects consumed their dinner and evening snack (either low- or high-fat) in the respiration chamber. In the RF and HF treatment energy intake for dinner and evening snack was fixed at $35 \%$ and $10 \%$ of estimated daily energy expenditure $(1.7 *$ BMR based on the Harris and Benedict equations; for women: $\mathrm{BMR}=2.74+0.774 * \mathrm{H}+$ $0.040^{*} \mathrm{BM}-0.020^{*} \mathrm{~A}$ and for men: $\mathrm{BMR}=0.28+2.093^{*} \mathrm{H}+0.058^{*} \mathrm{BM}-0.028^{*} \mathrm{~A}$, in which $\mathrm{BMR}$ is in $\mathrm{MJ} / \mathrm{day}, \mathrm{H}$ is height in $\mathrm{m}, \mathrm{BM}$ is body mass in $\mathrm{kg}$, and $\mathrm{A}$ is age in 
years) (10). In the $\mathrm{RF}+\mathrm{EX}$ and $\mathrm{HF}+\mathrm{EX}$ treatments, the evening snack had an energy content equal to energy expended during the exercise test. On day 4 , subjects were given an amount of energy equal to 1.55 times sleeping metabolic rate (SMR), as measured during the preceding night. In a previous study it was shown that with a comparable activity protocol used in the chamber a physical activity index of 1.58 was reached (16).

\section{Body composition}

Subjects weighed themselves in the respiration chamber on the morning of day 4 and 5 , without clothing, after voiding and before eating and drinking. Measurements were done on a digital balance (Seca delta, model 707) with an accuracy of $0.1 \mathrm{~kg}$.

Whole body density was determined by underwater weighing in the morning in the fasted state. Body weight was measured with a digital balance with an accuracy of $0.01 \mathrm{~kg}$ (Sauter, type E1200). Lung volume was measured simultaneously with the helium dilution technique using a spirometer (Volugraph 2000, Mijnhardt). Percent body fat was calculated using the equations of Siri (22). Fat-free mass (FFM) in $\mathrm{kg}$ was calculated by subtracting fat mass from total body mass.

\section{Indirect calorimetry and physical activity}

Oxygen consumption and carbon dioxide production were measured in a wholeroom indirect calorimeter (19). The respiration chamber is a $14 \mathrm{~m}^{3}$ room furnished with a bed chair, television, radio, telephone, intercom, wash bowl and toilet. The room is ventilated with fresh air at a rate of $70-80 \mathrm{l} / \mathrm{min}$. The ventilation rate is measured with a dry gas meter (Schlumberger, type G6, The Netherlands). The concentrations of oxygen and carbon dioxide are measured using a paramagnetic $\mathrm{O}_{2}$ analyzer (Hartmann \& Braun, type Magnos G6, Germany) and an infrared $\mathrm{CO}_{2}$ analyzer (Hartmann \& Braun, type Uras $3 G$, Germany). Ingoing air is analyzed every 15 minutes and outgoing air once every 5 minutes. The gas sample to be measured is selected by a computer that also stores and processes the data. Energy expenditure is calculated from $\mathrm{O}_{2}$ consumption and $\mathrm{CO}_{2}$ production according to the method of Weir (26).

In the respiration chamber subjects followed an activity protocol consisting of fixed times for breakfast, lunch and dinner, sedentary activities and bench stepping exercise. The bench stepping exercise was performed for 30 minutes at intervals of 5 minutes exercise alternated with 5 minutes rest, at a rate of 60 steps per minute with a bench height of $33 \mathrm{~cm}$, and was repeated three times a day. Thus, subjects exercised for 45 minutes per day, at a relative low-to-medium intensity. At daytime, no sleeping or other exercise was allowed during the stay in the respiration chamber. All physical activity of the subjects was monitored by means of a radar system based on the Doppler principle.

\section{Urinary nitrogen excretion}

During the stay in the respiration chamber urine was collected in two batches, one from $20.00 \mathrm{pm}$ to 8.00 am and the second over the subsequent $24 \mathrm{~h}$ interval. Subjects 
were requested to empty the bladder at $8.00 \mathrm{am}$. The urine produced was included in the urine sample of the previous batch. Samples were collected in containers with 10 $\mathrm{ml} \mathrm{H}_{2} \mathrm{SO}_{4}$ to prevent nitrogen loss through evaporation; volume and nitrogen concentration were measured, the latter using a nitrogen analyzer (Carlo-Erba, type CN-O-Rapid).

\section{$24 h$ energy expenditure and substrate oxidation}

Subjects stayed in the respiration chamber for 36 hours. Data from 20.00 pm on day 3 to 8.00 am on day 4 are presented to study short term effects of treatments. For calculating balances, $24 \mathrm{~h}$ energy expenditure ( $24 \mathrm{~h} \mathrm{EE}$ ) and $24 \mathrm{~h}$ respiratory quotient (24h RQ) were measured from $8.00 \mathrm{~h}$ am on day 4 to $8.00 \mathrm{~h}$ am on day 5 . Sleeping metabolic rate (SMR) was defined as the lowest mean energy expenditure measured during three subsequent hours between $0.00 \mathrm{~h}$ am and $8.00 \mathrm{~h}$ am with a minimal activity level as indicated by the radar system.

Carbohydrate, fat and protein oxidation were calculated using $\mathrm{O}_{2}$ consumption, $\mathrm{CO}_{2}$ production and urinary nitrogen losses with the equations of Brouwer (5).

Protein oxidation $(\mathrm{g} / \mathrm{d})=6.25 * \mathrm{~N}$

Fat oxidation $(\mathrm{g} / \mathrm{d})=1.718 * \mathrm{VO}_{2}-1.718 * \mathrm{VCO}_{2}-0.315 * \mathrm{P}$

Carbohydrate oxidation $(\mathrm{g} / \mathrm{d})=4.17 * \mathrm{VCO}_{2}-2.965 * \mathrm{VO}_{2}-0.390 * \mathrm{P}$

where $\quad \mathrm{N}$ is the total nitrogen excreted in urine ( $\mathrm{g} / \mathrm{day})$

$\mathrm{VO}_{2}$ is the oxygen consumption (I/day)

$\mathrm{VCO}_{2}$ is the carbon dioxide production (1/day)

$\mathrm{P}$ is protein oxidation ( $\mathrm{g} /$ day)

\section{Blood analysis}

On all four occasions blood samples were taken on the morning of days 4 and 5 after an overnight fast. For the collection of blood on day 4 , without disruption of the respiration chamber measurement, subjects put their arm through an air lock with a rubber sleeve to fit around the upper arm, positioned under a window for eye contact. On one occasion blood was sampled on the morning of day 3 . Ten $\mathrm{ml}$ of venous blood was sampled in tubes containing EDTA to prevent clotting and immediately centrifuged at $3000 \mathrm{rpm}$ (100 g) for 10 minutes. Plasma was frozen in liquid nitrogen and stored at $-80^{\circ} \mathrm{C}$ until further analysis. Plasma substrates were determined using the hexokinase method (LaRoche, Basel, Switzerland) for glucose, the Wako NEFA C testkit (Wako chemicals, Neuss, Germany) for free fatty acids, the glycerolkinaselipase method (Boehringer, Mannheim) for glycerol and triacylglycerols and the ultra sensitive human insulin ria kit (linco research, St. Charles, U.S.A.).

\section{Statistical analysis}

All data are presented as mean \pm S.E.M. Equality of $R Q$ and food quotient (FQ), energy intake and energy expenditure as well as substrate intake and substrate oxidation was determined by calculating the $95 \%$ confidence intervals for differences. Repeated measure one-way analysis of variance (ANOVA) was used to detect differences in any variables between treatments. When significant differences were found, a Scheffe post hoc test was used to determine the exact location of the 
difference. Differences in any variables between day 4 and day 5 were tested using paired $t$-test.

\section{Results}

Time till exhaustion during the exercise test was not significantly different between the $\mathrm{RF}+\mathrm{EX}$ and $\mathrm{HF}+\mathrm{EX}$ treatment: $61 \pm 3$ and $67 \pm 6 \mathrm{~min}$, respectively. Also, no difference in energy expended during the exercise tests was found: $2.5 \pm 0.2$ and 2.8 $\pm 0.3 \mathrm{MJ}$ for RF+EX and HF+EX treatments, respectively.

Body weight, as measured in the respiration chamber, was not significantly different between any of the treatments (table 5.3).

Table 5.3 Sleeping metabolic rate (SMR), physical activity index (PAI), and body weight as measured in the respiration chamber

\begin{tabular}{llllc}
\hline treatment & $\begin{array}{c}\text { SMR night 1 } \\
\mathrm{kJ} / \mathrm{min}\end{array}$ & $\begin{array}{c}\text { SMR night 2 } \\
\mathrm{kJ} / \mathrm{min}\end{array}$ & PAI \# & $\begin{array}{c}\text { body weight } \\
\mathrm{kg}\end{array}$ \\
\hline $\mathrm{RF}$ & $5.09 \pm 0.26$ & $5.11 \pm 0.29$ & $1.60 \pm 0.05$ & $98.5 \pm 6.0$ \\
$\mathrm{RF}+\mathrm{EX}$ & $5.25 \pm 0.29$ & $5.15 \pm 0.28$ & $1.61 \pm 0.04$ & $98.7 \pm 5.9$ \\
$\mathrm{HF}$ & $5.11 \pm 0.29$ & $5.22 \pm 0.27 \$$ & $1.57 \pm 0.03$ & $98.2 \pm 5.9$ \\
$\mathrm{HF}+\mathrm{EX}$ & $5.33 \pm 0.32 *$ & $5.30 \pm 0.29$ & $1.61 \pm 0.04$ & $98.2 \pm 5.9$ \\
\hline
\end{tabular}

Values are mean \pm s.e.m.

\# physical activity index: 24 h energy expenditure/ $24 \mathrm{~h}$ sleeping metabolic rate

* $\mathrm{p}<0.05$ compared to $\mathrm{RF}$

$\$ \mathrm{p}<0.05$ compared to night 1

Sleeping metabolic rate measured during the first night was significantly increased in the $\mathrm{HF}+\mathrm{EX}$ treatment compared to the RF treatment $(\mathrm{p}<0.05)$, most likely due to the effect of exercise on post-exercise energy expenditure. However, sleeping metabolic rate measured during the second night was not significantly different between any of the treatments (table 5.3). Twenty-four hour energy expenditure (table 5.4) and physical activity index $(=24 \mathrm{~h}$ EE/SMR, table 5.3) were not significant different between treatments.

\section{First 12 hours measurements}

On the evening following the exercise test subjects were given an amount of energy, as high-fat or low-fat diet, to compensate for the energy expended during the exercise bout. Therefore, of course, a positive energy balance was measured during the first 12 hours in the chamber. However, this positive energy balance was not significantly different between the RF+EX and HF+EX treatment $(2.10 \pm 0.26$ vs. $2.46 \pm 0.35 \mathrm{MJ}$ ). Respiratory quotient (RQ) during the first 12 hours in the respiration chamber was $0.890 \pm 0.009,0.862 \pm 0.014,0.848 \pm 0.006$ and $0.807 \pm 0.01$ for the $\mathrm{RF}, \mathrm{RF}+\mathrm{EX}, \mathrm{HF}$ and $\mathrm{HF}+\mathrm{EX}$ treatments respectively, and was significantly different between treatments $(p<0.01)$. The RQ in the HF+EX was significantly lower compared to the RF, RF+EX and HF treatment $(p<0.01)$. Also the RQ in the RF and HF treatment were significantly different $(p<0.01)$. In the RF+EX treatment a positive 
carbohydrate balance of $94.5 \pm 16.5 \mathrm{~g}$ and a positive fat balance of $4.5 \pm 6.4 \mathrm{~g}$ was reached, while in the HF+EX treatment those figures were $+27.1 \pm 11.7$ and $+38.8 \pm$ $5.7 \mathrm{~g}$ for carbohydrate and fat respectively. Thus, glycogen was more repleted in the $\mathrm{RF}+\mathrm{EX}$ treatment compared to the $\mathrm{HF}+\mathrm{EX}$ treatment and, as a result, differences in glycogen store were obtained.

\section{4 hour measurements}

In all four tests, 24 h energy balance (day 4) was not significantly different from zero (table 5.4). Twenty four hour RQ was significantly different between all treatments $(\mathrm{p}<0.05) . \mathrm{RQ}$ in the $\mathrm{RF}$ and $\mathrm{RF}+\mathrm{EX}$ treatment was significantly higher compared to the $\mathrm{HF}$ and $\mathrm{HF}+\mathrm{EX}$ treatment (figure 5.1). Respiratory quotient was significantly different from food quotient $(F Q)$ in the RF, HF and HF+EX treatment $(p<0.05)$. In the RF+EX treatment RQ and FQ were not significantly different (figure 5.1).

Table 5.4 Energy intake, energy expenditure and energy balance (MJ/day) as measured in the respiration chamber $(8: 00-8: 00)$ on four different treatments

\begin{tabular}{lccc}
\hline treatment & Intake & Expenditure & Balance \\
& MJ & MJ & MJ \\
\hline RF & $12.55 \pm 0.82$ & $11.65 \pm 0.49$ & $0.90 \pm 0.49$ \\
RF+EX & $12.51 \pm 0.82$ & $11.93 \pm 0.62$ & $0.58 \pm 0.43$ \\
HF & $12.53 \pm 0.81$ & $11.76 \pm 0.58$ & $0.77 \pm 0.32$ \\
HF+EX & $12.39 \pm 0.72$ & $12.21 \pm 0.64$ & $0.19 \pm 0.33$ \\
\hline
\end{tabular}

Values are mean \pm s.e.m.

RF: reduced-fat diet, HF: high-fat diet, EX: exercise

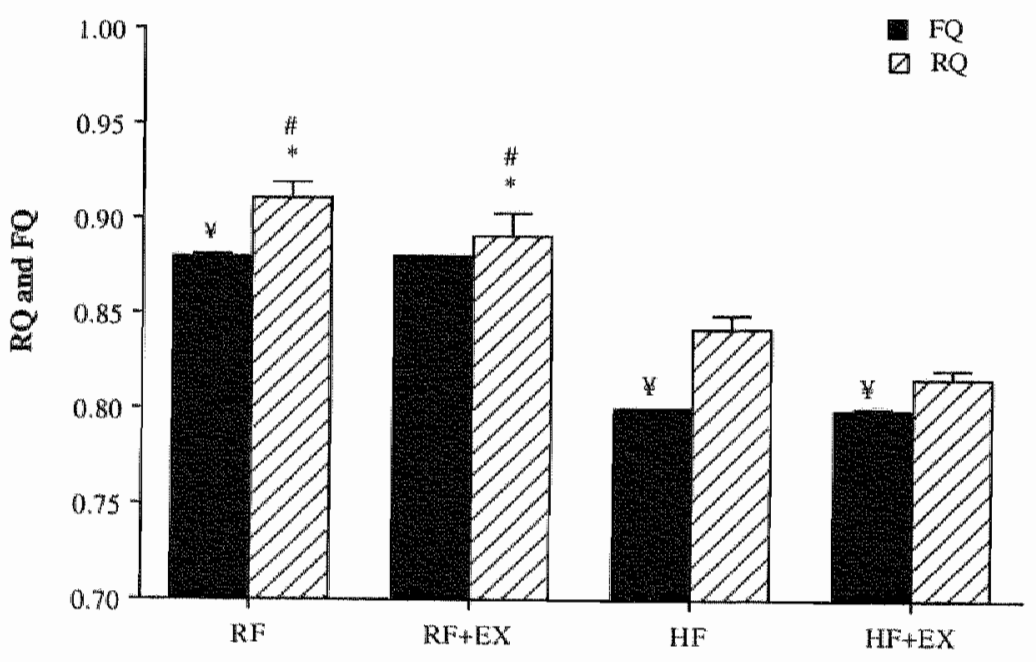

Figure 5.1 Twenty-four hour respiratory (RQ) and food quotients (FQ) as measured in respiration chamber for day 4 (mean \pm s.e.m.). HF, high-fat diet; RF, reducedfat diet; Ex, glycogen-lowering exercise. Significant difference $(\mathrm{p}<0.05)$ ws. *HF; \#HF+EX; $¥ \mathrm{RQ}$. 
Twenty-four hour protein oxidation was not significantly different among treatments (table 5.5). In all treatments 24 hour protein balance was significantly different from zero (figure $5.2, \mathrm{p}<0.05$ ).

Table 5.5 Carbohydrate, fat and protein intake and oxidation (g/day) as measured in the respiration chamber (8:00-8:00) on the four different treatments

\begin{tabular}{|c|c|c|c|c|c|c|}
\hline \multirow[t]{2}{*}{ treatment } & \multicolumn{2}{|c|}{$\mathrm{CHO}$} & \multicolumn{2}{|c|}{ Fat } & \multicolumn{2}{|c|}{ Protein } \\
\hline & intake & oxidation & intake & oxidation & intake & oxidation \\
\hline$R F$ & $417 \pm 29 *$ & $446 \pm 25 *$ & $103 \pm 7 * \#$ & $65 \pm 8$ *\# & $101 \pm 6$ & $69 \pm 5$ \\
\hline$R F+E\rangle$ & $417 \pm 29 * \#$ & $400 \pm 21 * \#$ & $102 \pm 7$ *\# & $91 \pm 15 \#$ & $101 \pm 6$ & $73 \pm 8$ \\
\hline $\mathrm{HF}$ & $207 \pm 14$ & $291 \pm 18$ & $197 \pm 13$ & $140 \pm 11$ & $98 \pm 6$ & $61 \pm 6$ \\
\hline $\mathrm{EF}+\mathrm{EX}$ & $203 \pm 12$ & $234 \pm 9$ & $195 \pm 12$ & $173 \pm 14$ & $98 \pm 5$ & $69 \pm 5$ \\
\hline
\end{tabular}

Values are mean \pm s.e.m.

RF: reduced-fat diet, HF: high-fat diet, EX: exercise

* $\mathrm{p}<0.05$ compared to HF

\# $\mathrm{p}<0.05$ compared to $\mathrm{HF}+\mathrm{EX}$

Twenty four hour carbohydrate oxidation was significantly different between the RF and $\mathrm{HF} / \mathrm{HF}+\mathrm{EX}$ treatment, as well as between the RF+EX and HF/HF+EX treatment ( $<<0.01$, table 5.5). Carbohydrate balance was significantly different from zero in the $\mathrm{RF}, \mathrm{HF}$ and HF+EX treatment (figure 5.2).

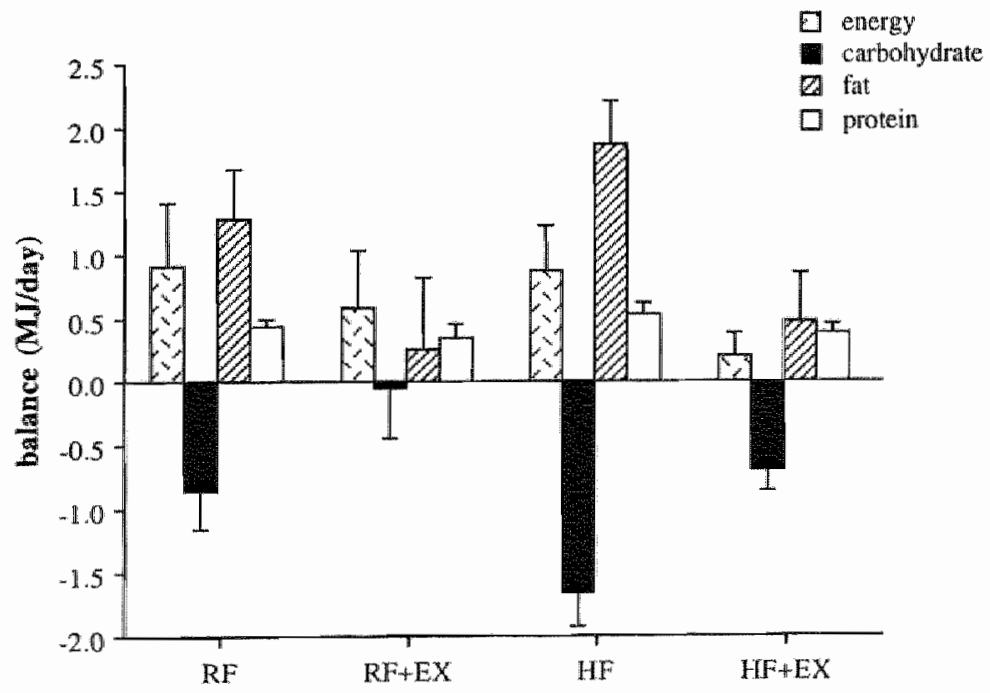

Figure 5.2 Twenty-four hour energy and substrate balances for day 4 as measured in respi ration chamber (mean \pm s.e.m.).

Twenty four hour fat oxidation was significantly different between the RF and $\mathrm{HF} / \mathrm{HF}+\mathrm{EX}$ treatments and between the RF+EX and HF+EX treatment $(\mathrm{p}<0.05$, table 5.5). Fat balance was significantly different from zero in the RF and HF treatment (figure 5.2). 
Fat oxidation can be adjusted for energy balance by assuming that in the case of a positive energy balance this surplus in energy will be stored as fat and in case of a negative energy balance, the deficit in energy is accomplished by increasing fat oxidation. When adjusted for energy balance, twenty four hour fat oxidation was 90 $\pm 13,106 \pm 15,161 \pm 16$ and $178 \pm 14 \mathrm{~g} /$ day in the RF, RF+EX, HF and HF+EX treatment respectively.

\section{Blood variables}

Plasma triacylglycerol concentration increased significantly between day 4 and 5 in the LF+EX treatment and decreased significantly in the HF treatment. On day 4 plasma triacylglycerol concentration was significantly different between the LF and $\mathrm{HF}+\mathrm{EX}$ treatment. On day 5 plasma triacylglycerol concentration was significantly higher in the LF treatment compared to the HF and HF+EX treatment. In the LF+EX treatment plasma triacylglycerol concentration was significantly higher compared to the HF+EX treatment ( $p<0.05$, table 5.6). Plasma glucose concentration significantly decreased in the LF treatment between day 4 and 5 and increased in the LF+EX and $\mathrm{HF}+\mathrm{EX}$ treatment. On day 4 plasma glucose concentration was significantly higher in the $\mathrm{LF}$ treatment compared to the $\mathrm{HF}$ and $\mathrm{HF}+\mathrm{EX}$ treatment. In the $\mathrm{LF}+\mathrm{EX}$ treatment plasma glucose concentration was significantly higher compared to the $\mathrm{HF}+\mathrm{EX}$ treatment. On day 5 no differences in glucose concentrations between treatments were found $(p<0.05)$. There were no significant differences between any days and treatments in plasma FFA and glycerol concentrations.

Table 5.6 Blood indexes measured on days 4 and 5 in the different treatments

\begin{tabular}{lccccc}
\hline treatment & day & $\begin{array}{c}\text { glucose } \\
\mathrm{mmol} / \mathrm{l}\end{array}$ & $\begin{array}{c}\text { triacylglycerols } \\
\text { mmol/l }\end{array}$ & $\begin{array}{c}\text { fatty acids } \\
\mu \mathrm{mol} / \mathrm{l}\end{array}$ & $\begin{array}{c}\text { glycerol } \\
\mu \mathrm{mol} /\end{array}$ \\
\hline $\mathrm{RF}$ & 4 & $4.95 \pm 0.14$ & $1.29 \pm 0.19$ & $396 \pm 47$ & $92 \pm 14$ \\
$\mathrm{RF}$ & 5 & $4.88 \pm 0.14 \$$ & $1.37 \pm 0.19$ & $360 \pm 37$ & $82 \pm 9$ \\
$\mathrm{RF}+\mathrm{EX}$ & 4 & $4.85 \pm 0.13$ & $1.04 \pm 0.16$ & $379 \pm 52$ & $90 \pm 15$ \\
$\mathrm{RF}+\mathrm{EX}$ & 5 & $4.85 \pm 0.14$ & $1.23 \pm 0.16 \$$ & $359 \pm 46$ & $90 \pm 15$ \\
$\mathrm{HF}$ & 4 & $4.79 \pm 0.13 *$ & $1.18 \pm 0.19$ & $394 \pm 53$ & $90 \pm 15$ \\
$\mathrm{HF}$ & 5 & $4.92 \pm 0.13 \$$ & $0.99 \pm 0.13 * \$$ & $366 \pm 43$ & $94 \pm 15$ \\
$\mathrm{HF}+\mathrm{EX}$ & 4 & $4.67 \pm 0.11 * \#$ & $0.92 \pm 0.12 *$ & $395 \pm 37$ & $119 \pm 17$ \\
$\mathrm{HF}+\mathrm{EX}$ & 5 & $4.83 \pm 0.14 \$$ & $0.96 \pm 0.11 * \#$ & $427 \pm 50$ & $107 \pm 12$ \\
\hline
\end{tabular}

Values are mean \pm s.e.m.

* $p<0.05$ compared to RF

\# $\mathrm{p}<0.05$ compared to RF+EX

$\$$ pe 0.05 compared to day 4

\section{Discussion}

The results of the present study demonstrate that obese subjects are capable of rapidly adjusting fat oxidation to fat intake when glycogen stores are lowered. Therefore these results are in concordance with the results obtained in lean subjects and do not provide evidence for an impaired capacity to rapidly change fat oxidation in obese subjects. After glycogen lowering exercise fat balance was reached, both 
when consuming a reduced-fat and a high-fat diet. These results indicate that obese subjects are capable of maintaining fat balance on a high-fat diet when glycogen stores are sufficiently lowered.

One model which can explain the high prevalence of obesity in western societies is the two compartment model of Flatt (7). According to this model, fat oxidation can be raised by two mechanisms. First, fat oxidation can be increased when glycogen stores are maintained in a low range. However, in the western society with the abundance of food available, people will eat to maintain glycogen stores filled. On a high-fat diet this means that people will overeat and therefore gain weight (7). Secondly, the associated expansion of the fat mass will lead to an increase in fat oxidation until a new equilibrium is reached in which average fat intake equals fat oxidation. Therefore obesity can be seen as an mechanism to adapt to a high-fat intake (1). The need for the human body to expand its body fat mass in response to a high fat intake can be prevented by regutar physical activity (18). It is evident that individuals who are regularly physical active are much less prone to become obese compared to sedentary individuals. Exercise reduces glycogen levels, thereby allowing fat oxidation to increase between meals. In this way fat oxidation can become commensurate with fat intake without expansion of the body fat mass (8). In the present study we found that fat oxidation was increased sufficiently to match fat intake when glycogen stores were lowered by exhaustive exercise. During the first twelve hours in the respiration chamber, carbohydrate balance was more positive in the RF+EX compared to the $\mathrm{HF}+\mathrm{EX}$ treatment ( $94 \pm 16$ vs. $27 \pm 12 \mathrm{~g}$ respectively). Therefore, it can be assumed that glycogen was more repleted in the RF+EX treatment. The difference in $24 \mathrm{~h}$ fat oxidation between the RF+EX and $\mathrm{HF}+\mathrm{EX}$ treatment can thus be explained by differences in both glycogen stores and exogenous carbohydrate availability. The higher fat oxidation in the HF+EX treatment compared to the HF treatment (same exogenous carbohydrate availability) indicates the role of the glycogen in the regulation of fat oxidation. Therefore, these results are in agreement with the model of Flatt and show the impact of physical activity on fat oxidation and indirectly on the prevention of obesity.

It is known that exercise can result in other (hormonal) adaptations that might influence fat oxidation. However, in a study about energy metabolism in the post exercise period it was found that 2.5 hours after cessation of exercise, free fatty acids, glycerol and glucagon concentrations returned to their control values (2). The (hormonal) disturbances induced by exercise therefore are not long lasting. In contrast, the elevation of fat oxidation on the HF+EX treatment was long lasting, indicated for example by $R Q$ during sleep, which was not significantly different between the first and second nights in the respiration chamber (data not shown). Therefore we conclude that the increase in fat oxidation can not be explained by the exercise itself.

The present study was performed as a follow up of our previous study in which we showed that lean subjects were capable of rapidly adjusting fat oxidation to fat intake on a high fat diet when glycogen stores were lowered by exhaustive exercise. 
Here we show the same capacity for obese subjects. However, there are some differences between the two studies. Therefore we used the data as described previously (20) to detect any difference between obese and lean subjects using unpaired t-tests. Respiratory quotient during the first 12 hours was not significantly different between obese and lean subjects. Twenty-four hour respiratory quotient was significantly lower in the $\mathrm{RF}+\mathrm{EX}$ and $\mathrm{HF}+\mathrm{EX}$ treatment in lean subjects. However, the results might be influenced by differences in energy balance between the two studies. Energy balance was significantly correlated with fat balance in both obese and lean subjects (fig 5.3, $\mathrm{r}^{2}: 0.51, \mathrm{p}<0.001$ ). When fat balance was corrected for energy balance, no differences in fat balance between treatments was found in obese and lean subjects. Therefore we conclude that obese subjects are as capable as lean subjects to increase fat oxidation to match fat intake on a high-fat diet when glycogen stores are lowered. Although the type of exercise used in this study is not likely to be performed by obese people in daily life, the results still indicate the importance of regular exercise in the prevention/management of obesity.

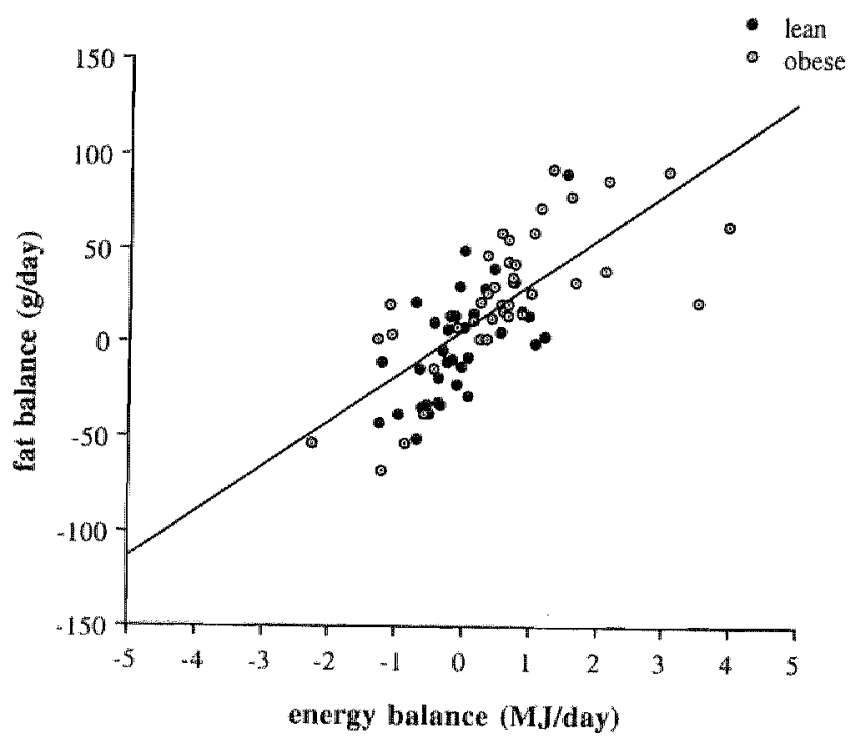

Figure 5.3 Relation between 24-h energy balance and 24-h fat balance in obese (present study) and lean subjects (from Ref. 20).

Our results seems to be in contrast with studies showing an impaired uptake/ oxidation of FFA by the muscle in obese subjects $(3,6)$. However, it is difficult to compare those studies with the present study, because we used a 24 hour approach. Although we did not find, with prior glycogen lowering exercise, an impaired capacity to increase fat oxidation on a high-fat diet when comparing obese to lean subjects, this does not rule out the possibility that there might be an impaired uptake/oxidation of FFA on the level of the muscle under certain (stimulated) circumstances. However, further studies must reveal the impact of impaired muscle FFA uptake rates on 24 hour fat oxidation. 
When we pool the data obtained in obese and lean subjects we find a negative correlation between carbohydrate balance found during the first 12 hours in the respiration chamber and next $24 \mathrm{~h}$ fat oxidation during the $\mathrm{RF}+\mathrm{EX}$ and $\mathrm{HF}+\mathrm{EX}$ treatment (fig $5.4, \mathrm{r}^{2}: 0.29, \mathrm{p}=0.005$ ). Carbohydrate balance was calculated as measured carbohydrate balance (20.00-8.00) minus estimated carbohydrate oxidation during exercise. To estimate the latter, it was assumed that $80 \%$ of energy expended during exercise was provided by carbohydrate $(\mathrm{RQ} \sim 0.94)$, which is an reasonable value for this kind of extremely intensive exercise. When carbohydrate oxidation was assumed to provide $90 \%$ of energy expended during exercise the correlation did not change. These data therefore show the important role of glycogen stores in determining the rate of fat oxidation.

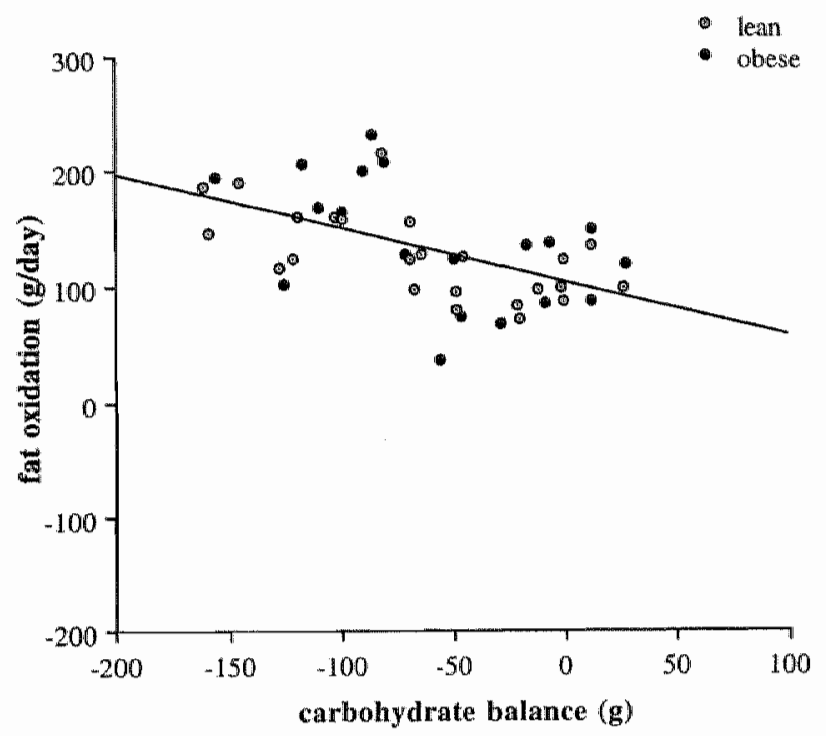

Figure 5.4 Relation between carbohydrate balance measured in respiration chamber from 2000 to 0800 and 24 -h fat oxidation for obese (present study) and lean subjects (from Ref. 20) in RF+Ex and HF+Ex treatments.

In conclusion this study shows that obese subjects are capable of rapidly adjusting fat oxidation to fat intake on a high-fat diet when glycogen stores are lowered by exhaustive exercise. These results may indicate that a lower level of regular physical. activity is a predisposing factor for obesity.

\section{References}

1. Astrup, A., Buemann, B., Western, P., Toubro, S., Raben, A., and Christensen, N. J. Obesity as an adaptation to a high-fat diet: evidence from a cross-sectional study. Am J Clin Nutr. 59: 350-5, 1994.

2. Bielinski, R., Schutz, $Y$, and Jéquier, E. Energy metabolism during the postexercise recovery in man. Am J Clin Nutr. 42: 69-82, 1985. 
3. Blaak, E. E., Baak, M. A. v., Kemerink, G. J., Pakbiers, M. T. W., Heidendal, G. A. K., and Saris, W. H.M. B-Adrenergic stimulation of energy expenditure and forearm skeletal muscle metabolism in lean and obese men. An J Physiol. 267: E306-E315, 1994.

4. Bouchard, C. Can obesity be prevented? Nutr Rev. 54: \$125-S130, 1996.

5. Brouwer, E. On simple formulae for calculating the heat expenditure and the quantities of carbohydrate and fat oxidized in metabolism of men and animals, from gaseous exchange (oxygen intake and carbonic acid output) and urine-n. Acta Phystol Pharmacol Neerlandica. 6: 795-802, 1957.

6. Colberg, S. R., Simoneau, J.-A., Thaete, F. L., and Kelley, D. E. Skeletal muscle utilization of free fatty acids in women with visceral obesity. J Clin Invest. 95: 1846-1853, 1995.

7. Flatt, J. P. The difference in the storage capacities for carbohydrate and for fat, and its implications in the regulation of body weight. Ann NYAcad Sci. 499: 104-23, 1987.

8. Flatt, J. P. Integration of the overall response to exercise. Int J Obesity. 19: S31-40, 1995.

9. Gaesser, G. A., and Brooks, G. A. Muscular efficiency during steady-state exercise: effects of speed and work rate. $J$ Appl Physiol. 38: 1132-1139, 1975.

10. Harris, J. A., and benedict, F. G.. A biometric study of basat metabolism in man. Washington, Carnegie Institution of Washington, 1919

11. Klesges, R. C., Klesges, I. M., Haddock, C. K., and Eck, L. H. A longitudinal analysis of the impact of dietary intake and physical activity on weight change in adults. Am $J$ Cin Nutr. 55: 818-22, 1992.

12. Kuipers, H., Keizer, H. A., Brouns, F., and Saris, W. H. M. Carbohydrate feeding and glycogen synthesis during exercise in man. Pflugers Arch. 410: 652-656, 1987.

13. Kuipers, H., Saris, W. H. M., Brouns, F, Keizer, H. A, and ten Bosch, C. Glycogen synthesis during exercise and rest with carbohydrate feeding in males and females. Int $J$ Sports Med. 10: \$63-\$67, 1989.

1.4. Miles, C. W. The metabolizable energy of diets differing in dietary fat and fiber measured in humans. J Nutr. 122: 306-11, 1992.

15. Miller, W. C., Lindeman, A. K., Wallace, I., and Niederpruem, M. Diet composition, energy intake, and exercise in relation to body fat in men and women. Am J Clin Nutr. 52: 426-30, 1990.

16. Pannemans, D. L. E., Bouten, C. V. C., and Westerterp, K. R. 24 h energy expenditure during a standardized activity protocol in young and elderly men. Eur J Clin Nurr. 49:49-56, 1995.

17. Ravussin, E, and Tataranni, P. A. Dietary fat and human obesity. I Am Diet Assoc. 97: S42S46. 1997.

18. Saris, W. H. M. Physical activity and body weight regulation. Regulation of body weight: Biological and behavorial mechanisms. John Wiley \& Sons Lid. 135-147, 1996.

19. Schoffelen, P. F. M., Westerterp, K. R., Saris, W. H. M., and ten Hoor, F. A dual-respiration chamber system with alutomated calibration. J Appl Physiol 83: 2064-2072, 1997.

20. Schrauwen, P., Marken Lichtenbelt, W. D. v., Saris, W. H. M., and Westerterp, K. R. Role of glycogen-lowering exercise in the change of fat oxidation in response to a high-fat diet. Am $J$ Physiol. 273: E623-629, 1997.

21. Schutz, Y., Flatt, J. P., and Jequier, E. Failure of dietary fat intake to promote fat oxidation: a factor favoring the development of obesity. Am J Clin Nutr. 50:307-14, 1989.

22. Siri, W. E. The gross composition of the body. Adv Biol Med Physiol. 4: 239-280, 1956. 
23. Stichting-Nederlands-Voedingsstoffenbestand. NEVO Tabel. Den Hagg, Voorlichtingsbureau voor de voeding, 1993.

24. Thomas, C. D. Peters, J. C., Reed, G. W., Abumrad, N. N., Sun, M., and Hill, J. O. Nutrient balance and energy expenditure during ad libitum feeding of high-fat and highcarbohydrate diets in humans. An J Clin Nur. 55: 934-942, 1992.

25. Wagenmakers, A. J. M., Beckers, E. J., Brouns, F., Kuipers, H., Soeters, P., Vusse, v. d. G. J., and Saris, W. H. M. Carbohydrate supplemenation, glycogen depletion, and amino acid metabolism during exercise. Am J Physiol. 260: E883-E890, 1991.

26. Weir, J. B. d. V. New methods for calculating metabolic rate with special reference to protein metabolism. J Physiol. 109: 1-9, 1949.

27. Zurlo, F., Lillioja, S., Esposito, D. P. A., Nyomba, B. L., Raz, 1., Saad, M. F., Swimburn, B. A., Knowler, W. C., Bogardus, C., and Ravussin, E. Low ratio of fat to carbohydrate oxidation as predictor of weight gain: study of 24-h RQ. Am d Physiol. 259: E650-E657, 1990. 



\title{
Chapter 6
}

\section{Validation of the $[1,2-13 \mathrm{C}]$-acetate recovery factor for correction of $[\mathrm{U}-13 \mathrm{C}]$-palmitate oxidation rates}

\author{
Patrick Schrauwen, Dorien P C van Aggel-Leijssen, Wouter D van Marken \\ Lichtenbelt, Marleen A van Baak, Annemie P Gijsen and Anton I M Wagenmakers
}

Department of Human Biology, Maastricht University, Maastricht, The Netherlands

Journal of Physiology, 1998, in press

\begin{abstract}
The validity of estimations of plasma fatty acid oxidation using tracers has often been questioned. The appearance of isotopic markers in breath $\mathrm{CO}_{2}$ is delayed and incomplete. Recently suggestions have been made that substantial amounts of tracer is incorporated into products of the tricarboxylic acid cycle (e.g. glucose, glutamine and glutamate) and that an acetate correction factor can be used to correct for tracer fixation. In the present study we investigated whether the appearance of ${ }^{13} \mathrm{CO}_{2}$ during a separate infusion of $[1,2-13 \mathrm{C}]$-acetate could be used for correction of [U${ }^{13} \mathrm{C}$ ]-palmitate oxidation rates in studies lasting $<2$ hours and we quantitated the appearance of tracer in the glutamine, glutamate and glucose pools of the body.

An infusion of either $[1,2-13 \mathrm{C}]$-acetate $(0.104 \mu \mathrm{mol} / \mathrm{min} . \mathrm{kg})$ or $[\mathrm{U}-13 \mathrm{C}]$-palmitate $(0.013 \mu \mathrm{mol} / \mathrm{min} . \mathrm{kg})$ was given to eight male subjects and continued for two hours at rest. In six subjects the infusion $[1,2-13 \mathrm{C}]$-acetate was repeated to determine reproducibility of the acetate recovery.

Fractional recovery in breath from $[1,2-13 \mathrm{C}]$-acetate gradually increased during the infusion period at rest from $1.4 .1 \pm 0.6$ at $\mathrm{t}=60$ to $26.5 \pm 0.5 \%$ at $\mathrm{t}=120$. Inter-subject coefficient of variance was $8.3 \pm 0.6 \%$ and intra-subject coefficient of variance of the acetate recovery tests was $4.0 \pm 1.5 \%$. After two hours of $\left[1,2-{ }^{13} \mathrm{C}\right]$-acetate infusion, $12.4 \pm 0.8 \%$ and $10.3 \pm 0.9 \%$ of infused ${ }^{13} \mathrm{C}$ was incorporated in the glutamine and glutamate pools respectively.

In conclusion, the $[1,2]-{ }^{13} \mathrm{C}$ acetate recovery factor can be used for correcting the rate of $[U-13 \mathrm{C}]$-palmitate oxidation in infusing studies of 2 hours in resting conditions. Failure to use this recovery factor leads to a substantial underestimation of the rate of plasma FFA oxidation. The extent of label fixation could largely be explained by accumulation of tracer carbon in glutamine and glutamate, and the accumulation in glucose is negligible.
\end{abstract}




\section{Introduction}

The use of ${ }^{13} \mathrm{C}$ - and ${ }^{14} \mathrm{C}$-fatty acid tracers to estimate the oxidation of plasma fatty acids has been questioned (6). The appearance of ${ }^{13} \mathrm{CO}_{2}$ (and ${ }^{14} \mathrm{CO}_{2}$ ) in breath, coming from the oxidation of fatty acid tracers, is very low in the first hours of infusion, especially under resting conditions (7). This means that part of the label is temporarily fixed in metabolic pools in the body. When, in resting conditions, labeled $\mathrm{NaHCO}_{3}$ is infused up to $70-90 \%$ of the label is recovered implying that only a minor fraction of the tracer is entrapped in the bicarbonate pool and $\mathrm{CO}_{2}$ fixation reactions (carboxylation and urea production) (8). Heiling et al. (6) suggested that the plasma tracer first had to mix with a large intracellular fatty acid pool before it would be oxidized and that this was the main reason for the delayed and incomplete appearance of ${ }^{13} \mathrm{CO}_{2}\left({ }^{14} \mathrm{CO}_{2}\right)$ in the breath. However, in contrast to Heiling et al. (6), Sidossis et al. $(12,13)$ recently showed that part of the tracer accumulated in products of the tricarboxylic acid (TCA) cycle (glucose, glutamate and glutamine, Fig. 6.1). It was claimed that the fixation of the tracer in these products, together with fixation in the bicarbonate pool, was the main reason for the delayed and incomplete appearance of ${ }^{13} \mathrm{CO}_{2}\left({ }^{14} \mathrm{CO}_{2}\right)$ in the breath. They suggested that the amount of this label fixation can be determined by measuring the ${ }^{13} \mathrm{CO}_{2}$ production during infusion of ${ }^{13} \mathrm{C}$ - (or ${ }^{14} \mathrm{C}$ ) acetate, because acetate, like palmitate, is converted to acetyl-CoA and then enters the TCA cycle before $\mathrm{CO}_{2}$ is produced. According to Sidossis et al. $(12,13)$ a constant value was observed for the acetate recovery factor between 3 and 4 hours after the start of the infusion and it was suggested that this steady state value should be used to correct palmitate oxidation rates. The first aim of the present study is to investigate whether the acetate recovery factor can be used during infusions lasting 2 hours maximally, which would allow a shorter and less demanding infusion period for healthy volunteers and patients.

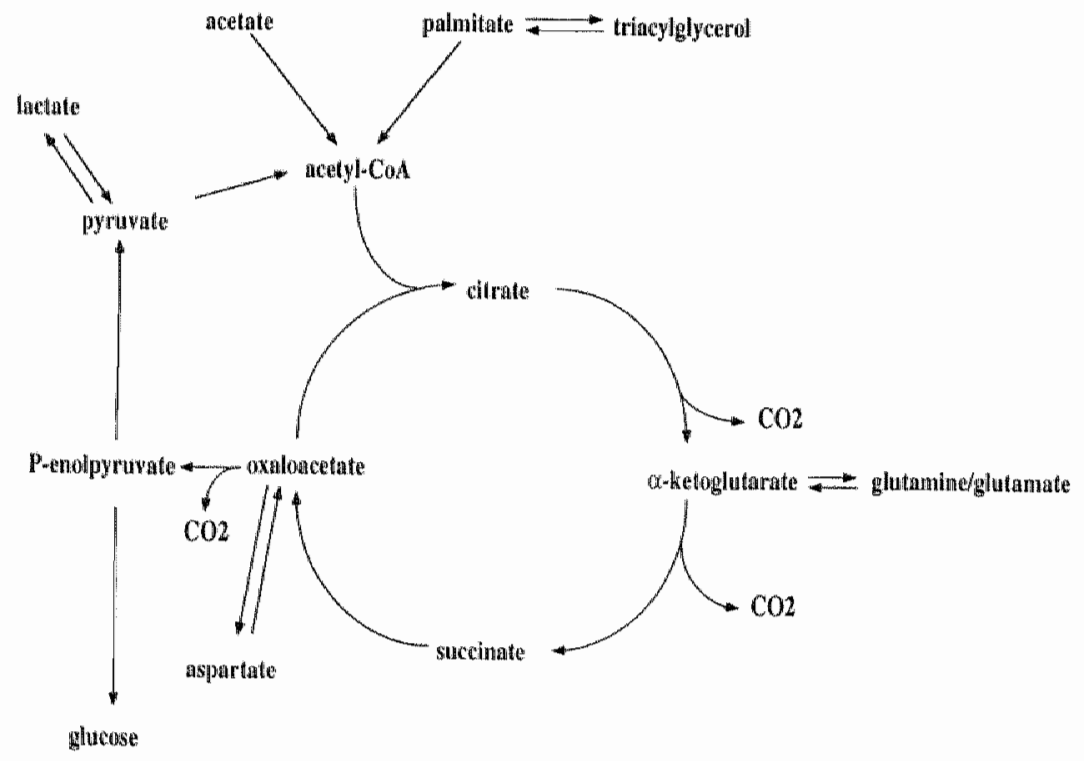

Figure 6.1 Pathway of acetate and palmitate and routes where label can be lost. 
Sidossis et al. $(12,13)$ used a simultaneous infusion of ${ }^{14} \mathrm{C}$-acetate and ${ }^{13} \mathrm{C}$-palmitate, so that only one experiment is needed to quantitate and correct the oxidation of the palmitate tracer. However, the use of radioactive tracers is under severe limitations in many countries due to medical ethical considerations (2). This implies that 2 separate experiments are needed; one to measure the ${ }^{13} \mathrm{CO}_{2}$ production from $\left[\mathrm{U}-{ }^{13} \mathrm{C}\right]$-palmitate and one to measure the ${ }^{13} \mathrm{CO}_{2}$ production from $\left[1,2-{ }^{13} \mathrm{C}\right]$-acetate under identical conditions. However, in that case, the reproducibility of the acetate recovery factor should be high to obtain a valid estimate in two separate experiments. Therefore, the second aim of the present study is to investigate whether the acetate recovery factor has to be measured in each individual or whether the mean of a group is representative for individuals. So, we both measured the intra- and inter-subject coefficient of variation of the acetate recovery factor in a group of healthy volunteers.

The main TCA cycle products in which label from $[1,2-13 \mathrm{C}]$-acetate and $\left[\mathrm{U}^{-13} \mathrm{C}\right]-$ palmitate may accumulate are glucose formed in the liver by gluconeogenesis (9), glutamate released by gut and liver and glutamine formed and released by skeletal muscle $(9,4,5)$. The final aim of the present study was to quantitate the appearance in time in these circulating products of the TCA cycle to judge which process and tissue are most important for tracer fixation from a quantitative point of view during a 2 hour infusion of acetate.

\section{Methods}

Subjects

Eight healthy, male volunteers (age: $35.1 \pm 1.8 \mathrm{y}$; height: $1.80 \pm 0.03 \mathrm{~m}$; weight: 79.5 \pm 5.3 ; \% body fat: $22.3 \pm 2.6$ ), with a body mass index ranging from 19 to $30 \mathrm{~kg} / \mathrm{m}^{2}$, participated. The nature and risks of the experimental procedure were explained to the subjects, and all subjects gave their written informed consent. The study was approved by the Ethical Committee of Maastricht University.

\section{Experimental design}

The experiment consisted of two tests separated by a minimum of one week to prevent carry over of tracer. Subjects came to the laboratory at 8:00 am after an overnight fast. Teflon catheters were inserted in an antecubital vein for isotope infusion and retrogradely into a contralateral dorsal hand vein for sampling of arterialized venous blood. After placement of the catheters subjects rested on a bed and the hand was placed in a hot-box where air was circulated at $60^{\circ} \mathrm{C}$ in order to obtain arterialized venous blood. After 30 minutes baseline oxygen consumption and carbon dioxide production was measured and breath and blood samples were collected. Immediately thereafter, subjects were given an intravenous dose of 0.085 $\mathrm{mg} / \mathrm{kg}$ of $\mathrm{NaH}^{13} \mathrm{CO}_{3}$ to prime the bicarbonate pool. Then, at $\mathrm{t}=0$, a constant intravenous infusion of $\left[\mathrm{U}-{ }^{13} \mathrm{C}\right]$-palmitate $(0.013 \mu \mathrm{mol} / \mathrm{min} . \mathrm{kg})$ or $[1,2-13 \mathrm{C}]$-acetate $(0.104 \mu \mathrm{mol} / \mathrm{min} . \mathrm{kg})$ was started and continued for 120 minutes. These infusion rates led to an equal amount of ${ }^{13} \mathrm{C}$-tracer infusion with both palmitate and acetate. The concentration of palmitate in the infusate was measured for each experiment, so that 
the exact infusion rate could be determined on an analytical GC using heptadecanoic acid as internal standard (see sample analysis). The palmitate tracer (60 $\mathrm{mg}$ of potassium salt of $\left[\mathrm{U}^{-13} \mathrm{C}\right]$-palmitate, $99 \%$ enriched, Cambridge Isotope Laboratories, Andover, MA) was dissolved in heated sterile water and passed through a $0.2 \mu \mathrm{m}$ filter into a $5 \%$ warm human serum albumin to make a $0.670 \mathrm{mM}$ solution. The acetate concentration was measured in each infusate with an enzymatic method (Boehringer, Mannheim, Germany). The acetate tracer (sodium salt of $\left[1,2-{ }^{13} \mathrm{C}\right]$-acetate, $99 \%$ enriched, Cambridge Isotope Laboratories) was dissolved in $0.9 \%$ saline. The chemical and isotopic purity (99\%) of palmitate and acetate tracers were checked by ${ }^{1} \mathrm{H}$ and ${ }^{13} \mathrm{C}$ NMR and GC/MS. Blood samples were taken every 30 minutes, and breath samples every 10 minutes. $\mathrm{VO}_{2}$ and $\mathrm{VCO}_{2}$ were also measured every 10 minutes. In 6 subjects the acetate test was repeated to determine the intra-subject reproducibility of the measurements.

Oxygen consumption and carbon dioxide production were measured using open circuit spirometry (Oxycon-B Mijnhard, The Netherlands). No changes in oxygen consumption, carbon dioxide production and respiratory quotient occurred during the last hour of the resting period and therefore measurements were averaged for the last hour of the resting period $(t=60-120)$.

\section{Diet and activity prior to testing}

Subjects were asked to fill in a three day food intake and activity record prior to the first test. In the other tests they were asked to repeat their activity schedule and eat the same food, making sure the diet was similar in the two tests. Also, subjects were asked not to consume any products with a high natural abundance of ${ }^{13} \mathrm{C}$ (carbohydrates derived from $\mathrm{C} 4$ plants: corn, sugar cane) one week before and during the entire experimental period.

\section{Body composition}

After an overnight fast, body density was determined by underwater weighing in the fasted state. Body weight was measured with a digital balance accurate to $0.01 \mathrm{~kg}$ (Sauter, type E1200). Lung volume was measured simultaneously with the helium dilution technique using a spirometer (Volugraph 2000, Mijnhardt). Body fat percentage was calculated using the equations of Siri (15). Fat-free mass (FFM) in kg was calculated by subtracting fat mass from total body mass.

\section{Sample analysis}

Oxygen saturation (Hemoximeter OSM2, Copenhagen, Denmark) was determined immediately after sampling in heparinized blood. $15 \mathrm{ml}$ of arterialized venous blood was sampled in tubes containing EDTA to prevent clotting and immediately centrifuged at $3000 \mathrm{rpm}(1000 \mathrm{~g})$ for 10 minutes at 4 o C. Plasma was frozen in liquid nitrogen and stored at $-80{ }^{\circ} \mathrm{C}$ until further analysis. Plasma substrates were determined using the hexokinase method (Roche, Basel, Switzerland) for glucose and the Wako NEFA C testkit (Wako Chemicals, Neuss, Germany) for free fatty acids. $P \rrbracket a s m a$ for the analysis of glutamine and glutamate was deproteinized with $0.3 \mathrm{M}$ perchloric acid (PCA) and analyzed enzymatically for glutamate with glutamate 
dehydrogenate performed on a COBAS FARA analyzer. Glutamine concentration was subsequently determined by converting glutamine to glutamate using glutaminase.

Breath samples were analyzed for ${ }^{13} \mathrm{C} / 12 \mathrm{C}$ ratio using a gas chromatography-isotope ratio mass spectrometry system (GC-IRMS, Finnigan MAT 252, Bremen, Germany). Plasma glutamine and glutamate tracer/tracee ratio (TTR) was determined as the MTBSTFA derivative using GC-IRMS. The resulting derivative contains 23 carbon atoms of which 5 are labeled. TTR is therefore corrected by the factor 23/5. For determination of plasma palmitate, FFA were extracted from plasma, isolated by thinlayer chromatography, and derivatised to their methyl esters. Palmitate concentration was determined on an analytical GC with flame ionization detection using heptadecanoic acid as internal standard and on average it comprised $24 \pm 1 \%$ of total FFA. Isotope tracer/tracee ratio of palmitate was determined using GC-IRMS and corrected for the extra methyl group in its derivative. For determination of the plasma glucose tracer/tracee ratio, the glucose was extracted with chloroform-methanolwater and derivatisation occurred with butylboronic acid and acetic anhydride as described before (11). The resulting derivative contains 16 carbon atoms of which 6 are labeled. TTR is therefore corrected by the factor $16 / 6$.

\section{Calculations}

${ }^{13} \mathrm{C}$ enrichment of breath $\mathrm{CO}_{2}$ and plasma metabolites is given in tracer/tracee ratio (TTR). TTR was defined as: $\left({ }^{13} \mathrm{C} /{ }^{12} \mathrm{C}\right)_{\mathrm{sa}}-\left({ }^{13} \mathrm{C} /{ }^{12} \mathrm{C}\right)_{\mathrm{bk}}$

in which $\mathrm{sa}=$ sample and $\mathrm{bk}=$ background

Total carbohydrate and fat oxidation were calculated using stoichiometric equations (10).

total fat oxidation $(\mathrm{g} / \mathrm{min})=1.695 \mathrm{VO}_{2}-1.701 \mathrm{VCO}_{2}$

total carbohydrate oxidation $(\mathrm{g} / \mathrm{min})=4.585 \mathrm{VCO}_{2}-3.226 \mathrm{VO}_{2}$

with $\mathrm{VO}_{2}$ and $\mathrm{VCO}_{2}$ in liters per minute.

Total fatty acid oxidation was determined by converting the rate of total fat oxidation to its molar equivalent, with the assumption that the average molecular weight of triglyceride is $860 \mathrm{~g} / \mathrm{mol}$, and multiplying the molar rate of triglyceride oxidation by three because each molecule contains three moles of fatty acids.

Fractional recovery of label in breath $\mathrm{CO}_{2}$, derived from the infusion of labeled palmitate or acetate was calculated as follows:

$$
\text { Fractional recovery of label }(\%)=\left(\mathrm{TTRCO}_{2} * \mathrm{VCO}_{2}\right) /(\mathrm{F}) * 100 \%
$$

where $T T R \mathrm{CO}_{2}$ is tracer/tracee ratio (TTR) in breath $\mathrm{CO}_{2}, \mathrm{VCO}_{2}$ is carbon dioxide production ( $\mathrm{mmol} / \mathrm{min})$ and $\mathrm{F}$ is infusion rate $(\mathrm{mmol} / \mathrm{min})$. 
Breath $13 \mathrm{CO}_{2}$ production, corrected for acetate recovery, during $[\mathrm{U}-13 \mathrm{C}]$-palmitate infusion was calculated as:

$$
\text { corrected }{ }^{13} \mathrm{CO}_{2} \text { production }=\left(\mathrm{TTRCO}_{2} * \mathrm{VCO} 2\right) / \mathrm{ar}
$$

where $\mathrm{TTRCO}_{2}$ is tracer/tracee ratio (TTR) in breath $\mathrm{CO}_{2}, \mathrm{VCO}_{2}$ is carbon dioxide production (mmol/min) and ar is fractional acetate recovery.

The rate of $\left[\mathrm{U}^{-13} \mathrm{C}\right]$-palmitate oxidation was calculated as follows:

$$
\text { Palmitate oxidation }(\mu \mathrm{mol} / \mathrm{min})=\left(\mathrm{TTRCO}_{2} * \mathrm{VCO}_{2}\right) /\left(\mathrm{TTR}_{\mathrm{p}} * \mathrm{ar}\right) * 1000
$$

where $\operatorname{TTR}_{\mathrm{p}}$ is the tracer/tracee ratio of fatty acid carbon in plasma and ar is the fractional acetate recovery.

Total plasma fatty acid oxidation was then calculated by dividing palmitate oxidation rate by the fractional contribution of palmitate to the total FFA concentration.

Rate of appearance $\left(\mathrm{R}_{\mathrm{a}}, \mu \mathrm{mol} / \mathrm{min}\right)$ of palmitate in plasma, which under steady state conditions is equal to the rate of disappearance $\left(R_{d}\right)$ minus tracer infusion rate, was calculated as $R_{\mathrm{a}}=\mathrm{F}^{*}\left(\mathrm{TTR}_{\mathrm{i}} / T T R_{\mathrm{p}}\right)$, with $T T R_{\mathrm{i}}$ is the tracer/tracee ratio of fatty acid carbon in infusion. Percentage of plasma FFA cleared from the circulation that was oxidized ( $\% \mathrm{R}_{\mathrm{a}}$ oxidized) was calculated as:

$$
\% \mathrm{R}_{\mathrm{a}} \text { oxidized = plasma FFA oxidation } / \mathrm{R}_{\mathrm{a}} \text { FFA }
$$

To estimate the amount of infused ${ }^{13} \mathrm{C}$ incorporated in the glutamine, glutamate and glucose pools it was assumed that the tracer/tracee ratio in plasma at the end of the infusion period was in equilibrium with the respectively body pools. Using available data on the size of the glutamine and glutamate pools, the amount of infused ${ }^{13} \mathrm{C}$ incorporated in the glutamine and glutamate pools could then be calculated, by multiplying the plasma enrichment with the body pool size, as follows:

$\%{ }^{13} \mathrm{C}$ incorporated in glutamine $=\left(\mathrm{TTR}_{\mathrm{glutamine}, 120} * 5.369 * \mathrm{BW}\right) /\left(\mathrm{F}^{*} 120\right) * 100 \%$ and

$\%{ }^{13} \mathrm{C}$ incorporated in glutamate $=\left(\mathrm{TTR}_{\text {glutamate, } 120} * 1.247 * \mathrm{BW}\right) /(\mathrm{F} * 120) * 100 \%$

with TTR $_{\text {glutamine/glutamate, } 120}$ is tracer/tracee ratio of plasma glutamine/glutamate at $t=120,5.369$ and 1.247 is the size of the glutamine and glutamate pools respectively ( $\mathrm{mmol} / \mathrm{kg})(4), \mathrm{BW}$ is body weight, and $\mathrm{F}$ is infusion rate ( $\mathrm{mmol} / \mathrm{min}$ ). 
For glucose there is inconsistency about the true volume of distribution. Therefore, a minimal and maximal estimation of the amount of infused ${ }^{13} \mathrm{C}$ incorporated in the glucose pools was calculated as follows:

${ }^{*}{ }^{13} \mathrm{C}$ incorporated in glucose $=\left(\operatorname{TTR}_{\text {glucose }} 120^{*} 40^{*}\right.$ conc glucose $\left.^{*} \mathrm{BW}\right) /\left(\mathrm{F}^{*} 120\right)^{*} 100 \%$ and

$\%^{13} \mathrm{C}$ incorporated in glucose $=\left(\mathrm{TTR}_{\text {glucose }, 120} * 200 *\right.$ conc $\left._{\text {glucose }}{ }^{* \mathrm{BW}}\right) /(\mathrm{F} * 120)^{*} 100 \%$

with $T T R_{\text {glucose, } 120}$ is tracer/tracee ratio of plasma glucose at $t=120,40$ and 200 are the minimum and maximum volume of distribution of glucose $(\mathrm{ml} / \mathrm{kg})$, conc $_{\text {glucose }}$ is the average glucose concentration $(t=90-120, \mathrm{mmol} / \mathrm{l}), \quad B W$ is body weight and $F$ is infusion rate $(\mathrm{mmol} / \mathrm{min})$.

\section{Statistical analysis}

To examine if there were individual differences in increase in acetate recovery factor linear regression lines were determined for the period of $t=60$ to $t=120$ and slopes and intercepts were tested using analysis of covariance (ancova). Coefficient of variance (CV) was calculated as $\mathrm{SD} /$ mean*100\%. All data are presented as mean \pm S.E.M and $\mathrm{p}<0.05$ is considered as significance level.

\section{Results}

Breath ${ }^{13} \mathrm{CO}_{2}$-tracer/tracee ratio gradually increased during the infusion period both when infusing palmitate and acetate (Fig. 6.2a). No plateau was reached at the end of the two hour infusion period.
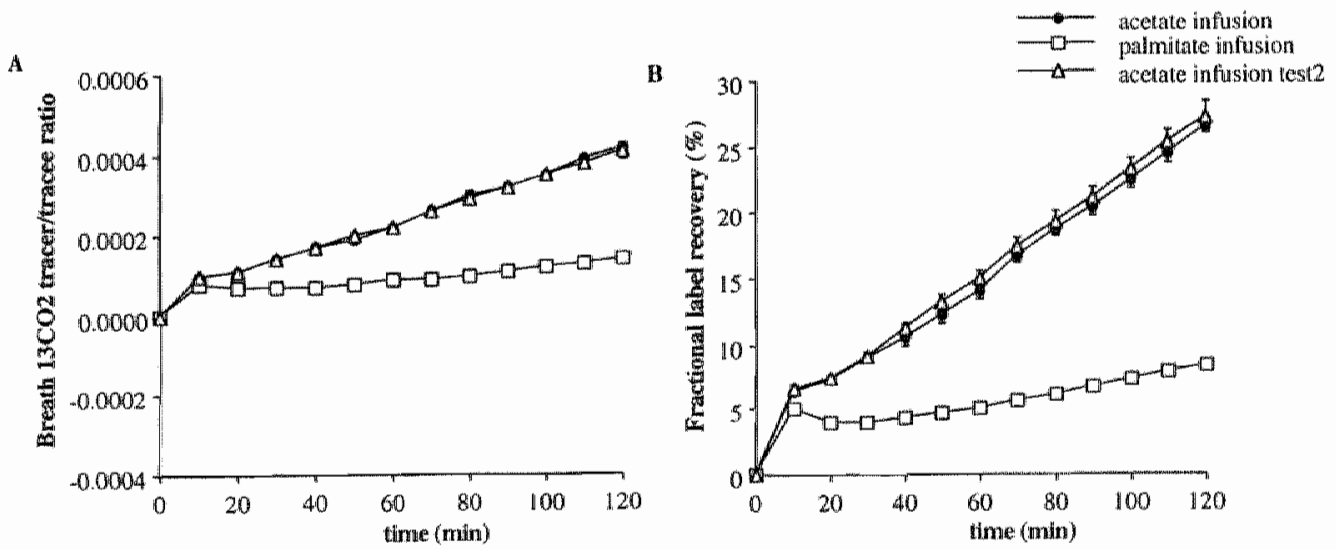

Figure 6.2 Breath ${ }^{13} \mathrm{CO}_{2}$ tracer/tracee ratio (A) and fractional label recovery (\%) in breath $\mathrm{CO}_{2}(\mathrm{~B})$ when infusing either $[1,2-13 \mathrm{C}]$-acetate or $[\mathrm{U}-13 \mathrm{C}]$-palmitate.

Fractional label recovery (in $\%$ ) in breath $\mathrm{CO}_{2}$ of $\left[\mathrm{U}-1^{3} \mathrm{C}\right]$-palmitate increased in a linear way (slope: $0.056 \% / \mathrm{min}, \mathrm{r}^{2}: 0.99$ ) from $5.1 \pm 0.2$ at $\mathrm{t}=60$ to $8.4 \pm 0.4$ at $\mathrm{t}=120$. Fractional label recovery in breath $\mathrm{CO}_{2}$ from $\left[1,2-{ }^{13} \mathrm{C}\right]$-acetate also increased in a linear way (slope: $0.20 \% / \mathrm{min}, \mathrm{r}^{2}: 0.99$ ) during the infusion period from $14.1 \pm 0.6$ at 
$t=60$ to $26.5 \pm 0.5$ at $t=120$ (Fig. 6.2b). With acetate, there were no significant differences in slopes of the linear regression lines between subjects, but the intercept was significantly different between subjects $(\mathrm{p}<0.05)$.

Percentage difference ( $\%$ of maximal value) in the fractional recovery in breath $\mathrm{CO}_{2}$ from $\left[1,2-{ }^{13} \mathrm{C}\right]$-acetate between subjects ranged from 15.1 to $32.9 \%$ at different time points. This resulted in a mean inter-subject coefficient of variation of $8.3 \pm 0.6 \%$.

\section{Reproducibility}

In six subjects, the determination of the acetate recovery factor was repeated after 2-4 weeks. There were no significant differences in fractional acetate recovery between the first and second test at any time point. Intraclass correlation coefficient between test 1 and test 2 was $0.985\left(r^{2}=0.97, p<0.0001\right)$. Percentage difference ( $\%$ of maximal value) in the fractional recovery in breath $\mathrm{CO}_{2}$ from $[1,2-13 \mathrm{C}]$-acetate between two tests in the same subject ranged from 0.1 to $14.0 \%$, with an average of $5.4 \%$. Mean intra-subject coefficient of variation over the whole infusion period was $4.0 \pm 1.5 \%$.

\section{Plasma substrate tracer/tracee ratio}

Plasma palmitate tracer/tracee ratio reached a plateau after 30 minutes of rest (Fig. 6.4a) but ${ }^{13} \mathrm{CO}_{2}$ production, corrected for recovery, reached a plateau during the last hour of infusion (Fig. 6.3). Therefore, substrate kinetics were averaged over the last hour. Plasma FFA concentration was $416.8 \pm 26.4 \mu$ mol/l and plasma palmitate concentration was $100.5 \pm 8.1 \mu \mathrm{mol} / 1(24 \pm 1 \%$ of FFA).

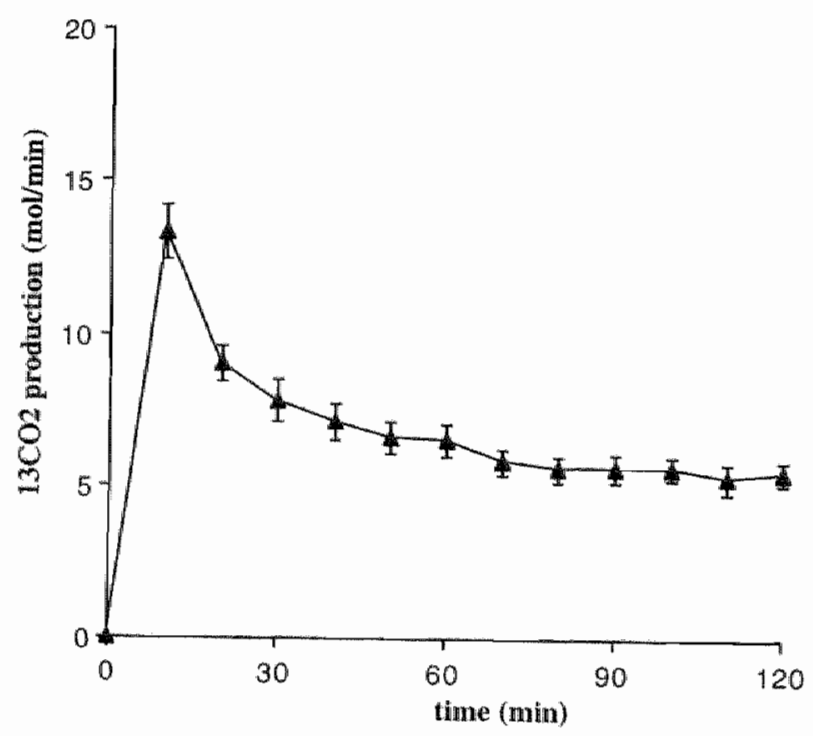

Figure 6.3 Breath ${ }^{13} \mathrm{CO}_{2}$ production corrected for recovery when infusing either $[1,2.13 \mathrm{C}]$ acetate or $\left[U-1{ }^{13} \mathrm{C}\right]$-palmitate.

Isotopically determined plasma FFA oxidation (Fig. 6.4b), rate of appearance and percentage of rate of appearance oxidized are given in table 6.1 , both with and without using the acetate correction factor. Using the acetate correction factor, rate 
of appearance $(\mathrm{Ra})$ of FFA was $7.32 \pm 0.31 \mu \mathrm{mol} / \mathrm{kg}$.min. Plasma FFA oxidation was $2.43 \pm 0.17 \mu \mathrm{mol} / \mathrm{kg} \cdot \min \left(=33.1 \pm 1.6 \%\right.$ of $\left.\mathrm{R}_{\mathrm{a}}\right)$.

A

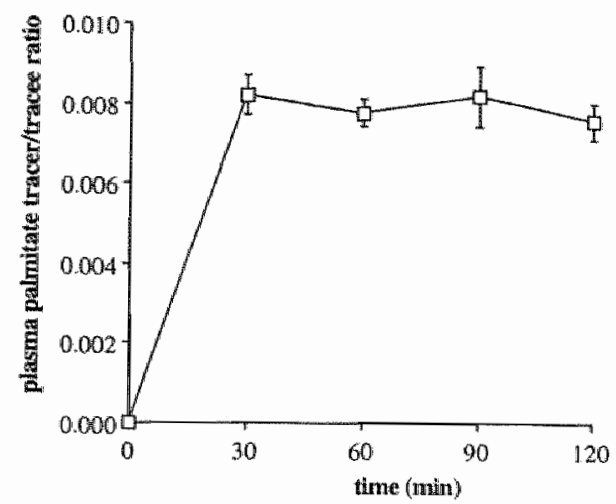

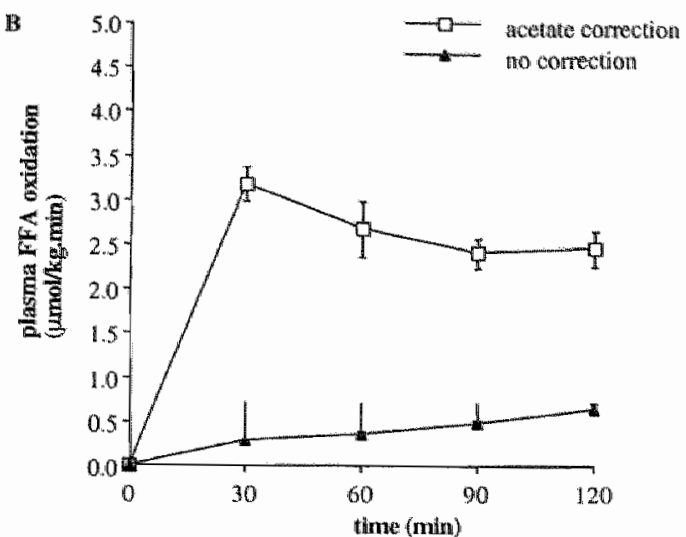

Figure $6.4{ }^{13} \mathrm{C}$-palmitate tracer/tracee ratio (A) and plasma FFA oxidation calculated using acetate correction factor $(B)$ when infusing $\left[\mathrm{U}-{ }^{13} \mathrm{C}\right]$-palmitate.

Table 6.1 Plasma (tracers) and total (indirect calorimetry) fatty acid kinetics for the last hours of [U-13 C]-palmitate infusion

\begin{tabular}{|c|c|c|c|c|}
\hline & $\begin{array}{c}\text { Plasma FA oxidation } \\
\mu \mathrm{mol} / \mathrm{kg} \text {.min }\end{array}$ & $\begin{array}{c}\text { Rate of appearance } \\
\text { umol/kg.min }\end{array}$ & $\begin{array}{c}\text { \%Ra oxidized } \\
\%\end{array}$ & $\begin{array}{c}\text { Total FA oxidation } \\
\mu \mathrm{mol} / \mathrm{kg} . \mathrm{min}\end{array}$ \\
\hline$\sqrt{a c}$ & $0.56 \pm 0.05$ & $7.32 \pm 0.31$ & $7.6 \pm 0.4$ & $3.83 \pm 0.28$ \\
\hline Acetate correction & $2.43 \pm 0.17$ & $7.32 \pm 0.31$ & $33.1 \pm 1.6$ & $3.83 \pm 0.28$ \\
\hline
\end{tabular}

Vallues are mean \pm s.e.m. $(\mathrm{n}=8)$

Plasma glutamine concentration was $539 \pm 13$ and $531 \pm 14 \mu \mathrm{mol} / 1$ when given palmitate and acetate respectively. Glutamine tracer/tracee ratio gradually increased during both palmitate and acetate infusion and did not reach a plateau after the 120 minutes of rest. The TTR at $t=120$ was 0.000101 and 0.000544 after palmitate and acetate infusion respectively (Fig. 6.5a),

Plasma glutamate concentration was $83 \pm 9$ and $76 \pm 6 \mu \mathrm{mol} / \mathrm{l}$ after palmitate and acetate infusion respectively. Glutamate tracer/tracee ratio gradually increased during both palmitate and acetate infusion and did not reach a plateau after the 120 minutes of rest. The TTR at $t=120$ was 0.000386 and 0.001946 after palmitate and acetate infusion respectively (Fig. 6.5b).

Plasma glucose concentration was $4.9 \pm 0.1$ and $5.1 \pm 0.1 \mathrm{mmol} / \mathrm{l}$ after palmitate and acetate infusion respectively. Glucose tracer/tracee ratio gradually increased during both palmitate and acetate infusion and did not reach a plateau after 120 minutes of rest. The TTR at $t=120$ was $0.0000214 \pm 0.0000017$ and $0.0000928 \pm 0.0000084$ after palmitate and acetate infusion respectively (Fig. 6.5c). 

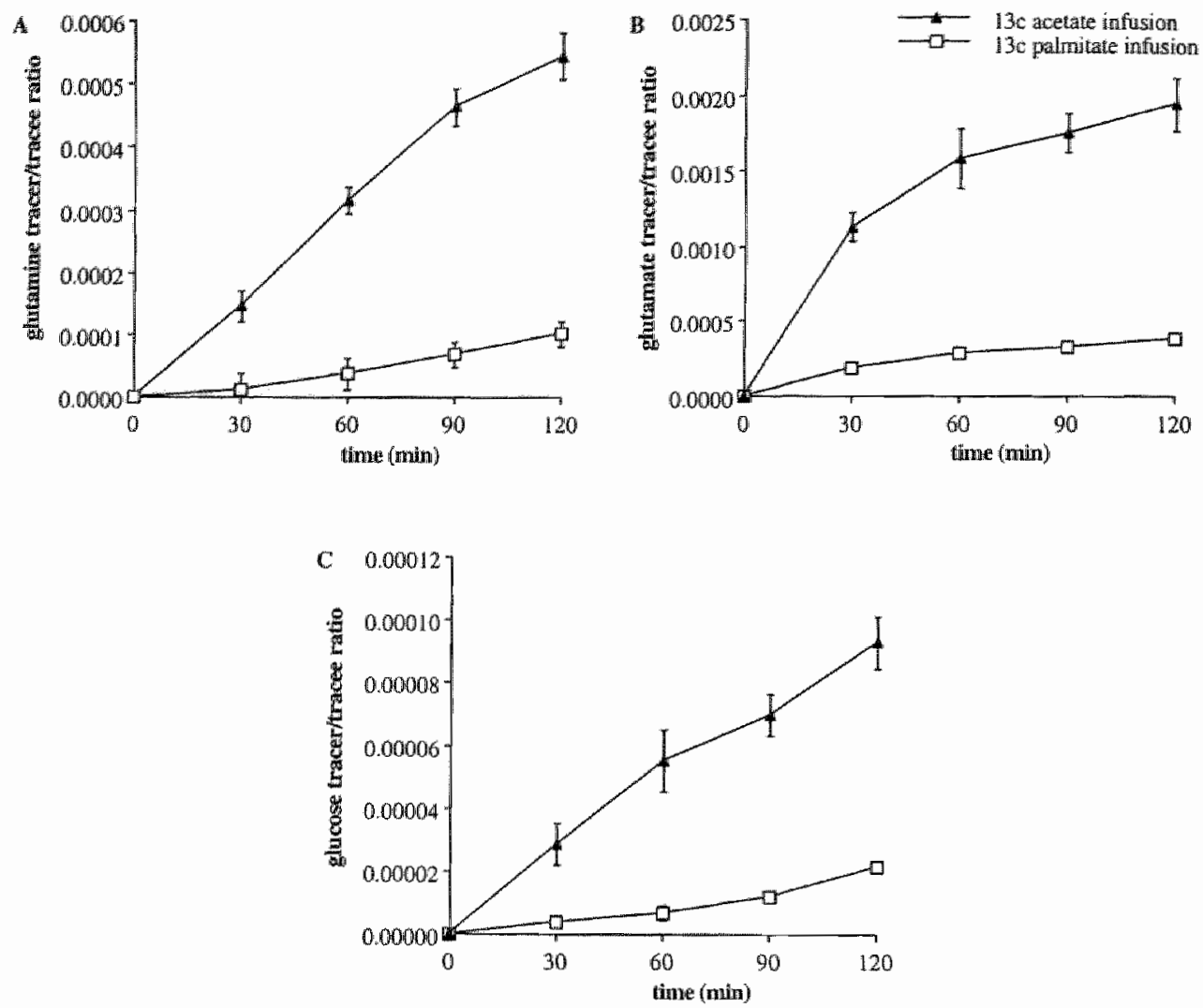

Figure $6.5{ }^{13} \mathrm{C}$ glutamine tracer/tracee ratio $(\mathrm{A}), 13 \mathrm{C}$ glutamate tracer/tracee ratio (B) and ${ }^{13} \mathrm{C}$ glucose tracer/tracee ratio $(\mathrm{C})$ when infusing either $\left[1,2-{ }^{13} \mathrm{C}\right]$-acetate or $\left[\mathrm{U}-{ }^{13} \mathrm{C}\right]$-palmitate.

\section{Discussion}

The results of the present study demonstrate that the acetate recovery factor can be used to correct palmitate oxidation rates in infusion studies of 2 hours or less. However, to correct palmitate oxidation rates, the acetate recovery factor needs to be determined for every time point, because the fractional label recovery in breath $\mathrm{CO}_{2}$ of both $\left[\mathrm{U}-{ }^{3} \mathrm{C}\right]$-palmitate and $\left[1,2-1^{13} \mathrm{C}\right]$-acetate increased in a linear way.

The present study demonstrates a good reproducibility for the acetate recovery factor. Intra-subject coefficient of variation was $4.0 \%$. However, this does not guarantee that in any given individual the acetate recovery factor can be determined in a separate experiment. Therefore the range in percentage difference in individual subjects between the two tests at different time points is more important. The maximum difference found within one subject between the two tests at any time point was $14.0 \%$. The mean difference between the two test was $5.4 \%$. These results show that it is valid to estimate the fractional recovery in a separate experiment, 
making it possible to use ${ }^{13} \mathrm{C}$ labeled acetate to determine the correction factor needed to correct the plasma FFA oxidation data.

To study whether it is necessary to determine the acetate correction factor in each individual the inter-subject coefficient of variance was calculated. Inter-subject coefficient of variance, was $8.3 \pm 0.6 \%$, with a percentage difference between subjects ranging from 15.1 to $32.9 \%$ at different time points. This means that an individual estimation of the recovery of ${ }^{13} \mathrm{C}$-acetate is needed. Using one average recovery factor for a group as a whole can lead to over- or underestimation of fatly acid oxidation with more than $30 \%$ in individual subjects.

One possible pathway for label fixation is the loss of ${ }^{13} \mathrm{C}$ from the TCA cycle in the form of glutamate and glutamine. The label is then stored in the glutamine and glutamate pools, which are in equilibrium with plasma glutamine and glutamate. We found a gradual increase in both glutamine and glutamate tracer/tracee ratio in plasma. This implies that the tracer/tracee ratio of the intracellular glutamine and glutamate pools will also gradually increase. Once the intracellular glutamine and glutamate pools increase in tracer/tracee ratio more tracer will be recovered after oxidation of these pools. Indeed, in our experiment, we did not reach a steady state in breath ${ }^{13} \mathrm{CO}_{2}$ tracer/tracee ratio at the end of the two hour infusion period. ${ }^{13} \mathrm{CO}_{2}$ tracer/tracee ratio increased in a linear way. As long as the glutamine/glutamate tracer/tracee ratio has not reached a plateau, the amount of recycling of ${ }^{13} \mathrm{C}$ will increase and therefore breath ${ }^{13} \mathrm{CO}_{2}$ tracer/tracee ratio will increase. Considering the large glutamine/glutamate pools in muscle, it is not to be expected that during a two hour infusion period an isotopic steady state can be derived. Even more, Van Acker et al. (1), showed that no isotopic steady state in both plasma and muscle glutamine tracer/tracee ratio was obtained after 11 hours of infusion of labeled glutamine. Wolfe \& Jahoor (17) also showed a gradually increasing ${ }^{13} \mathrm{CO}_{2}$ production for a period of four hours. In contrast, Sidossis et al. (12) reported an apparent plateau in breath ${ }^{13} \mathrm{CO}_{2}$ tracer/tracee ratio at the end of 3 hours of infusion at rest. However they also reported an increase in glutamine tracer/tracee ratio which had not reached a plateau at the end of the infusion period. The extracellular glutamine pool has been estimated to be $110 \mu \mathrm{mol} / \mathrm{kg}$, the intracellular muscle glutamine pool to be $5200 \mu \mathrm{mol} / \mathrm{kg}$ and the intracellular liver glutamine pool to be $39 \mu \mathrm{mol} / \mathrm{kg}$ (4). Using these figures, and assuming that the plasma glutamine tracer/tracee ratio at the end of the two hour infusion period is in equilibrium with the muscle glutamine tracer/tracee ratio, it can be estimated that $12.4 \pm 0.8 \%$ of infused ${ }^{13} \mathrm{C}$ was incorporated in the glutamine pools after two hours of $[1,2-1.3 \mathrm{C}]$-acetate infusion. The same estimation can be performed for the glutamate pools, considering an extracellular glutamate pool of $7 \mu \mathrm{mol} / \mathrm{kg}$, an intracellular liver free glutamate pool of $40 \mu \mathrm{mol} / \mathrm{kg}$ and intracellular muscle glutamate pool of $1200 \mu \mathrm{mol} / \mathrm{kg}(4)$, resulting in $10.3 \pm 0.9 \%$ of infused ${ }^{13} \mathrm{C}$ incorporated in the glutamate pools. It should be kept in mind that these calculations reflect the minimal amount of tracer that is incorporated in the glutamine and glutamate pools as it may well be possible that after two hours of infusion ${ }^{13} \mathrm{C}$ tracer/tracee ratio of glutamine and glutamate at the endogenous production site is higher than plasma tracer/tracee 
ratio. Thus the loss of ${ }^{13} \mathrm{C}$ from the TCA cycle in the form of glutamate and glutamine contributes significantly to the low recovery of acetate at rest.

Another possible pathway for label fixation is the loss of ${ }^{13} \mathrm{C}$ from the TCA cycle to glucose in gluconeogenic pathways. In our experiment glucose tracer/tracee ratio gradually increased. When only the plasma volume $(40 \mathrm{ml} / \mathrm{kg})$ is considered as the volume of distribution for glucose, it can be calculated that $0.06 \pm 0.09 \%$ of infused ${ }^{13} \mathrm{C}$ is incorporated in the glucose pools. When the total extracellular fluid is assumed to be 0.2 liter $/ \mathrm{kg}$ (4) these figures become $0.32 \pm 0.04 \%$. There is some discrepancy about the true distribution volume of glucose, but the true value will be somewhere between these two figures. Thus it can be concluded that the loss of ${ }^{13} \mathrm{C}$ to glucose is negligible. This also means that gluconeogenesis contributes only little to label fixation and forms a minor component of the acetate recovery factor in post absorptive subjects in resting conditions. Label fixation in glutamine and glutamate from a quantitative point of view is more important.

In our experiment, recovery of uniformly labeled acetate was $\pm 27 \%$ at the end of the 2 hour infusion period. These figures are far less than the results obtained by Sidossis et al. (12). They found an acetate recovery of $56 \%$ at the end of a 3 hours infusion period at rest. In our experiment, the recovery increased in a linear way and extrapolation to 3 hours results in an acetate recovery of $38 \%$. This is still less then the recovery found in the studly of Sidossis. However, Sidossis et al. (12) used ${ }^{14} \mathrm{C}$ acetate, which was labeled in the $(\mathrm{C}-1)$ position, while in our experiment acetate was uniformly labeled ( $\mathrm{C}-1$ and $\mathrm{C}-2)$. The effect of the position of the labeled carbon atom on percentage recovered label was studied by Wolfe \& Jahoor (17). After a four hour infusion period $81 \%$ of infused $1-{ }^{13} \mathrm{C}$ acetate was recovered, while only $53 \%$ of $2-13 \mathrm{C}$ acetate was recovered. The difference in tracer position therefore may explain a major part of the difference in acetate recovery found between our study and the study of Sidossis.

The acetate correction factor had to be determined using uniformly labeled acetate because it was used to correct the oxidation rate of $\left[\mathrm{U}-{ }^{13} \mathrm{C}\right]$-palmitate. A major reason for use of $\left[\mathrm{U}^{-13} \mathrm{C}\right]$-palmitate is that only one sixteenth of the dose of $\left[1-{ }^{13} \mathrm{C}\right]$-palmitate tracer is required to get an equivalent amount of ${ }^{13} \mathrm{CO}_{2}$ production. A major practical limitation with the use of palmitate tracers is the low solubility in aqueous solutions. For this reason palmitate is infused bound to human albumin. In case of the $\left[1-{ }^{13} \mathrm{C}\right]-$ palmitate tracer the amount of albumin infused is so large that infusion periods maximally may last 1-2 hour (to prevent unacceptable osmotic shifts in the plasma). This period can be substantially lengthened when a $\left[\mathrm{U}-{ }^{13} \mathrm{C}\right]$-palmitate tracer is used. The amount of fixation of tracer in TCA cycle products will be larger with $\left[\mathrm{U}-1{ }^{13} \mathrm{C}\right]-$ palmitate then with $\left[1-{ }^{13} \mathrm{C}\right]$-palmitate but can be corrected by measuring the breath ${ }^{13} \mathrm{CO}_{2}$ recovery from $[1,2-13 \mathrm{C}]$-acetate.

The impact of the acetate correction factor is shown in table 6.1. In this table plasma FFA oxidation is shown with and without applying an acetate correction factor. In our study, without the correction factor plasma FFA oxidation at rest is 
underestimated 4-fold. Using the acetate correction factor, the calculated plasma fatty acid oxidation was approximately $66 \%$ of total fatty acid oxidation. The contribution of other fatty acids than those derived from plasma to energy expenditure in the resting state is controversial. In their study, Sidossis et al. (12) suggest that, at rest, nearly all fatty acids used for oxidation are plasma-borne fatty acids. However in an other study by Sidossis (14) plasma fatty acid oxidation is only responsible for $80 \%$ of total FFA oxidation, leaving $20 \%$ for other tissues (intramuscular oxidation, liver oxidation or VLDL oxidation).

The need to correct oxidation for the recovery of infused label not only concerns fat metabolism. Because loss of label occurs in the TCA cycle, the fraction of label which is recovered should also be determined when studying carbohydrate and protein metabolism. Recently, it was shown that during glucose infusion exogenous glucose oxidation (determined by tracer) accounted for all glucose oxidation (determined by indirect callorimetry) when the acetate recovery factor was applied, whereas with only using a bicarbonate correction factor (i.e. $0.8,(3)$ ) endogenous glycogen oxidation attributed substantially to total glucose oxidation. (16).These studies indicate the importance of the recovery factor in studying oxidation rates of ${ }^{13} \mathrm{C}$-enriched substrates especially at rest.

In conclusion, the $[1,2]-{ }^{13} \mathrm{C}$ acetate recovery factor can be used for correcting the rate of $\left[\mathrm{U}-{ }^{13} \mathrm{C}\right]$-palmitate oxidation in infusing studies of 2 hours in resting conditions. Intra-subject coefficient of variation was small which makes it possible to determine the acetate recovery factor in a second separate experiment using ${ }^{13} \mathrm{C}$-acetate in one experiment and ${ }^{13} \mathrm{C}$-palmitate in the other. However, the acetate recovery factor should be dletermined in each individual and for every time point, because the acetate recovery increases in time. From a quantitative point of view accumulation of tracer carbon in glutamine and glutamate seems much more important to explain the label fixation than accumulation in glucose released by the liver. Failure to correct for the low acetate recovery under these conditions leads to dramatic underestimation of the oxidation rate of plasma fatty acid tracers. Therefore, most previous estimates of plasma fatty acid oxidation published in the literature are major underestimations.

\section{References}

1. Acker, B. A. C. v., Hulsewe, K. W. E., Wagenmakers, A. J. M., Deutz, N. E., Kreel, B. K. v., Soeters, P. B., and Meyenfeld, M. F. v. Measurement of glutanine metabolism in gastrointestinal cancer patients. Clin Nutr. 15:1,1996.

2. Beckers, E. J., Halliday, D., and Wagenmakers, A. J. M. Glucose metabolism and radioactive labeling: what are the real dangers? Med Sci Sports Exercise. 26: 1316-1318, 1994.

3. Bonadonna, R. C., Groop, L. C., Zych, K., Shank, M., and Defronzo, R. A. Dose-dependent effect of insulin on plasma free fatty acid turnower and oxidation in humans. Am J Physiol. 259: E736-E750, 1990.

4. Darmaun, D., Matthews. D. E., and Bier, D. M. Glutamine and glutamate kinetics in humans. Ann J Physiol. 251: E117-E126, 1986. 
5. Elia, M., Schlatmann, A., Goren, A., and Austin, S. Amino acid metabolism in muscle and in the whole body of man before and after ingestion of a single mixed meal. Am $J$ Clin Nutr. 49: 1203-1210, 1989.

6. Heiling, V. J, Miles, J. M., and Jensen, M. D. How valid are isotopic measurements of fatty acid oxidation? Am I Physiol. 261: E572-E577, 1991.

7. Irving, C. S., Wong, W. W., Shulman, R. J., Smith, E. O., and Klein, P. D. ${ }^{13} \mathrm{C}$ bicarbonate kinetics in humans: intra- vs. interindividual variations. Am $/$ Physiol. 245: R190-R202, 1983.

8. Leijssen, D. P. C., and Elia, M. Recovery of ${ }^{13} \mathrm{CO}_{2}$ and ${ }^{14} \mathrm{CO}_{2}$ in human bicarbonate studies: a critical review with original data. Clin Science. 91: 665-677, 1996.

9. Marliss, E. B., Aoki, T. T., Pozefsky, T., Most, A. S., and Cahill, G. F. Muscle and splanchnic glutamine and glutamate metabolism in postabsorptive and starved man. $J$ Clin Invest. 50: $814-817,1971$.

10. Péronnet, $F_{,}$and Masssicotte, D. Table of nonprotein respiratory quotient: an update. Can. J. Spt. Sci, 16: 23-29, 1991 .

11. Pickert, A., Overkamp, D., Renn, W., Liebich, H., and Eggstein, M. Selected ion monitoring gas chromatography/mass spectrometry using uniformly labelled (13C)glucose for determination of glucose turnover in man. Biol Mass Spectrometry. 20: 203-209, 1991.

12. Sidossis, L. S., Coggan, A. R., Gastaldelli, A., and Wolfe, R. R. A new correction factor for use in tracer estimations of plasma fatty acid oxidation. Am d Phystol. 269: E649-E656, 1995.

13. Sidossis, L. S., Coggan, A. R., Gastaldelli, A., and Wolfe, R. R. Pathway of free fatty acid oxidation in human subjects: implications for tracer studies. $J$ Clin Invest. 95: 278-284, 1995.

14. Sidossis, L. S., Stuart, C. A., Shulman, G. I., Lopaschuk, G. D., and Wolfe, R. R. Glucose plus insulin regulate fat oxidation by controling the rate of fatty acid entry into the mitochondria. If Clin Invest. 98: 2244-2250, 1996.

15. Siri, W. E. The gross composition of the body. Adv Biol Med Physiol. 4: 239-280, 1956.

16. Tounian, P., Schneiter, P., Henry, S., and Tappy, L. Effects of infused glucose on glycogen metabolism in healthy humans. Clinical Physiology, 16: 403-416, 1996.

17. Wolle, R. R., and Jahoor, F. Recovery of labeled $\mathrm{CO}_{2}$ during the infusion of $\mathrm{C}-1-\mathrm{vs} \mathrm{C}-2$ labeled acetate: implications for tracer studies of substrate oxidation. Am $J$ Clin Nutr. 51: 248-252, 1990 


\title{
Chapter 7
}

\section{The effect of high-fat diet on plasma-derived fatty acid oxidation}

Patrick Schrauwen, Anton J M Wagenmakers, Wouter D van Marken Lichtenbelt, Wim H M Saris, Klaas R Westerterp

Department of Human Biology, Maastricht University, Maastricht, The Netherlands

Submitted American Journal of Physiology

\begin{abstract}
Within seven days after the start of a high-fat diet fat oxidation is raised to balance fat intake. The aim of this study is to investigate which triglyceride compartment supplies the fatty acids for this increased fat oxidation. Therefore, we determined the rate of appearance and oxidation of plasma-derived fatty acids in seven healthy non-obese males (age: $23 \pm 2 \mathrm{y}$; height: $1.85 \pm 0.03 \mathrm{~m}$; weight: $70.4 \pm 2.3 ; \%$ body fat: $13 \pm 1$ ). Prior to testing, they consumed a low-fat diet ( $30 \mathrm{en} \%$ as fat, $55 \mathrm{en} \%$ as CHO) at home for three days. Rate of appearance and oxidation of palmitate was determined after 1 day consumption of either a low-fat diet (LF), a high-fat diet (HF1, 60 en\% as fat, $25 \mathrm{en} \%$ as $\mathrm{CHO}$ ) or a high-fat preceded by a glycogen lowering exercise test $(\mathrm{HFI}+\mathrm{EX})$, and after 7 days on a high-fat diet (HF7). After an overnight fast, an infusion of $\left[\mathrm{U}-{ }^{13} \mathrm{C}\right]$-palmitate $(0.00806 \mu \mathrm{mol} / \mathrm{min} . \mathrm{kg})$ was started and continued for 2 hours at rest followed by 1 hour of exercise at $50 \% \mathrm{~W}_{\max }$. Whole-body fat oxidation was measured using indirect calorimetry and plasma derived fatty acid oxidation by measuring breath ${ }^{13} \mathrm{CO}_{2}$ enrichment. Fixation of label in the TCA cycle was determined in every individual both on a LF and a HF diet by measuring breath ${ }^{13} \mathrm{CO}_{2}$ enrichment after $[1,2-13 \mathrm{C}]$-acetate infusion.

Plasma-derived fatty acid oxidation was not significanlly different between treatments at rest, but tended to be higher during exercise in the HFI+EX treatment. Non-plasma fatty acid oxidation $(\mathrm{P}<0.07)$ tended to be different between treatments at rest $(\mathrm{P}<0.07)$, and was significantly different during exercise $(\mathrm{P}<0.05)$.

In conclusion, the results from this study suggest that non-plasma fatty acid oxidation (VLDL or intramuscular triglycerides) plays a role in the increase in fat oxidation on a high-fat diet, but plasma-derived fatty acids remain the major source for fat oxidation.
\end{abstract}




\section{Introduction}

In a previous study we demonstrated that, after a switch from low-fat to high-fat diet, fat oxidation gradually increases and equals fat intake after 7 days (15). The adaptation was reached without an increase in plasma FFA and glycerol concentration, possibly indicating that the increase in fat oxidation was not accomplished by an increased FFA availability. Furthermore, during the first days on the high-fat diet, subjects were in positive fat balance and in negative carbohydrate balance. We therefore hypothesized that a gradual decrease in muscle glucose oxidation caused by a reduced blood glucose availability and decreasing glycogen stores was responsible for this increase in fat oxidation. Indeed, we showed in a second study that fat oxidation could be raised more rapidly to match fat intake on a high-fat diet, when glycogen was lowered by exhaustive exercise (16).

The mechanism by which a decrease in glycogen stores leads to an increase in fat oxidation is unclear. Firstly, insulin might play a role, because insulin is known to be an important inhibitor of lipolysis (1). Therefore, lower insulin levels on a high-fat diet might lead to less inhibition of lipolysis, resulting in higher FFA availability and FFA oxidation. In this case, an increased plasma-derived fatty acid oxidation, through higher rate of disappearance of FFA from plasma, would be responsible for the increased fat oxidation on the high-fat diet. Secondly, the malonyl-CoA hypothesis might explain the increased fat oxidation when glycogen stores are low (13). AcetylCoA from glycolysis of muscle glycogen and blood glucose can be converted to malonyl-CoA, which is an important inhibitor of carnitine palmitoyltransferase-I (CPTI). Inhibition of CPT-I will lead to a reduced uptake of fatty acids into the mitochondria and thus decrease fatty acid oxidation. In our study, the decreasing carbohydrate oxidation could have led to lower malonyl-CoA concentration, less inhibition of fatty acid uptake into the mitochondria and thus increased fat oxidation. In this case, the oxidation of plasma FFA disappearing from the circulation, or the oxidation of intramuscular fat, would be increased.

In rats, it has been shown that exercise-induced glycogen depletion does not result in increased plasma FFA uptake and oxidation, but increased uptake and oxidation of plasma glucose as long as blood glucose concentration was maintained (26). When total carbohydrate availability decreased an increase in intramuscular triglyceride oxidation was observed (23).

The aim of this study was to investigate which triglyceride compartment supplies the fatty acids for the increased fat oxidation on a high-fat diet. When the adipose tissue is the main supplier of fatty acids for oxidation, an increase in rate of appearance and oxidation of plasma-derived fatty acids would be observed. In contrast, when VLDL triglycerides or intramuscular triglycerides are the main source for the increase in fat oxidation, no change in rate of appearance and oxidation of plasma derived fatty acids will occur. Therefore, we determined the rate of appearance and oxidation of plasma-derived fatty acids in seven healthy non-obese males on a low- and high-fat diet and on a high-fat diet with prior glycogen depleting exercise. To study the 
effects of high-fat diet in the active and inactive state, the measurements were performed both at rest and during exercise.

\section{Methods}

Subjects

The characteristics of the seven healthy, non-obese male volunteers are presented in table 1 . The nature and risks of the experimental procedure were explained to the subjects, and all subjects gave their written informed consent. The study was approved by the Ethical Committee of Maastricht University.

Table 7.1 Subjects characteristics

\begin{tabular}{lcc}
\hline Subject & mean \pm s.e.m. & range \\
\hline Age $(\mathrm{y})$ & $23.1 \pm 1.8$ & $19-33$ \\
Height $(\mathrm{m})$ & $1.85 \pm 0.03$ & $1.73-1.96$ \\
Weight $(\mathrm{kg})$ & $70.4 \pm 2.3$ & $63.2-78.9$ \\
Body fat (\%) & $13 \pm 1$ & $11-17$ \\
BMI (kg/m2) & $20.6 \pm 0.6$ & $19.1-29.6$ \\
Wmax (watt) & $267 \pm 22$ & $190-337$ \\
Wmax/kg (watt) & $3.8 \pm 0.2$ & $2.8-4.5$ \\
\hline
\end{tabular}

\section{Experimental design}

The experimental design is presented in figure 1. The experiment consisted of three treatments: high-fat diet (HF), low-fat diet (LF) and high-fat diet with prior glycogen lowering exercise $(\mathrm{HF} 1+\mathrm{EX})$ and prior to all treatments, subjects consumed a low-fat diet for 3 days at home (day 1-3).

\section{$H F \perp+E X$ and $L F$ treatment}

Treatment HF1+EX and LF were performed twice using different tracers, namely once with $[\mathrm{U}-13 \mathrm{C}]$-palmitate infusion and once with $[1,2-13 \mathrm{C}]$-acetate infusion to determine the acetate recovery factor (18) under the different experimental circumstances. On day 3 subjects came to the laboratory. In the HFI +EX treatment subjects came to the laboratory at $15: 00$ to perform a glycogen depletion test on a cycle ergometer. After this, subjects entered a respiration chamber for a $36 \mathrm{~h}$ stay. During the stay in the respiration chamber they were given a high fat diet. In the LF treatment, subjects came to the laboratory at $18: 00$ for a $36 \mathrm{~h}$ stay in the respiration chamber without performing a glycogen depletion test, and consumed a low-fat diet. On the morning of days 5 subjects left the respiration chamber at 8.00 and subsequently underwent an isotope infusion test, with either $\left[U_{-13} \mathrm{C}\right]$-palmitate infusion or $\left[1,2-1{ }^{3} \mathrm{C}\right]$-acetate infusion. After this, the HF1+EX and LF treatment was ended. 

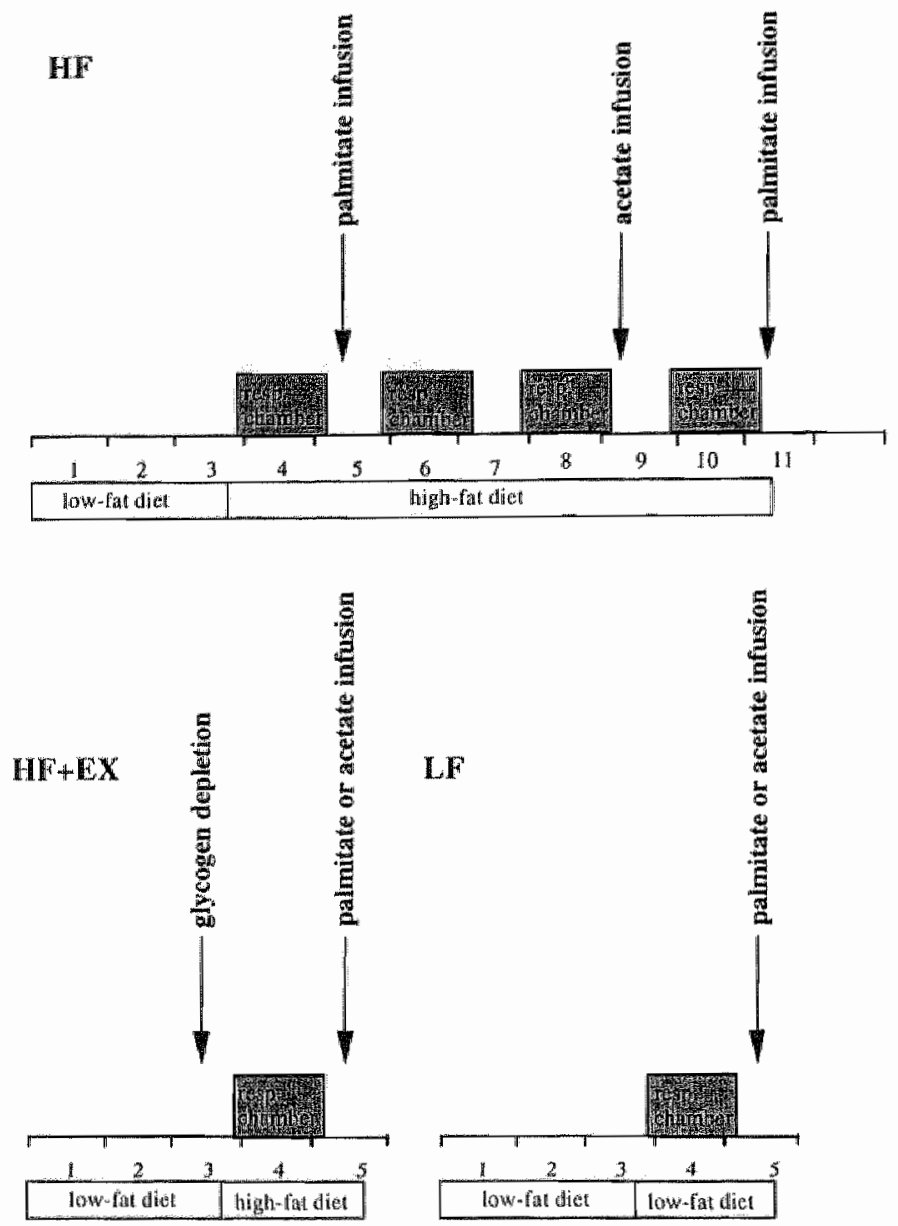

isotope infusion

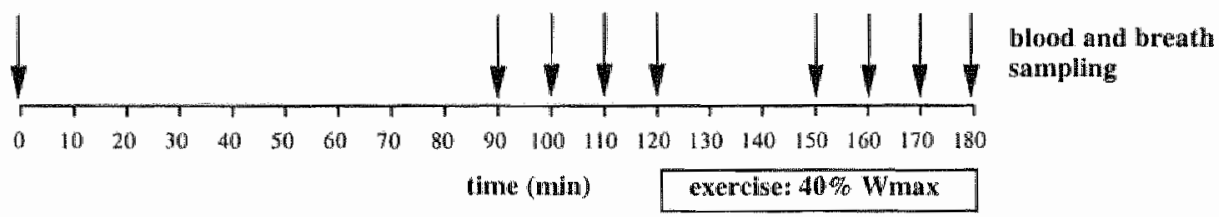

Figure 7.1 Experimental design of the study.

\section{HF treatment}

The $\mathrm{HF}$ treatment consisted of four $36 \mathrm{~h}$ periods in the respiration chamber, starting on the evening of day 3,5,7 and 9. During this whole period, subjects consumed a highfat diet. On the morning of day 5 (HFl) and day 11 (HF7), after leaving the respiration chamber, subjects underwent a [ $\mathrm{U}-13 \mathrm{C}]$-palmitate infusion test, and on the morning of day 9 they underwent a $[1,2-13 \mathrm{C}]$-acetate infusion test. The calculated acetate 
recovery factor on day 9 was used to correct plasma FFA oxidation on day 5 (HFI) and day 11 (HF7) of the HF treatment.

\section{Isotope infusion test}

In the morning at 8:00 am, after leaving the respiration chamber, subjects underwent an isotope infusion test. Teflon catheters were inserted in an antecubital vein for isotope infusion and retrogradely into a contralateral dorsal hand vein for sampling of arterialized venous blood. After placement of the catheters subjects rested on a bed and the cannulated hand was placed in a hot-box where air was circulated at $60^{\circ} \mathrm{C}$ in order to obtain arterialized venous blood. After 30 minutes, baseline oxygen consumption and carbon dioxide production was measured and breath and blood samples were collected. Immediately thereafter, subjects were given an intravenous dose of $0.085 \mathrm{mg} / \mathrm{kg}$ of $\mathrm{NaH}^{13} \mathrm{CO}_{3}$ to prime the bicarbonate pool. Then, at $\mathrm{t}=0$, a constant intravenous infusion of either $\left[\mathrm{U}-{ }^{13} \mathrm{C}\right]$-palmitate $(0.00806 \mu \mathrm{mol} / \mathrm{min} . \mathrm{kg})$ or $\left[1,2-{ }^{13} \mathrm{C}\right]$-acetate $(0.0645 \mu \mathrm{mol} / \mathrm{min} . \mathrm{kg})$ was started and continued for 120 minutes at rest. After this subjects cycled at 50\% Wmax for 1 hour and the infusion rate of palmitate and acetate was doubled. The concentration of palmitate in the infusate was measured for each experiment, to determine the exact infusion rate, on an analytical $\mathrm{GC}$ using heptadecanoic acid. as internal standard (see sample analysis). The palmitate tracer $\left(60 \mathrm{mg}\right.$ of potassium salt of $\left[\mathrm{U}-{ }^{3} \mathrm{C}\right]$-palmitate, $99 \%$ enriched, Cambridge Isotope Laboratories, Andover, MA) was dissolved in heated sterile water and passed through a $0.2 \mu \mathrm{m}$ filter into a $5 \%$ warm human serum albumin to make a $0.670 \mathrm{mM}$ solution. The acetate concentration was measured in each infusate with an enzymatic method (Boehringer, Mannheim, Germany). The acetate tracer (sodium salt of $[1,2-$ ${ }^{13} \mathrm{C}$ ]-acetate, $99 \%$ enriched, Cambridge Isotope Laboratories) was dissolved in $0.9 \%$ saline. The chemical and isotopic purity $(99 \%)$ of palmitate and acetate tracers were checked by $1 \mathrm{H}$ and ${ }^{13} \mathrm{C}$ NMR and GC/MS. Blood samples and breath samples were taken at $\mathrm{t}=0,90,100,110$ and 120 at rest and $\mathrm{t}=150,160,170$ and 180 during exercise. At rest, $\mathrm{VO}_{2}$ and $\mathrm{VCO}_{2}$ was measured continuously during the first 90 minutes using open circuit spirometry (Oxycon- $B$ Mijnhard, The Netherlands). During exercise, $\mathrm{VO}_{2}$ and $\mathrm{VCO}_{2}$ were measured immediately before the measurement of breath ${ }^{13} \mathrm{CO}_{2}$ enrichment.

\section{Diets}

The low-fat diets consisted of 30 energy $\%$ as fat, 55 energy $\%$ as carbohydrate and 15 energy $\%$ as protein. The high-fat diets consisted of 60 energy $\%$ as fat, 25 energy $\%$ as carbohydrate and 15 energy $\%$ as protein. Prior to the experiment subjects filled in a three day food intake record, to estimate habitual dietary intake. Metabolizable energy intake and macro nutrient composition of the diet was calculated using the Dutch food composition table (25). On days 1 and 2 and the first part of day 3 , a lowfat diet for consumption at home was provided. Subjects were given a fixed amount of food (based on their food intake record) and ad libitum access to لow-fat snacks. On the evening of day 3 , subjects consumed their dinner and evening snack (either low- or high-fat) in the respiration chamber. In the LF and HF treatment energy intake for dinner and evening snack was fixed at $35 \%$ and $10 \%$ of estimated daily energy expenditure (1.7* BMR based on the Harris and Benedict equations) (4). In the 
HF1+EX treatment, the evening snack had an energy content equal to energy expended during the exercise test. On day 4 , subjects were given an amount of energy equal to 1.55 times sleeping metabolic rate (SMR), as measured during the preceding night. In a previous study it was shown that with a comparable activity protocol used in the chamber a physical activity index of 1.58 was reached (15). Subjects were asked not to consume any products with a high abundance of ${ }^{13} \mathrm{C}$ (carbohydrates derived from $\mathrm{C} 4$ plants like mais and sugar cane) one week before and during the entire experimental period.

\section{Body composition}

After an overnight fast, body density was determined by underwater weighing in the fasted state. Body weight was measured with a digital balance accurate to $0.01 \mathrm{~kg}$ (Sauter, type E1200). Lung volume was measured simultaneously with the helium dilution technique using a spirometer (Volugraph 2000, Mijnhardt). Body fat percentage was calculated using the equations of Siri (22). Fat-free mass (FFM) in $\mathrm{kg}$ was calculated by subtracting fat mass from total body mass.

\section{Sample analysis}

Oxygen saturation (Hemoximeter OSM2, Copenhagen, Denmark) was determined immediately after sampling in heparinized blood and was used to arterialization. $15 \mathrm{ml}$ of arterialized venous blood was sampled in tubes containing EDTA to prevent clotting and immediately centrifuged at $3000 \mathrm{rpm}(1000 \mathrm{~g})$ for 10 minutes at $4{ }^{\circ} \mathrm{C}$. Plasma was frozen in liquid nitrogen and stored at $-80^{\circ} \mathrm{C}$ until further analysis. Plasma substrates were determined using the hexokinase method (Roche, Basel, Switzerland) for glucose, the Wako NEFA C testkit (Wako Chemicals, Neuss, Germany) for free fatty acids, the glycerolkinase-lipase method (Boehringer, Mannheim) for glycerol and triglycerides and the ultra sensitive human insulin RIA kit (linco research, St. Charles, U.S.A.) for plasma insulin.

Breath samples were analyzed for ${ }^{13} \mathrm{C} / 12 \mathrm{C}$ ratio using a gas chromatography-isotope ratio mass spectrometry system (GC-IRMS, Finnigan MAT 252, Bremen, Germany). For determination of plasma palmitate, FFA were extracted from plasma, isolated by thin-layer chromatography, and derivatised to their methyl esters. Palmitate concentration was determined on an analytical GC with flame ionization detection using heptadecanoic acid as internal standard and on average it comprised $24 \pm 1 \%$ of total FFA. Isotope tracer/tracee ratio of palmitate was determined using GC-IRMS and corrected for the extra methyl group in its derivative.

\section{Calculations}

${ }^{13} \mathrm{C}$ enrichment of breath $\mathrm{CO}_{2}$ and plasma metabolites is given in tracer/tracee ratio (TTR). TTR was defined as: $\left({ }^{13} \mathrm{C} / 12 \mathrm{C}\right)_{\mathrm{sa}}-\left({ }^{13} \mathrm{C} /{ }^{12} \mathrm{C}\right)_{\mathrm{bk}}$

in which sa $=$ sample and $b k=$ background 
Total carbohydrate and fat oxidation were calculated using stoichiometric equations (11):

$$
\begin{aligned}
& \text { total fat oxidation }(\mathrm{g} / \mathrm{min})=1.695 \mathrm{VO}_{2}-1.701 \mathrm{VCO}_{2} \\
& \text { total carbohydrate oxidation }(\mathrm{g} / \mathrm{min})=4.585 \mathrm{VCO}_{2}-3.226 \mathrm{VO}_{2}
\end{aligned}
$$

with $\mathrm{VO}_{2}$ and $\mathrm{VCO}_{2}$ in liters per minute.

Total fatty acid oxidation was determined by converting the rate of total fat oxidation to its molar equivalent, with the assumption that the average molecular weight of triglyceride is $860 \mathrm{~g} / \mathrm{mol}$, and multiplying the molar rate of triglyceride oxidation by three because each molecule contains three moles of fatty acids.

Fractional recovery of label in breath $\mathrm{CO}_{2}$, derived from the infusion of labeled acetate was calculated as follows:

$$
\text { Fractional recovery of label }(\mathrm{ar}, \%)=\left(\mathrm{TTRCO}_{2} * \mathrm{VCO}_{2}\right) /(\mathrm{F}) * 100 \%
$$

where $\mathrm{TTRCO}_{2}$ is tracer/tracee ratio (TTR) in breath $\mathrm{CO}_{2}, \mathrm{VCO}_{2}$ is carbon dioxide production $(\mathrm{mmol} / \mathrm{min})$ and $\mathrm{F}$ is infusion rate $(\mathrm{mmol} / \mathrm{min})$.

The rate of $\left[\mathrm{U}-{ }^{13} \mathrm{C}\right]$-palmitate oxidation was calculated as follows:

$$
\text { Palmitate oxidation }(\mu \mathrm{mol} / \mathrm{min})=\left(\mathrm{TTRCO}_{2} * \mathrm{VCO}_{2}\right) /\left(\mathrm{TTR}_{\mathrm{p}} * \text { ar }\right)^{*} 1000
$$

where $\mathrm{TTR}_{\mathrm{p}}$ is the tracer/tracee ratio of fatty acid carbon in plasma and ar is the fractional acetate recovery.

Total plasma fatty acid oxidation was then calculated by dividing palmitate oxidation rate by the fractional contribution of palmitate to the total FFA concentration.

Rate of appearance $\left(\mathrm{R}_{\mathrm{a}}, \mu \mathrm{mol} / \mathrm{min}\right)$ of palmitate in plasma, which under steady state conditions is equal to the rate of disappearance $\left(R_{d}\right)$ minus tracer infusion rate, was calculated as $R_{a}=F^{*}\left(T T R_{i} / T T R_{p}\right)$, with $T T R_{i}$ is the tracer/tracee ratio of fatty acid carbon in infusion. Percentage of plasma FFA cleared from the circulation that was oxidized ( $\% \mathrm{R}_{\mathrm{a}}$ oxidized) was calculated as:

$$
\% \mathrm{R}_{\mathrm{a}} \text { oxidized }=\text { plasma FFA oxidation } / \mathrm{R}_{\mathrm{a}} \text { FFA }
$$

\section{Statistical analysis}

All data are presented as mean \pm S.E.M and $\mathrm{P}<0.05$ is considered as significance level. Equality of RQ and FQ was tested using paired t-tests. Repeated measures oneway ANOVA was used to detect differences in any variables between treatments. When significant differences were found, a Scheffé post hoc test was used to determine the exact location of the difference. For testing differences in blood parameters between treatments, areas under the curve where calculated for $t=0$ to $t=120$ at rest and $t=150$ to $t=180$ during exercise. 


\section{Results}

Twenty-four hour substrate oxidation determined in respiration chamber

While in the respiration chamber subjects consumed diets based on their energy requirements. However, on average subjects were in a positive energy balance ( 0.44 $\pm 0.34,0.81 \pm 0.26,0.98 \pm 0.26$ and $0.43 \pm 0.22 \mathrm{MJ} /$ day for LF, HFI, HF7 and $\mathrm{HF} 1+\mathrm{EX}$ respectively). There were no significant differences in energy balance between treatments, allowing comparison of the treatments.

"Twenty-four hour respiratory quotient was significantly different between treatments $(\mathrm{P}<0.0001)$. 24h-RQ was significantly higher in the LF treatment compared to the HF1, HF7 and HF1+EX treatment (figure 7.2). Furthermore, RQ was significantly different from FQ in the HF1, HF7 and HF1+EX treatment $(\mathrm{P}<0.05)$, but not in the LF treatment.

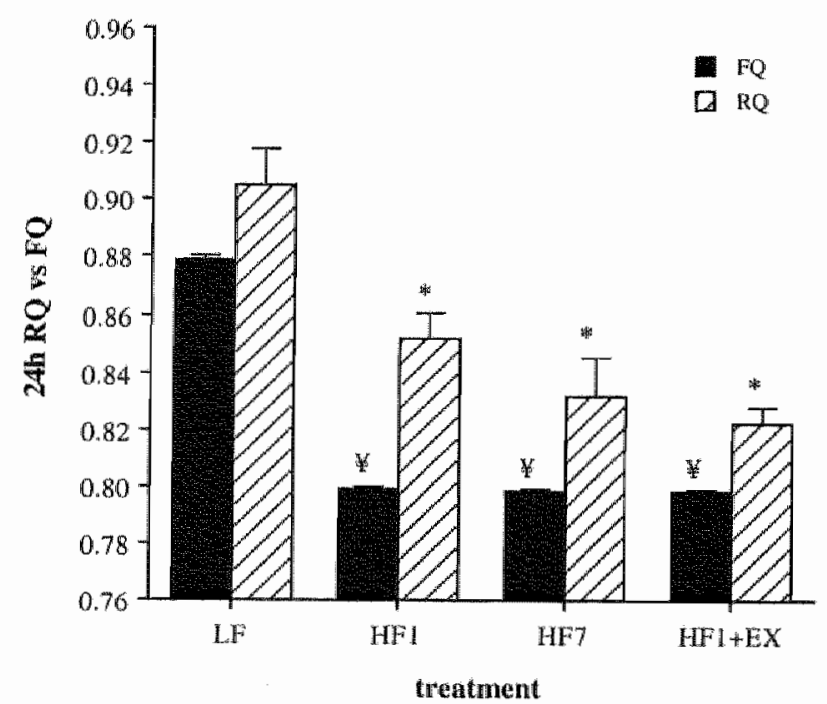

Figure 7.2 Twenty-four hour respiratory quotients (RQ) and food quotients (FQ) as mea sured in respiration chamber (mean \pm s.e.m.). * $\mathrm{P}<0.01$ compared to LF, F $\mathrm{P}<0.05$ compared to $\mathrm{FQ}$.

Twenty-four hour fat oxidation, as measured in the respiration chamber, was significantly different between treatments $(\mathrm{P}<0.002)$. Fat oxidation was significantly lower in the LF treatment compared to the HF7 and HF1+EX treatments, but the difference with HF1 did not reach statistical significance. Twenty-four hour carbohydrate oxidation was also significantly different between treatments $(\mathbb{P}<0.0001)$. Post-hoc testing revealed that carbohydrate oxidation was significantly higher in the LF treatment compared to the HF1, HF7 and HFI+EX treatments. No differences in twenty-four hour protein oxidation between treatments were observed. 
Post-absorptive substrate oxidation at rest and exercise during infusion test At rest, whole-body fat oxidation (indirect calorimetry) tended to be different between treatments $(\mathrm{P}<0.1)$ The difference became significant during exercise $(\mathbb{P}<0.05$, table 7.2 ). Post-hoc testing revealed that fat oxidation was significantly lower in the LF treatment compared to the HFL $+\mathrm{EX}$ treatment.

Acetate recovery gradually increased at rest during all treatments (figure 7.3). During exercise, a plateau in acetate recovery was present at about $80 \%$ (figure 7.3 ). There were no significant differences in acetate recovery between the treatments. Plasma palmitate enrichment reached a plateau, both at the end of the resting period and at the end of the exercise period (figure 7.4) in all treatments.
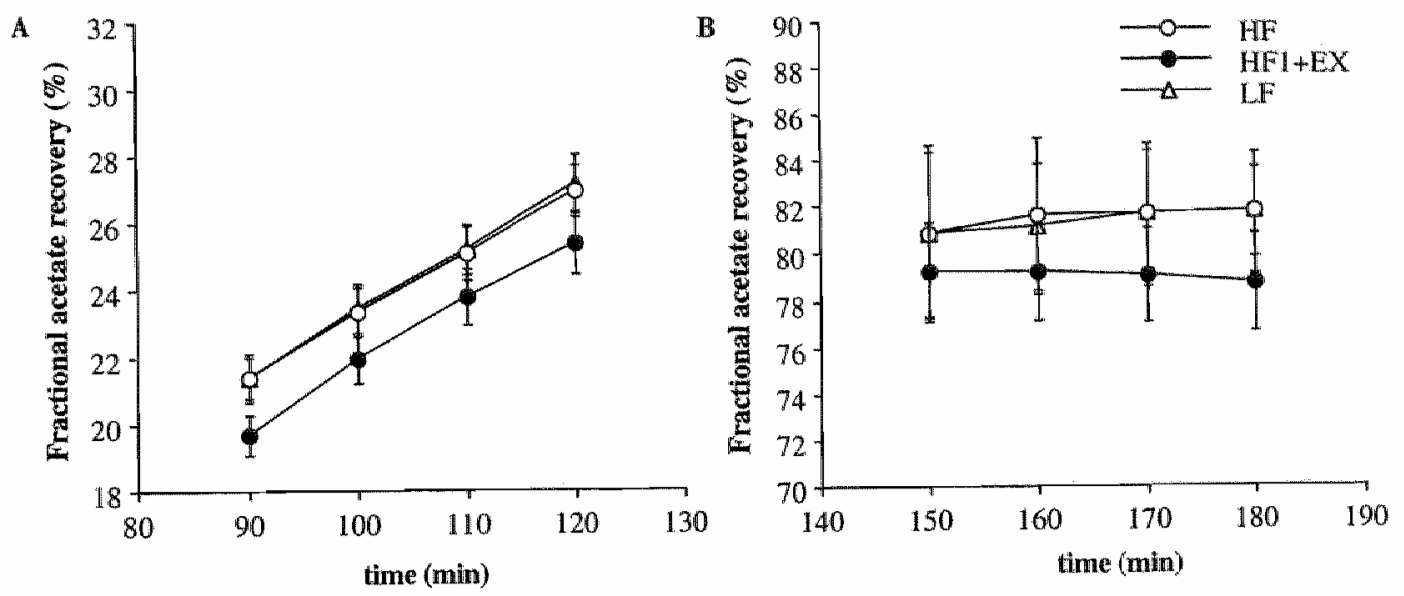

Figure 7.3 Fractional acetate recovery at rest (A) and during exercise (B) during LF, HF and $\mathrm{HFI}+\mathrm{EX}$ treatment.

Rate of appearance of free fatty acids was not significantly different between treatment at rest, but tended to be higher in the HFI $+\mathrm{EX}$ treatment during exercise $(\mathrm{P}=0.1$, table 7.2$)$. In figure $7.5 \mathrm{a}-\mathrm{b}$, the relative contribution of plasma-derived FFA and non-plasma FFA to total FFA oxidation is depicted, both at rest as during exercise. Plasma-derived fatty acid oxidation was not significantly different between treatments at rest or during exercise, but tended to be higher in the HF $1+\mathrm{EX}$ treatment during exercise ( $\mathrm{P}<0.07$, table 7.2$)$. Non-plasma fatty acid oxidation tended to be higher in the HF7 treatment compared to the LF treatment at rest $(\mathrm{P}=0.06$, table 7.2). This difference became significant during exercise $(\mathrm{P}<0.05$, tablle 7.2$)$. Percentage of palmitate uptake that was oxidized was not significantly different between treatments, both at rest and during exercise (table 7.2). 


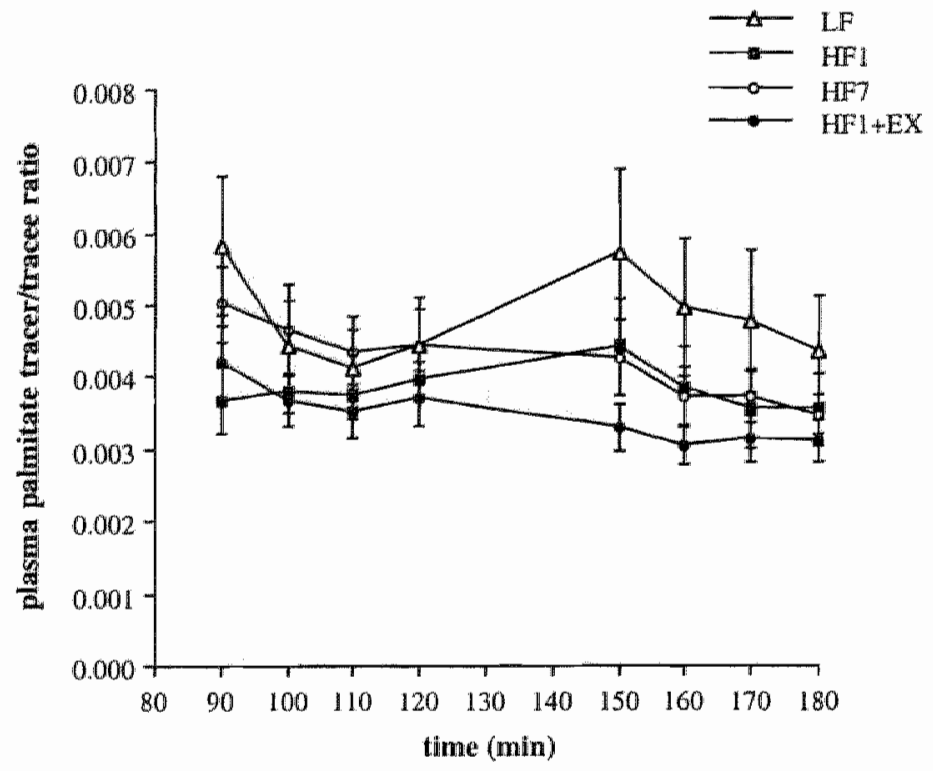

Figure 7.4 Plasma palmitate enrichment during the different treatments.

Table 7.2 Plasma (tracers) and total (indirect calorimetry) fatty acid kinetics at rest and during exercise in different treatments

\begin{tabular}{llcccc}
\hline Treatment & $\begin{array}{c}\text { Total FA } \\
\text { oxidation } \\
\mu \text { mol/min }\end{array}$ & Ra of FA & $\begin{array}{c}\text { Plasma FA } \\
\text { oxidation } \\
\mu \text { mol/min }\end{array}$ & $\begin{array}{c}\text { \% Rd } \\
\text { oxidized } \\
\%\end{array}$ & $\begin{array}{c}\text { Non-plasma } \\
\text { FA oxidation } \\
\mu \text { mol/min }\end{array}$ \\
\hline Rest & $227 \pm 27$ & $661 \pm 71$ & $220 \pm 26$ & $33.0 \pm 1.6$ & $8 \pm 18$ \\
LF & $240 \pm 17$ & $653 \pm 47$ & $217 \pm 18$ & $33.2 \pm 1.7$ & $24 \pm 18$ \\
HF1 & $270 \pm 24$ & $623 \pm 54$ & $213 \pm 26$ & $34.1 \pm 2.5$ & $57 \pm 13 \#$ \\
HF7 & $281 \pm 15$ & $758 \pm 68$ & $265 \pm 16$ & $35.8 \pm 2.1$ & $15 \pm 15$ \\
HF+EX & & & & & \\
Exercise & $1282 \pm 130$ & $1215 \pm 160$ & $867 \pm 103$ & $72.2 \pm 4.6$ & $398 \pm 160$ \\
LF & $1415 \pm 96$ & $1279 \pm 139$ & $940 \pm 81$ & $75.0 \pm 3.5$ & $475 \pm 59$ \\
HF1 & $1780 \pm 202$ & $1301 \pm 104$ & $1007 \pm 106$ & $77.0 \pm 3.4$ & $773 \pm 127 *$ \\
HF7 & $1955 \pm 204 *$ & $1676 \pm 205 \#$ & $1245 \pm 175 \#$ & $74.0 \pm 2.9$ & $710 \pm 108$ \\
\hline HF+EX & 1675
\end{tabular}

Values are mean \pm SEM for 7 volunteers

* $\mathrm{P}<0.05$ compared to LF

\# P<0.1 compared to LF

\section{Blood parameters}

At baseline, triglyceride concentration was significantly lower in the HF7 and HF $1+\mathrm{EX}$ treatment compared to the LF treatment $(\mathrm{P}><0.01$, table 7.3). There were no signilicant differences in baseline concentrations of any of the other blood parameters. Both at rest and during exercise, the area under the curve for triglycerides was significantly different between treatments $(P<0.01)$. The triglyceride concentration was significantly higher in the LF compared to the HF7 and HF1+EX 
treatment. Similar results were found for glycerol during exercise $(P<0.01)$ but not at rest. The area under the curve for insulin during exercise was significantly different between treatments $(\mathrm{P}<0.05)$. Post hoc testing revealed that this area was higher in the LF treatment compared to the HF treatment. No differences in area under the curves for any other blood parameters were found.

Table 7.3 Blood parameters at baseline during the different treatments

\begin{tabular}{|c|c|c|c|c|c|}
\hline treatment & $\begin{array}{l}\text { glucose } \\
\text { mmol/l } \\
\end{array}$ & $\begin{array}{l}\text { insulin } \\
\mu \mathrm{U} / \mathrm{mL}\end{array}$ & $\begin{array}{c}\text { triglycerides } \\
\mu \mathrm{mol} / 1\end{array}$ & $\begin{array}{c}\text { fatty acids } \\
\mu \text { moll }\end{array}$ & $\begin{array}{l}\text { glycerol } \\
\text { umold }\end{array}$ \\
\hline LF & $5.17 \pm 0.21$ & $3.5 \pm 0.5$ & $687 \pm 85$ & $356 \pm 63$ & $53 \pm 7$ \\
\hline HF 1 & $5.10 \pm 0.23$ & $4.4 \pm 0.8$ & $556 \pm 66$ & $401 \pm 64$ & $52 \pm 3$ \\
\hline $\mathrm{HFT}$ & $4.79 \pm 0.12$ & $5.5 \pm 2.0$ & $435 \pm 57 *$ & $380 \pm 89$ & $49 \pm 5$ \\
\hline $\mathrm{HF} 1+\mathrm{EX}$ & $4.84 \pm 0.13$ & $5.1 \pm 1.0$ & $454 \pm 55 *$ & $385 \pm 50$ & $60 \pm 9$ \\
\hline
\end{tabular}

Values are mean \pm s.e.m.

* $\mathrm{p}<0.01$ compared to LF
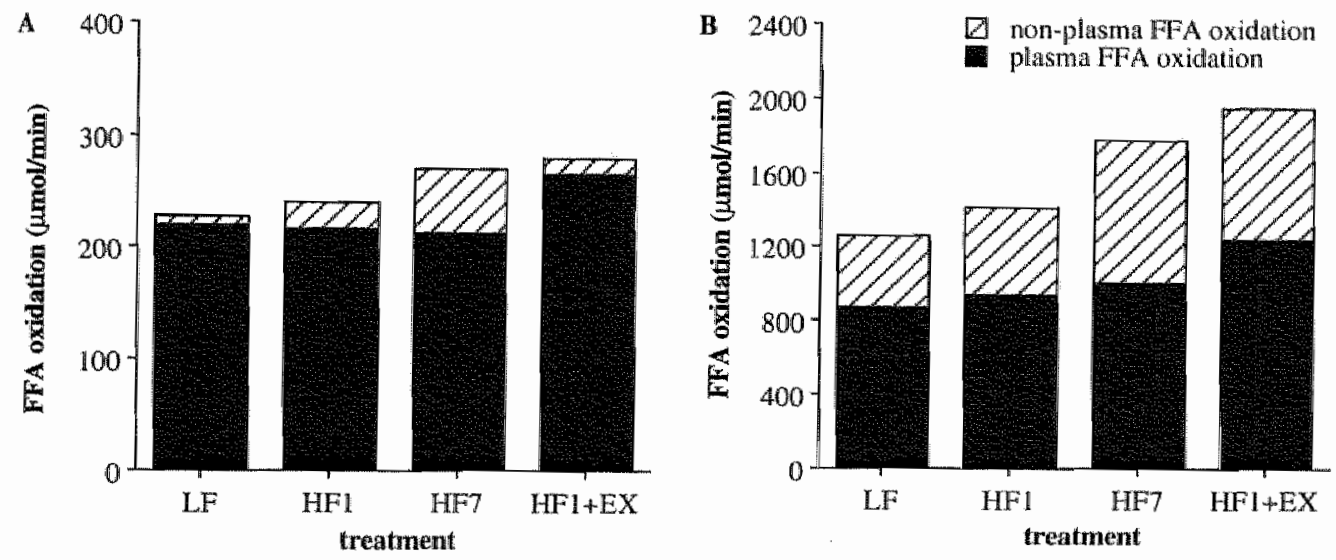

Figure 7.5 Relative contribution of plasma-derived, and non-plasma fatty acid oxidation to total fat oxidation at rest (A) and during exercise (B) in the different treatments.

\section{Discussion}

The results of the present study show that the increase in fat oxidation, observed after seven days of a high-fat diet, is not accompanied by a significant increase in plasmaderived fatty acid oxidation. In the resting state, non-plasma fatty acid oxidation tended to be increased after seven days of a high-fat diet and this difference was significant during exercise. This suggests a role for intramuscular or VLDL triglyceride oxidation in the adaptation of fat oxidation to a high-fat diet.

Little data is available on the contribution of plasma-derived fatty acid oxidation to total fat oxidation, especially at rest. The main reason is that the use of ${ }^{13} \mathrm{C}$ - and ${ }^{14} \mathrm{C}$ fatty acid tracers to estimate the oxidation of plasma fatty acids has been questioned, especially in the resting state (6). Sidossis et al.(19) recently showed that part of the tracer accumulated in products of the tricarboxylic acid (TCA) cycle and that the 
fixation of the tracer in these products, together with fixation in the bicarbonate pool, was the main reason for the delayed and incomplete appearance of ${ }^{13} \mathrm{CO}_{2}\left({ }^{14} \mathrm{CO}_{2}\right)$ in the breath. However, they suggested that the recovery of ${ }^{13} \mathrm{C}$ - (or $\left.{ }^{14} \mathrm{C}\right)$ acetate in breath ${ }^{13} \mathrm{CO}_{2}\left({ }^{14} \mathrm{CO}_{2}\right)$ can be used to determine the amount of label fixation, because acetate immediately enters the TCA cycle (18). We recently showed that this acetate recovery factor is reproducible, but has a high inter-individual variability (14). Furthermore, it increases linear with isotope infusion duration $(10,14)$. The acetate recovery factor is also much higher during exercise than at rest (18) (figure 3). Therefore, this acetate recovery factor has to be determined at similar time points and under similar conditions as the measurement of plasma-derived fatty acid oxidation and has to be repeated in every single individual. In the present study, we measured the acetate recovery factor in each individual on the LF, HF and HF1+EX treatment and in this way we were able to correct plasma-derived fatty acid oxidation rate for loss of label in the TCA cycle.

We have previously shown that it takes seven days for fat oxidation to match fat intake when diet composition is iso-energetically switched from low-fat to high-fat (15). Fat oxidation, as measured in a respiration chamber, gradually increased after the dietary switch. After seven days on the high-fat diet fat oxidation matched fat intake. In the present study, these results were confirmed. Furthermore, the present results show that, at least a part of the increase in fat oxidation was accounted for by an increase in non-plasma fatty acid oxidation. From our results we can not determine whether the increase in non-plasma fatty acid oxidation observed after seven days on the high-fat diet is an increase in VLDL-or intramuscular triglyceride oxidation. The contribution of intramuscular triglyceride oxidation to total fat oxidation is under debate. At rest, it is assumed that the oxidation of intramuscular triglycerides is negligible (18). However, during exercise, the contribution of intramuscular triglyceride oxidation to total fat oxidation has been estimated at maximally $15-35 \%$ $(7,8)$. In our experiment, the contribution of non-plasma fatty acid oxidation to total fat oxidation was negligible on the low-fat diet, but increased to approximately $20 \%$ after seven days on the high-fat diet. During exercise, the contribution of non-plasma fatty acid oxidation to total fat oxidation increased from $\pm 27 \%$ on the low-fat diet to $\pm 42 \%$ after seven days on the high-fat diet. It has previously been shown that after consumption of a high-fat diet intramuscular triglyceride concentration was elevated in healthy subjects $(9,24)$. It can be suggested that an increased intramuscular triglyceride concentration allows an increased intramuscular triglyceride oxidation. After switching from a low-fat to a high-fat diet, intramuscular triglyceride concentration will gradually increase and this might result in the gradual increase in fat oxidation. Another source for the increased non-plasma fatly acid oxidation are VLDL-triglycerides. The contribution of VLDL triglyceride oxidation was estimated to account for only $5 \%$ to total fat oxidation during exercise (5). Lipoprotein lipase activity, the enzyme responsible for releasing fatty acids from the lipoproteins (VLDL) is increased after consumption of a high-fat diet (9). Furthermore, a relation between LPL activity and whole-body fat oxidation has been shown (3). In our sludy, we measured plasma-derived fatty acid oxidation at rest and during exercise in the post absorptive state. It is possible that a higher LPL activity on a high-fat diet facilitates 
the uptake and storage of triglycerides in muscle, and that these intramuscular triglycerides are oxidized in the post absorptive state and during exercise. However, part of the fatty acids released from VLDL triglycerides might be directly oxidized in the muscle, especially in the post-absorptive state. From our data we can not conclude what the relative contribution of intramuscular and VLDL triglyceride oxidation to total fat oxidation is.

The mechanism behind the increase in fat oxidation on a high-fat diet is unknown. Randle et al. (12) introduced the "glucose-fatty acid cycle" in 1963 to describe the interaction between fat and carbohydrate oxidation. They suggested that an increased availability of FFA leads to an increased fat oxidation. In our study, the increase in fat oxidation after seven days on the high-fat diet was not accompanied by an increase in rate of appearance of plasma FFA. Coyle et al. (2) and Sidossis et al. $(20,21)$ suggested that intracellular availability of glucose determines the rate of fat oxidation. We recently showed, and confirmed here, that, after glycogen depleting exercise, fat oxidation could be increased rapidly to match fat intake on a high-fat diet, both in lean and obese subjects $(16,17)$. These results suggest that declining carbohydrate availability might be responsible for the increase in fat oxidation on a high-fat diet. This observation was confirmed in the present study, because fat oxidation on the HF1+EX treatment was similar to fat oxidation after seven days of a high-fat diet. The increase in fat oxidation in the HF1+EX treatment was accompanied by an increased rate of appearance of fatty acids, and both an increased plasma-derived fatty acid and non-plasma fatty acid oxidation. This indicates, that, even after acute lowering of the glycogen stores, followed by an acute increase in fat oxidation. FFA availability is not the only mechanism responsible for the observed increase in fat oxidation.

In conclusion, the results from this study suggest that non-plasma fatty acid oxidation (VLDL or intramuscular triglycerides) plays a role in the increase in fat oxidation on a high-fat diet. The contribution of non-plasma fatty acids to total fat oxidation is increased after a switch from a low-fat to a high-fat diet, but plasma-derived fatty acids remain the major source for fat oxidation.

\section{References}

1. Campbell, P. J., Carlson, M. G., Hill, J. O., and Nurjhan, N. Regulation of free fatty acid metabolism by insulin in humans: rolle of lipolysis and reesterification. Am $J$ Physiol. 263 : E1063-E1069, 1992.

2. Coyle, E. F., Jeukendrup, A. E., Wagenmakers, A. I. M., and Saris, W. H. M. Fatty acid oxidation in man is directly regulated by carbohydrate metabolism. submitted, 1996.

3. Ferraro, R. T., Eckel, R. H. Larson, D. E., Fontvieille, A., Rising, R., Jensen, D. R., and Ravussin, E. Relationship between skeletal muscle lipoprotein lipase activity and 24-hour macronutrient oxidation. J Clin Invest. 92: 441-445, 1993.

4. Harris, J. A., and benedict, F. G. A biometric study of basal metabolism in man. Washington, Carnegie Institution of Washington, 1919. 
5. Havel, R. J., Pernow, B., and Jones, N. L. Uptake and release of free fatty acids and other metabolites in the legs of exercising men. $J$ Appl Physiol. 23: 90-99, 1967.

6. Heiling, V. J., Miles, J. M., and Jensen, M. D. How walid are isotopic measurements of fatty acid oxidation? Am I Physiol. 261: E572-E577, 1991.

7. Hurley, B. F., Nemeth, P. M., Martin, W. H. I., Hagberg, J. M., Dalsky, G. P, and Holloszy, J. O. Muscle triglyceride utilization during exercise: effect of training. $J$ Appl Physiol. 60 : $562-567,1986$.

8. Janson, E., and Kaijser, L. Substrate utilization and enzymes in skeletal muscle of extremely endurance-trained men. I Appl Physiol. 62: 999-1005, 1987.

9. Kiens, B., Essen-Gustavsson, B., Gad, P, and Lithell, H. Lipoprotein lipase activity and intramuscular triglyceride stores after long-term high-fat and high-carbohydrate diets in physically trained men. Clin Physiol, 7: 1-9, 1987.

10. Mittendorfer, B., Sidossis, L. S., Walser, E., Chinkes, D. Ln, and Wolfe, R. R. Regional acetate kinetics and oxidation in thuman volunteers. Am J Physiol. 274: E978-E983, 1998.

11. Péronnet, $F$, and Masssicotte, D. Table of nonprotein respiratory quotient: an update. Can. J. Spt. Sci. 16:23-29, 1991 .

12. Randle, P. J., Garland, P. B., Hales, C. N., and Newsholme, E. A. The glucose-fatry acid cycle: Its role in insulin sensitivity and the metabolic disturbances of diabetes mellitus. Lancet. i: 785-789, 1963.

13. Saha, A. K., Kurowski, T. G., and Ruderman, N. B. A malonyl-coA fuel-sensing mechanism in muscle: effects of insulin, glucose, and denervation. Am J Physiol. 269: E283-E289, 1995.

14. Schrauwen, P., Aggel-Leijssen, D. P. C. v., Marken Lichtenbelt, W. D. w., Baak, M. A. v., Gijsen, A. P., and Wagenmakers, A. J. M. Validation of the $[1,2-13 \mathrm{C}]$-acetate recovery factor for correction of [U. $\left.{ }^{13} \mathrm{C}\right]$-palmitate oxidation rates. J Physiol. in press: 1998.

15. Schrauwen, P., Marken Lichtenbelt, W. D. v., Saris, W. H. M, and Westerterp, K. R. Changes in fat oxidation in response to a high-fat diet. Am J Clin Nutr.66: 276-282, 1997.

16. Schrauwen, P., Marken Lichtenbelt, W. D. v., Saris, W. H. M., and Westerterp, K. R. Role of glycogen-lowering exercise in the change of fat oxidation in response to a bigh-fat diet. Am I Physiol. 273: E623-629, 1997.

17. Schrauwen, P., Marken Lichtenbelt, W. D. v., Saris, W. H. M., and Westerterp. K. R. Fat balance in obese subjects: role of glycogen stores. An J Physiol. 274: E1027-1033, 1998.

18. Sidossis, L. S., Coggan, A. R. Gastaldelli, A., and Wolfe, R. R. A new correction factor for use in tracer estimations of plasma fatty acid oxidation. Am J Physiol. 269: E649-E656, 1995.

19. Sidossis, L. S., Coggan, A. R., Gastaldelli, A., and Wolfe, R. R. Pathway of free fatty acid oxidation in human subjects: implications for tracer studies. J Clin lmest. 95: 278-284, 1995 .

20. Sidossis, L. S., Stuart, C. A., Shulman, G. I., Lopaschuk, G. D., and Wolfe, R. R. Glucose plus insulin regulate fat oxidation by controling the rate of fatty acid entry into the mitochondria. I Clin Invest. 98: 2244-2250, 1996.

21. Sidossis, L. S., and Wolfe, R. R. Glucose and insulin-induced inhibition of fatty acid oxidation: The glucose fatry acid cycle reversed. Amer I Physiol-Endocrinol Met. 33: E733E738, 1996.

22. Siri, W. E. The gross composition of the body. Adv Biol Med Physiol. 4: 239-280, 1956. 
23. Stankiewicz-Choroszucha, B., and Gorski, J. Effect of decreased availability of substrates on untramuscular triglyceride utilization during exercise. Eur J Appl Physiol. 40: 27-35, 1978.

24. Starling, R. D., Trappe, T. A., Parcell, A. C., Kerr, C. G., Fink, W. J., and Costill, D. L. Effects of diet on muscle triglyceride and endurance performance. J Appl Physial. 82: 1185-1189, 1997.

25. Stichting-Nederlands-Voedingsstoffenbestand. NEVO Tabel. Den Haag, Voorlichtingsbureau voor de voeding 1993.

26. Turcotte, L. P., Hespel, P., and Richter, E. A. Circulating palmitate uptake and oxidation are not altered by glycogen depletion in contracting skeletal muscle. $J$ Appl Physiol. 78: 12661272,1995 . 



\title{
Chapter 8
}

\section{Effect of diet composition on leptin concentration in lean subjects}

Patrick Schrauwen, Wouter D van Marken Lichtenbelt, Klaas R Westerterp and Wim H M Saris

Department of Human Biology, Maastricht University, Maastricht, The Netherlands

Metabolism, 46 (4): 420-424, 1997.

\begin{abstract}
The recently discovered leptin is thought to be a satiety signal regulating food intake. In mice it has been shown that on a high-fat diet leptin concentration increases, but the increase was explained by increased fat mass. It is yet unknown whether leptin is influenced by other nutritional factors. Here, leptin was measured in human volunteers on a high-fat diet, while maintaining energy balance.

Twelve healthy, non-obese males and females (age: $26 \pm 2, \mathrm{BMT}: 21.4 \pm 0.5$, habitual fat intake: $29 \pm 1$ en\%) consumed a high-fat diet ( 60 en\% fat) for 7 days (day 1-7). Subjects were in energy balance (range -0.15 to $+0.23 \mathrm{MJ} / \mathrm{day}$ ), as measured in a respiration chamber on days $1-3$ and 7 .

Fasting baseline plasma leptin concentrations correlated with body fat percentage $\left(\mathrm{r}^{2}\right.$ : $0.64, \mathrm{p}<0.005$ ). On average, no changes in leptin concentration on the high-fat diet were observed. However, on an individual basis changes in leptin concentrations in response to the high-fat diet correlated with changes in insulin concentrations.

In conclusion: in case of energy balance, short-term changes in diet composition have no effect on fasting leptin concentration in lean subjects.
\end{abstract}




\section{Introduction}

High fat diets often are considered to be fattening. Apart from a lowering effect of the high-fat diet on energy expenditure (diet induced thermogenesis), a higher energy intake while consuming high-fat diets has been observed $(11,25,24)$. This can be explained by the fact that people might eat to maintain carbohydrate stores(5), leading to overeating on a high-fat diet. It is however still unclear whether people really eat to maintain carbohydrate stores $(22,17,21,23)$. Another explanation for the hyperphagia and obesity seen on high-fat diets is the high energy density of those diets. A number of studies showed that subjects eat a similar weight of food irrespective of the diet composition, resulting in higher energy intake on energy dense (high-fat) diets $(11,9)$ However, although high-fat diets seem to result in a higher energy intake and obesity, in most people with a relatively stable body weight, fat balance over a life-time period is maintained within a $1 \%$ range (6).This observation has led to a lipostatic theory, first postulated in 1953 by Kennedy (10) and developed by Weigle (26). Recently the discovery of the $o b$ gene product leptin (28) renewed the interest in this theory. Leptin is produced by adipose tissue and is supposed to act as a satiely factor in regulating food intake. Administration of leptin decreased food intake and body weight in mice with a leptin deficiency due to mutation of the $a b$ gene $(2,8,14,19)$. In humans, leptin concentrations have been found to correlate well with body fat percentage $(12,3)$. It is therefore suggested that obese subjects are resistant to leptin, possibly due to a defect in the leptin-receptor (15). Little is known about the factors that regulate or influence leptin concentrations in humans.

Frederich et al. (7) demonstrated that after 12 weeks ad libitum consumption of a high-fat diet, leptin levels were significantly increased in mice. The increase in leptin levels could be explained by the increase in body fat content. The increased leptin levels did not result in reduced energy intake. One possibility therefore is that leptin plays no role in the defense against obesity induced by high-fat diets. It is however also possible that leptin does play a defendant role, but not sufficiently to reduce food intake and to prevent obesity. In humans no effects of high-fat diets on leptin have been reported so far.

We therefore measured leptin levels in human lean subjects given a high-fat diet for one week, while being fed in energy balance. In this way, we could examine whether a high-fat diet, which normally leads to overeating, has an effect on leptin levels when no marked change in body weight and body composition occurs.

\section{Methods}

Subjects

The characteristics of the 12 volunteers ( 6 men, 6 women) participating in this study are shown in table 8.1 . Women had significantly lower body weight $(\mathrm{p}<0.05)$, greater body fat percentage $(p<0.05)$, and less fat-free mass $(p<0.001)$. No significant differences in age, body mass index and fat mass were observed between men and women. All subjects were healthy and had a habitual diet that could be considered as low-fat (mean \pm s.e.m. energy intake: $9.0 \pm 0.7 \mathrm{MJ}$, of which $29 \pm 1 \%, 54 \pm 2 \%$ and 
$16 \pm 1 \%$ provided as fat, carbohydrates and proteins respectively, as determined with a 3 day food-intake record). All subjects were non-obese and did not have a family history of obesity. The study was approved by the Ethical Committee of the University of Limburg and all subjects gave their written informed consent.

Table 8.1 Subjects characteristics measured at the end of the experimental period

\begin{tabular}{lccccc}
\hline Subject & $\begin{array}{c}\text { Age } \\
\mathrm{y}\end{array}$ & $\begin{array}{c}\text { Height } \\
\mathrm{m}\end{array}$ & $\begin{array}{c}\text { Weight } \\
\mathrm{kg}\end{array}$ & $\begin{array}{c}\text { Body fat\% } \\
\%\end{array}$ & $\begin{array}{c}\text { BMI } \\
\mathrm{kg} / \mathrm{m}^{3}\end{array}$ \\
\hline total & $26 \pm 2$ & $1.77 \pm 0.03$ & $67.0 \pm 2.4$ & $19 \pm 2$ & $21.4 \pm 0.5$ \\
males & $29 \pm 3$ & $1.83 \pm 0.03$ & $72.0 \pm 3.4$ & $15 \pm 1$ & $21.4 \pm 0.7$ \\
females & $23 \pm 1$ & $1.71 \pm 0.03^{*}$ & $62.0 \pm 1.9^{*}$ & $23 \pm 2^{*}$ & $21.3 \pm 0.8$ \\
\hline
\end{tabular}

Values mean \pm s.e.m.

$* p<0.05$ compared to men

\section{Experimental design}

Subjects consumed a high-fat diet for one week (day 1 to day 7). The first three days, as well as the last day, subjects stayed in the respiration chamber. On the other days the high-fat diet was consumed at home. On the morning of day 4 subjects left the respiration chamber at $8: 00 \mathrm{am}$. They re-entered the respiration chamber at the evening of day 6 for another 36h stay and left the chamber at 8:00 am on day 8. Prior to the start of the high-fat diet subjects were given a diet with the same composition as their habitual diet for 6 days. The last two days on the habitual diet, subjects spent in the respiration chamber as part of another experiment on substrate utilization. Here only data on the high-fat diet is presented.

\section{Diets}

All food was consumed as breakfast, lunch, dinner and 2 or more snacks per day. The high-fat diet consisted of $60 \%$ of energy as fat, $25 \%$ of energy as carbohydrate and $15 \%$ of energy as protein. Metabolizable energy intake and macronutrient composition of the diets were calculated using the Dutch food composition table (20).In the table metabolizable energy is calculated by multiplying the amount of protein, fat and carbohydrate with the Atwater factors. For calculating macronutrient balances the amount of protein, fat and carbohydrate was multiplied with 0.909 , 0.948 and 0.953 respectively to correct for digestibility of macronutrients.

On the days spent at home, the high-fat diet was fully supplied to guarantee an unchanged macronutrient composition of the diet. The amount was based on the energy expenditure in the respiration chamber, plus free access to snacks with the same macronutrient composition. On the days spent in the respiration chamber, subjects were given an amount of energy equal to the $24 \mathrm{~h}$ energy expenditure measured on the day prior to the high-fat diet. In this way, energy intake could be individually adjusted to energy expenditure, assuming that energy expenditure did not change during the experiment. 


\section{Body composition}

Subjects weighed themselves every morning during their stay in the respiration chamber, after voiding and before eating and drinking. Measurements were done on a digital balance (Seca delta, model 707) accurate to $0.1 \mathrm{~kg}$. On the morning of day 8 body density was determined by underwater weighing in the fasted state, directly after subjects left the respiration chamber. Body weight was measured with a digital balance accurate to $0.01 \mathrm{~kg}$ (Sauter, type E1200). Lung volume was measured simultaneously with the helium dilution technique using a spirometer (Volugraph 2000 , Mijnhardt). Body fat percentage was calculated using the equations of Siri (18). Fal-free mass (FFM) in $\mathrm{kg}$ was calculated by subtracting fat mass from total body mass.

\section{Indirect calorimetry and physical activity}

Oxygen consumption and carbon dioxide production were measured in a wholeroom indirect calorimeter, which was described previously (16). Energy expenditure was calculated from $\mathrm{O}_{2}$ consumption and $\mathrm{CO}_{2}$ production according to the method of Weir (27).

In the respiration chamber subjects followed an activity protocol consisting of fixed times for breakfast, lunch and dinner, sedentary activities and bench stepping exercise. The bench stepping exercise was performed for 30 minutes at intervals of 5 minutes exercise alternated with 5 minutes rest, at a rate of 60 steps per minute with a bench height of $33 \mathrm{~cm}$, and was repeated three times a day. Thus subjects exercised for 45 minutes per day, at a relative low-to-medium intensity. At daytime, no sleeping or other exercise was allowed during the stay in the respiration chamber. Spontaneous physical activity of the subjects was monitored by means of a radar system based on the Doppler principle.

During the stay in the respiration chamber $24 \mathrm{~h}$ urine was collected from $8.00 \mathrm{~h}$ am to $8.00 \mathrm{~h}$ am. Subjects had to empty the bladder at $8.00 \mathrm{~h}$ am so urine produced during the night could be included with the urine sample of the previous day. Samples were collected in containers with $10 \mathrm{ml} \mathrm{H}_{2} \mathrm{SO}_{4}$ to prevent nitrogen loss through evaporation; volume and nitrogen concentration were measured, the latter using a nitrogen analyzer (Heraeus, type CHN-O-Rapid).

24h Energy expenditure (24h EE) and $24 \mathrm{~h} \mathrm{RQ}$ were calculated from $8.00 \mathrm{~h}$ am to $8.00 \mathrm{~h} \mathrm{am}$. Carbohydrate, fat and protein oxidation were calculated using $\mathrm{O}_{2}$. consumption, $\mathrm{CO}_{2}$-production and urinary nitrogen losses with the equations of Brouwer (1).

\section{Blood analysis}

Ten $\mathrm{ml}$ of venous blood was sampled on the morning before entering the respiration chamber (baseline) and on the morning of days 4 and 8 after an overnight fast. Blood was collected in tubes containing EDTA to prevent clotting and immediately centrifuged at $3000 \mathrm{rpm}$ for 10 minutes. Plasma was frozen in liquid nitrogen and stored at $-80^{\circ} \mathrm{C}$ until further analysis. Plasma substrates were determined using the hexokinase method (LaRoche, Basel, Switzerland) for glucose, the Wako NEFA C 
testkit (Wako chemicals, Neuss, Germany) for free fatty acids, the glycerolkinaselipase method (Boehringer, Mannheim) for glycerol and triglycerides and the ultra sensitive human insulin ria kit (Linco research, St. Charles, U.S.A.) for insulin and with a radio immunoassay (Linco research, St. Charles, U.S.A.) for leptin. The intra- and inter-assay coefficients of variation for the leptin assay are $<8 \%$.

\section{Statistical analysis}

All data are presented as mean \pm S.E.M. Equality of energy intake and energy expenditure was determined by calculating the $95 \%$ confidence intervals for energy intake minus energy expenditure. The same method was used to determine equality of nutrient intakes and oxidation. A one way analysis of variance (Anova) of repeated measures was used to detect any differences in body weight or plasma substrates between days. When significant differences were found, a Tukey post-hoc test was used to determine the exact location of this difference. Factorial Anova was used to examine all parameters for gender differences.

\section{Results}

There were no significant differences in body weight between day 1 and day 3 (table 8.2). A slight but significant decline in body weight with $0.4 \pm 0.2 \mathrm{~kg}$ was observed between day 3 and day 7 (female: $0.25 \pm 0.30 \mathrm{~kg}$ vs. male: $0.57 \pm 0.27 \mathrm{~kg}$, n.s.) (table $8.2, \mathrm{p}<0.05)$.

Table 8.2 Body weight and energy balance as measured in the respiration chamber

\begin{tabular}{ccc}
\hline day & $\begin{array}{c}\text { Body weight } \\
\mathrm{kg}\end{array}$ & $\begin{array}{c}\text { energy balance } \\
\mathrm{MJ} / \text { day }\end{array}$ \\
\hline day 1 & $67.4 \pm 2.5^{*}$ & $-0.037 \pm 0.131$ \\
day 2 & $67.5 \pm 2.5^{*}$ & $0.068 \pm 0.116$ \\
day 3 & $67.3 \pm 2.5 *$ & $-0.150 \pm 0.176$ \\
day 7 & $66.9 \pm 2.4$ & $0.226 \pm 0.134$ \\
\hline * $<<0.05$ compared to day 7 &
\end{tabular}

Energy balance was not significantly different from zero on days spent in the respiration chamber (table 8.2 ). Protein balance was not significantly different from zero during the measurement days. On the high-fat diet carbohydrate oxidation gradually declined $(p<0.001)$. This resulted in a significantly negative carbohydrate balance on days 1 to 3 . On day 7 carbohydrate balance was not significantly different from zero (table 8.3). Fat oxidation gradually increased on the high-fat diet ( $\mathrm{p}<0.001)$. On day 1 to 3 fat balance was significantly positive. On day 7 fat balance was not significantly different from zero (table 8.3 ).

\section{Blood parameters}

There were no significant differences in fasting leptin, glucose, and FFA concentrations between baseline, day 4 and day 8 . In women, insulin was significantly lower on day 4 and 8 compared to baseline $(p<0.05$, table 8.4$)$. 
Triglyceride concentration was significantly lower on day 4 compared to baseline in men and glycerol concentration was significantly higher on day 4 compared to baseline in women $(\mathrm{p}<0.005$, table 8.4).

Table 8.3 Substrate balances as measured in the respiration chamber day carbohydrate balance fat balance protein balance

\begin{tabular}{lccc} 
& g/day & g/day & g/day \\
\hline day 1 & $-72 \pm 10^{*}$ & $27 \pm 4^{*}$ & $8 \pm 2$ \\
day 2 & $-45 \pm 8 *$ & $19 \pm 4^{*}$ & $3 \pm 2$ \\
day 3 & $-33 \pm 6 *$ & $14 \pm 4^{*}$ & $-8 \pm 3$ \\
day 7 & $-1 \pm 10$ & $6 \pm 5$ & $0 \pm 3$ \\
\hline
\end{tabular}

* $\mathrm{p}<0.05$ compared to zero balance

Leptin concentration (day 8) was significantly correlated with body fat percentage $\left(r^{2}: 0.64, p<0.005\right.$, figure 8.1). Baseline leptin concentration correlated significantly with insulin concentration $\left(r^{2}: 0.44, p<0.05\right)$. On days 4 and 8 leptin correlated significantly with triglycerides concentration $\left(\mathrm{r}^{2}: 0.45, \mathrm{p}<0.05\right.$ resp. $\left.\mathrm{r}^{2}: 0.52, \mathrm{p}<0.01\right)$. On day 4 also a significant correlation with glucose concentration $\left(r^{2}: 0.48, p<0.05\right)$ was found.

Table 8.4 Blood parameters measured before, during and after high-fat diet

\begin{tabular}{cccccccc}
\hline Sex & day & $\begin{array}{c}\text { glucose } \\
\text { mmol/L }\end{array}$ & $\begin{array}{c}\text { triglycerides } \\
\mu \text { mol/L }\end{array}$ & $\begin{array}{c}\text { FFA } \\
\mu \mathrm{mol} / \mathrm{L}\end{array}$ & $\begin{array}{c}\text { glycerol } \\
\mu \mathrm{mol} / \mathrm{L}\end{array}$ & $\begin{array}{c}\text { insulin } \\
\mu \mathrm{U} / \mathrm{mL}\end{array}$ & $\begin{array}{c}\text { leptin } \\
\mathrm{ng} / \mathrm{mL}\end{array}$ \\
\hline $\mathrm{F}$ & baseline & $4.73 \pm 0.23$ & $908 \pm 217$ & $289 \pm 54$ & $54 \pm 5$ & $12.03 \pm 2.35$ & $12.72 \pm 3.46^{*}$ \\
4 & $4.57 \pm 0.06$ & $666 \pm 91^{*}$ & $386 \pm 36^{*}$ & $86 \pm 12 \%$ & $8.16 \pm 0.74 \pm$ & $10.24 \pm 2.27^{*}$ \\
8 & $4.72 \pm 0.10$ & $703 \pm 100$ & $352 \pm 31$ & $73 \pm 11$ & $8.12 \pm 1.09 \neq$ & $10.74 \pm 2.83^{*}$ \\
\hline $\mathrm{M}$ & baseline & $5.13 \pm 0.34$ & $721 \pm 93$ & $253 \pm 35$ & $61 \pm 8$ & $6.58 \pm 1.84$ & $3.33 \pm 0.48$ \\
4 & $4.80 \pm 0.10$ & $421 \pm 40 *$ & $248 \pm 26$ & $59 \pm 5$ & $8.05 \pm 1.06$ & $3.47 \pm 0.43$ \\
8 & $4.86 \pm 0.10$ & $482 \pm 40$ & $263 \pm 45$ & $64 \pm 6$ & $7.08 \pm 0.61$ & $4.11 \pm 0.43$ \\
\hline
\end{tabular}

* $p<0.05$ compared to men

¥ $<0.05$ compared to baseline

Changes in leptin concentration between day 4 and baseline correlated significantly with changes in free fatty acid concentration (figure $8.2, \mathrm{r}^{2}: 0.41 \mathrm{p}<0.05$ ). Changes in leptin concentration between day 8 , as well as day 4 and baseline correlated significantly with changes in insulin concentration between those days (figure $8.3, \mathrm{r}^{2}$ : 0.44 resp. figure $8.4, r^{2}: 0.45, p<0.05$ ). Between day 4 and baseline, changes in free fatty acid and insulin concentration explained $56 \%$ of the variance in changes in leptin concentration $(p<0.05)$ as calculated with multiple regression analysis. Between day 8 and baseline, $61 \%$ of the variance in changes in leptin concentration were explained by changes in free fatty acid, glycerol and insulin concentration $(p<0.05)$. 


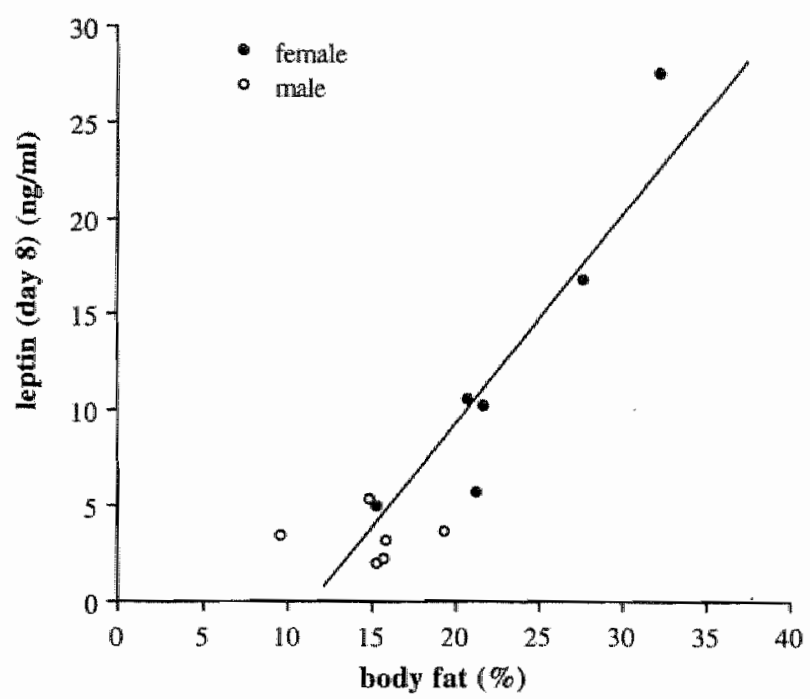

Figure 8.1 Relation between body fat percentage and fasting plasma leptin concentration.

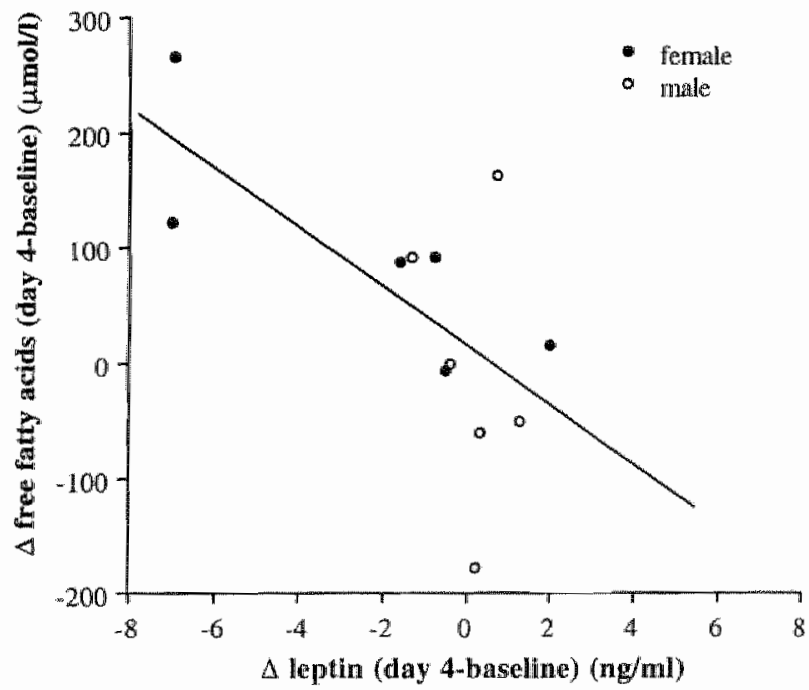

Figure 8.2 Relation between changes in FFA and leptin concentrations between day 4 and baseline.

Leptin concentrations were significantly higher for women compared to men on all days $(p<0.05$, table 8.4). Triglycerides and FFA concentrations were significantly higher for women compared to men on day 4. 


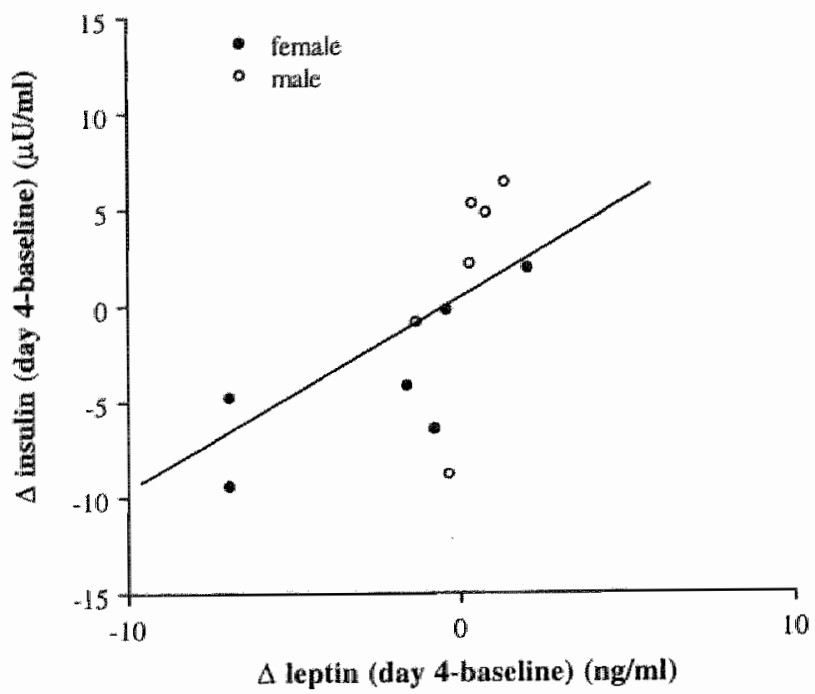

Figure 8.3 Relation between changes in insulin and leptin concentrations between day 4 and baseline.

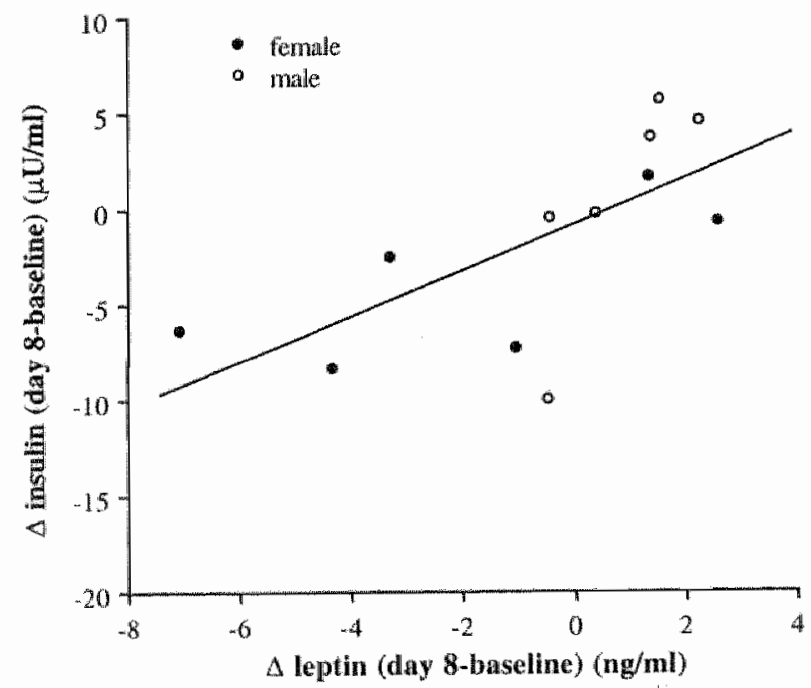

Figure 8.4 Relation between changes in insulin and leptin concentrations between day 8 and baseline.

\section{Discussion}

The results of the present study demonstrate that, in situations where energy balance is maintained, changing the fat content of the diet has no influence on leptin concentrations over a period of 7 days. 
In 1953 Kennedy postulated that the adipose tissue regulates its size by transmitting a satiety signal to feeding centers in the central nervous system (10). An increase in total adipose tissue mass leads to a decreased appetite and a decreased energy intake (26). Leptin is since its discovery thought to be this satiety signal. One prerequisite for leptin to be a satiety signal that regulates fat mass, is a positive correlation between body fat percentage and leptin levels. This has indeed been demonstrated in both mice and humans $(12,3,13)$. In this study we also observed a positive correlation between leptin levels and body fat percentage, even though the range of body fat percentage in our group of subjects was limited. It therefore seems that leptin levels reflect the amount of fat in the body.

The question remains whether leptin plays a defendant role in diet-induced obesity. High-fat foods often have been linked to obesity, both due to an impaired capacity of humans to oxidize fats (compared to carbohydrates), and/or due to a high energy density (and therefore higher energy intake) of those foods. Obesity seems to be a compensatory mechanism for a high dietary fat content. With increasing fat mass, also fat-free mass will be gained and energy expenditure will rise. Furthermore it has been shown that increasing fat mass leads to higher rates of fat oxidation. It is therefore possible that an expansion of fat mass is necessary to maintain a stable body weight when high-fat diets are consumed, by 1) increasing fat oxidation and energy expenditure and 2) limiting further increase in energy intake through elevated leptin levels.

When fed ad libitum it has been shown that consumption of a high-fat diet leads to overeating and weight gain $(11,25,24)$. Frederich et al. (7) demonstrated that consuming a high-fat diet increases leptin levels in mice. The increase in leptin observed was a reflection of the increase in adipose tissue stores. They therefore suggested that endogenous leptin, although increased by a high-fat diet, is not increasing sufficiently to prevent the occurrence of diet-induced obesity. They also reported that despite the increased leptin levels, energy intake was not reduced compared with mice fed the standard diet.

When food intake is at energy balance another mechanism is responsible for increasing fat oxidation when the dietary fat content increases. Flatt (5) proposed a model in which he states that, when energy intake is restricted, lower carbohydrate stores have to be maintained to increase fat oxidation. In our study subjects were fed in energy balance on a high-fat diet. This resulted in changes in nutrient oxidation, with a gradually increasing fat oxidation observed on the high-fat diet. Most likely this must have been due to decreasing carbohydrate stores as indicated by the negative carbohydrate balance during days 1 to 3 . The first three days on the high-fat diet, subjects were in a positive fat balance. This positive fat balance or changes in nutrient oxidation did not result in changes in leptin levels. It therefore appears that leptin does not respond to changes in nutrient oxidation or to an acute positive fat balance accompanied by a zero energy balance, at least in lean subjects. Possibly, greater changes in fat mass, or changes in energy balance are necessary to produce any change in leptin levels. So, within 7 days, diet composition seems to play no role 
in the production of leptin as long as body weight is maintained and energy balance is achieved. It has to be established whether this is also true for long-term adaptation to a high-fat diet.

In the current study a decrease in body weight was observed after the subjects left the respiration chamber (day $3 \mathrm{ks}$. day 7). It is possible that after a stay in the respiration chamber subjects increased their physical activity withow an accompanying increase in energy intake and therefore were in a negative energy balance. However, the decrease in body weight might also be due to decreased glycogen concentrations. The small decrease in body weight might have had some influence on leptin levels. However, no correlation was found between changes in body weight and changes in leptin levels.

Considine et al. (3) showed that a $10 \%$ loss of body weight resulted in a $53 \%$ decrease in leptin concentration. Therefore they suggested that leptin concentrations are regulated by other factors in addition to the adipose tissue size. One of the proposed factors is a declining fasting insulin concentration that was observed during the weight loss period. Cusin et al. (4) showed that in lean rats insulin can be viewed as an up- and down regulator of ob expression. In our study subjects were fed at energy balance consuming a high-fat diet. This resulted in a near stable body weight, increased fat intake and increased fat oxidation and, on average, no effect on fasting leptin levels. However, on an individual basis, changes in leptin levels in response to altered fat content of the diet correlated with changes in insulin concentration (and therefore with changes in free fatty acid concentration). It therefore seems that changes in diet composition, when accompanied by changes in insulin concentration (which might help to increase fat oxidation by regulating lipolysis), also lead to changes in leptin concentration. This indicates that insulin has a possible role in the up- and down regulation of leptin production as was suggested in an animal study (4).

Fasting leptin levels were closely correlated with both body fat percentage and with total body fat mass. The concentrations were three-fold higher for women compared to men as was observed earlier $(12,3)$. In this study, fat mass and body mass index were not different between men and women. Therefore, the higher leptin concentrations in women were not explained by body mass index or fat mass, a finding that was also reported in mice (7), but might be explained by a higher body fat percentage in women. If leptin regulates the absolute amount of adipose tissue, then, most likely, women are less sensitive to leptin, because with equal amounts of fat mass more leptin is needed in women than in men to maintain adipose tissue stores. Whether leptin plays an important role in the differences in body composition between women and men is yet unknown.

We conclude that, in case of near energy balance, changes in diet composition for a period of 7 days, have no effect on fasting leptin concentration. So, as long as energy balance is (nearly) maintained, changes in diet composition are not accompanied by changes in leptin, which might help to defend against obesity often observed on 
high-fat diets. It is more likely that on a higher dietary fat content, elevation of the body's fat mass is necessary to maintain a stable body weight, both by elevated leptin levels and increased rates of fat oxidation and energy expenditure.

\section{References}

1. Brouwer, E. On simple formulae for calculating the heat expenditure and the quantities of carbohydrate and fat oxidized in metabolism of men and animals, from gaseous exchange (oxygen intake and carbonic acid output) and urine-n. Acta Physiol Pharmacol Neerlandica. 6: 795-802, 1957.

2. Campfield, L. A., Smith, F. J., Guisez, Y., Devos, R., and Burn, P. Recombinant mouse OB protein: evidence for a peripheral signal linking adiposity and central neural networks Science. 269: 546-549, 1995.

3. Considine, R. V., Sinha, M. K., Heiman, M. L., Kriauciunas, A., Stephens, T. W., Nyce, M. R., Ohannesian, J. P., Marco, C. C., McKee, L. J., Bauer, T. L. Serum immunoreactive-leptin concentrations in normal-weight and obese humans. $N$ Eng J Med. 334: 292-295, 1996.

4. Cusin, I., Sainsbury, A., Doyle, P., Rohner-Jeanrenaud, F., and Jeanrenaud, B. The ob gene and insulin: A relationship leading to clues to the understanding of obesity. Diabetes. 44 : $1467-1470,1995$.

5. Flatt, J. P. The difference in the storage capacities for carbohydrate and for fat, and its implications in the regulation of body weight. Ann N Y Acad Sci. 499: 104-23, 1987.

6. Frayn, K. N. Physiological regulation of macronutrient balance. Int J Obes. 19: S4-S10, 1995.

7. Frederich, R. C., Hamann, A., Anderson, S., Löllmann, B., Lowell, B. B., and Flier, J. S. Leptin levels reflect body lipid content in mice: evidence for diet-induced resistance to leptin action. Nature medicine. 1: 1311-1314, 1995.

8. Halaas, J. L., Gajiwala, K. S., Maffei, M., Cohen, S. L., Chait, B. T., Rabinowitz, D., Lallone, R. L., Burley, S. K., and Friedman, J. M. Weight-reducing effects of the plasma protein encoded by the obese gene. Science. 269: 543-546, 1995 ,

9. Kendall, A., Levitsky, D. A., Strupp, B. J., and Lissner, L. Weight loss on a low-fat diet: consequence of the imprecision of the control of food intake in humans. Am J Clin Nutr. 53: $1124-1129,1991$.

10. Kennedy, G. C. The role of depot fat in the hypothalamic control of food intake in the rat. Proc Royal Soc B. 140: 578-592, 1953.

11. Lissner, L., Levitsky, D. A., Strupp, B. J., Kalkwarf, H. J., and Roe, D. A. Dietary fat and the regulation of energy intake in human subjects. Am J Clin Nutr. 46: 886-892, 1987.

12. Maffei, M., Halaas, J., Ravussin, E., Pratley, R. E., Lee, G. H., Zhang, Y., Fei, H., Kim, S., Lallone, R., Ranganathan, S. Leptin levels in human and rodent: measurement of plasma leptin and $a b$ RNA in obese and weight-reduced subjects. Nature. 1: 1155-1161, 1995.

13. Mcgregor, Gr. P., Desaga, J. F. Ehlenz, K., Fischer, A., Heese, F., Hegele, A., Lammer, C., Peiser, C., and Lang, R. E. Radioimmunological measurement of leptin in plasma of obese and diabetic human subjects. Endocrinology. 137: 1501-1504, 1996.

14. Pelleymounter, M. A., Cullen, M. J., Baker, M. B., Hecht, R., Winters, D., Boone, T., and Collins, F. Effects of the obese gene product on body weight regulation in $a b / o b$ mice. Science. 269: 540-543, 1995. 
15. Rohner-Jeanrenaud, F, and Jeanrenawd, B. Obesity, leptin and the brain. $N$ Engl $J$ Med. 334: $324-325,1996$.

16. Schoffelen, P. F. M., Saris, W. H. M., Westerterp, K. R., and ten Hoor, F. Evalution of an automatic indirect calorimeter for measurement of energy balance in man. Human Energy Metabolism: Physical Activity and Energy Expenditure Measurements in Epidemiological Research Based Upon Direct and Indirect Calorimetry. Wageningen, Euro-Nut. 51-54, 1984.

17. Shetty, P. S., Prentice, A. M., Goldberg, G. R., Murgatroyd, P. R, Mckenna, A. P. M., Stubbs, R. J., and Volschenk, P. A. Alterations in fuel selection and woluntary food intake in response to isoenergetic manipulation of glycogen stores in humans. Am J Clin Nutr. 60: 534-543, 1994.

18. Siri, W. E. The gross composition of the body. Adv Biol Med Physiol. 4: 239-280, 1956.

19. Stephens, T. W., Basinski, M., Bristow, P. K., Bue-Valleskey, J. M., Burgett, S. G., Craft, L., Hale. J., Hoffmann, J. "Hsiung, H. M., Kriauciunas, A. The role of neuropeptide $Y$ in the antiobesity action of the obese gene product. Narure. 377:530-532, 1995.

20. Stichting-Nederlands-Voedingsistoffenbestand. NEVO Tabel. Den Haag, Voorlichtingsbureau woor de voeding.

21. Stubbs, R. J., Harbron, C. G., Murgatroyd, P. R., and Prentice, A. M. Covert manipulation of dietary fat and energy density: Effect on substrate flux and food intake in men eating ad libitum. Am J Clin Nutr, 62: 316-329, 1995.

22. Stubbs, R. J., Murgatroyd, P. R., Goldberg, G. R., and Prentice, A. M. Carbohydrate balance and the regulation of day-to-day food intake in humans. Am J Clin Nutr. 57: 897-903, 1993.

23. Stubbs, R. J., Ritz, P., Coward, W. A., and Prentice, A. M. Covert manipulation of the ratio of dietary fat to carbohydrate and energy density: Effect on food intake and energy balance in free-living men eating ad libitum. Am J Clin Nur. 62: 330-337, 1995.

24. Thomas, C. D., Peters, J. C., Reed, G. W., Abumrad, N. N., Surn, M., and Hill, J. O. Nutrient balance and energy expenditure during ad libitum feeding of high-fat and highcarbohydrate diets in humans. Am J Clin Nwtr. 55; 934-942, 1992.

25. Tremblay, A., Plourde, G., Despres, J. P., and Bouchard, C. Impact of dietary fat content and fat oxidation on energy intake in humans. Am J Clin Nutr. 49: 799-805, 1989.

26. Weigle, D. S. Appetite and the regulation of body composition. FASEB J. 8: 302-310, 1994.

27. Weir, J. B. d. V. New methods for calculating metabolic rate with special reference to protein metabolism. I Physiol. 109: $\mathbb{1}-9,1949$.

28. Zhang, Y., Proenca, R., Maffei, M., Barone, M., Leopold, L, and Friedman, I. M. Positional cloning of the mouse obese gene and its human homoloque. Nature. 372: 425-432, 1994. 


\title{
Chapter 9
}

\section{The role of uncoupling proteins in energy balance}

Patrick Schrauwen ${ }^{* \#}$, Ken Walder\# and Eric Ravussin ${ }^{\#}$

"Department of Human Biology, Maastricht University, Maastricht, The Netherlands "Clinical Diabetes and Nutrition Section, National Institutes of Health, Phoenix, Arizona, USA

This chapter will be published as Chapter 21 in: Westerterp-Plantega, M. S., Steffens, A. B., Tremblay, A. (editors). Regulation of food intake and energy expenditure. EDRA, Milan, Italy, 1999.

\begin{abstract}
Uncoupling proteins 2 and 3 are newly discovered proteins which can uncouple ATP production from mitochondrial respiration, thereby dissipating energy as heat and affecting energy metabolism efficiency. In contrast to UCP1, which is only present in brown adipose tissue, UCP2 has a wide tissue distribution, whereas UCP3 is expressed predominantly in skeletal muscle. Some evidence of a role for UCPs in modulating metabolic rate was provided by linkage and association studies. Furthermore, UCP3 gene expression was correlated negatively with BMI, and positively with SMR in Pima Indians.

Treatment with thyroid hormone increased expression of the UCP2 and UCP3 genes. Other regulators of UCP2 and UCP3 gene expression are B3-adrenergic agonists and glucocorticoids. Fasting had a stimulatory effect on UCP2 and UCP3 mRNA levels, whereas a reduction was expected to conserve energy in times of decreased energy intake. Possibly these results can be explained by the stimulatory effects of FFA on UCP2 and UCP3 gene expression.
\end{abstract}




\section{Introduction}

Many processes in living cells consume energy. These processes include muscle contraction, protein turnover, $\mathrm{Na}^{+}-\mathrm{K}^{+}$pump, $\mathrm{Ca}^{2+}$ pump and substrate cycles. In these processes, the energy is provided by adenosine triphosphate (ATP). This molecule can release energy by donating 1 or 2 phosphate groups, leaving adenosine diphosphate (ADP) or adenosine monophosphate (AMP), respectively. At any time, the amount of ATP in the human body is sufficient to supply the body"s energy needs for only a few seconds. Therefore ATP has to be continuously resynthesised from ADP in a process called oxidative phosphorylation. During the oxidation of substrates (fat, carbohydrate, protein) the co-factors $\mathrm{NADH}$ and $\mathrm{FADH}_{2}$ are formed in the mitochondrial matrix. At the mitochondrial membrane, $\mathrm{NADH}$ and $\mathrm{FADH}_{2}$ are converted to $\mathrm{NAD}^{+}$and FADH and $\mathrm{H}^{+}$. According to the chemiosmotic hypothesis of Mitchell (24), the protons are then transported to the cytosolic side of the inner mitochondrial membrane by a series of reactions. This eventually generates a proton gradient across the membrane, which causes protons to flow back over the inner mitochondrial membrane. The energy generated is used by ATPase to transform ADP into ATP. Therefore the processes of substrate oxidation are coupled to the formation of ATP.

The resting metabolic rate (RMR) represents the basal energy requirements of the body, and constitutes $60-70 \%$ of total energy expenditure (30). Under resting conclitions and without change in heat storage, all of the energy expenditure is lost as heat, since no external work is performed. The processes involved in energy expenditure can be divided into two categories: ATP consuming processes and nonATP consuming processes.

\section{ATP consuming processes}

Many processes in the body require ATP as an energy delivering substrate, including the $\mathrm{Na}^{+}-\mathrm{K}^{+}$pump which is responsible for approximately $20 \%$ of the ATP consuming energy expenditure, protein turnover (12-25\% of RMR), and the $\mathrm{Ca}^{2+}$ pump (4-6\% of RMR). Muscle contraction, and more specifically actin-myosin ATPase, is also a significant contributor to energy expenditure. Substrate cycling contributes up to $8 \%$ of RMR, composed mainly of cycling in glycolysis, triglyceride turnover and the Cori cycle. Other ATP consuming processes include gluconeogenesis (5-8\% of RMR), urea synthesis (2\%), enzyme phosphorylation and RNA/DNA turnover (figure 9.1). All of these processes are repeated continuously because they are counterbalanced by opposing reactions: protein degradation vs. protein synthesis, $\mathrm{Na}^{+}$channels vs. $\mathrm{Na}^{+}$pumping, muscle relaxation vs. muscle contraction etc. Therefore a continuous supply of ATP is required. It has been estimated that ATP consuming processes account for approximately $80 \%$ of RMR (34). 


\section{Non-ATP consuming processes}

Not all energy expenditure in the human body is coupled to ATP use. There are at least two processes that contribute to energy expenditure and thus heat production without the involvement of ATP:

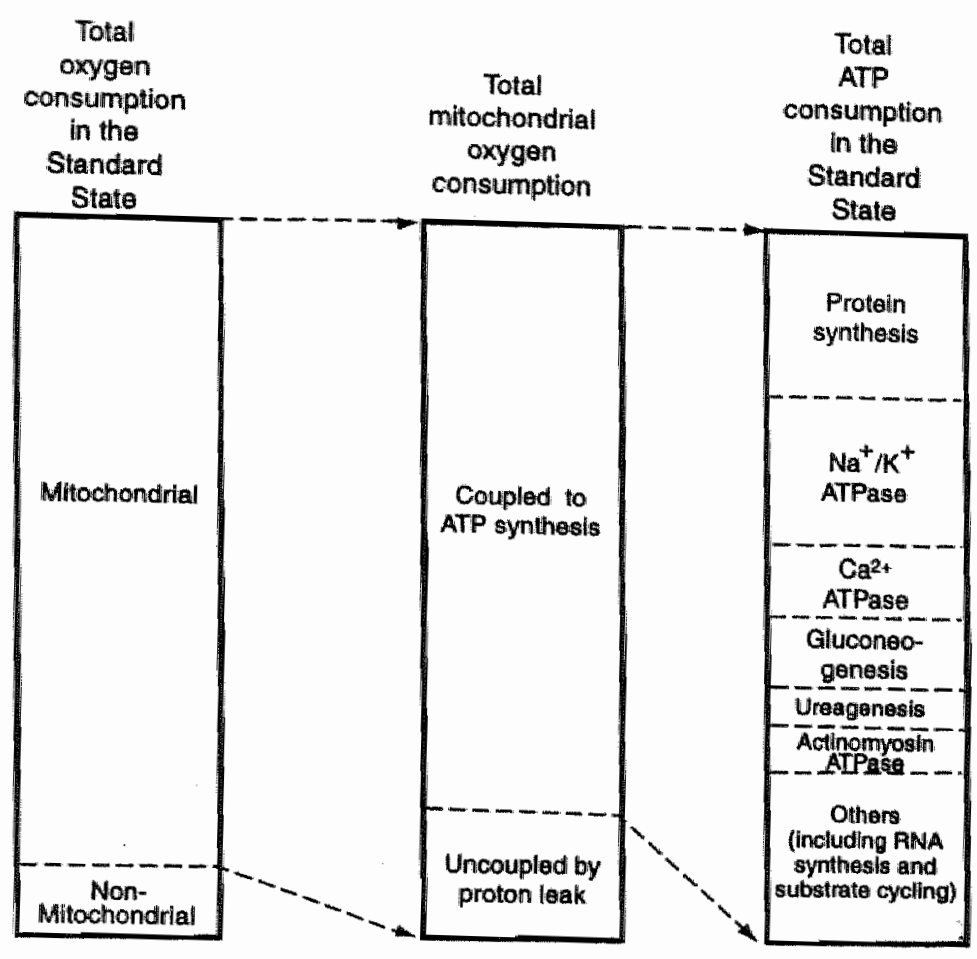

Figure 9.1 From: David F.S. Rolfe and Guy C. Brown. Cellular energy utilization and molecular origin of standard metabolic rate in mammals. Physiological Reviews, Vol 77 (3), July 1997.

\section{Non-mitochondrial oxygen consumption}

There are a number of processes in the human body that use oxygen outside the mitochondria, for example peroxisomal fatty acid oxidation. The total contribution of non-mitochondrial oxygen consumption has been estimated at approximately $10 \%$ of RMR (34).

\section{Mitochondrial proton leak}

As stated above, the formation of ATP from ADP requires a proton gradient across the inner mitochondrial membrane. The flow of protons from the cytosolic side of the membrane into the mitochondrial matrix provides the energy to transform ADP to ATP. However, when inner mitochondrial membrane proton conductance is increased, insufficient proton gradient is generated and oxygen consumption is uncoupled from ATP production. In humans such proton leaks are present in many tissues, partly uncoupling oxygen consumption from ATP synthesis and thus directly dissipating 
energy as heat. It has been calculated that the overall contribution of proton leaks to RMR is approximately $20 \%$ (34).

\section{The role of brown adipose tissue in energy metabolism}

Mammals have two types of adipose tissue. White adipose tissue, which consists of lipid storing adipocytes, and brown adipose tissue which is composed of multilocular lipid storing adipocytes, and also contains abundant mitochondria. The functions of the two types of adipose tissue are different. The primary function of white adipose tissue is energy storage and obesity is characterized by an increase in the amount of white adipose tissue. In contrast, brown adipose tissue, has a very active metabolism resulting in thermogenesis. It has been shown that brown adipose tissue can account for up to $40 \%$ of the twofold increase in RMR of rats infused with norepinephrine or exposed to cold $(12,13)$. Food intake can also increase the thermogenic activity of brown adipose tissue, thereby contributing to diet induced thermogenesis (39). Mitochondria of brown adipose tissue are exceptionally permeable to protons and this could lead to leakage (28). Possible pathways for the mitochondrial proton leak are membrane proteins, the phospholipid bilayer and protein/phospholipid interfaces (7). In 1978, three groups demonstrated that a $32 \mathrm{kDa}$ mitochondrial membrane protein, called thermogenin or uncoupling protein (UCP1), was responsible for the mitochondrial proton leak, and therefore the thermogenic activity of brown adipose tissue $(16,27,33$ ) (figure 9.2).

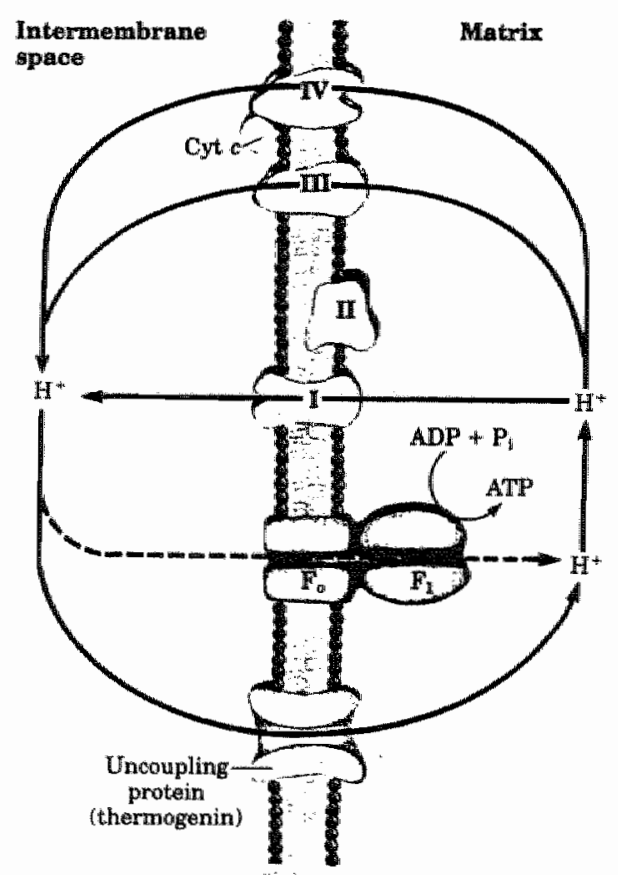

Figure 9.2 From: Principles of Biochemistry. Chapter 18: Oxidative phosphorylation and photophosphorylation. Eds Lehninger, A.L., Nelson, D.L., Cox, M.M. 2nd Edition, Worth Publishers, New york, 1993. 
Brown adipose tissue thermogenesis is thought to play a role in the development of obesity in animals. For example, leptin-deficient $o b / o b$ mice, which are morbidly obese, have defective BAT thermogenesis and are cold-sensitive (17). In 1993 a transgenic mouse was created with targeted ablation of brown adipose tissue. These mice lacked UCP1 and became obese at a young age, before developing hyperphagia (20). This indicates the importance of UCP1 in the thermogenic activity of brown adipose tissue and in the development of obesity.

\section{Uncoupling protein in humans: UCP2}

In humans, brown adipose tissue is very scarce. In neonates brown adipose tissue is present but later in life, the expansion of white adipose tissue overgrows brown adipose tissue. Under prolonged periods of cold exposure, some brown adipose tissue may remain in adult humans, but in general the amount is very limited. Therefore the role of UCP1 in human energy expenditure has long been controversial. However, Fleury et al. (1997) and Gimeno et al. (1997) recently cloned a homologue of UCP1, called UCP2 $(11,14)$. The amino acid sequence of UCP2 is $59 \%$ identical to UCP1 and consists of 309 amino acids with a molecular weight of 33 kilodaltons. Several protein motifs are conserved in the two UCPs, including three mitochondrial carrier protein motifs and the amino acids essential for ATP binding, suggesting that UCP2 also has a functional role as a mitochondrial uncoupler. To test this, the decrease in mitochondrial potential was measured in yeast after (26) introducing UCP2 in a vector. The results showed that UCP2 influenced mitochondrial activity and could partially uncouple respiration from ATP synthesis (11). The tissue distribution of UCP2 gene expression was investigated by Northern blot analysis, and was shown to be markedly different from UCP1. UCP2 mRNA was present in skeletal muscie, lung, heart and kidney, as well as in tissues of the immune system (11). Further evidence for the uncoupling capacity of UCP2 was provided by Negre-Salvayre et al. (1997), who showed that in brown adipose tissue, the production of $\mathrm{H}_{2} \mathrm{O}_{2}$ (an index of mitochondrial respiration) was increased by GDP, probably by an inhibiting effect on UCP1 and/or UCP2 . GDP had a similar effect on $\mathrm{H}_{2} \mathrm{O}_{2}$ production in nonparenchymal cells as in brown adipose tissue, but had no effect on $\mathrm{H}_{2} \mathrm{O}_{2}$ production in hepatocytes (26). In contrast to hepatocytes, nonparenchymal cells do contain UCP2, and therefore these results suggested that the effect of GDP was through an inhibiting effect on UCP2, giving further evidence for an uncoupling effect of UCP2.

\section{Uncoupling protein in skeletal muscle: UCP3}

Inspired by the discovery of $\mathrm{UCP} 2$ and by the fact that skeletal muscle determines $40 \%$ of whole-body adrenaline-induced thermogenesis, Boss et al. (1997) searched for UCP homologues in skeletal muscle (4). They found three products similar to the rat muscle UCP1 product, with amino acid lengths of 309,312 and 275 . The 309 amino acid product turned out to be the recently discovered UCP2 protein. The other two products were identical for the first 275 amino acids, suggesting that they were isoforms of the same protein. They had $57 \%$ and $73 \%$ amino acid identity to UCP1 and UCP2 respectively, and were called UCP3 long and short forms (UCP3L, 
UCP3S). When comparing UCP1, UCP2 and UCP3, it appeared that many of the nonidentical residues were conservative substitutions, and in regions which also showed substantial variation in UCP1 between species (4). This indicated that all three UCPs belonged to the same gene family. Both UCP2 and UCP3L contain six transmembrane domains and have a potential purine nucleotide binding region (aa 279-301). Binding of GDP to this nucleotide binding region in UCP1 has been shown to result in a change in conformation and inhibition of $\mathrm{H}^{+}$and $\mathrm{Cl}^{-}$permeability (25). UCP3S only has five transmembrane domains and lacks the purine nucleotide binding region. Northern blotting revealed that the UCP3 gene was expressed predominantly in skeletal muscle and at low levels in heart muscle, and that UCP3 gene expression in skeletal muscle was 4-fold higher than that of the UCP2 gene (41). Furthermore, the ratio of UCP3L to UCP3S gene expression was 1 (4). The genomic structure of the UCP3 gene was first described by Solanes et al. (1997), who reported that the UCP3 gene consists of 7 exons, of which exon 1 is untranslated (36). Furthermore, intron 6 contains a cleavage and polyadenylation site which terminates the message elongation about $50 \%$ of the time. If this occurs, message elongation terminates in exon 6, where a stop codon (codon 275) is located and UCP3S is produced. If message elongation is not ended by the polyadenylation signal in intron 6 , message elongation continues to a polyadenylation signal in exon 7 , producing UCP3L. The last exon (exon 7) encodes a 37 amino acid C-terminus. In UCP1, this segment has been shown to be important in purine nucleotide-mediated inhibition of UCP1 activity (6). It is therefore suggested that UPC3S may have altered uncoupling activity.

In summary, both UCP2 and UCP3 have uncoupling activity and are expressed in tissues which have an important role in energy expenditure. Therefore, it can be assumed that those UCPs might have a major influence on energy balance.

\section{Role of UCP2 and UCP3 in obesity and energy expenditure}

In animals, a direct comparison of UCP2 gene expression in obesity resistant (A/J) mice and obesity-prone (B6) mice showed higher UCP2 mRNA levels in the obesityresistant mice (11). mRNA levels of UCP2 were increased in white adipose tissue by a high-fat diet in the $\mathrm{A} / \mathrm{J}$ strain but not in the B6 strain mice (11). This result suggested that UCP2 plays a role in preventing obesity in $\mathrm{A} / \mathrm{J}$ mice fed a high-fat diet, possibly by increasing energy expenditure. Surprising results were provided by Enerbäck et al. (1997), who showed that mice lacking UCP1 (UCP1 knock-out mice) did not become obese when fed a high-fat diet (10). Therefore additional mechanism(s) (other than UCP1) for maintaining body weight must be present. UCP2 was upregulated five-fold in brown adipose tissue of these mice, possibly compensating for the absence of UCP1. These results suggest that UCP2 is involved in the regulation of energy balance.

In humans, Millet et al. (1997) showed a positive correlation between UCP2 mRNA levels in adipose tissue and BMI (23). However, no difference in the expression of UCP2 and UCP 3 in skeletal muscle was found between obese and lean subjects, suggesting no major role for UCPs in obesity (23). In contrast, we recently showed a 
negative correlation between skeletal muscle UCP3 expression and BMI and a positive correlation between UCP3 mRNA levels and RMR in Pima Indians (35) (figure 9.3). Assuming that mRNA levels reflect UCP3 protein concentrations and activity, these data indicate that reduced skeletal muscle UCP3 may result in a reduced RMR. Since a low relative resting metabolic rate is a predisposing factor for weight gain (31) it was expected that individuals with low UCP3 gene expression would have increased BMI, which is in accordance with the negative correlation between BMI and UCP3 gene expression in our study (35).
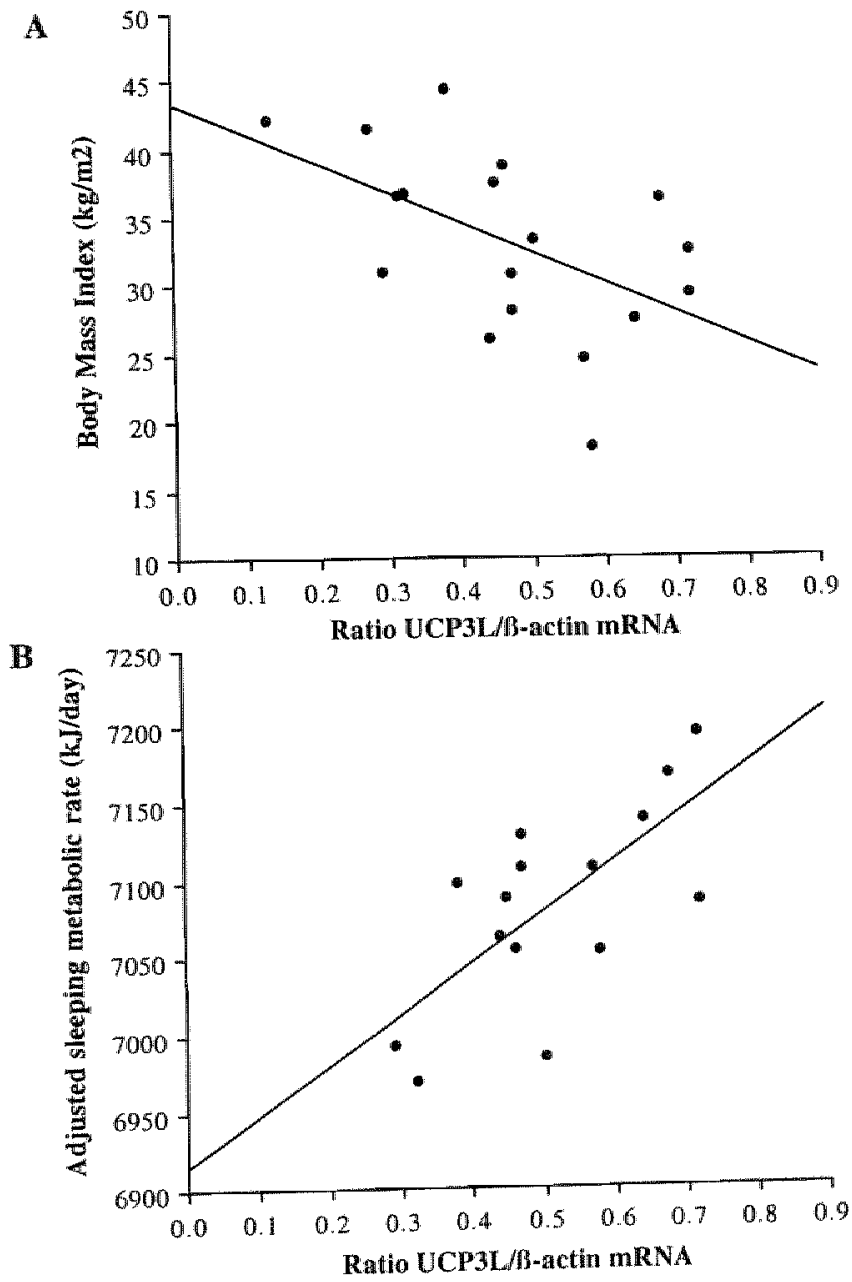

Figure 9.3 Relationship between body mass index $(A)$ and sleeping metabolic rate (B) and relative $U C P 3 L$ mRNA expression (UCP3L $3 \beta$-actin) in skeletal muscle determined by RT-PCR. The mRNA expression is the mean of triplicate measurements. A, Body mass Index $(r=-0.53, p=0.025)$. B, sleeping metabolic rate $(r=0.69, p=0.006)$. Sleeping metabolic rate is adjusted for fat-free mass and fat mass. 
Both the UCP2 and UCP3 genes have been mapped to human chromosome 11q13. Solanes et al. (1997) demonstrated that P1 clones containing human genomic inserts contained both the UCP2 and UCP3 genes. This indicated that the UCP2 and UCP3 genes were located within $75-150 \mathrm{~kb}$ of each other (36). Chromosome 11q13 is in the proximity $(\sim 15 \mathrm{cM})$ of a locus $(11 \mathrm{q} 21-\mathrm{q} 22)$ which was found to be linked to percent body fat in Pima Indians (29). Bouchard et al. (1997) typed three markers in the vicinity of $11 \mathrm{~g} 13$ in 640 individuals from 155 pedigrees from the Quebec Family Study. A linkage between marker D11S911 and RMR was found, suggesting a role for UCP2 and/or UCP3 in energy metabolism (5). In contrast, Elbein et al. (1997) did not find linkage between markers in the 11q13 region and BMI in 42 North European families with type 2 diabetic siblings (9).

Urhammer et al. (1997) were the first to report a common polymorphism in the UCP2 gene (40). This polymorphism was a single nucleotide substitution, which resulted in an alanine to a valine amino acid substitution at position 55 . The Ala55Val variant was located in a non-functional domain and the substitution of valine for alanine is a conservative amino acid substitution, probably not resulting in major changes in the structure of the protein. In Danish Caucasians, this polymorphism was not associated with BMI, fat mass or waist-to-hip ratio (40). We identified a second polymorphism in UCP2, a 45 bp insertion/deletion (I/D) variant located 158 base pairs after the stop codon in exon 8 . This polymorphism was found to be associated with sleeping metabolic rate in a small group $(n=76)$ of full blooded Pima Indians. There was also some evidence of association between this polymorphism and BMI in Pima Indians over 45 years of age $(\mathrm{p}=0.04, \mathrm{n}=105)$ (unpublished results). The insertion/deletion variant was highly polymorphic in this population, with a genotype frequency of 16 , 49 and $35 \%$ for I/I, I/D and D/D respectively. Although the position of this polymorphism suggests possible involvement in mRNA stability, no differences in UCP2 mRNA levels were found between the genotypes.

In summary, the above data suggests a significant role for these new uncoupling proteins in energy balance. Impairment of the expression of these proteins, or expression of less active forms, could lead to reduced energy expenditure and therefore contribute to the development of obesity. Therefore, uncoupling proteins may represent a new possible target for the treatment of obesity. However, a lot more data is required regarding the regulation of these genes in normal human physiology.

\section{Regulation of UCP2 and UCP3 gene expression}

Cold exposure

In brown adipose tissue, UCP1 is responsible for the increase in energy expenditure during cold exposure $(12,13)$. The increase in UCP1 leads to more energy dissipated as heat for the regulation of body temperature. Therefore, cold exposure is one of the candidates for upregulation of UCP2 and UCP3 expression. In one study, UCP2 in mice was not upregulated after 10 days of cold exposure $\left(4^{\circ} \mathrm{C}\right)$ in brown adipose tissue, white adipose tissue, skeletal muscle or liver (11). In contrast, Boss et al. (1997) found that both UCPI and UCP2 mRNA in brown adipose tissue were upregulated 
by 48 hours of cold exposure $\left(6^{\circ} \mathrm{C}\right)$ in rats (2). As described above, UCP1 knock-out mice had a 5 -fold increase in brown adipose tissue UCP2, but were not able to maintain body temperature when exposed to cold $\left(5^{\circ} \mathrm{C}\right)(10)$. This indicates that, even if UCP2 expression is increased in brown adipose tissue by cold exposure, this increase is not sufficient for the maintenance of body temperature. In two studies, UCP 3 mRNA expression was found to be upregulated by 10 days of cold exposure $\left(4^{\circ}\right.$ or $6^{\circ} \mathrm{C}$ ) in brown adipose tissue of rats, but not in skeletal muscle $(4,19)$. Overall, these results indicate a role for the UCPs in the adaptive response to cold exposure in rodent brown adipose tissue, but not skeletal muscle. The role of these UCPs in human response to cold exposure is unclear.

\section{Thyroid hormone}

An explanation for the different effects of cold exposure on UCP2 and UCP3 in brown adipose tissue and skeletal muscle was provided by Larkin et al (19). In brown adipose tissue cold exposure leads to an increase in triiodothyronine (T3), by the conversion of $\mathrm{T} 4$ to $\mathrm{T} 3$. This conversion is catalyzed by thyroxine 5 deiodinase type II, an enzyme induced 17 fold by cold exposure in brown adipose tissue, but not present in skeletal muscle. T3 is secreted by the thyroid gland and has widespread stimulatory effects on metabolism such as increasing the rate of oxygen consumption, protein synthesis, glycogenolysis and lipolysis. $\mathrm{T} 3$ had a stimulatory effect on the expression of UCP2 and UCP3 (19). Masaki et al. (1997) gave rats daily infusions of T3 for 7 days. This procedure made the rats hyperthyroid and they lost weight, compared to a control group given daily infusions of saline. UCP2 mRNA expression increased in brown adipose tissue, white adipose tissue and skeletal muscle and UCP1 increased in brown adipose tissue of the T3 treated rats (21). A stimulatory effect of T3 injection for 1 week on UCP2 mRNA in heart and skeletal muscle was also found by Lanni et al. (18). The effect of thyroid hormone on UCP3 mRNA expression was examined by Larkin et al. (1997), who showed a 5 -fold increase in UCP3 mRNA expression after 5 days of T3 hormone treatment (19). In hypothyroid rats skeletal muscle UCP3 mRNA levels were decreased 3-fold and treatment of these rats with a single dose of T3 increased the UCP3 mRNA levels 6-fold (15). Overall, these results provide clear evidence of a role for thyroid hormone on both $\mathrm{UCP} 2$ and UCP3 gene expression in rodents.

\section{Fasting and high fat feeding}

Fasting is known to cause a decrease in RMR. In rodents UCP1 expression was decreased in brown adipose tissue with fasting (39). However, after a 48-hour fast, UCP2 gene expression was not changed in brown adipose tissue of rats, but was increased in skeletal muscle (2). Fasting (48 hours) decreased UCP3 mRNA in brown adipose tissue of rats, but increased UCP3 expression 6-fold in skeletal muscle $(15,3)$. In humans, Millet et al. (1997) showed that a 5 day hypocaloric diet (1045 kJ/day) resulted in a $2-3$ fold increase in UCP2 $\mathrm{mRNA}$ in white adipose tissue and skeletal muscle and a 2-3 fold increase in UCP3 mRNA in skeletal muscle (23). These results are surprising since fasting decreases metabolic rate and an increase in UCP2 and 3 would be expected to increase metabolic rate. One possible explanation is that the increase in lipolysis and FFA during fasting may upregulate UCP2 and UCP3 gene 
expression. FFA are ligands for peroxisome proliferator-activated receptors, which stimulate UCP2 expression (1). Therefore, Weigle et al. (1998) examined whether the effects of fasting on UCP3 mRNA expression could be explained by the effects of FFA. They administered infusions of an emulsion of triglycerides to rats, resulting in FFA concentrations similar to those induced by fasting, and showed an increase in UCP3 mRNA in skeletal muscle similar to that induced by fasting (43). This suggests an important role for FFA in the regulation of UCP3 expression. In addition, in obesity resistant $A / J$ mice, UCP2 mRNA levels in white adipose tissue were increased after consumption of a high-fat diet for 7,18 and 25 days. Matsuda et al. (1997) also found increased UCP3 levels in skeletal muscle and increased UCP2 levels in white adipose tissue of rats after 4 weeks of high-fat diet (22). In contrast, Surwit et al. (1998), observed no change in UCP2 or UCP3 mRNA levels in skeletal muscle after 2 weeks of a high-fat diet in obesity-prone and obesity-resistant strains of mice (38). Overall, these results suggest a role for diet and FFA in the regulation of UCP2 and UCP3 expression.

\section{Leptin}

Leptin is absent in a strain of obese mice $(a b / o b)$ and injection of these mice with leptin caused weight loss by decreasing food intake and increasing energy expenditure $(8,42)$. UCP3 mRNA levels in skeletal muscle of $a b / a b$ mice were not different to wild type mice. Treatment of the $o b / o b$ mice with leptin $(2 \mu \mathrm{g} / \mathrm{d})$ resulted in an increase in UCP3 mRNA levels in skeletal muscle and brown adipose tissue (21). However, no data on food intake was presented in this study, so the increase in UCP3 gene expression may have been the result of decreased food intake and weight loss. Zhou et al. (1997) studied UCP2 mRNA levels in hyperleptinemic rats compared to pair-fed controls, thereby controlling for the effect of food intake. UCP2 mRNA levels in pancreatic islets were increased 10 -fold in hyperleptinemic rats compared to pairfed controls (44). These data suggest a role for leptin in the regulation of expression of UCP2 and 3 . However, it should be remembered that both of these animal models are very unusual compared to the physiology of human obesity. Evidence against a role for leptin on UCP expression was given by Surwit et al. They found no effect of twice-daily leptin $(20 \mu \mathrm{g})$ injections for 4 days on UCP2 expression in white adipose tissue of mice (37). Indirect evidence against a role for leptin was provided by the stimulatory effects of fasting on UCP2 and UCP3 levels. Fasting decreases plasma leptin, yet UCP2 and UCP3 are upregulated (23). Overall the data indicate that leptin has no direct effect on the expression of the UCP2 and UCP3 genes under normal physiological conditions.

\section{B3-agonists}

The sympathetic nervous system (SNS) is thought to play an important role in energy balance. A low sympathetic output has been associated with obesity in animal models, and low SNS activity predicts weight gain in Pima Indians (32). B3-adrenergic stimulation of adipocytes results in increased lipolysis and thermogenesis, largely mediated by B3-adrenoreceptors. UCP1 is induced by B3-agonists, but treatment of mice for 10 days with a B3-agonist (C316243) did not affect UCP2 mRNA levels in brown adipose tissue, white adipose tissue, muscle or liver (11). In contrast, an 
increase in UCP2 mRNA levels in brown adipose tissue after treatment with B3agonist (Ro-168714) for 32 hours was reported in rats (2). Interestingly, treatment of rats with a B3-agonist (CL214613) increased UCP3 mRNA levels in white adipose tissue, in which no UCP3 can normally be detected (15) It has been shown previously that under strong B3-adrenergic stimulation white adipose tissue dlevelops some characteristics of brown adipose tissue.

\section{Gincocorticoids}

During fasting an increase in glucocorticoids is observed and glucocorticoids are regulators of fuel metabolism and gene transcription. Gong et al. showed an increase in UCP3 mRNA in muscle and a decrease in brown adipose tissue 18 hours after a single dose $(3.7 \mu \mathrm{g} / \mathrm{g})$ of dexamethasone in mice (15). However, food intake was not controlled in this study. In contrast, Weigle et al. compared fasted rats, fed rats and fed rats given twice-daily injections of hydrocortisone $(50 \mathrm{mg} / \mathrm{kg})$. They found no effect of glucocorticoids on UCP2 and UCP3 mRNA expression (43).

\section{Conclusions and future directions}

The discovery of the UCP2 and UCP3 genes could be a breakthrough in understanding the complex mechanisms regulating energy expenditure and has given new stimuli for research in this field. The results so far strongly suggest a role for the UCPs in energy balance and obesity. However, a lot of questions have yet to be answered to fully understand the importance of these novel genes. The first barrier to be overcome is generating antibodies for the proteins and developing assays to directly measure protein levels. Only then the question of whether mRNA levels reflect protein concentrations can be answered. Furthermore, it would be even better to measure the activity of the proteins in vivo. Alterations of the activity of the UCPs could be a new therapeutic target for obesity.

\section{References}

1. Aubert, J., Champigny, O., Saint-Marc, P., Negrel, R., Collins, S., Ricquier, D., and Ailhaud, G. Up-regulation of UCP-2 gene expression by PPAR agonists in preadipose and adipose cells. Biochem Biophys Res Commun. 238: 606-611, 1997.

2. Boss, O., Samec, S., Dulloo, A., Seydoux, J., Muzzin, P., and Giacobino, J.-P. Tissuedependent upregulation of rat uncoupling protein-2 expression in response to fasting or cold. FEBS lett. 412: 111-114, 1997.

3. Boss, O., Samec, S., Kühne, F., Bijlenga, P., Assimacopoulos-Jeannet, F., Seydoux, J., Giacobino, J.-P.. and Muzzin, P. Uncoupling protein-3 expression in rodent skeletal muscie is modulated by food intake but not by changes in environmental temperature. $J$ Biol Chem. 273: 5-8, 1998.

4. Boss, O., Samec, S., Paoloni-Giacobino, A., Rossier, C., Dulloo, A., Seydoux, J., Muzzin, P., and Giacobino, J.-P. Uncoupling protein-3: a new member of the mitochondrial carrier family with tissue-specific expression. FEBS lett. 408: 39-42, 1997. 
5. Bouchard, C., Pếrusse, L. Chagnon, Y. C., Warden, G., and Ricquier, D. Linkage between markers in the vicinity of the uncoupling protein 2 gene and resting metabolic rate in humans. Hum Mol Genet. 6: 1887-1889, 1997.

6. Bouilaud, F, Arechage, I., Petit, P. X., Raimbault, S., Levi-Meyrueis, C., Casteilla, L.. Laurent, M., Rial, E., and Ricquier, D. A sequence related to a DNA recognition element is essential for the inhibition by nucleotides of proton transport through the mitochondrial uncoupling protein. $E M B O$ J. 13: 1990-1997, 1994.

7. Brown, G. C., and Brand, M. D. On the nature of the mitochondrial proton leak. Biochem Biophys Acta. 1059: 55-62, 1991 .

8. Campfield, L. A., Sinith, F. J., Guisez, Y., Devos, R., and Burn, P. Recombinant mouse OB protein: evidence for a peripheral signal linking adiposity and central neural networks. Science. 269: 546-549, 1995.

9. Elbein, S. C., Leppert, M., and Hasstedt, S. Uncoupling protein 2 region on chromosome $11 \mathrm{q} 13$ is not linked to markers of obesily in familial type 2 diabetes. Diabetes. 46: 2105 $2107,1997$.

10. Enerback, S., Jacobsson, A., Simpson, E. M., Guerra, C., Yamashita, H., Harper, M.-E., and Kozak, L. P. Mice lacking mitochondrial uncoupling protein are cold-sensitive but not obese. Nature Genetics. 387: 90-94, 1997.

11. Fleury, C., Neverova, M., Collins, S., Raimbault, S., Champigny, O., Levi-Meyrueis, C., Bouillaud, F., Seldin, M. F., Surwit, R. S., Ricquier, D. Uncoupling protein-2: a novel gene linked to obesity and hyperinsulinemia. Nature Genetics. 15: 269-273, 1997.

12. Foster, D. O., and Frydman, M. L. Nonshivering thermogenesis in the rat. II. Measurements of blood flow with microspheres point to brown adipose tissue as the dominant site of the calorigenesis induced by noradrenaline. Can J Physiol Pharmacol. 56: $110-122,1978$.

13. Foster, D. O, and Frydman, M. L. Tissue distribution of cold-induced thermogenesis in conscious warm- or cold-acclimated rats reevaluated from changes in tissue blood flow: the dominant role of brown adipose tissue in the replacement of shivering by nonshivering thermogenesis. Can J Physiol Pharmacol. 57: 257-270, 1979.

14. Gimeno, R. E., Dembski, M., Weng, X, Deng, N., Shyjan, A. W., Gimeno, C. J., Iris, F., Ellis, S. J., Woolf, E. A., and Tartaglia, L. A. Cloning and characterization of an uncoupling protein homolog: a potential molecular mediator of human thermogenesis. Diabetes. 46: 900-906, 1997.

15. Gong, D.-W., He, Y., Karas, M., and Reitman, M. Uncoupling protein-3 is a mediator of thermogenesis regulated by thyroid homone, B3-adrenergic agonists, and leptin. $J$ Biol Chem. 272: 24129-24132, 1997 .

16. Himms-Hagen, J., Cerf, J., Desautels, M., and Zaror-Behrens, G. Thermogenic mechanisms and their control. Effectors of thermogenesis. Basel, Birkhauser Verlag. 119-134, 1978,

17. Himms-Hagen, J., and Desautels, M. A mitochondrial defect in brown adipose tissue of the obese $(o b / o b)$ mouse: reduced binding of purine nucleotides and a failure to respond to cold by an increase in binding. Biochem Biophys Res Commun. 83: 628-634, 1978.

18. Lamni, A., De Felice, M., Lombardi, A., Moreno, M., Fleury, C., Ricquier, D., and Goglia, F. Induction of UCP2 mRNA by thyroid hormones in rat heart. FEBS lett. 418: 171-174, 1997.

19. Larkin, S., Mull, E., Mao, W., Pitner, R., Albrandt, K., Moore, C., Young, A., Denaro, M., and Beaumont, $K$. Regulation of the third member of the uncoupling protein family, UCP3, by cold and thyroid hormone. Biochem Biophys Res Commun. 240: 222-227, 1997. 
20. Lowell, B., Susulic, V. S., Hamann, A., Lawitts, J. A., Himms-Hagen, I., and Boyer, B. B. a a. Development of obesity in transgenic mice after genetic ablation of brown adipose tissue. Nanure, 366: 740-742, 1993.

21. Masaki, T., Yoshimatsu, H., Kakuma, T., Hidaka, S., Kurokawa, M., and Sakata, T. Enhanced expression of uncoupling protein 2 gene in rat white adipose tissue and skeletal muscle following chronic treatment with thyroid hormone. FEBS lett. 418: 323-326, 1997.

22. Matsuda, J, Hosoda, K., Itoh, H., Son, C., Doi, K., Tanaka, T., Fukunaga, Y., Inoue, G., Nishimura, H., Yoshimasa, Y. Cloning of rat uncoupling protein-3 and uncoupling protein-2 cDNAs: their gene expression in rats fed high-fat diet. FEBS lett. 418:200-204, 1997.

23. Millet, L., Vidal, H., Andreelli, F., Larrouy, D., Riou, J.-P., Ricquier, D., Laville, M., and Langin, D. Increased uncoupling protein -2 and -3 mRNA expression during fasting in obese and lean humans. $J$ Clin lnvest. 100: 2665-2670, 1997.

24. Mitchell, P. Chemiosmotic coupling in oxidative and photosynthetic phosphorylation. Biol Rev Camb Philos Soc. 41: 445-502, 1966.

25. Nedergaard, J., and Cannon, B. New comprehensive biochemistry (bioenergetics). Stockholm, Elsevier Science. 383-420, 1992.

26. Nègre-Salvayre, A., Hirtz, C., Carrera, G., Cazenave, R., Trolly, M., Salvayre, R., Pénicaud, L., and Casteilla, L. A role for uncoupling protein-2 as a regulator of mitochondrial hydrogen peroxide generation. Faseb J. 11: 809-815, 1997.

27. Nicholls, D., Bernson, V., and Heaton, G. The identification of the component in the inner membrane responsible for regulating energy dissipation. Effectors of thermogenesis. Basel, Birkhauser Verlag. 89-93, 1978.

28. Nicholls, D. G., and Locke, R. M. Thermogenic mechanisms in brown fat. Physiol Rev. 64: $1-64,1984$.

29. Norman, R. A., Thompson, D. B., Foroud, T., Garvey, W. T., Bennett, P. H., Bogardus, C., Ravussin, E., and al, e. Genomewide search for genes influencing percent body fat in Pima Indians: suggestive linkage at chromosome 11q21-q22. Am J Hum Genet. 60: 166-173, 1997.

30. Ravussin, E, Lillioja, S., Anderson, T. E., Christin, L., and Bogardus, C. Determinants of 24hour energy expenditure in man. Methods and results using a respiratory chamiber. $I \mathrm{Clim}$ Invest. 78: 1568-1578, 1986.

31. Ravussin, E., Lillioja, S., Knowler, W. C., Christen, L., Freymond, D., Abbott, W. G. H., Boyce, V., Howard, B. V., and Bogardus, C. Reduced rate of energy expenditure as a risk factor for body-weight gain. N Engl J Med. 318:467-472, 1988 .

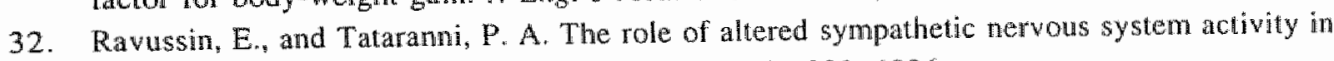
the pathogenesis of obesity. Proc Nour Soc. 55: 793-802, 1996.

33. Ricquier, D., and Kader, J.C. Mitochondrial protein alteration in active brown fat: a sodium dodecyl sulfate-polyacrylamide gel electrophoresis study. Biochem Biophys Res Commun. $73: 577-583,1978$.

34. Rolfe, D. F. S., and Brown, G. C. Cellular energy utilization and molecular origin ol: standard metabolic rat in mamuals. Physiol Rew. 77: 731 758, 1997.

35. Schrauwen, P., Xia, J., Bogardus, C., Pratley, R., and Ravussin, E. skeletal muscle UCP3 expression is a determinant of energy expenditure in Pima Indians. Diabetes, in press. 1998. 
36. Solanes, G, Vidal-Puig, A., Grujic, D., Flier, J. S., and Lowell, B. B. The human uncoupling protein-3 gene: genomic structure, chromosomal localization, and genetic basis for short and long form transcripts. J Biol Chem. 272: 25433-25436, 1997.

37. Surwit, R. S., Petro, A. E., Parekh, P., and Collins, S. Low plasma leptin in response to dietary fat in diabetes- and obesity-prone mice. Diabetes. 46: 1516-1520, 1997.

38. Surwit, R. S., Wang, S., Petro, A. E., Sanchis, D., Raimbault, S., Ricquier, D., and Collins, S. Diet-induced changes in uncoupling proteins in obesity-prone and obesity-resistant strains of mice. Proc Nall Acad Sci USA. 95: 4061-4065, 1998.

39. Trayhum, $P$, and Jennings, G. Nonshivering thermogenesis and the thermogenic capacity of brown fat in fasted and/or refed mice. An J Physiol. 254: R11-R16, 1988.

40. Urhammer, S. A., Dallgaard, L. T., Sørensen, T. I. A., Møller, A. M., Andersen, T., TybjœrgHansen, A., Hansen, T., Clausen, J. O., Vestergaard, H., and Pedersen, O. Mutational analysis of the coding region of the tuncoupling protein 2 gene in obese NIDDM patients: Impact of a common amino acid polymorphism on juvenile and maturity onset forms of obesity and insulin resistance. Diaberologia. 40*1227-1230, 1997.

41. Vidal-Puig, A., Solanes, G., Grujic, D., Flier, J. S., and Lowell, B. B. UCP3: An uncoupling protein homologue expressed preferentially and abundantly in skeletal muscle and brown adipose tissue. Biochem Biophys Res Commun. 235: 79-82, 1997.

42. Weigle, D. S., Bukowski, T. R., Foster, D. C., Holderman, S., Kramer, J. M., Lasser, G., Lofton-Day, C. E., Prunkard, D. E., Raymond, C., and Kuijper, J. L. Recombinant $o b$ protein reduces feeding and body weight in the ob/ob mouse. $J$ Clin Invest. 96: 2065-2070, 1995.

43. Weigle, D. S., Selfridge, L. E., Schwartz, M. W., Seeley , R. J., Cummings, D. E., Havel, P. J., Kuijper, J. L., and BertrandelRio, H. Elevated free fatty acids induce uncoupling protein 3 expression in muscle. A potential explanation for the effect of fasting. Diabetes. 47: 298$302,1998$.

44. Zhou, Y.-T., Shimabukuro, M., Koyama, K., Lee, Y., Wang. M.-Y., Trieu, F., Newgard, C. B., and Unger, R. H. Induction by leptin of uncoupling protein-2 and enzymes of fatty acid oxidation. Proc Natl Acad Sci USA. 94: 6386-6390, 1997. 


\title{
Skeletal muscle UCP3 expression is a determinant of energy expenditure in Pima Indians
}

Patrick Schrauwen * , James Xia , Clifton Bogardus" , Richard Pratley and Eric Ravussin"

*Department of Human Biology, Maastricht University, Maastricht, The Netherlands \#Clinical Diabetes and Nutrition Section, National Institutes of Health, Phoenix, Arizona, USA

Diabetes, in press

\begin{abstract}
The recent discovery of uncoupling protein-2 and -3 (UCP2 and UCP3), and their high expression in skeletal muscle, has renewed interest in a possible role for these proteins in underlying the variability in energy expenditure and therefore metabolic efficiency.

Using RT-PCR, levels of expression of UCP2 and long and short forms of UCP3 were measured in skeletal muscle of 19 non-diabetic, male Pima Indians covering a wide range of body weight. Twenty four hour energy expenditure was measured in a respiratory chamber in 16 of these individuals.

BMI was negatively correlated with the expression levels of the long ( $r=-0.53$, $p=0.025)$ and short $(r=-0.46, p=0.047)$ forms of $U C P 3$. BMI was not correlated with $U C P 2$ expression. Metabolic rate during sleep, adjusted for fat-free mass and fat mass, was positively correlated with the long form of $U C P 3(\mathrm{r}=0.69, \mathrm{p}=0.004)$.

These results indicate that UCP3 may be a determinant of energy expenditure and metabolic efficiency in Pima lndians.
\end{abstract}




\section{Introduction}

The development of obesity is characterized by an imbalance between energy intake and energy expenditure. Resting metabolic rate comprises 50-80\% of daily energy expenditure (12), and is quite variable among individuals, even after adjusting for differences in body weight and body composition (17). More importantly, the variability in resting metabolic rate adjusted for fat-free mass, fat mass, age and sex aggregates in families, suggesting genetic determinants $(1,4)$. In addition, a low adjusted resting metabolic rate is risk factor for weight gain in Pima Indians (13). It is therefore important to understand the physiological mechanism(s) underlying the variability in resting metabolic rate. Some of this variability has been shown to be associated with the variability in skeletal muscle metabolism (21).

In rodents, brown adipose tissue plays an important role in thermogenesis, via the activation of an uncoupling protein gene, $U_{c p}$ l. This uncoupling protein gene encodes for a mitochondrial protein carrier, which uncouples respiration from ATP production and stimulates heat production (14). $U_{c p l} l$ is only expressed in brown adipose tissue, which is scarce in adult humans and is not thought to play a major role in energy balance. Recently, two new uncoupling proteins, UCP2 $(6,7)$ and UCP3 $(2,18)$, were discovered. UCP2 and UCP3, which have approximately $55 \%$ amino acid identity with UCP1, have been shown to have uncoupling activity $(6,8), U C P 2$ has a wide tissue distribution, whereas UCP3 is mainly expressed in skeletal muscle $(2,18)$. These new UCPs are likely candidates to underlie the variability in energy metabolism in humans and may be involved in the development of obesity.

$U C P 2$ was mapped to chromosome $11 \mathrm{q} 13$ (6) and $U C P 3$ is thought to be only 75-100 $\mathrm{kb}$ away from $U C P 2$ (15). In the Quebec Family study, resting metabolic rate (RMR) was genetically linked to DNA microsatellite markers in the vicinity of 11 q13 (3). Recently, Walder et al. (19) reported an association between polymorphisms in $U C P 2$ and sleeping metabolic rate in Pima Indians. UCP 3 is expressed in a long $(U C P 3 L)$ and a short form (UCP3S), the latter lacking part of exon 6 and exon 7 , likely resulting in a truncated protein (15). It is yet unknown whether this difference is functionally important although this C-terminal region ( 37 amino acids) is thought to contain a nucleotide binding region.

In the present study we investigated the relationship between UCP2/UCP 3 expression in skeletal muscle and obesity/energy metabolism in non- diabetic Pima lndians.

\section{Methods}

Subjects

Nineteen male non-diabetic Pima Indians were studied. Sixteen of them also had a measure of 24-h energy expenditure in a respiratory chamber (12). Subjects characteristics are given in Table 10.1. All subjects were in good health as determined by physical examination and routine blood and urine tests. All subjects were clinically euthyroid and serum thyroid stimulating hormone concentrations were within the 
normal range (Table 10.1). None took prescribed or over-the-counter medications. Glucose tolerance was assessed by an oral glucose tolerance test according to the WHO criteria (9), and insulin concentrations were also measured (Concept 4, ICN, Forsham, PA). This study was approved by the ethics committee of the National Institute of Diabetes and Digestive and Kidney Diseases and by the Tribal Council of the Gila River Indian Community, and all subjects gave written informed consent prior to participation. Subjects were admitted to the Clinical Research Unit for 7-10 days and were provided a standard weight-maintaining diet containing $50 \%$ carbohydrates, $30 \%$ fat and $20 \%$ protein for at least 3 days prior to metabolic testing.

\section{Body composition and energy metabolism}

Percent total body fat was measured by dual-energy x-ray absorptiometry using a total body scanner (DPX-L, Lunar Radiation Corp, Madison, WI) as previously described (16). After at least three days on a weight maintenance diet, subjects entered the respiration chamber at 7:30 AM for a 23-hour stay (12). Sleeping metabolic rate was calculated between $11 \mathrm{PM}$ and 5 AM, using all 15 minutes periods during which spontaneous physical activity was detected less than $1.5 \%$ of the time by a microwave motion detector (12).

\section{Muscle biopsy and RNA analysis}

After at least seven days on a weight maintenance diet, a percutaneous muscle biopsy was taken from the vastus lateralis muscle after an overnight fast. After local anesthesia, a $5 \mathrm{~mm}$ diameter side cutting needle was passed through a $7 \mathrm{~mm}$ skin incision. The muscle biopsy was immediately frozen in liquid nitrogen and stored at $-70^{\circ} \mathrm{C}$ until assayed. Muscle specimens were homogenized in denaturation solution and total RNA was isolated using a kit (Ambion, Inc, Austin, TX). Oligo-dT-primed cDNAs were synthesized from $2 \mu \mathrm{g}$ of total RNA in a $20 \mu \mathrm{l}$ volume using SuperScript cDNA synthesis kit from Gibco BRL (Gaithersburg, MD). For quantitative comparisons, reverse transcription PCR (RT-PCR) was performed and all primer combinations were designed to span at least one intron to avoid co-amplification of genomic DNA which may contaminate the RNA preparation. For $U C P 2$, a 964 bp CDNA fragment was obtained using $5^{\prime}$-catctcctgggacgtag- $3^{\prime}$ as a sense and $5^{\prime}-$ atcaggtcagcagcaggagag $3^{\prime \prime}$ as an antisense primer. A 993 bp UCP3L cDNA fragment was obtained using $5^{\prime}$-aggactatggttggactgaa-3' as a sense primer and $5^{\prime}$ cattcttaactggttcggacac- $3^{\prime}$ as an antisense primer. These primers are in exon 2 and exon 7 respectively. For $U C P 3 S$, a 868 bp cDNA fragment was obtained using the same sense primer as in UCP $3 L$, and an antisense 5'-gttctctgggagggagtgc-3' primer, which is in the untranslated region of exon 6 . A $535 \mathrm{bp}$ fragment of the $\beta$-actin gene was co-amplified as an internal control. Aliquots $(5 \mu \mathrm{l})$ were taken from each tube every four cycles following 22 cycles to determine whether the amplification was in the linear phase for each product. The products were resolved on a $1 \%$ agarose gel containing $1 \mu \mathrm{l}$ ethidium bromide which was photographed using Polaroid $665 \mathrm{film}$ (Cambridge, MA), and the relative concentration of PCR products was measured by scanning densitometry (Biolmage version 3.3, Sun SparcStation 5, Ann Arbor, MI). Each experiment was performed in triplicate and the mean value was calculated for analysis. Levels of mRNA were expressed as the ratio of signal intensity for the target 
genes relative to $B$-actin and were corrected for the size of the product. Total $U C P 3$ expression (UCP3total) was calculated by summing the corrected ratios for UCP $3 L$ and $U C P 3 S$. For determination of the ratio of $U C P 3 S: U C P 3 L$, the target genes were amplified together without the control gene $\beta$-actin.

\section{Statistical analysis}

All data were analyzed using the procedures of the SAS Institute (Cary, NC). Pearson correlation coefficients were calculated to determine the relationship between selected variables. Multiple regression models assessed the effect of UCP2 and $U C P 3$ expression, independently of fat-free mass and fat mass, on energy metabolism. Data are expressed as means $\pm \mathrm{SD}$ and $\mathrm{P}$ values $<0.05$ are considered significant.

\section{Results}

The mean levels of expression of $U C P 2, U C P 3 L, U C P 3 S$, total $U C P 3$ and ratio of UP3S/UCP3L are given in Table 10.1. The expression of $U C P 3 L$ correlated with the expression of UCP3S $(\mathrm{r}=0.60, \mathrm{p}<0.01)$. The ratio of UCP $3 S$ to UCP $3 L$ mRNA expression did not correlate with any of the measured variables.

Table 10.1 Subjects characteristics, energy expenditure and UCP2/3 expression in 19 nondiabetic Pima Indians

\begin{tabular}{lcc}
\hline & mean $\pm \mathrm{SD}$ & range \\
\hline Age $(\mathrm{y})$ & $33 \pm 8$ & $19-50$ \\
Height $(\mathrm{m})$ & $1.71 \pm 0.05$ & $1.63-1.81$ \\
Weight $(\mathrm{kg})$ & $94.0 \pm 20.8$ & $54.1-1.40 .7$ \\
Body mass index $(\mathrm{kg} / \mathrm{m} 2)$ & $33 \pm 7$ & $18-44$ \\
Body fat $(\%)$ & $33 \pm 8$ & $10-44$ \\
Fasting insulin (pmol/l) & $113 \pm 66$ & $24-258$ \\
Thyroid stimulating hormone (mU/1) & $2.1 \pm 1.2$ & $0.8-4.8$ \\
24h energy expenditure (kJ/day) * & $9802 \pm 1504$ & $7440-13223$ \\
Sleeping metabolic rate (kJ/day) * & $7079 \pm 896$ & $5384-9.123$ \\
& & \\
UCP2 mRNA expression (ratio with B-actin) & $0.21 \pm 0.10$ & $0.12-0.49$ \\
UCP3long mRNA expression (ratio with B-actin) $\dagger$ & $0.47 \pm 0.16$ & $0.13-0.72$ \\
UCP3short mRNA expression (ratio with B-actin) & $0.46 \pm 0.15$ & $0.18-0.78$ \\
UCP3total mRNA expression (ratio with B-actin) $\dagger$ & $0.93 \pm 0.29$ & $0.31-1.50$ \\
UCP3short/UCP3long & $0.99 \pm 0.22$ & $0.67-1.49$ \\
\hline
\end{tabular}

\footnotetext{
$* n=16$
}

$+n=18$

Body Mass Index (BMI) was negatively correlated with UCP3L $(\mathrm{r}=-0.53, \mathrm{p}=0.025$, Figure 10.1), UCP3S $(\mathrm{r}=-0.46, \mathrm{p}=0.047)$, and UCP3total $(\mathrm{r}=-0.56, \mathrm{p}=0.017)$. BMI was not correlated with $U C P 2$. Percent body fat tended to correlate negatively with UCP3L $(\mathrm{r}=-0.42, \mathrm{p}=0.09), U C P 3 S(\mathrm{r}=-0.40, \mathrm{p}=0.09)$ and UCP3total $(\mathrm{r}=-0.46$, $\mathrm{p}=0.06$ ), but not with $U C P 2$. Fasting plasma insulin concentration was correlated negatively with UCP $3 L \quad(\mathrm{r}=-0.53, \mathrm{p}=0.04)$ and only tended to correlate with 
$U C P 3$ total $(\mathrm{p}=0,09)$. None of the UCPs were correlated with thyroid stimulating hormone concentration.

Twenty-four hour energy expenditure and sleeping metabolic rate (SMR) were adjusted for their two major determinants, fat-free mass and fat mass. Adjusted SMR was positively correlated with $U C P 3 L(\mathrm{r}=0.69, \mathrm{p}=0.006$, Figure 10.1) and UCP3total $(\mathrm{r}=0.60, \mathrm{p}=0.02)$, but not with $U C P 2$ expression. Twenty four hour energy expenditure only tended to correlate with UCP3total $(\mathrm{p}=0.07)$.
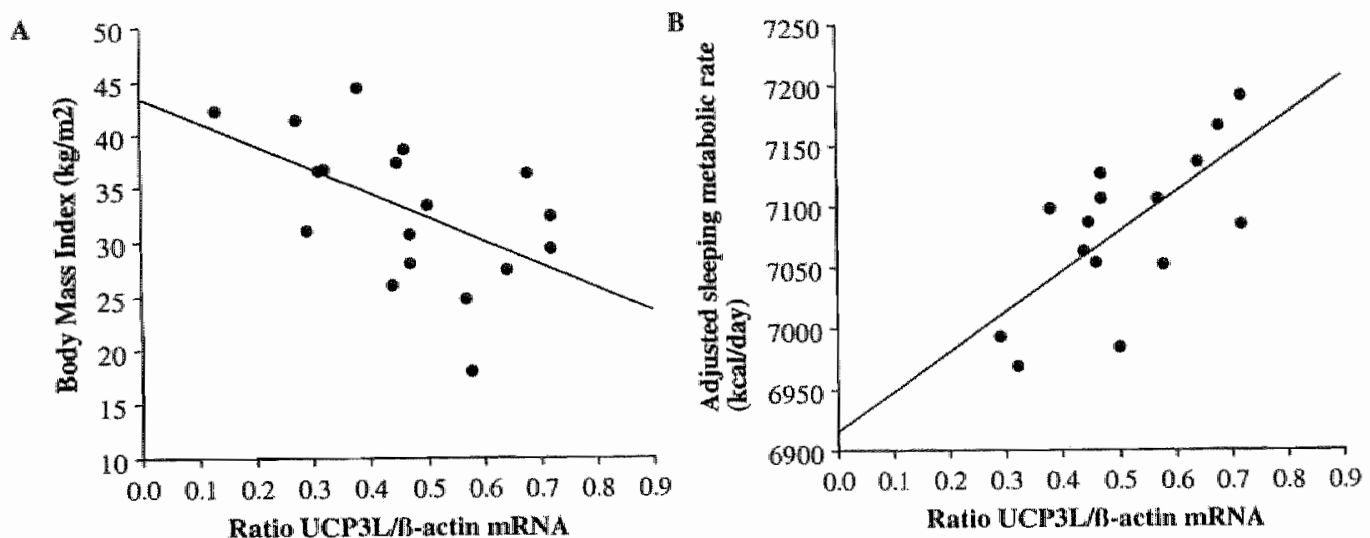

Figure 10.1 Relationship between body mass index $(A)$ and sleeping metabolic rate $(B)$ and relative UCP3L mRNA expression (UCP3L/B-actin) in skeletal muscle determined by RT-PCR. The mRNA expression is the mean of triplicate measurements. A, Body mass Index ( $r=-0.53, p=0.025$ ). B, sleeping metabolic rate $(r=0.69, p=0.006)$. Sleeping metabolic rate is adjusted for fat-free mass and fat mass.

\section{Discussion}

Resting metabolic rate is an important determinant of 24-hour energy expenditure, accounting for approximately $50-80 \%$ of daily energy expenditure (12). The major determinants of resting metabolic rate are fat-free mass, fat mass and sex, but even after adjustment for these factors there is still considerable variability between individuals. It is important to understand the determinants of this variability, since a low "relative" metabolic rate is a predictor of weight gain (13). Part of the remaining variability in resting metabolic rate can be accounted for by differences in skeletal muscle metabolism (21). The recently discovered mitochondrial proteins, UCP2 $(6,7)$ and UCP3 $(2,18)$, are both expressed in skeletal muscle and have been shown to have uncoupling activity, thereby dissipating energy as heat. Therefore these UCPS are likely candidates to underlie the physiological variability in resting energy expenditure in humans. In this study, we found positive correlations between sleeping metabolic rate, adjusted for fat-free mass and fat mass, and the expression of the UCP 3 gene, indicating that UCP3 may be a determinant of energy expenditure in humans. 
Recently, Walder et al. (19) reported an association between polymorphisms in UCP2 and sleeping metabolic rate in Pima Indians. $U C P 3$ is located in the same BAC and P1 clones as $U C P 2(15)$, indicating that the two genes are physically nearby. Therefore, it is possible that the association between UCP2 polymorphisms and SMR might be due to variants in UCP3. In this study we found a positive correlation between SMR and UCP3 mRNA levels. Assuming that mRNA levels reflects UCP3 protein concentrations, these data indicate that reduced skeletal muscle UCP3 results in a low resting metabolic rate. Since a low relative resting metabolic rate is a predisposing factor for weight gain (13), it is expected that individuals with low UCP3 gene expression would eventually have higher body weight. Indeed, BMI correlated negatively with UCP3 gene expression. UCP2 expression was not correllated with energy expenditure or obesity. The expression of UCP 3 in skeletal muscle was 4.5fold higher than the expression of $U C P 2$, similar to previously published data (18). $U C P 2$ is expressed in a variety of tissues, with the highest expression in tissues of the immune system and adipose tissue $(6,7)$. In contrast, $U C P 3$ is mostly expressed in skeletal muscle $(2,18)$. These pronounced differences in distribution suggest different roles for $U C P 2$ and $U C P 3$ in humans.

$U C P 3$ is expressed as a long and a short form. UCP3S lacks part of exon 6 and the entire exon 7 , which encodes for a domain that is highly homologous to $\mathrm{C}$-terminal residues found in $U C P I$ and $U C P 2$ (13). In UCP1, this terminal region is believed to participate in purine nucleotide-mediated inhibition of uncoupling activity (5). This suggests that UCP3S might have altered uncoupling activity. In the present study, $U C P 3 L$ and $U C P 3 S$ were equally expressed in skeletal muscle, confirming previous results (15). There was however some variability in the ratio between UCP3S and $U C P 3 L$ expression among individuals, but this ratio was not related to any of the measured variables.

In the present study we found a negative correlation between skeletal muscle $U C P 3$ expression and BMI in Pima Indians. This is in contrast with the results of Millet et al. (18), who found no difference in UCP3 mRNA expression in skeletal muscle between obese and lean Caucasians. In Pima Indians, the prevalence of obesity is higher compared to Caucasians, probably due to a stronger genetic susceptibility. The lack of correlation between BMI and $U C P 3 L$ in Caucasians might be explained by a lower susceptibility to obesity in this population and does not rule out a role for $U C P 3$ in energy expenditure and obesity.

Fasting insulin concentrations was negatively correlated with UCP $3 L$ expression. This relation is unlikely to be due to a direct effect of insulin, as acute hyperinsulinemia does not appear to alter the expression of UCP3 in skeletal muscle(10). Since fasting insulin concentrations are related to BMI and percent body fat, it is possible that $U C P 3 L$ expression and insulin concentrations were related through their common association with obesity. However, it is also possible that UCP3 or a closely linked gene directly effects insulin. In support of this, Ucp2 was linked to hyperinsulinemia in mice (6) and somewhat linked to 2-hour insulin concentrations during an oral glucose tolerance test in non-diabetic Pima Indians (11). 
The cause(s) of the 2-3 fold variation in skeletal muscle UCP3 mRNA expression in Pima Indians remains to be determined. $U c p 3 \mathrm{mRNA}$ concentrations are increased by thyroid hormones (8), leptin (8), B3 agonists (8), glucocorticoids (8), and free-fatty acids (20). In this study, subjects were not taking medications, were clinically healthy and euthyroid and had normal serum concentrations of thyroid stimulating hormone. Thus, it is unlikely that the large variation in UCP3 mRNA levels was due to large variations in glucocorticoid or thyroid hormone concentrations. The most obese subjects, who probably would have the highest plasma free-fatty acid and leptin concentrations, had the lowest $U C P 3$ expression, making it unlikely that higher $U C P 3$ expression was due to higher free-fatty acid or leptin concentrations. These observations, and the association of polymorphisms in the nearby UCP2 gene with sleeping metabolic rate in Pima Indians, favor the hypothesis that there are DNA polymorphisms in, or near, the $U C P 3$ gene that result in differential expression of UCP3 mRNA, but this remaims to be proven.

In conclusion, our results indicate that UCP3 mRNA expression in skeletal muscle varies 2-3 fold and may be a determinant of the variability in rates of energy expenditure and thereby, in the degree of obesity. Additional studies are needed to demonstrate that UCP3 protein concentrations are reflected by UCP 3 mRNA concentrations and that UCP3 protein concentrations are also correlated with rates of energy expenditure. Also, the genetic and/or other hormonal and metabolic determinants of variations in skeletal muscle $U C P 3 \mathrm{mRNA}$ and protein concentrations in Pima Indians need to be identified.

\section{References}

1. Bogardus, C., Lillioja, S., Ravussin, E., Abbott, W., Zawadzki, J. K., Young, A., Knowler, W. C., Jacobowitz, R., and Moll, P. P. Familial dependence of the resting metabolic rate. New Eng J Med. 315: 96-100, 1986.

2. Boss, O., Samec, S., Paoloni-Giacobino, A., Rossier, C., Dulloo, A., Seydoux, $J_{*}$ Muzzin, P., and Giacobino, J,-P. Uncoupling protein-3: a new member of the mitochondrial carrier family with tissue-specific expression. FEBS lett. 408: 39-42, 1997.

3. Bouchard, C., Pérusse, L., Chagnon, Y. C., Warden, G., and Ricquier, D. Linkage between markers in the vicinity of the uncoupling protein 2 gene and resting metabolic rate in humans. Hum Mol Genet. 6: 1887-1889, 1997.

4. Bouchard, C., Tremblay, A., Nadeau, A., Després, J. P., Therrault, G., Boulay, M. R., Lortie, G. Leblanc, $C_{\text {., }}$ and Foumier, $G_{\text {. }}$ Genetic effect in resting and exercise metabolic rate. Metabolism. 38: 364-370, 1989.

5. Bouillaud, F., Arechage. I., Petit, P. X., Raimbault, S., Levi-Meyrueis, C., Casteilla, L., Laurent, M., Rial, E, and Ricquier, D. A sequence related to a DNA recognition element is essential for the inhibition by nucleotides of proton transport through the mitochondrial uncoupling protein. EMBO J. 13: 1990-1997, 1994.

6. Fleury, C., Neverova, M., Collins, S., Raimbault, S., Champigny, O., Levi-Meyrueis, C., Bouillaud, F., Seldin, M. F., Surwit, R. S., Ricquier, D. Uncoupling protein-2: a novel gene linked to obesity and hyperinsulinemia. Nature Genetics. 15: 269-273, 1997. 
7. Gimeno, R. E., Dembski, M., Weng, X., Deng, N., Shyjan, A. W., Gimeno, C. J., Iris, F., Ellis, S. J., Woolf, E. A., and Tartaglia, L. A. Cloning and characterization of an uncoupling protein homolog: a potential molecular mediator of human thermogenesis. Diabetes. 46 : 900-906, 1997.

8. Gong, D.-W., He, Y., Karas, M., and Reitman, M. Uncoupling protein-3 is a mediator of thermogenesis regulated by thyroid hormone, B3-adrenergic agonists, and leptin. J Biol Chem. 272: 24129-24132, 1997.

9. WHO Study Group. Prevention of diabetes mellitus. WHO Technical Report Series 727. World Health Organisation, 1994.

10. Millet, L., Vidal, H., Andreelli, F., Larrouy, D., Riou, J.-P., Ricquier, D., Laville, M., and Langin, D. Increased uncoupling protein-2 and -3 mRNA expression during fasting in obese and lean humans. J Clin Invest. 100: 2665-2670, 1997.

11. Pratley, R. E., Thompson, D. B., Prochazka, M., Baier, L., Mott, D., Ravussin, E., Sakul, H., Ehm, M. G., Burns, D. K., Foroud, T. An autosomal genomic scan for loci linked to prediabetic phenotypes in Pima Indians. J Clin Invest. In Press: 1998.

12. Ravussin, E., Lillioja, S., Anderson, T. E., Christin, L., and Bogardus, C. Determinants of 24hour energy expenditure in man. Methods and results using a respiratory chamber. $J$ Clin Invest. $78: 1568-1578,4986$.

13. Ravussin, E., Lillioja, S., Knowler, W. C., Christen, L., Freymond, D., Abbott, W. G. H., Boyce, V., Howard, B. V., and Bogardus, C. Reduced rate of energy expenditure as a risk factor for body-weight gain. N Engl J Med. 318: 467-472, 1988.

14. Ricquier, D., Casteilla, L., and Bouillaud, F. Molecular studies of the uncoupling protein. FASEB J. 5: 2237-2242, 1991 .

15. Solanes, G., Vidal-Puig, A., Grujic, D., Flier, J. S.n and Lowell, B. B. The human uncoupling protein-3 gene: genomic structure, chromosomal localization, and genetic basis for short and long form transcripts. If Biol Chem. 272: 25433-25436, 1997.

16. Tataranni, $\mathbb{P}$. A, and Ravussin, E. Use of dual X-ray absorptiometry in obese individuals. Am J Clin Nutr. 55: 730-734, 1995.

17. Tataranni, P. A., and Ravussin, E. Variability in metabolic rate: biological sites of regulation. Int J Obesity. 19: S102-106. 1995.

18. Vidal..Puig, A, Solanes, G, Grujic, D., Flier, J. S., and Lowell, B. B. UCP3: An uncoupling protein homologue expressed preferentially and abundantly in skeletal muscle and brown adipose tissue. Biochem Biophys Res Commun. 235: 79-82, 1997.

19. Walder, K., Norman, R. A., Hanson, R. L., Schrauwen, P., Neverova, M., Jenkiruson, C. P., Easlick, J., Warden, C. H., Pecqueur, C., Raimbault, S., Ricquier, D., Harper, M., Silver, K., Shuldiner A.R., Solanes, G., Lowell, B. B., Chung, W. K., Leibel, R. L., Pratley, R., Ravussin, E. Association between uncoupling protein polymorphisms (UCP2-UCP3) and energy metabolism/obesity in Pirna Indians. Hum Molecular Genetics. 7: 1431-1435, 1998.

20. Weigle, D. S., Selfridge, L. E., Schwartz, M. W., Seeley, R. J., Cummings, D. E., Havel, P. J., Kuipper, J, L., and BertrandelRio, H. Elevated free fatty acids induce uncoupling protein 3 expression in muscle. A potential explamation for the effect of fasting. Diabetes, 47: 298 . $302,1998$.

21. Zurlo, F., Larson, K., Bogardus, C., and Ravussin, E. Skeletal muscle metabolism is a major determinant of resting energy expenditure. J Clin Invest. 86" $1423-1427,1990$. 


\title{
Chapter 11
}

\section{Skeletal muscle UCP2 and UCP3 expression in trained and untrained male subjects}

Patrick Schrauwen*\#, Freddy J Troost*, Jamex Xiä, Eric Ravussin" and Wim H M Saris*

* Department of Human Biology, Maastricht University, Maastricht, The Netherlands *Clinical Diabetes and Nutrition Section, National Institutes of Health, Phoenix, Arizona, USA

submitted American Journal of Physiology

\begin{abstract}
The new uncoupling proteins, UCP2 and UCP3, are thought to play a role in energy efficiency in humans. Endurance training has been suggested to have effects on resting metabolic rate and energy efficiency. We therefore determined UCP2 and $U C P 3$ mRNA levels in skeletal muscle of trained and untrained male subjects.

Using RT-PCR, expression of $U C P 2, U C P 3 L$ and $U C P 3 S \mathrm{mRNA}$ were measured in muscle biopsies from the quadriceps femoris in 8 trained $(23.9 \pm 1.6 \mathrm{y} ; 70.6 \pm 3.1 \mathrm{~kg}$; $14 \pm 3 \%$ body fat; $W_{\max }: 5.6 \pm 0.4 \mathrm{Watt} / \mathrm{kg}$; mean $\pm \mathrm{SD}$ ) and 10 lean, untrained (22.1 $\pm 2.9 \mathrm{y} ; 72.0 \pm 7.9 \mathrm{~kg} ; 18 \pm 4 \%$ body fat; $\mathrm{W}_{\text {max }}: 3.9 \pm 0.4 \mathrm{Watt} / \mathrm{kg} ;$ mean $\pm \mathrm{SD}$ ) subjects. In six of the trained subjects, $U C P 2$ and $U C P 3 \mathrm{mRNA}$ were measured before and after an exercise bont to exhaustion. To correct for differences in mitochondrial content, levels of $U C P 2$ and $U C P 3 \mathrm{mRNA}$ were expressed relative to cytochrome-b, a marker of milochondrial content.

Acute exercise had no effect on the expression of $U C P 3 L$ or $U C P 3 S$, but in 5 out of 6 subjects $U C P 2$ expression decreased after exercise, although the difference was not statistically significant $(p=0.11)$. Trained subjects had significantly reduced mRNA levels of $U C P 3 L(\mathrm{p}=0.028)$ and $U C P 3 S(\mathrm{p}=0.031) . V \mathrm{VO}_{2 \max }$ expressed per $\mathrm{kg}$ of fatfree mass was negatively correlated with UCP3L $(\mathrm{r}=-0.61, \mathrm{p}=0.009)$ and UCP $3 S(\mathrm{r}=-$ $0.52, p=0.028)$. Mechanical efficiency correlated negatively with $U C P 3 L(\mathrm{r}=-0.56$, $\mathrm{p}=0.019), U C P 3 S(\mathrm{r}=-0.47, \mathrm{p}=0.048)$ and tended to correlate with UCP2 $(\mathrm{r}=-0.46$, $\mathrm{p}=0.06$ ).

The lower levels of $U C P 3$ mRNA in trained subjects and the inverse relationship of $U C P 3$ expression and mechanical efficiency suggest that exercise training produces an adaptive physiological response in skeletal muscle improving mechanical efficiency.
\end{abstract}




\section{Introduction}

In rodents, brown adipose tissue plays an important role in thermogenesis and energy balance, via the activation of an uncoupling protein gene, UCPI. This gene encodes for a mitochondrial protein carrier, which uncouples respiration from ATP production and stimulates heat production (18). UCPI is only expressed in brown adipose tissue, which is scarce in adult humans and is not thought to play a major role in energy balance. Recently, two new uncoupling proteins, UCP2 $(6,8)$ and UCP3 $(2,25)$, were discovered. UCP2 and UCP3 have approximately $55 \%$ amino acid identity with UCP1 and have been shown to have uncoupling activity $(6,10)$. UCP2 is expressed in many tissues, whereas UCP 3 is mainly expressed in skeletal muscle $(2,25)$. UCP2 was mapped to chromosome $11 \mathrm{q} 13$ (6) and $U C P 3$ is only $8 \mathrm{~kb}$ away from $U C P 2$ (21). In the Quebec Family study, resting metabolic rate (RMR) was genetically linked to DNA microsatellite markers in the close vicinity of $U C P 2 / U C P 3$ (4). Recently, we found an association between polymorphisms in $U C P 2$ and sleeping metabolic rate in Pima Indians (26). UCP3 mRNA levels in Pima Indians were found to be positively correlated with sleeping metabolic rate (unpublished observation). Taken together, these results indicate that the new uncoupling proteins may be important determinants of energy expenditure in humans.

The effect of endurance training on energy metabolism has been extensively studied but results are quite controversial. Some studies have shown an increase in resting metabolic rate, adjusted for fat-free mass and fat mass, in response to training $(24,16)$, whereas others did not $(5,19,28)$. Also, endurance training has been proposed to decrease the thermic effect of food (15). Furthermore, an increase in gross energy efficiency in response to training has been reported $(7,9)$. In the present study we measured mRNA levels of $U C P 2$ and the different isoforms of $U C P 3$, the long $(U C P 3 L)$ and short form (UCP $3 S)$ of $U C P 3$, in two groups of untrained and trained subjects. We hypothesized that endurance training results in decreased $U C P 2$ and UCP3 levels, making endurance trained athletes more energy efficient.

\section{Methods}

Subjects

Eighteen lean male volunteers were recruited: 10 were untrained and 8 were highly trained young individuals. All subjects had to be in good health, were non-smokers and had a BMI between $18-25 \mathrm{~kg} / \mathrm{m}^{2}$. Subjects who had never participated in competitive endurance sports and had less than 3 hours of activity per week for the last 3 years, were included in the untrained group. Subjects who were regularly involved in competitive endurance sports for at least the past 3 years and had more than 15 hours/week of endurance training were included in the trained group. Body density was determined by underwater weighing, with simultaneous measurement of lung volume with the helium dilution technique using a spirometer (Volugraph 2000, Mijnhardt). Percent body fat was calculated using the equations of Siri (20). Subjects characteristics are given in Table 11.1. Trained and untrained subjects had similar body weight, BMI and fat-free mass (FFM). The study was approved by the Ethical Committee of the Maastricht University and all subjects gave their written informed consent. 
Table 11.1 Subjects characteristics

\begin{tabular}{lcl}
\hline group & Trained & Untrained \\
\hline Age $(\mathrm{y})$ & $23.9 \pm 0.6$ & $22.1 \pm 0.9$ \\
Weight $(\mathrm{kg})$ & $70.6 \pm 1.1$ & $72.0 \pm 2.5$ \\
Height $(\mathrm{m})$ & $1.82 \pm 0.02$ & $1.80 \pm 0.01$ \\
BMII $\left(\mathrm{kg} / \mathrm{m}^{2}\right)$ & $21.3 \pm 0.6$ & $22.3 \pm 0.8$ \\
\% body fat & $14 \pm 1$ & $18 \pm 1$ \\
Fat-free mass & $60.5 \pm 0.5$ & $59.1 \pm 1.8$ \\
VO2max (ml/min.kg) & $66.9 \pm 2.6 *$ & $51.5 \pm 1.5$ \\
Wmax $(\mathrm{W})$ & $396 \pm 8 *$ & $277 \pm 9$ \\
Wmax $/ \mathrm{kg}(\mathrm{W})$ & $5.62 \pm 0.16 *$ & $3.87 \pm 0.12$ \\
\hline
\end{tabular}

Values are expressed as mean \pm s.e.m.

* p<0.0001 compared to untrained

\section{Exercise testing}

Each subject performed an incremental exercise test to exhaustion on an electronically braked cycle ergometer (Lode Excalibur, Groningen, The Netherlands) to determine maximal power output ( $W_{\max }$ ) and maximal oxygen consumption $\left(\mathrm{VO}_{2 \max }\right)$. Exercise was performed until voluntary exhaustion or until the subject could no longer maintain a pedaling rate of $\geq 60 \mathrm{rpm}$. Subjects started at 100 Watt for $5 \mathrm{~min}$. Thereafter, work load was increased by 50 Watt every $2.5 \mathrm{~min}$. When subjects were approaching exhaustion, as indicated by heart rate and subjective scoring, the increment was reduced to 25 Watt. In practice, this meant that the last 1 to 3 load increments were 25 Watt. Heart rate was measured continuously using a Polar Sport tester (Kempele, Finland). $W_{\max }$ was calculated from:

$$
W_{\text {max }}=W_{\text {out }}+(t / 150) * \partial W
$$

in which $W_{\text {out }}$ is the highest workload completed by the subject, $t$ is the time (in seconds) performed on the last workload and $\partial \mathrm{W}$ is the final uncompleted load increment (13). Oxygen consumption and carbon dioxide production were measured using open circuit spirometry (Oxyconm 3 Mijnhard, The Netherlands).

At least 7 days after the determination of $W_{\text {max }}$, mechanical efficiency was determined as follows: subjects cycled for $15 \mathrm{~min}$ at 30,45 and $60 \%$ of $\mathrm{W}_{\mathrm{max}}$. Oxygen consumption and carbon dioxide production were measured using open circuit spirometry (Oxycon-B Mijnhard, The Netherlands) and energy expenditure was calculated as described previously (12). Mechanical efficiency was regarded as the slope of the regression between energy expenditure and workload.

In order to measure UCP2/3 mRNA expression before and after exercise, six of the trained subjects performed internittent exercise bouts to exhaustion. Alter a warm-up at $50 \%$ of their $W_{\max }$ for 5 min, subjects cycled 2 min on $90 \%$ of $W_{\max }$ followed by 2 min on $50 \%$ of $W_{\max }$. This was repeated until subjects were no longer able to perform the high intensity exercise. The maximal intensity was then lowered to $80 \%$ of $W_{\max }$. Again, when this intensity could no longer be maintained, the maximal intensity was decreased to $70 \%$ of $\mathrm{W}_{\max }$. The test was ended after exhaustion. Subjects were 
allowed to consume water during exercise. Heart rate was measured continuously with a polar sport tester.

\section{Basal metabolic rate and blood sampling}

After an overnight fast, subjects came to the laboratory at 8 am. Instructions were given to refrain from any exercise on the previous day. Subjects rested on a bed for $40 \mathrm{~min}$ and oxygen consumption and carbon dioxide production were measured using a open circuit ventilated hood system. Metabolic rate was averaged over the last 20 min, when subjects were in a steady state. Before the measurement of the basal metabolic rate, $20 \mathrm{ml}$ of venous blood was taken, $10 \mathrm{ml}$ for plasma in tubes containing EDTA and $10 \mathrm{ml}$ in vacutainers for serum. Plasma FFA were determined using a kit (Wako chemicals, Neuss, Germany), insulin (Kabi Pharmacia) and leptin (Linco Research, St. Charles, USA.) by RIA. Serum T3 was determined using DPC immulite T3.

\section{Muscle bropsy and RNA analysis}

After measurement of resting metabolic rate, a percutaneous muscle biopsy was taken from the vastus lateralis. After local anesthesia, a $5 \mathrm{~mm}$ diameter side cutting needle was passed through a $7 \mathrm{~mm}$ skin incision. The muscle biopsy was immediately frozen in liquid nitrogen and stored at $-70^{\circ} \mathrm{C}$ until assayed. Muscle specimens were homogenized and total RNA was isolated using Trizol kit (Gibco-BRI, Gaithersburg, MD). Oligo-dT-primed cDNAs were synthesized from $2 \mu \mathrm{g}$ of total RNA in a $20 \mu l$ volume using SuperScript cDNA synthesis kit from Gibco BRL (Gaithersburg, MD). Quantitative comparisons were performed by reverse transcription PCR (RT-PCR), and all primer combinations were designed to span at least one intron to avoid coamplification of genomic DNA which may contaminate the RNA preparation. The primers used for amplifying cDNA fragments are shown in Table 11.2. It has been shown that, in response to training, the expression of mitochondrial mRNAs is increased in direct proportion to total mitochondrial content (17). Therefore, $c y$ tochrome-b expression was measured for determination of mitochondrial content. During PCR, aliquots $(5 \mu \mathrm{l})$ were taken from each tube every four cycles following 22 cycles to determine whether the amplification was in the linear phase for each product. The products were resolved on a $1 \%$ agarose gel containing $1 \mu$ ethidium bromide which was photographed using Polaroid 665 film (Cambridge, MA), and the relative concentration of PCR products was measured by scanning densitometry (Biolmage version 3.3, Sun SparcStation 5. Ann Arbor, M1). Each experiment was performed in triplicate and the mean value was calculated for analysis. Levels of mRNA were expressed as the ratio of signal intensity for the target genes relative to $\beta$-actin (i.e. $U C P 2 / \beta$-actin). To correct for mitochondrial content, $\mathrm{mRNA}$ levels were also expressed relative to cytochrome-b (i.e. UCP2/cytochrome-b). All ratios were corrected for the size of the products.

\section{Staristical analysis}

Differences between trained and untrained subjects were tested using unpaired ttests. The effect of exercise on mRNA levels was tested using paired t-lests. Pearson correlation coefficients were calculated to determine the relationship between 
selected variables. Data are expressed as means \pm S.E.M. and $P$ values $<0.05$ are considered significant.

Table 11.2 Sequences of PCR primers

\begin{tabular}{lllc}
\hline Gene & Sense primer $\left(5^{\prime}-3^{\prime}\right)$ & Antisense primer $\left(5^{\prime}-3^{\prime}\right)$ & Size of cDNA, bp \\
\hline UCP2 & catctcctgggacgtag & atcaggtcagcagcaggagag & 964 \\
UCP3L & aggactatggttggactgaa & cattcttaactggtttcggacac & 993 \\
UCP3S & aggactatggttggactgaa & gttctctgggagggagtgc & 868 \\
B-actin & actgactacctcatgaagat & cgtcatactcetgcttgctgat & 535 \\
cytochrome-b ggttctggaataagaatatagg & gacaacacagtaagaaccagg & 367 \\
\hline
\end{tabular}

\section{Results}

Effect of acute exercise

Six subjects performed intermittent bouts of exercise to exhaustion. In 5 subjects, $U C P 2$ expression decreased in response to exercise, but this difference did not reach statistical significance ( $\mathrm{p}=0.11$, Figure 11.1). UCP $3 L$ and UCP3S did not change after exercise (Figure 11.1).

A

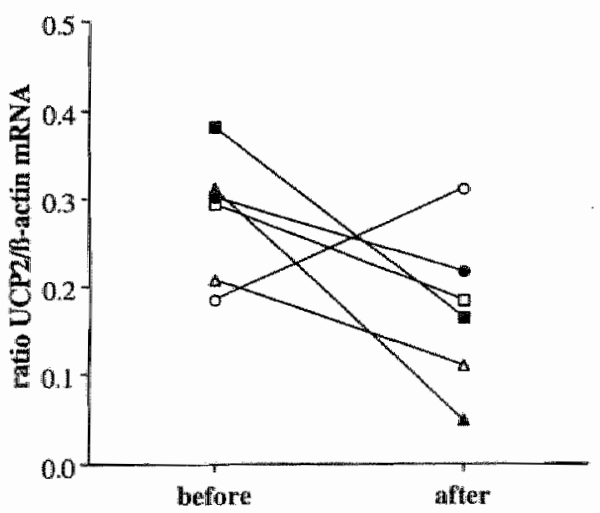

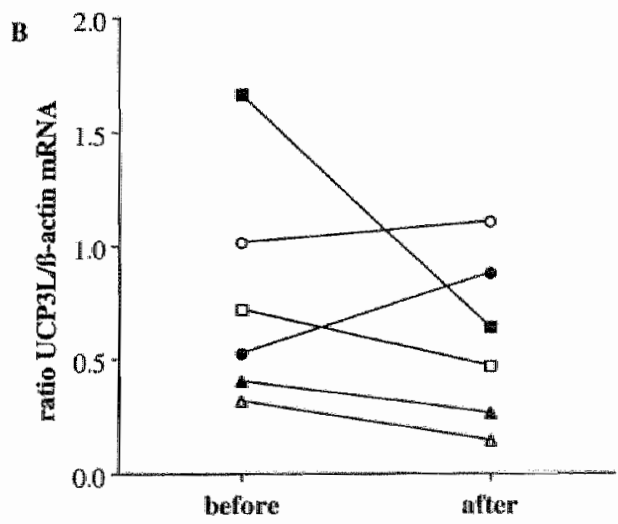

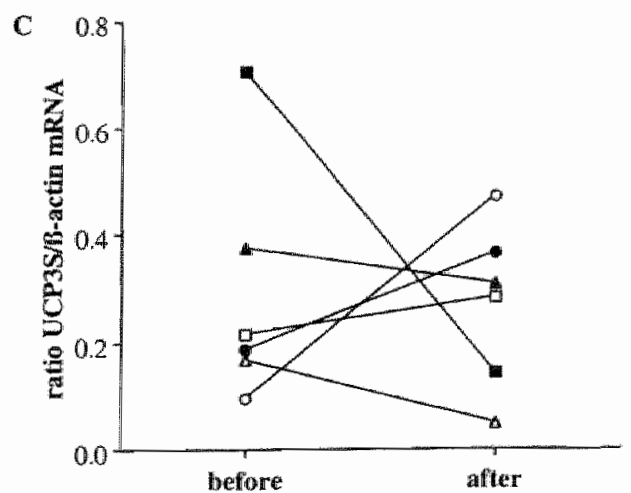

Figure 11.1 The effect of acute exercise on skeletal muscle $U C P 2(\mathrm{~A}), U C P 3 L(\mathrm{~B})$ and $U C P 3 S(C)$ expression in six trained subjects. 


\section{Effect of endurance training}

In the total group of 18 subjects, the expression of $U C P 3 L$ correlated with the expression of UCP3S $(\mathrm{r}=0.77, \mathrm{p}<0.001)$.

The mRNA levels of UCP $3 L, U C P 3 S$ and $U C P 2$ were not significantly different between trained and untrained subjects. However, when expressed relative to cytochrome- $b, U C P 3 L(\mathrm{p}=0.028)$ and UCP3S $(\mathrm{p}=0.031)$ were significantly lower in trained compared to untrained subjects (Figure 11.2). UCP2 expression relative to cytochrome-b tended to be lower in trained subjects vs. untrained $(\mathrm{p}=0.09$, Figure 11.2). In the remainder of the results, UCP2/UCP3 mRNA values are expressed relative to cytochrome-b.
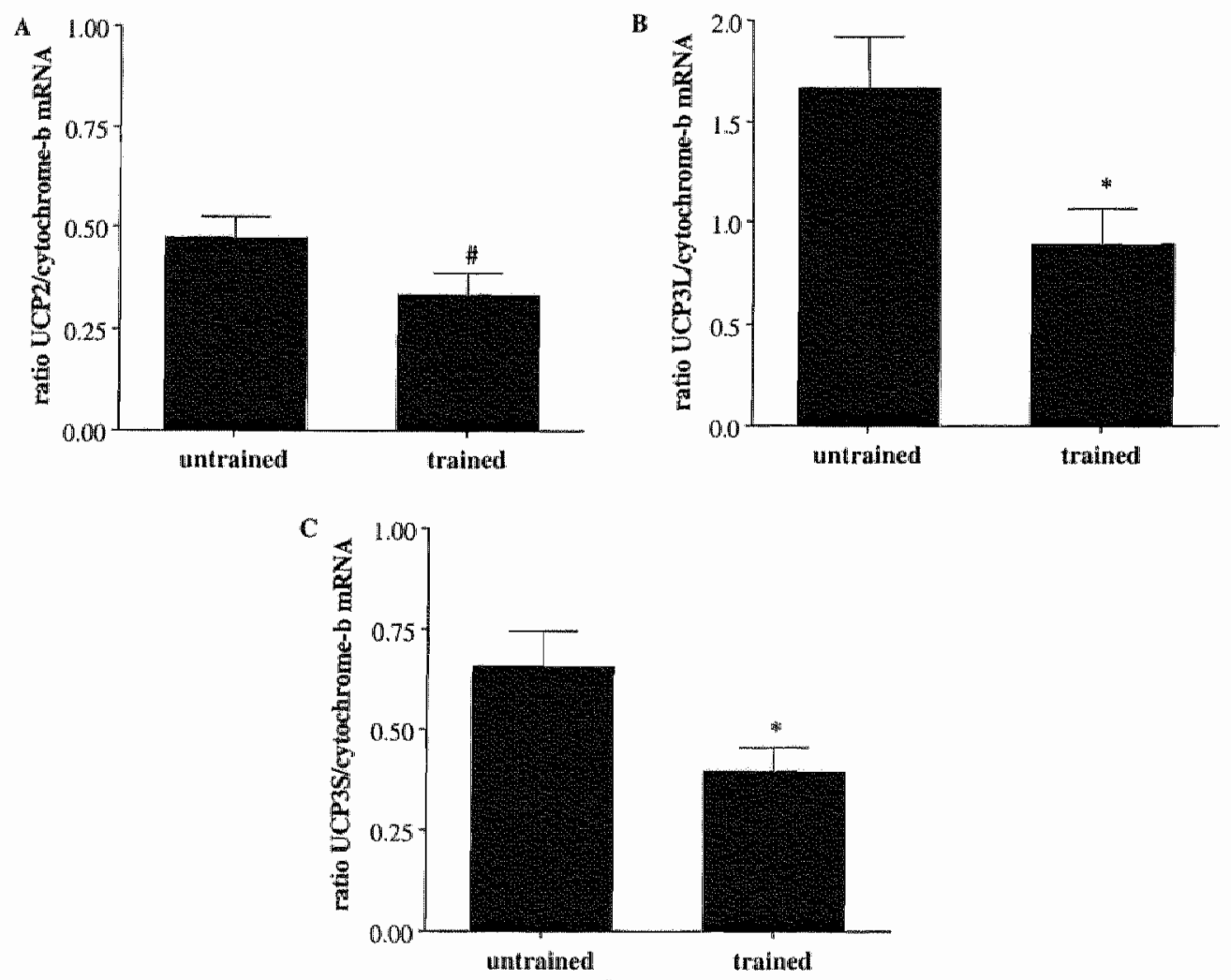

Figure 11.2 Expression of $U C P 2$ (A), $U C P 3 L$ (B) and $U C P 3 S$ (C) relative to cytochrome-b in skeletal muscle of trained and untrained subjects in the resting state. Values are mean \pm S.E.M. $* \mathrm{P}<0.05, \# \mathrm{P}=0.09$.

$U C P 3 L(\mathrm{r}=-0.52, \mathrm{p}=0.034), U C P 3 S(\mathrm{r}=-0.56, \mathrm{p}=0.015)$ and $U C P 2(\mathrm{r}=-0.54, \mathrm{p}=0.027)$ correlated negatively with $W_{\max }$ in absolute value or when expressed per $\mathrm{kg}$ FFM $(\mathrm{r}=-0.61, \mathrm{p}=0.01 ; \mathrm{r}=-0.49, \mathrm{p}=0.042 ; \mathrm{r}=-0.48, \mathrm{p}=0.051)$ respectively. Similarly, UCP3L $(\mathrm{r}=-0.49, \mathrm{p}=0.048), U C P 3 S(\mathrm{r}=-0.64, \mathrm{p}=0.005)$ and UCP2 $(\mathrm{r}=-0.55, \mathrm{p}=0.023)$ correlated negatively with $\mathrm{VO}_{2 \max }$ in absolute value or when expressed per $\mathrm{kg} F \mathrm{FM}$ $(r=-0.61, p=0.009$, figure $11.3 ; r=-0.52, p=0.028 ; r=-0.44, p=0.08)$ respectively. 
UCP $3 L \quad(\mathrm{r}=-0.56, \mathrm{p}=0.019$, figure 11.3) and UCP3S $(\mathrm{r}=-0.47, \mathrm{p}=0.048)$ were negatively correlated with mechanical efficiency, but this correlation did not reach statistical significance for $U C P 2(r=-0.46, \mathrm{p}=0.06)$.
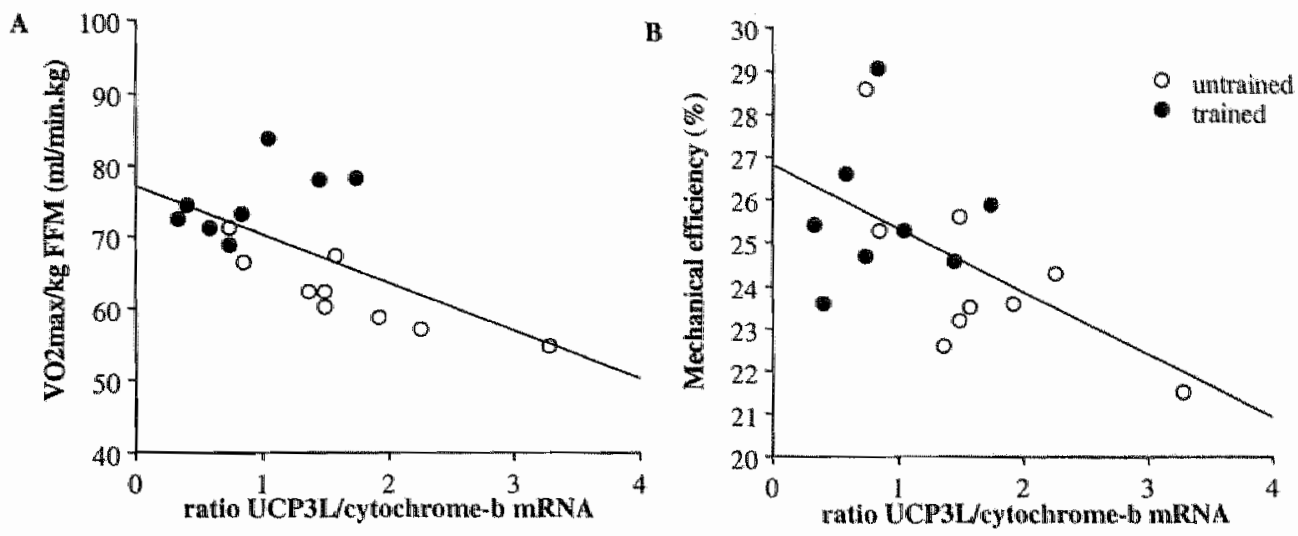

Figure 11.3 Relationship between (A) $V \mathrm{O}_{2 \text { max }}$ expressed per $\mathrm{kg} F \mathrm{FM}$ and (B) mechanical efficiency and $U C P 3 L \mathrm{mRNA}$ expression relative to cyrochrome-b

(UCP3L/cytochrome-b) in skeletal muscle of trained and untrained subjects.

$A: V_{2 \max }(r=-0.61, p=0.009)$. B: mechanical efficiency $(r=-0.56, p=0.019)$.

Resting metabolic rate, adjusted for fat-free mass and fat mass, was not significantly different between trained and untrained subjects and did not correlate with mRNA levels of $U C P 3 L, U C P 3 S$ or $U C P 2$. Resting respiratory quotient correlated positively with $U C P 2$ mRNA levels $(\mathrm{r}=0.52, \mathrm{p}=0.033)$ and FFA concentrations tended to correlate negatively with $U C P 2$ mRNA $(r=-0.49, p=0.06)$. Multiple regression revealed that the correlation between $U^{\prime} C P 2$ and respiratory quotient was independent of FFA. There were no differences in mean plasma concentrations of insulin, T3, leptin and FFA between trained and untrained subjects. Except for the above mentioned correlation between $U C P 2$ and FFA, concentrations of the measured hormones did not correlate with the expression of UCP $3 L, U C P 3 S$ or UCP2.

\section{Discussion}

The recent discovery of two new uncoupling proteins, UCP2 and UCP3, has renewed interest in the study of human energy metabolism. Both UCP2 and UCP3 have been shown to uncouple respiration from ATP synthesis $(6,10)$ and are therefore likely candidates to underlie the variability in energy expenditure and energy efficiency in humans. In this study we found a negative correlation between mechanical efficiency and the expression of $U C P 3 L$ and $U C P 3 S$ relative to cytochrome-b, indicating that $U C P 3$ may underlie the variability in energy efficiency in humans.

The acute effect of exercise on $U C P 2 / 3$ expression was measured in six trained subjects. We did not find a decrease in UCP3 immediately after a bout of exercise to 
exhaustion. The expression of $V C P 2$, however, tended to decrease in response to exercise. It has been suggested that $U C P 2$ and $U C P 3$ are differently regulated $(22,27)$. Regarding the abundant expression of $U C P 2$ in adipose tissue, it is tempting to suggest that the uncoupling activity of $U C P 2$ is the result of fatty acid ion transport through the mitochondrial membrane. In support with this is our finding that $U C P 2$ was positively correlated with resting respiratory quotient and negatively with FFA concentrations. Therefore, the decrease in $U C P 2$ expression after exercise may be explained by elevated FFA concentrations.

To study the effect of endurance training on $U C P$ expression, we compared levels of $U C P 2$ and $U C P 3$ expression in trained and untrained subjects. The expression of $U C P 3 L, U C P 3 S$ and $U C P 2 \mathrm{mRNA}$ was not different between groups. However, an important metabolic adaptation to endurance training is an increase in mitochondrial content (11). We therefore expressed the mRNA levels of $U C P 2 / 3$ relative to the mitochondrial mRNA level of cytochrome-b. It has previously been shown that mitochondrial mRNAs for enzymes involved in energy metabolism are increased in direct proportion to the increase in mitochondrial content in response to training (17). When expressed relative to cytochrome-b, UCP $3 L$ and UCP $3 S$ expression was significantly lower in trained compared to untrained subjects. Furthermore, we found negative correlations between maximal performance/maximal oxygen consumption and $U C P 3 L / U C P 3 S$ expression. These results indicate that endurance training and/or physical fitness reduces the expression of UCP3 per mitochondria, leading to higher energy efficiency in trained subjects.

The negative correlations observed between $U C P 3$ and $\mathrm{W}_{\max }, \mathrm{VO}_{2 \mathrm{nax}}$ and metabolic efficiency persisted when only the untrained subjects were considered (data not shown). So even in a group of untrained subjects physical fitness can influence $U C P 3$ expression. Physical fitness is mainly a result of physical activity and even in a group of untrained subjects there is variability in physical activity. However, it has also been shown that $\mathrm{VO}_{2 \max }$ is genetically determined (3). From our cross sectional results we can not determine whether the lower UCP3 expression in trained subjects is the cause or the consequence of physical fitness. However, our results in response to exercise, as well as findings in rats (1) seem to indicate that training may induce a decrease in UCPs.

Our finding that the expression of UCP3 relative to cytochrome-b decreases with training is consistent with an increased energy efficiency in trained subjects. This is in support with the finding that gross energy efficiency increases in response to training $(7,9)$. Also, a decreased thermic effect of food in trained compared to untrained subjects has been found $(23,16)$. Furthermore, after cessation of training a rapid increase in body weight has been shown, even when food intake is not altered, indicating an increased feeding efficiency (14). Regular physical activity has been prescribed in the prevention of obesity. Apart from the increased energy expenditure related to exercise, suggestions have been made that exercise can increase resting metabolic rate. Indeed, endurance training increases resting metabolic rate by increasing fat-free mass. Whether endurance training influences resting metabolic rate 
after adjustment for body composition is still controversial $(24,16,15)$. Recently we showed a positive correlation between $U C P 3$ and resting metabolic rate, adjusted for fat-free mass and fat mass, in Pima Indians (unpublished data). Therefore we would expect training to decrease metabolic rate and not increase it. Taken together, these results do not support the hypothesis that exercise training increases resting metabolic rate after adjustment for body composition.

In conclusion, the decreased levels of $U C P 3 \mathrm{mRNA}$ in trained subjects and the inverse relationship of $U C P 3$ expression and mechanical efficiency suggest that exercise training produces an adaptive physiological response in skeletal muscle improving energy efficiency.

\section{References}

1. Boss, O., Samec, S., Desplanches, D., Mayet, M.-H., Seydoux, J., Muzzin, P., and Giacobino, J.-P. Effect of endurance training on MRNA expression of uncoupling proteins 1,2, and 3 in the rat. FASEB J. 12:335-339, 1998.

2. Boss, O., Samec, S., Paoloni-Giacobino, A., Rossier, C., Dulloo, A., Seydoux, J., Muzzin, P., and Giacobino, J.-P. Uncoupling protein-3: a new member of the mitochondrial carrier family with tissue-specific expression. FEBS lett. 408: 39-42, 1997.

3. Bouchard, C., Dionne, F. T., Simoneau, J. A., and Boulay, M. R. Genetics of aerobic and anaerobic performances. Exerc Spont Sei Rev. 20: 27-58, 1992

4. Bouchard, C., Pérusse, L., Chagnon, X. C., Warden, G., and Ricquier, D. Linkage between markers in the vicinity of the uncoupling protein 2 gene and resting metabolic rate in humans. Hum Mol Genet. 6: 1887-1889, 1997.

5. Davis, J. R., Tagliaferro, A. R., Kertzer, R., Gerardo, T., Nichols, J., and Wheeler, J. Variations in dietary-induced thermogenesis and body fatness with aerobic capacity. Eur I Appl Physiol. 50: 319-329, 1983.

6. Fleury, C., Neverova, M., Collins, S., Raimbault, S., Champigny, O., Levi-Meyrueis, C., Bouillaud, F., Seldin, M. F., Surwit, R. S. Ricquier, D. Uncoupling protein-2: a novel gene linked to obesity and hyperinsulinemia. Nature Genetics. 15:269-273, 1997.

7. Gardner, A. W., Poehlman, E. T., and Corrigan, D. L. Effect of endurance training on gross energy expenditure during exercise. Hum Biol. 61: 559-569, 1989.

8. Gimeno, R. E., Dembski, M., Weng, X., Deng, N., Shyjan, A. W., Gimeno, C. J., Iris, F, Ellis, S. J., Woolf, E. A., and Tartaglia, L. A. Cloning and characterization of an uncoupling protein homolog: a potential molecular mediator of human thermogenesis. Diabetes. 46: 900-906, 1997.

9. Gissane, C. Corrigan, D. L., and White, J. A. Gross efficiency responses to exercise conditioning in adult males of various ages. J Sports Sci. 9: 383-391, 1991.

10. Gong, D.W., He, Y., Karas, M., and Reitman, M. Uncoupling protein-3 is a mediator of thermogenesis regulated by thyroid hormone, B3-adrenergic agonists, and leptin. $J$ Biol Chem. 272: 24129-24132, 1997.

11. Holloszy, J., and Coyle, E. F. Adaptations of skeletal muscle to endurance exercise and their metabolic consequences. I Appl Physiol. 56:831-838, 1984.

12. Janson, $E$ On the significance of the respiratory exchange ratio after different diets during exercise in man. Acta Physiol Scand. $144: 103-110,1982$. 
13. Kuipers, H., Keizer, H. A. Brouns, F., and Saris, W. H. M. Carbohydrate feeding and glycogen synthesis during exercise in man. Pflugers Arch. 410: 652-656, 1987.

14. Lambert, E. V., Wooding, G., Lambert, M. 1., Koeslag, J. H. and Noakes, T. D. Enhanced adipose tissue lipoprotein lipase activity in detrained tats: independent of changes in food intake. I Appl Physiol. 77: 2564-2571, 1994.

15. Poehlman, E. T. A review: exercise and its influence on resting energy metabolism in man. Med Scl Sports Exerc. 21: 515-525, 1989.

16. Poehlman, E. T., Melby, C. L., Bradylak, S. F, and Calles, J. Resting metabolic rate and postprandial thermogenesis in highly trained and untrained males. Am J Clin Nutr. 47: 793$798,1988$.

17. Puntschart, A., Claassen, Hin., Jostandt, K., Hoppeler, H., and Billeter, R. mRNAs of enzymes involved in energy metabolism and mtDNA are increased in endurance-trained athletes. Am J Physiol. 269: C619-C625, 1995.

18. Ricquier, D., Casteilla, L., and Bouillaud, F. Molecular studies of the uncoupling protein. FASEB J. 5: 2237-2242, 1991.

19. Schulx, L. O. Nyomba, B. L., Alger, S., Anderson, T. E., and Ravussin, E. Effect of endurance training on sedentary energy expenditure measured in a respiratory chamber. Am I Physiol. 260: E257-E261, 1991.

20. Siri, W. E. The gross composition of the body. Adv Biol Med Physiol. 4: 239-280, 1956.

21. Solanes, G., Vidal-Puig, A., Grujic, D., Flier, J. S., and Lowell, B. B. The human uncoupling protein-3 gene: genomic structure, chromosomal localization, and genetic basis for short and long form transcripts. J Biol Chem. 272: 25433-25436, 1997.

22. Surwit, R. S., Wang, S., Petro, A. E., Sanchiss, D., Raimbault, S., Ricquier, D., and Collins, S. Diet-induced changes in uncoupling proteins in obesity-prone and abesity-resistant strains of mice. Proc Natl Acad Sci USA. 95: 4061-4065, 1998.

23. Tremblay, A., Fontaine, E., and Nadeau, A. Contribution of post-exercise increment in glucose storage to variations in glucose induced thermogenesis in athletes. Can J Physial Pharmacol. 63: 1165-1169, 1985.

24. Tremblay, A., Fontaine, E., Poehlman, E. T., Mitchell, D., Perron, L.., and Bouchard, C. The effect of exercise-training on resting metabolic rate in lean and obese moderately obese individuals. Int J Obesity. 10: $511-517,1986$.

25. Vidal-Puig, A., Solanes, G., Grujic, D., Flier, J. S., and Lowell, B. B. UCP3: An uncoupling prokin homologue expressed preferentially and abundantly in skeletal muscle and brown adipose tissue. Biachem Biophys Res Commun. 235: 79m82, 1997.

26. Walder, K., Norman, $\mathbb{R}$. A., Hanson, R. L., Schrauwen, P., Neverova, M., Jenkinson, C. P., Easlick, J., Warden, C. H., Pecqueur, C., Raimbault, S., Ricquier, D., Harper, M., Silver, K., Shluldiner, A.R., Solanes, G., Lowell, B. B., Chung, W. K., Leibel, R. L., Pratley, R., Ravussin, E. Association between uncoupling protein polymorphisms (UCP2-UCP3) and energy metabolism/obesity in Pima Indians. Hum Molecular Genetics. 7: 1431-1435, 1998.

27. Weigle, D. S., Selfridge, L. E., Schwartz, M. W., Seeley, R. J., Cummings, D. E., Havel, P. II", Kuijper, I. L., and BertrandelRio, H. Elevated free fatty acids induce uncoupling protein 3 expression in muscle. A potential explanation for the effect of fasting. Diabetes. 47: 298$302,1998$.

28. Westerterp, K. R., Meifer, G. A. L., Schoffelen, P., and Janssen, E. Body mass, body composition and sleeping metabolic rate before, during and after endurance training. Eur $J$ Appl Physiol. 69: 203-208, 1994. 


\section{Chapter 12}

\section{General discussion}

The increase in the prevalence of obesity has often been attributed to changes in environmental circumstances. The increase in fat intake in westernized societies and the decrease in physical activity have been mentioned as most important environmental determinants. However, recently the impact of the level of dietary fat intake on human obesity has been argued (20). The prevalence of obesity in the United States is still increasing, whereas the intake of fat is decreasing (23). This kind of thinking, however, is an oversimplification of the obesity problem. As shown in this thesis, high-fat diets do have an influence on substrate metabolism, and might lead to obesity by cumulative positive fat balances over a period of years. Therefore, nutritional advises to decrease dietary fat intake will also take years to exert its effect on the prevalence of obesity. In this thesis we show that dietary fat is not the only environmental determinant leading to obesity, decreased physical activity is another potential determinant explaining the increase in obesity. Furthermore, there are individual differences in the response of body weight and body composition to altered environmental conditions, suggesting an interaction between environmental and genetic determinants of energy and substrate metabolism. Here we will discuss the effect of high-fat diets and physical activity on substrate metabolism and its implications for obesity. Furthermore, some recently discovered genetic determinants of obesity will be discussed.

\section{High-fat diets as a determinant of energy and substrate metabolism}

The effect of high-fat diets on fat oxidation

As we have seen in the introduction, weight maintenance requires apart from energy balance also macronutrient balance $(1,2,3)$. Previous experiments have shown that the oxidation of proteins and carbohydrates is readily adjusted to their intakes, whereas this is not the case with fat $(2,40,19)$. Therefore, numerous studies examined the effects of high-fat diets on substrate oxidation. These studies can be divided in studies examining either the effect of fat supplements or the effect iso-energetic highand low-fat diets given in energy balance.

The results from studies examining the effect of a fat supplement on substrate oxidation are consistent. Fat supplements in excess of energy requirements do not stimulate fat oxidation, but are stored in the adipose tissue and fat balance is closely correlated with energy balance $(10,16,40,4,19)$. An excess carbohydrate intake, on the other hand, stimulates its own oxidation $(2,44)$. This result also shows an important condition that must be met, when iso-energetic high- and low-fat diets are compared. 
These studies can only provide valuable information, when subjects are fed in energy balance. Most studies on the effect of iso-energetic high- and low-fat diets on substrate oxidation, attempt to feed subjects in energy balance. These studies found an effect of diet composition on substrate oxidation, with respiratory quotient (RQ) shifting in the direction of food quotient (FQ) $(18,24,27,1,17,3,47)$, and several studies even suggest that the RQ is closer to FQ on high-fat diets compared to low-fat diets $(18,24,1)$. However, most studies have difficulties in achieving energy balance and the results are confounded by energy imbalance. In chapter 2 we showed that the dayto-day variance in energy expenditure in a respiration chamber, especially when the level of activity is controlled for, is limited. Thus, when energy expenditure is measured on one day, energy intake can be adjusted to energy requirements and subjects can be fed in energy balance. We used this approach to study the effect of diet composition on substrate oxidation when subjects were shifted from a low-fat diet to a high-fat diet. Subjects were in close balance between energy expenditure and energy intake and $F Q$ was equal to $R Q$ on the low-fat diet. On the high-fat diet we found that RQ shifted in the direction of $F Q$ but that only after seven days an equality of $R Q$ and $F Q$ was reached. This is in contrast with the finding that $R Q$ is closer to FQ on high-fat diets $(18,24,1)$ and illustrates the impact of energy balance on substrate oxidation.

Another confounder of studies on the effect of diet composition on substrate metabolism is the subjects' habitual diet. Although there are many studies on the effect of high- and low-fat diets on substrate metabolism, no clear definition of highand low-fat diets is available. High-fat diets vary from 40 to $80 \mathrm{en} \%$ fat, and low-fat diets vary from 3 to $25 \mathrm{en} \%$ fat. The lack of a definition can have its influence on the conclusion from these studies. It is likely that the high-fat diet had a diet composition which was more similar to the subjects' habitual diet composition, whereas a low-fat diet with $3 \mathrm{en} \%$ fat will not occur in practice. This leads to an erroneous conclusion which does not illustrate the impact of high-fat diets on substrate metabolism. Therefore, we studied subjects on their habitual diet and subsequently switched to a high-fat diet, while they were fed in energy balance (chapter 3). In this way we showed that only after 7 days on a high-fat diet, $R Q$ was equal to $F Q$. This means, that on the short term ( 1 day), high-fat diets will lead to an imbalance between fat intake and fat oxidation, resulting in positive fat balance. In practice, high-fat diets will not be consumed for several days in a row, but fat intake will show substantial day-to-day variation. Therefore, no complete adaptation of fat oxidation to a high-fat diet will occun but day-to-day fluctuations in fat intake may lead to cumulative positive fat balances, possibly resulting in obesity. Furthermore, the impact of high-fat diets on the prevalence of obesity will be even more pronounced when the elevated energy intake, observed on high-fat diets, is taken into account.

\section{The effects of high-fat diets on energy intake}

High-fat diets have a high energy density and high palatability and are therefore considered to be fattening $(28,34,22,46)$. In the Leeds high-fat study, among the consumers with a high fat content of their habitual diet ( $>45$ en $\%$ fat) there were 19 times more obese subjects than among the consumers with a low fat content of their 
habitual diet ( $<35 \mathrm{en} \%$ fat) (6). This result can be explained by a higher energy intake on diets with a high fat content. Numerous studies indeed show that voluntary energy intake is higher on a high-fat diet $(26,5,25,53)$. Furthermore, suggestions have been made that iso-energetic high-fat diets are more fattening compared to low-fat diets, i.e. independent of an effect on energy intake $(36,28)$. However, recent data clearly illustrate that the fat content of the diet only has an effect on body fat when also energy intake is increased (53). The voluntary over-consumption on diets with a high fat content can be explained by the palatability and energy density of high-fat foods. High-fat diets are often considered to be more palatable compared to low-fat diets and therefore might stimulate voluntary food consumption. Furthermore, in commercially available foods, the percentage of energy derived from fat is highly correlated with energy density $(33,55)$. Thus, when a similar volume of food is consumed, energy intake will be higher on high-fat diets compared to low-fat diets. Therefore, suggestions have been made that it is simply the energy density of the diet instead of the dietary fat content, which promotes over-consumption. Indeed, when low-fat ( $20 \mathrm{en} \%$ fat) and high-fat ( $40 \mathrm{en} \%$ fat) diets were matched for energy density and palatability, Saltzman et al. (37) found no difference in voluntary energy intake between the diets. This means that dietary advises to prevent the development of obesity should focus on a reduction of the consumption of energy-dense food items. However, although low-fat food items can also have a high energy density, in practice the fat content is the major determinant of energy density and the consumption of high-fat diets will therefore favor over-consumption, possibly leading to obesity.

Although the above discussed suggests that a high dietary fat content is a determinant which can favor the development of obesity, there are more determinants that can influence energy and substrate metabolism. One of these, physical activity, is also suggested as a major contributor to the development of obesity (38).

\section{Physical activity as a determinant of energy and substrate metabolism}

Physical activity increases daily energy expenditure, due to increased energy expended during these activities. Beyond this, physical activity might have other beneficial effect on energy metabolism. Furthermore, physical activity has been used as a tool to promote fat oxidation. Here we will discuss some effects of physical activity on energy and substrate metabolism.

According to the model of Flatt $(14,13,15)$, fat oxidation can be raised sufficiently to match fat intake on a high-fat diet, by maintaining lower glycogen levels. In our studies we found support for this aspect of Flatt's model. In chapter 3, we found that fat oxidation started to increase gradually on a high-fat diet and that a positive fat balance and negative carbohydrate balance was reached during the first days. We hypothesized that declining glycogen stores, as indicated by the negative carbohydrate balance, were responsible for the gradual increase in fat oxidation. In Chapter 4 and 5 we showed that lean and obese subjects were capable of adjusting fat oxidation to fat intake within one day, when glycogen stores were low. 
As we discussed above, obesity might result from day-to-day fluctuations in fat intake. These fluctuations are not followed by rapid changes in fat oxidation, and will thus result in cumulative positive fat balances. After lowering of the glycogen stores, however, fat oxidation could be increased rapidly and sufficiently to match fat intake on a high-fat diet. In this way, lowering of the glycogen stores might prevent the cumulative positive fat balances, associated with day-to-day fluctuations in fat intake. One way to lower the glycogen stores is by means of physical activity. Especially high intensity exercise, as we used in chapter 4 and 5 , will lead to low glycogen levels. When high-intensity exercise is performed on a regular basis, it might prevent against the development of obesity.

Several lines of evidence for a role of physical activity in the prevention of obesity exist. Training studies showed that, after a 40 weeks training program, previously untrained subjects had an increased in fat-free mass and decrease in fat mass (51). Also, physical activity is negatively correlated with body fat percentage in males (50). The positive effect of physical activity in the prevention of obesity is often ascribed to an elevation of daily energy expenditure. Apart from the elevation in energy expenditure during physical activity, suggestions have been made that physical activity also increases resting energy needs. Indeed, endurance training increases resting metabolic rate by increasing fat-free mass. Whether endurance training influences resting metabolic rate after adjustment for body composition is still controversial. Some studies have shown an increase in resting metabolic rate, adjusted for fat-free mass and fat mass, in response to training $(45,32)$, whereas others did not $(11,39,51)$. In chapter 11 we showed that UCP3 expression is decreased in trained subjects, leading to a higher energy efficiency. Furthermore, in chapter 10 we showed a positive correlation between $U C P 3$ and resting metabolic rate, adjusted for fat-free mass and fat mass, in Pima Indians. Together, these results do not support the hypothesis that exercise training increases resting metabolic rate after adjustment for body composition.

Apart from the effect of physical activity on energy and substrate metabolism, regular physical activity might have an effect on food intake preferences. Subjects with a higher spontaneous activity level consumed more carbohydrates (52), and exercise resulted in a short term reduction in hunger and energy intake (54).

Together these results suggest that regular physical activity might be an important strategy in the prevention of (diet-induced) obesity. Apart from an effect on energy intake, our results from chapter 5 suggest that high-intensity activity, leading to low glycogen stores, might be a good strategy for obese people to enhance their substrate metabolism. Furthermore, physical activity will increase fat-free mass and thus resting energy needs, and daily energy expenditure, but the positive effect of physical activity on energy metabolism is weakened by a higher energy efficiency in trained subjects. 


\section{Mechanisms behind the effect of high-fat diets on fat oxidation}

From the studies described in chapter 3 to 5 we concluded that declining glycogen stores will lead to an increase in fat oxidation. One important drawback from studies in respiration chambers is the fact that only whole-body fat oxidation can be studied and that only measurement over prolonged periods of time can be done. To achieve more insight in the mechanisms behind the increase in fat oxidation observed on a high-fat diet we used stable isotope techniques to measure the components of fat oxidation. Whole-body fat oxidation can be divided into oxidation of fat derived from plasma, intra-muscular triglycerides or VLDL-triglycerides. Using labeled fatty acids it is possible to measure the oxidation of plasma-derived free fatty acids. Until recently it was impossible to make an accurate determination of oxidation of tracers, because part of the tracer will be lost in other non-oxidative pathways. However, the use of the acetate recovery factor, as recently described (41), allows estimations of the fractional loss of label in non-oxidative pathways and thus allows estimations of tracer oxidation. In chapter 6 we determined the intra- and intersubject variation of this new correction factor and showed that the factor is time-dependent and has to be determined for every individual separately. However, when the acetate recovery factor is correctly applied, tracers provide an important tool to examine different components of whole-body fat oxidation and can be an useful extension of our knowledge established from indirect calorimetry studies.

In chapter 7 we applied the acetate recovery factor and the stable isotope techniques to examine the change in plasma free fatty acid oxidation when subjects consumed low- or high-fat diets. We observed an increase in whole-body fat oxidation, as we observed in our previous studies. This increase in fat oxidation was, at least in part, accounted for by an increase in non-plasma fatty acid oxidation. This suggests that the oxidation of VLDL-triglycerides or intramuscular triglycerides is increased. It bas previously been shown that after consumption of a high-fat diet intramuscular triglyceride concentration was elevated in healthy subjects $(21,42)$ and it can be suggested that an increased intramuscular triglyceride concentration allows an increased intramuscular triglyceride oxidation. After switching from a low-fat to a high-fat diet, intramuscular triglyceride concentration will gradually increase and this might result in the gradual increase in fat oxidation, as we observed in chapter 3 . On the other hand, lipoprotein lipase activity, the enzyme responsible for releasing fatty acids from the lipoproteins (VLDL) is increased after consumption of a high-fat diet (21), and a relation between LPL activity and whole-body fat oxidation has been shown (12). The increased LPL activity on a high-fat diet might facilitate the uptake of intramuscular triglycerides, possibly explaining the increase in intramuscular triglyceride concentration on a high-fat diet. However, part of the fatty acids released from VLDL triglycerides might also be directly oxidized in the muscle, especially in the post-absorptive state. More studies are required to establish the role of either intramuscular or VLDL triglyceride oxidation in the adaptation of fat oxidation to a high-fat intake. A role for intramuscular triglyceride concentration and oxidation in the adaptation to a high-fat diet is interesting, because a relationship between intramuscular triglyceride concentration and insulin sensitivity has been shown (31). 


\section{The influence of novel genes and its products on human obesity}

From the above results it seems reasonable to conclude that (over)consumption of high-fat diets in combination with inactivity will, eventually, lead to obesity. However, their is great intra-individual variation in the resistance to become obese when subjects are exposed to high-fat diets and an inactive lifestyle, suggesting an interaction between environmental and genetic factors.

Recently some genes were discovered, which were associated with the regulation of obesity. In 1994, the $o b$-gene, encoding for the $a b$-protein (leptin) was discovered by Zhang et al. (56). In a strain of extremely obese mice, $(o b / o b)$, leptin is absent due to a mutation in the ob-gene, and administration of leptin to these mice led to an increase in food intake and a decrease in body weight. Another strain of extremely obese mice $(d b / d b)$ have a mutation in the gene encoding for the leptin receptor and therefore leptin can not exert its effects. In humans, only in a few families, mutations in the leptin (receptor) gene have been found which resulted in extreme obesity $(29,9,43)$. This indicates that leptin plays a physiological role in the regulation of body weight, but defects in leptin expression or leptin receptor can not explain the high prevalence of human obesity.

Like with other hormones, environmental effects, such as diet and physical activity, might interact with leptin levels and leptin might be one of the many determinants of energy and substrate metabolism. Leptin is secreted by the adipose tissue and supposed to act as a satiety factor regulating food intake and fat mass. When the size of the fat mass increases, leptin levels are elevated, leading to a decrease in food intake. In this way further expansion of the fat mass is prevented. In rats, it was shown that 12 weeks of high-fat diets led to an increase in leptin levels. However, after 12 weeks, fat mass was also increased. Therefore, we studied whether in lean subjects, leptin levels play a role in the defense against obesity induced by high-fat diets. We examined the effect of iso-energetic low- and high-fat diets, thus without changes in fat mass, on leptin levels (chapter 8). We did not find an effect of isoenergetic change of diet composition on leptin concentrations, but showed a correlation between leptin levels and body fat percentage, as was shown before. This suggests that leptin does not play a role in the prevention of diet-induced obesity. Most likely, leptin should be considered as a novel hormone which in interaction with other hormones might have an effect on food intake, but leptin might play a less important role in the development of obesity as was originally thought.

How leptin expression is regulated is yet not completely understood. Fasting and energy restriction acutely decreases leptin gene expression and plasma leptin levels. This decrease in leptin expression and plasma levels during fasting can be prevented by infusion of small amounts of glucose, which prevents a decrease in glucose concentrations(7). Furthermore, glucose uptake and utilization is a determinant of leptin expression and secretion from isolated adipocytes (30). Recently, Wang et al. (49) proposed a mechanism by which the role of glucose metabolism on leptim expression can be explained. After uptake in skeletal muscle and adipocytes, glucose will be converted to glucose-6-phosphate, which can enter the glycogen synthesis or 
glycolysis pathways. However, approximately 1-3\% of glucose-6-phosphate enters the hexosamine biosynthetic pathway and the flux of glucose through this pathway regulates the expression of several genes, underwhich the leptin gene. In this way, glucose uptake might be linked to increased leptin expression. It is interesting to keep in mind that glucose uptake is rate limiting for triglyceride storage in adipose cells, which might explain an elevation in leptin levels when fat mass is expanded. However, more information is required to completely understand the regulation of leptin and its role in human obesity.

Two other recently discovered, and previously undescribed obesity genes are the UCP2 and $U C P 3$ genes, located on chromosome $11 \mathrm{q} 13$, a region which was linked to sleeping metabolic rate (8) and weakly to obesity (48) in humans. Uncoupling proteins uncouple oxygen consumption from ATP production and are thus predicted to play a role on energy metabolism. In Chapter 10 we measured UCP2 and UCP3 mRNA levels in skeletal muscle of Pima Indians. In these Pima Indians, who have a predisposition to obesity, the mRNA levels of UCP3 were positively correlated with sleeping metabolic rate, suggesting that low UCP3 levels results in a low sleeping metabolic rate. It has been shown that a low sleeping metabolic rate is a predictor of weight gain (35), and thus a low UCP3 level would result in obesity. This is consistent with the positive correlation between UCP3 and body mass index that we found. In chapter 11 we investigated the effect of endurance training on UCP2 and UCP3 mRNA levels in skeletal muscle. UCP2 and UCP3 mRNA levels were decreased in trained subjects compared to untrained subjects. Furibermore, we found a negative correlation between UCP3 and mechanical energy efficiency. This suggests that a decrease in UCP3 expression due to exercise training is one of the adaptive physiological responses in skeletal muscle improving energy efficiency. A decrease in UCP3, and an increase in energy efficiency, due to training is beneficial for endurance performance capacity, but is disadvantageous in the prevention of obesity. However, it can explain the observation that many elite athletes, after cessation of training have difficulties in maintaining body weight. These results thus indicate that UCPs might be determinants of energy metabolism in humans. However, more studies are necessary to elicit the role of UCPs in the development of human obesity.

\section{Directions for future research}

When switched from a low-fat diet to a high-fat diet, lean and obese subjects were not capable of adjusting fat oxidation to fat intake within one day, and a positive fat balance was reached. We concluded that obesity might result from such cumulative positive fat balance, due to day-to-day fluctuation in fat intake. Future research should examine the effect of fluctuations in fat intake on energy and substrate metabolism. What would have happened if we switched the high-fat diet back to a low-fat diet after one day? Is fat oxidation still increased and will a negative fat balance be reached?

One of the conclusions of this thesis is, that regular physical activity might play an important role in the development of obesity. Our results suggest that high-intensity 
exercise, leading to lower glycogen levels, will stimulate fat oxidation and might prevent positive fat balance. However, low-intensity exercise has also been prescribed in the prevention of obesity, because fat oxidation during this type of exercise is high. Future research should determine the optimum duration and intensity of physical activity in the prevention of obesity.

UCP3 is a determinant of energy metabolism. In animals, high-fat diets upregulate the expression of UCP2 and UCP3. In humans no data are available on the regulation of UCP2 or UCP3 expression. Studies should be performed to examine this regulation. Do high-fat diets have an effect on UCPs in humans?

\section{Conclusions}

1. On the short term (1-3 days) fat oxidation does not adjust to fat intake when diet composition is switched from low-fat to high-fat, under sedentary conditions.

2. Lean subjects are capable of adjusting fat oxidation to fat intake within seven days on a high-fat diet, when fed in energy balance.

3. Lowering of the glycogen stores by high-intensity exercise accelerates the adaptation of fat oxidation to fat intake on a high-fat diet.

4. Lean and obese subjects have similar capacity to rapidly adjusting fat oxidation to fat intake on a high-fat diet when glycogen stores are lowered by exhaustive exercise.

5. The acetate recovery factor to correct palmitate oxidation rates is reproducible, but has a high inter-individual variability and at rest, increases linear with isotope infusion duration. Therefore, the acetate recovery factor should be determined at similar time points as the measurement of palmitate oxidation and has to be repeated in every single individual.

6. The increase in fat oxidation after seven days on a high-fat diet is not accompanied by an increase in plasma-derived free fatty acid oxidation.

7. Regular physical activity resulting in lower glycogen stores, might be a useful tool in the prevention of obesity.

8. Leptin concentrations are not influenced by iso-energetic changes from low-fat to high-fat diets.

9. Uncoupling protein 3 might be a determinant of sleeping metabolic rate.

10. The decreased levels of UCP3 mRNA in trained subjects and the inverse relation between UCP3 mRNA and mechanical efficiency, suggests a role for UCP3 in energy efficiency. 


\section{References}

1. Abbott, W. G., Howard, B. V., Ruotolo, G., and Ravussin, E. Energy expenditure in humans: effects of dietary fat and carbohydrate. Am I Physiol. 258: E347-351, 1990.

2. Abbott, W. G. H., Howard, B. V., Christin, L., Freymond, D., Lillioja, S., Boyce, V. L., Anderson, T. E., Bogardus ${ }_{v}$ C, and Ravussin. E. Short-term energy balance: relationship with protein, carbohydrate, and fat balances. Am J Physiol. 255: E332-337, 1988.

3. Astrup, A. Buemann, B., Christensen, N. J. and Toubro, S. Failure to increase lipid. oxidation in response to increasing dietary fat content in formerly obese women. Am $J$ Physiol. 266: E592-599, 1994.

4. Bennett, C., Reed, G. W., Peters, J. C., Abumrad, N. N., Sun, M., and Hill, J. O. Short-term effects of dietary-fat ingestion on energy expenditure and nutrient balance. Am $J$ Clin Nur. 55: $1071-1077,1992$.

5. Blundell, J. E., Burley, V. J., Cotton, J. R., and Lawton, C. L. Dietary fat and the control of energy intake: evaluating the effects of fat on meal size and postmeal satiety. Am I Clin Nutr. 57: 7725-7775, 1993.

6. Blundell, J. E, and Macdiarmid, J. I. Fat as a risk factor for overconsumption: satiation, satiety, and patterns of eating. I Am Diet Assoc. 97: S63-\$69, 1997.

7. Boden, G., Chen, X., Mozzoli, M., and Ryan, 1. Effect of fasting on serum leptin in normal human subjects. $J$ Clin Endo Metab. 81: 3419-3423, 1996.

8. Bouchard, C., Pérusse, L., Chagnon, Y. C., Warden, G., and Ricquier, D. Linkage between markers in the vicinity of the uncoupling protein 2 gene and restimg metabolic rate in humans. Hum Mol Genet. 6: 1887-1889, 1997.

9. Clément, K., Vaisse C... Lahlou, N., Cabrol, S., Pelloux, V., Cassuto, D., Goumelen, M., Dina, C., Chambaz, J., Lacorte, J. M. A mutation in the human leptin receptor gene causers obesity and pituitary dysfunction. Nature. 392: 398-401, 1998.

10. Dallosso, H. M., and James, W. P. Whole-body calorimetry studies in adult men. 1. The effect of fat over-feeding on $24 \mathrm{~h}$ energy expenditure. Br $J$ Nutr. 52: 49-64, 1984.

11. Davis, J. R., Tagliaferro, A. R., Kertzer, R., Gerardo, T., Nichols, J., and Wheeler, J. Variations in dietary-induced thermogenesis and body fatness with aerobic capacity. Eur $J$ Appl Physiol. 50: $319-329,1983$.

12. Ferraro, R. T., Eckel, R. H., Larson, D. E., Fontvieille, A., Rising, R., Jensen, D. R., and Ravussin. E. Relationship between skeletal muscle lipoprotein lipase activity and 24-hour macronutrient oxidation. J Clin Invest. 92: 4411-445, 1993.

13. Flatt, J. P. Dietary fat, carbohydrate balance, and weight maintenance: effects of exercise, Am J Clin Nurr. 45:296-306, 1987.

14. Flatt, J. P. The difference in the storage capacities for carbohydrate and for fat, and its implications in the regulation of body weight. Ann N Y Acad Sci. 499: 104-23, 1987.

15. Flatt, J. P. Importance of nutrient balance in body weight regulation. Diabetes Metab Rev. 4: $571-81,1988$.

16. Flatt, J. P., Ravussin, E., Acheson, K. J, and Jequier, E. Effects of dietary fat on postprandial substrate oxidation and on carbohydrate and fat balances. J Clin Invest. 76: 1019-24, 1985.

17. Hill, J. O., Peters, J. C., Reed, G. W., Schlundt, D. G., Sharp, T., and Greene, H. L. Nutrient balance in humans: effects of diet composition. Am J Clin Nurr. 54: 10-17, 1991.

18. Hurni, M., Burnand, B., Pittet, P., and Jequier, E. Metabolic effects of a mixed and a highcarbohydrate low fat diet in man, measured over $24 \mathrm{~h}$ in a respiration chamber. Br I Nutr. 47: $33-43,1982$. 
19. Jebb, S. A., Prentice, A. M., Goldberg, G. R., Murgatroyd, P. R., Black, A. E., and Coward, W. A. Changes: in macronutrient balance during over- and underfeeding assessed by 12-d continwous whole-body callorimetry. Am J Clin Nutr: 64: 259-66, 1996.

20. Katan, M. B., Grundy, S. M., and Willet, W. C. Beyond low-fat diets. N Eng J Med. 337: $563-566,1997$.

21. Kiens, B., Essen-Gustavsson, B., Gad, P., and Lithell, H. Lipoprotein lipase activity and intramuscular triglyceride stores after long-term high-fat and high-carbohydrate diets in physically trained men. Clin Physiol. 7: 1-9, 1987.

22. Klesges, R. C. Klesges, L. M., Haddock, C. K., and Eck, L. H. A longitudinal analysis of the impact of dietary intake and physical activity on weight change in aduits. Am $J$ Clin Nutr. $55: 818-22,1992$.

23. Kuczmarski, R. J., Flegal, K. M., Campbell, S. M., and Johnson, C. L. Increasing prevalance of overweight among US adults. The National Health and Nutrition Examination Surveys, 1960 to 1991. JAMA. 272: 205-211, 1994.

24. Lean, M. E., and James, W. P. Metabolic effects of isoenergetic nutrient exchange over 24 hours in relation to obesity in women. Int $J$ Obes. 12: 15-27, 1988.

25. Lissner, L., and Heitmann, B. L. Dietary fat and obesity: evidence from epidemiology. Eur $J$ Clin Nutr. 49: 79-90, 1995.

26. Lissner, L., Levitsky, D. A., Strupp, B. J., Kalkwarf, H. J., and Roe, D. A. Dietary fat and the regulation of energy intake in human subjects. An J Clin Nutr. 46: 886-892, 1987.

27. McNeill, G., Bruce, A. C., Ralph, A., and James, W. P. Inter-individual differences in fasting nutrient oxidation and the influence of diet composition. Int $J$ Obesity. 12:455-63, 1988.

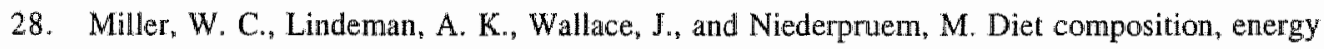
intake, and exercise in relation to body fat in men and women. Am J Clin Nutr. 52: 426-30, 1990.

29. Montague, C. T., Farooqi, I. S., Whitehead, J. P., Soos, M. A., Rau, H., Wareham, N. J., Sewter, C. P., Digby, J. E., Mohammed, S. N., Hurst, J. A. Congentinal leptin deficiency is associated with severe early-onset obesity in humans. Nature. 387: 903-908, 1997.

30. Mueller, W. M., Gregoire, F., Stanhope, K. L., Mobbs, C. V., Mizuno, T. M., Warden, C. H., Stern, J. S., and Havel, P. J. Evidence that glucose metabolism regulates leptin secretion from cultured adipocytes. Endocrinology. 139: 551-558, 1998.

31. Philips, D. I. W., Caddy, S., Ilic, V., Fielding, B. A., Frayn, K. N., Borthwick, A. C., and Taylor, R. Intramuscular triglyceride and muscle insulin sensitivity: evidence for a relationship in nondiabetic subjects. Metabolism. 45: 947-950, 1996.

32. Poehlman, E. T., Melby, C. L., Bradylak, S. F., and Calles, J. Resting metabolic rate and postprandial thermogenesis in highly trained and untrained males. Am J Clin Nutr. 47: 793798. 1988.

33. Poppitt, S. D. Energy density of diets and obesity. Int J Obesity. 19: S20-S26, 1995.

34. Prewitt, T. E., Schmeisser, D., Bowen, P. E., Aye, P., Dolecek, T. A., Langenberg, P., Cole, T., and Brace, $L$. Changes in body weight, body composition, and energy intake in women fed high- and low-fat diets. Am I Clin Nutr. 54: 304-10, 1991.

35. Ravussin, E., Lillioja, S., Knowler, W. C., Christen, L., Freymond, D., Abbott, W. G. H., Boyce, V., Howard, B. V., and Bogardus, C. Reduced rate of energy expenditure as a risk factor for body-weight gain. N Engl J Med. 318:467-472, 1988. 
36. Romieu, I., Willet, W. C., Stampfer, M. J., Colditz, G. A., Sampson, L., Rosner, B., Hennekens, C. H., and Speizer, F. E. Energy intake and other deteminants of relative weight. Am $J$ Clin Nutr. 47: 406-412, 1988.

37. Saltzman, E., Dallal, G. E., and Roberts, S. B. Effect of high-fat and low-fat diets on voluntary energy intake and substrate oxidation: studies in identical twins consuming diets matched for energy density, fiber, and palatability. Am $J$ Clin Mwtr. 66: 1332-1339, 1997.

38. Saris, W. H. M. Physical activity and body weight regulation. Regulation of body weigh: Biological and behavarial mechanisms. John Wiley \& Sons Ltd. 135-147, 1996.

39. Schulz, L. O., Nyomba, B. L., Alger, S., Anderson, T. E., and Ravassin, E. Effect of endurance training on sedentary energy expenditure measured in a respiratory chamber. Am J Physiol. 260: E257-E261, 1991.

40. Schutz, Y., Flatt, J. P., and Jequier, E. Failure of dietary fat intake to promote fat oxidation: a factor favoring the development of obesity. Am J Clin Nut. 50:307-14, 1989.

41. Sidossis, L. S., Coggan, A. R., Gastaldelli, A., and Wolfe, R. R. A new correction factor for use in tracer estimations of plasma faty acid oxidation. Am J Physiol. 269: E649-E656, 1995.

42. Starling, R. D., Trappe, T. A., Parcell, A. C., Kerr, C. G., Fink, W. J., and Costill, D. L. Effects of diet on muscle triglyceride and endurance performance. $J$ Appl Physiol. 82: 1185-1189, 1997.

43. Strobel, A., Issad, T., Camoin, L., Ozata, M., and Strosberg, A. D. A leptin missense mutation associated with hypogonadism and morbid obesity. Nature Genetics. 18: 213-215, 1998.

44. Thomas, C. D., Peters, J. C., Reed, G. W., Abumrad, N. N., Sun, M., and Hill, J. O. Nutrient balance and energy expenditure during ad libitum feeding of high-fat and highcarbohydrate diets in humans. Am J Clin Nutr. 55: 934-942, 1992.

45. Tremblay, A., Fontaine, E., Poehlman, E. T., Mitchell, D., Perron, L., and Bouchard, C. The effect of exercise-training on resting metabolic rate in lean and obese moderately obese individuals. Int J Obesity. 10: 511-517, 1986.

46. Verboeket-van de Venne, W. P. H. G., Westerterp, K. R., Hermans-Limpens, T. J. F. M. B., Griaf, C. d., Hof, K. v. h., and Weststrate, J. A. Long-term effects of consumption of full-fat or reduced-fat products in thealthy non-obese volunteers: assessment of energy expenditure and substrate oxidation. Metabolism. 45: 1004-1010, 1996.

47. Verboeket-wan de Venne, W. P. H. G., Westerterp, K. R., and ten Hoor, F. Substrate utilization in man: effects of dietary fat and carbohydrate. Metabolism. 43: 152-156, 1994.

48. Walder, K., Norman, R. A., Hanson, R. L., Schrauwen, P., Neverova, M., Jenkinson, C. P., Easlick, J., Warden, C. H., Pecqueur, C., Ratmbault, S. Association between uncoupling protein polymorphisms (UCP2 UCP3) and energy metabolism/obesity in Pima Indians. Hun Molecular Genefics. 7: 1431-1435, 1998.

49. Wang, J., Rong, L., Hawkins, M., Barziliai, N., and Rossetti L. A nutrient-sensing pathway regulates lleptin gene expression in muscle and fat. Nature. 393:684-688, 1998.

50. Westerterp, K. R., and Goran, M. I. Relationship between physical activity related energy expenditure and body composition: a gender difference. Int $J$ obesity. 21 : 184-188, 1997 .

51. Westerterp, K, R., Meijer, G. A. L., Schoffelen, P., and Janssen, E. Body mass, body composition and sleeping metabolic rate before, during and after endurance training. Eur $J$ Appl Physiol. 69: 203-208, 1994. 
52. Westerterp, K. R., Verboeket-yan de Venne, W. P. H. G., and Bouten, C. Energy expenditure and physical activity in subjects consuming full-or reduced-fat products as part of their normal diet. Brit $J$ Nutr. 76: 785-795, 1996.

53. Westerterp, K. R., Verboeket-van de Venne, W. P. H. G., Westerterp-Plantega, M. S., Velthuis-te Wierik, E. J. M., Graaf, C. d., and Weststrate, J. A. Dietary fat and body fat an intervention study. Int J Obesity. 20: 1022-1026, 1996.

54. Westerterp-Plantega, M. S., Verwegen, C. R. T., IJedema, M. J. W., Wijckmans, N. E. G., and Saris, W. H M. Acute effects of exercise or sauna on appetite in obese and nonobese men. Physiology \& Behavior. 62: 1345-1354, 1997.

55. Westerterp-Plantenga M. S., Pasman, W. J., and Wijckmans-Duijsens, N. E. G. Energy intake adaptation of food intake to extreme energy densities of food by obese and non-obese women. Eur J Clin Nutr. 50: 401-407, 1996.

56. Zhang, $Y_{.,}$Proenca, R., Maffei, M., Barone, M., Leopold, L., and Friedman, J. M. Positional cloning of the mouse obese gene and its human homoloque. Nature. 372: 425-432, 1994. 


\section{Summary}

Obesity is becoming a major health problem in affluent societies and the prevalence of obesity is still increasing. The consumption of a high-fat diet and a decreased physical activity are factors that have been considered as the most important environmental factors promoting the development of obesity. Dietary fat is the most energy dense macronutrient ( $38 \mathrm{~kJ} / \mathrm{g}$ vs $17 \mathrm{~kJ} / \mathrm{g}$ for carbohydrate and protein) and therefore the consumption of high-fat diets will easily lead to overconsumption. Furthermore, it has been shown that fat intake does not result in an immediate increase in fat oxidation and therefore the fat will be stored. In chapter 3 we showed that it took seven days before fat oxidation was raised sufficiently to match fat intake, when diet composition was iso-energetically switched from low-fat to high-fat. Subjects were fed at energy balance in a respiration chamber and fat oxidation gradually increased after the switch from low-fat to high-fat. As a result, subjects were in negative carbohydrate balance during the first days on the high-fat diet. This must have resulted in a lowering of the glycogen stores. In chapter 4 we showed that, most likely, lowering of the glycogen stores was responsible for the increased fat oxidation observed after seven days on the high-fat diet. After glycogen-lowering exercise, fat oxidation could be increased rapidly to match a high-fat intake. These results are in concordance with the two-compartment model of Flatt, which states that fat oxidation can be increased by 1) maintaining glycogen stores in a lower range, or by 2) expansion of the fat mass. In chapter 5 we showed that obese subjects had the same capacity to rapidly increase fat oxidation to match fat intake on a high-fat diet, after glycogen lowering exercise. This was unexpected, because it had been suggested that obese subjects have an impaired fat oxidation capacity. Together these results indicate that glycogen stores play a role in determining fat oxidation and suggest that physical activity, which lowers glycogen stores, might be helpfull in the handing of high-fat diets and thus in the prevention of obesity.

To achieve more insight in the mechanisms behind the effects of high-fat diets on fat oxidation, we used stable isotope techniques to measure the components of fat oxidation. Using respiration chambers only whole-body fat oxidation can be assessed, using stable isotope infusions this whole-body fat oxidation can be divided into the oxidation of plasma-derived fatty acids and non-plasma (VLDL-triglycerides, intramuscular triglycerides) fatty acids. In chapter 7 we showed, with infusion of labeled (stable) ${ }^{13} \mathrm{C}$-palmitate and measurement of ${ }^{13} \mathrm{CO}_{2}$ production, that part of the increase in whole-body fat oxidation after seven days on a high-fat diet was achieved by an increase in non-plasma fatty acid oxidation. This is interesting because the contribution of non-plasma fatty acid oxidation to total fat oxidation is still under debate and not completely understood. The main reason for the latter is that the use of ${ }^{13} \mathrm{C}$ fatty acid tracers to estimate fat oxidation has long time been questioned. Part of the label $\left({ }^{13} \mathrm{C}\right)$ is accumulated in products of the TCA cycle and does not appear in breath. Therefore, the calculation of ${ }^{13} \mathrm{C}$-palmitate oxidation will be underestimated. 
Recently it has been suggested that the accumulation of tracer in the TCA cycle can be estimated by measuring the recovery of ${ }^{13} \mathrm{CO}_{2}$ after infusion of ${ }^{13} \mathrm{C}$-acetate, which can not be stored in the body and immediately enters the TCA cycle. In chapter 6 we validated this "acetate recovery factor" and determined the inter- and intrasubject coefficient of variation. We showed that the acetate recovery factor can be used to estimate loss of tracer in the TCA cycle, but has a large intersubject coefficient of variance and thus has to be determined in each individual separately. Furthermore, we showed that the recovery factor increases with infusion time and thus has to be determined at similar time points as the measurement of ${ }^{13} \mathrm{C}$ palmitate oxidation. Failure to correct the oxidation of labeled plasma fatty acid oxidation for loss of label in the TCA cycle leads to dramatic underestimation.

Apart from environmental factors, also genetic factors play a role in the development of obesity. Some individuals are more susceptible to become obese than others. Recently some genes were discovered, which were associated with obesity. In 1994, the $o b$-gene was discovered. This gene encodes for the adipose tissue hormone, leptin, which has an effect on food intake and energy expenditure. A strain of extremely obese mice $(o b / o b)$ has a mutation in this gene and therefore does not produce leptin. Another strain of extremely obese mice $(d b / d b)$ has a mutation in the gene encoding for the leptin receptor and therefore leptin can not exert its effects. These results suggest that leptin might be an important factor in the regulation of body weight and the development of obesity. Because it is known that high-fat diets are fattening, we examined the effect of diet composition on leptin levels. In chapter 8 we showed that leptin levels were correlated with body fat percentage, as was shown before, and that acute switching from a low-fat diet to a high-fat diet had no direct effect on leptin levels in lean human subjects. However, more information is required to understand the role of leptin in human obesity.

Two other recently and previously undescribed obesity genes are UCP2 and UCP3. These genes encode for uncoupling proteins, which uncouple oxygen consumption from ATP production. In this way energy can be dissipated as heat, and thus UCPS might play an important role in the regulation of energy metabolism. In chapter 10 we showed that UCP3 mRNA expression was positively correlated with sleeping metabolic rate and negatively with BMI. This indicates that a low UCP3 mRNA expression is associated with a low SMR. Previously it had been shown that a low SMR is an important determinant of weight gain and thus UCP3 might play a role in the development of obesity. This is consistent with the negative correlation between UCP3 and BMI. In chapter 11 we compared UCP2 and UCP3 mRNA expression in trained and untrained subjects. We found that the UCP3 mRNA expression, when expressed per mitochondria, was decreased in endurance trained subjects compared to untrained subjects. Furthermore we found a negative correlation between UCP3 mRNA expression and mechanical efficiency. These results suggest that endurance training might down regulate UCP3 expression, improving energy efficiency. Taken together, the results suggest that UCPs are important determinants of energy metabolism and might play a role in the development of obesity. More studies are necessary to investigate the exact role of these UCPs in human energy metabolism. 


\section{Samenvatting}

De prevalentie van obesitas neemt de laatste jaren toe in de westerse samenleving. Obesitas onstaat doordat de energie-inname groter is dan het energiegebruik. Een lage fysieke activiteit en de consumptie van voedsel met een hoog vetgehalte zijn factoren die een positieve energie balans en daarmee ook het ontstaan van obesitas bevorderen. Van de drie macronutriënten is vet het macronutriënt met de hoogste energiedichtheid ( $38 \mathrm{~kJ} / \mathrm{g}$ vs $17 \mathrm{~kJ} / \mathrm{g}$ voor koolhydraat en eiwit) en daarom zal het consumeren van voedsel met een hoog vetgehalte gemakkelijk tot overconsumptie leiden. Bovendien heeft onderzoek aangetoond dat de inname van vet de vetverbranding niet acuut stimuleert, met als gevolg dat er vet zal worden opgeslagen. Flatt heeft de effecten van fysieke activiteit en de consumptie van voedsel met een hoog vetgehalte op de vetverbranding verklaard door middel van een twee-compartimenten model. Volgens dit model wordt het verbrandingssubstraat bepaald door de omvang van de twee belangrijkste substratvoorraden in het lichaam: de vetvoorraad en de glycogeenvoorraad. De vetverbranding kan verhoogd worden door 1) het verkleinen van de glycogeenvoorraad of 2) door het vergroten van de vetmassa. In het algemeen wordt aangenomen dat de consumptie van voedsel met een hoog vetgehalte zal leiden tot overconsumptie en dus een toename van de lichaamsvetmassa. Dit zal vervolgens leiden tot een toename van de vetverbranding, totdat de vetverbranding gelijk is aan de vetinname en er dus een nieuwe balans is ontstaan. De rol van de glycogeenvoorraad in de vetverbranding is nog weinig onderzocht. Daarom is de rol van de glycogeenvoorraad op de vetverbranding bestudeerd in de hoofdstukken $3 \mathrm{t} / \mathrm{m} 5$ van dit proefschrift. Door middel van indirecte calorimetrie werd gedurende 7 dagen de vetverbranding en koolhydraatverbranding gemeten terwijl voedsel met een hoog vetgehalte werd geconsumeerd. Gedurende deze 7 dagen werden de proefpersonen in energiebalans gevoed, zodat de lichaamsvetmassa niet veranderde. Het bleek dat de vetverbranding geleideiijk toenam en na 7 dagen gelijk was aan de vetinname. De eerste dagen waren de proefpersonen dus in een positieve vetbalans en een negatieve koolhydraatbalans, wat geleid moet hebben tot een geleidelijke afname van de glycogeenvoorraad. Volgens het twee-compartimenten model van flatt kan deze afname van de glycogeenvoorraad de toename in vetverbranding verklaren. Daarom werd vervolgens onderzocht of een inspanning-geinduceerde verlaging van de glycogeenvoorraad een snellere verhoging van de vetverbranding veroorzaakt. Na een inspanningstest, die de glycogeenvoorraad verlaagde, nam de vetverbranding binnen 24 uur toe, zowel bij mensen met als zonder obesitas. Deze resultaten onderschrijven het model van Flatt en onderstrepen de rol. van de glycogeenvoorraad bij de vetverbranding. Lichamelijke activiteit, en daarmee verlaging van de glycogeenvoorraad, lijkt dan ook een belangrijk onderdeel in de preventie en behandeling van obesitas. 
In de bovenstaande onderzoeken is de vetverbranding gemeten met indirecte calorimetrie. Hiermee kan alleen de totale vetverbranding gemeten worden. Met behulp van het intraveneus infunderen van vetzuren, waarvan het koolstofatoom gemerkt is $\left({ }^{13} \mathrm{C}\right)$, kan deze vetverbranding verder worden onderverdeeld in de verbranding van vrije vetzuren uit het plasma en uit spiertriglyceriden. Het gemerkt koolstof zal, na oxidatie, in de uitademingslucht verschijnen als ${ }^{13} \mathrm{CO}_{2}$ en is daarmee een maat voor de verbranding van plasma vetzuren. Een nadeel van deze methode is dat een deel van het gemerkte koolstof niet in de uitgeademde koolstofdioxide terecht zal komen, omdat dit in de citroenzuurcyclus wordt uitgewisseld met ongemerkt $\left({ }^{12} \mathrm{C}\right)$ koolstof. Hierdoor wordt de plasma vetzuuroxidatie onderschat. Recentelijk is voor dit probleem een oplossing gevonden: door het infunderen van ${ }^{13}$ C-acetaat kan een schatting worden gemaakt van de fractie gemerkt koolstof die in de citroenzuurcyclus uitgewisseld wordt. Omdat er geen opslagvorm voor acetaat in het licham is, moet $100 \%$ van het geïnfundeerde acetaat de citroenzuurcyclus in gaan. Het verschil tussen de hoeveelheid ${ }^{13} \mathrm{C}$ die geïnfundeerd is en de hoeveelheid die in ${ }^{13} \mathrm{CO}_{2}$ teruggevonden wordt, is een maat voor het veries van ${ }^{13} \mathrm{C}$ koolstof in de citroenzuurcyclus en kan als correctiefactor worden gebruikt bij de bepaling van de plasma vetzuuroxidatie. In hoofdstuk 6 bleek dat de correctiemethode valide is, maar een grote variabiliteit tussen individuen vertoont, waardoor de correctiefactor in elk individu opnieuw bepaald moet worden. Bovendien is de correctiefactor tijdsafhankelijk en moet dus op meerdere tijdstippen bepaald worden. In hoofdstuk 7 werd met behulp van deze correctiefactor aangetoond dat de toename in vetverbranding na 7 dagen consumeren van voedsel met een hoog vetgehalte gepaard ging met een toename van de spiervetoxidatie. Dit is een opvallende bevinding omdat verwacht werd dat bij consumptie van voedsel met een hoog vetgehalte de plasma vetzuuroxidatie toe zou nemen, door een toename van de lipolyse.

Naast gedragsfactoren, zoals fysieke activiteit en de voedselkeuze, die kunnen leiden tot het ontstaan van obesitas, spelen ook genetische factoren een rol. Sommige individuen hebben meer aanleg voor obesitas dan anderen. Recentelijk zijn er een aantal genen ontdekt die in verband worden gebracht met obesitas. In 1994 werd het ob-gen ontdekt. Dit gen codeert voor een hormoon dat gesecreteerd wordt door het vetweefsel, leptine. Leptine heeft een effect op de voedselinname en het energiegebruik. In twee rassen muizen zijn mutaties gevonden in respectievelijk het ob-gen, waardoor ze geen leptine produceren en in het gen dat codeert voor de leptine receptor, waardoor leptine zijn werking niet kan hebben. Beide muizenrassen zijn extreem obees. Deze resultaten suggereren dat leptine een belangrijke rol speelt bij de regulatie van het lichaamsgewicht en daarmee het ontstaan van obesitas. Ook in het vetweefsel van de mens wordt leptine gesecreteerd en de plasma leptine concentratie is sterk gecorreleerd met de lichaamsvetmassa. Omdat leptine een effect heeft op de voedselinname is in hoofdstuk 8 onderzocht of de consumptie van voedsel met een hoog vetgehalte een effect heeft op de plasma leptine concentratie. Het bleek dat de plasma leptine concentratie niet beïnvloed werd door de consumptie van vet voedsel, maar de relatie tussen lichaamsvetmassa en plasma leptine concentratie werd wel bevestigd. Het lijkt daarom dat leptine in de mens een minder 
eenduidige rol speelt bij de regulatie van het lichaamsgewicht dan bij de eerder genoemde muizen.

Twee andere recent ontdekte genen zijn $U C P 2$ en UCP3. Deze genen coderen voor ontkoppelingseiwitten, UCP2 en UCP3, die de zuurstofconsumptie ontkoppelen van ATP productie. Hierdoor gaat energie verloren als warmte. Deze ontkoppelingseiwitten kunnen dan ook een belangrijke rol spelen in de regulatie van het energiemetabolisme. In hoofdstuk 10 en 11 bleek dat de hoeveelheid mRNA, de voorloper van het eiwit, van met name UCP3 in de skeletspier positief gecorreleerd was met het energiegebruik tijdens slaap en negatief gecorreleerd was met de Quetelet index. Het was reeds bekend dat een laag energiegebruik tijdens slaap een factor is die gewichtstoename bevordert en dus kan UCP3 een rol spelen in het ontstaan van obesitas. Verder bleek dat de hoeveelheid mRNA voor UCP2 en UCP3 bij duurgetrainde proefpersonen lager was dan bij ongetrainde, inactieve proefpersonen. Bovendien was de hoeveelheid mRNA voor UCP3 negatief gecorreleerd met de mechanische efficiëntie van de proefpersonen. Dit toont aan dat duurtraining de hoeveelheid IRNA voor UCP3 verlaagt waardoor de energetische efficiëntie kan toenemen. Samengevat suggereren deze resultaten een belangrijke potentiële rol voor ontkoppelingseiwitten in het energiemetabolisme en het ontstaan van obesitas. 



\section{Dankwoord}

Aan het eind van het proefschrift gekomen is het de hoogste tijd om alle mensen te bedanken die op enigerlei wijze hebben bijgedragen aan het tot stand komen van dit proefschrift.

Veel dank ben ik verschuldigd aan mijn direct begeleidingsteam, Klaas Westerterp, Wim Saris en Wouter van Marken Lichtenbelt. Klaas, eerst als tweede begeleider en later, in de eindfase van mijn AIO periode als promotor, wil ik bedanken voor de vele nuttige discussies over mijn onderzoeken, waar altijd wel wat tijd voor ingeruimd kon worden. Verder ben ik je erg dankbaar voor de suggesties die je gedaan hebt om de lijn in mijn proefschrift te krijgen en richting aan mijn loopbaan te geven. Belangrijker nog is het feit dat ik het samenwerken altijd als erg prettig heb ervaren. Wim, mijn tweede promotor, wil ik bedanken voor de mogelijkheden die hij heeft geschapen om de uitvoering van het onderzoek mogelijk te maken en de interesse en het vertrouwen die hij heeft getoond in de voortgang van het onderzoek. Wouter, ik heb het erg gewaardeerd dat je altijd tijd maakte voor een bespreking van de resultaten en nieuwe ideeën. Ook de vele brainstorms, meer of minder serieus, heb ik erg gewaardeerd. En natuurlijk kijk ik met veel genoegen terug op obesitas congressen die we samen hebben bezocht.

De beoordelingscommissie, bestaande uit prof. Tjerk de Bruin, prof. David Halliday, prof. Ger van de Vusse, prof. Joep Geraerdts en prof. Jean-Pierre Flatt, wil ik bedanken voor het kritisch doorlezen van mijn proefschrift. I would like to address a special word of thanks to prof. Flatt, for being a member of my exam committee but also for your kind and helpfull comments on my papers and your interest and enthusiasm for my work.

Mijn paranimfen, Marco Mensink en Freddy Troost. Marco, vooral tijdens onze studie hebben we veel tijd doorgebracht, op en naast de fiets. Ik ben erg blij dat je nu, na je studie geneeskunde, toch weer de weg van de wetenschap lijkt op te gaan. Ik hoop van harte dat je snel weer terug naar Maastricht komt. Freddy, jou will ik bedanken voor de vele zinnige discussies over belangrijke zaken in het leven. Als iedereen zo serieus als ons zou discussiëren, zag de wereld er heel wat mooier uit. Ik ben ook nog steeds onder de indruk hoe je, in zeer korte tijd, het onderzoek beschreven in hoofdstuk 11, samen met Reinout, hebt kunnen uityoeren.

Mijn stagiaires, Carol en Mirjam, Karin en Manuela, Marjolein en Sander en Gabby ben ik veel dank verschuldigd. Zonder jullie hulp hadden de in dit proefschrift beschreven onderzoeken nooit zo snel uitgevoerd kunnen worden. Onderzoek met de respiratiekamer vereist het continue klaar staan voor je proefpersonen, waak wan 7:00 tot 22:00, wat jullie veelal veelal zelfstandig gedaan hebben, waarvoor mijn 
dank. De samenwerking is bovendien met elk van jullie erg plezierig verlopen, waardoor de zware en lange experimenten minder zwaar leken.

Speciale dank gaat ook uit naar de mensen die een aanzienlijke inhoudelijke bijdrage hebben geleverd aan het tot stand komen van dit proefschrift. Naast het al eerder genoemde begeleidingsteam, ben ik zeker dank verschuldigd aan Ton Wagenmakers. De hoofstukken 6 en 7 zijn met name door jouw inhoudelijke suggesties en enorme metabole kennis aanzienlijk in kwaliteit vooruit gegaan. Bij de totstandkoming van hoofdstuk 6 ben ik zeker ook veel hulp verschuldigd aan Dorien, met wie ik deze studie in snel tijd tot een goed eind heb kunnen brengen. Ook Ellen wil ik bedanken voor de discussie over het stabiele isotopen werk. Thanks also to Ken Walder for his help in writing the UCP review (Chapter 9) and for giving many advices during my stay in Phoenix. Clifton Bogardus and Richard Pratley are kindly acknowledged for the discussion and interpretation of the results, described in chapter 10. Hoofdstuk 11 van dit proefschrift was onmogelijk geweest zonder de voortreffelijke hulp van Freddy en Reinout.

Veel dank ben ik verschuldigd aan al het analytisch en ondersteunend personeel van de vakgroep Humane Biologie. Marianne en Frank voor het bepalen van de palmitaat-concentraties/verrijkingen, Annemie voor de bepaling van de glycerol, glucose en glutamine/glatamaat verrijkingen. Jos voor het vele derivatiseringswerk en allerlei andere bepalingen. Bovendien als kamergenoot, voor de altijd even vriendelijke en opbeurende woorden. Joan, voor de leptines, insulines en alle overige cobasbepalingen. Bovendien voor het fejt dat hij in zijn nadagen van zijn wielercarrière het nog aandurfde om met een renner in de bloei van zijn leven lange trainingsritten te maken. Paul en Loek voor de computertechnische ondersteuning en de hulp bij de respiratiekameranalyses. Paul, het feit dat ik een fervent Mac aanhanger ben, moet voor jou toch een groot compliment zijn.

Acht maanden van mijn 4-jarige AIO periode heb ik doorgebracht in de USA. Reden genoeg om hier een belangrijk deel van mijn dankwoord aan te wijden. Firstly, $\mathbb{I}$ would like to express my thanks to Eric Ravussin. Eric, I really appreciate all the time you made available for discussing results during my stay in Phoenix. I even more appreciate your way of working: very disciplined and hard, but leaving plenty of room for fun things in life. And I will never forget your comforting words, after our Lancet paper was finally rejected:"Cheer up, it is only publications". I hope we keep in touch in the near future. Secondly, James, who I can not thank enough. James, in eight months, you learned me a lot about molecular biology, and you were a great teacher. But apart from learning how to work with PCR, you learned me a lot about the Chinese philosophy and I really enjoyed it. And remember that we will meet in the year 20?? in Stockholm! Many thanks also to my roommate in Phoenix, Jean-Francois Gautier and his family, for the times we spent together during and after work, and of course for learning me some essential french words! Also many thanks to Susanne, with whom I shared my room during this period and watched Seinfeld every evening. Finally I would like to thank Rod, Ken, Arline, Sören, Richard, Chris, Bonnie and Kirm, who made my stay a pleasant one! 
In de drie en een half jaar die ik als AIO doorgebracht heb bij Humane Biologie, heb ik in totaal 4 zitkamers aangedaan. Dit levert dan ook een lijst aan kamergenoten op die ik zeker wil bedanken voor de leuke sfeer: Gerrit, Olav, Asker (heel even), Annemie, Wilrike, Stefan (soms), Luc en Jos. Als eerste kamergenoot ben ik veel dank verschuldigd aan Gerrit. Jouw kritische kijk op wetenschap hebben zeker zijn invloed gehad op mijn wetenschapsvisie. Mijn huidige kamergenoot Luc wil ik bedanken voor zijn wijze levenslessen en voor het verruimen van mijn muzikale

Lars en Matthijs van de vakgroep Bewegingswetenschappen wil ik bedanken omdat ze altijd klaar stonden om lastige of minder lastige vragen te beantwoorden en op cruciale momenten de nodige hulp boden.

Een woord van dank is er nog voor alle collega's van Humane Biologie en Bewegingswetenschappen, die de afgelopen 4 jaar voor een goede werksfeer hebben gezorgd.

Alle proefpersonen die deel hebben genomen aan de vele, lange en soms invasieve experimenten wil ik van harte bedanken voor hun vriendelijke medewerking, zonder welke dit proefschrift nooit voltooid had kunnen worden.

Tenslotte wil ik nog alle mensen in mijn prive-leven bedanken voor de interesse en steun die ik heb mogen ontvangen. Nicole, wil ik bedanken voor de steun en vertrouwen gedurende de afgelopen vijf jaar, die het mogelijk makte zo nu en dan wat meer tijd in het onderzoek te steken dan eigenlijk goed voor een relatie is. 



\section{Abbreviations}

$24 \mathrm{~h}$

ADP

AMP

ANOVA

ATP

BAT

BMI

BMR

$\mathrm{BW}$

$\mathrm{CO}_{2}$

CV

DIT

DNA

EDTA

EE

EI

en $\%$

EX

FFA

FFM

FM

$\mathrm{FQ}$

$\mathrm{GC}$

$\mathrm{HF}$

IRMS

$\mathrm{kJ}$

LF

LPL

M

MJ

mRNA

MS

NS

$\mathrm{O}_{2}$

$\mathrm{p}$

PAI

PCR

$\mathrm{Ra}$

$\mathrm{Rd}$

RF twenty-four hour

adenosine diphosphate

adenosine monophosphate

analysis of variance

adenosine triphosphate

brown adipose tissue

body mass index

basal metabolic rate

body weight

carbon dioxide

coefficient of variance

diet induced thermogenesis

deoxyribose nucleic acid

ethyleen-diamine-tetra-acetate

energy expenditure

energy intake

energy percent

exercise

free fatty acids

fat-free mass

fat mass

food quotient

gas chromatography

high-fat

isotope ratio mass spectrometry

kilojoule

low-fat

lipoprotein lipase

molair

megajoule

messenger RNA

mass spectrometry

not significant

oxygen

probability

physical activity index

polymerase chain reaction

rate of appearance

rate of disappearance

reduced-fat 
RIA

RMR

RNA

Ipm

RQ

SD

SEM

SMR

SNS

T3

TCA

TEF

TTR

UCP

$\mathrm{VCO}_{2}$

VLDL

$\mathrm{VO}_{2}$

$\mathrm{VO}_{2 \max }$

W

$W_{\max }$

WHO radio-immuno assay

resting metabolic rate

ribonucleic acid

revolutions per minute

respiratory quotient

standard deviation

standard error of the mean

sleeping metabolic rate

sympathetic nervous system

triiodothyronine

tricarboxylic acid

thermic effect of food

tracer/tracee ratio

uncoupling protein

carbon dioxide production

very low density lipoprotein

oxygen consumption

maximal oxygen consumption

watt

maximal power output

world health organisation 


\section{Curriculum vitae}

Patrick Schrauwen werd geboren op 4 april 1971 te Hoogerheide (Noord-Brabant). In 1989 behaalde hij het VWO diploma aan het Mollerlyceum te Bergen op Zoom. Aansluitend studeerde hij Gezondheidswetenschappen, met als afstudeerrichting Bewegingswetenschappen, aan de Universiteit Maastricht, te Maastricht. Van januari 1992 tot en met juni 1994 was hij als student-assistent werkzaam bij de capaciteitsgroep Anatomie \& Embryologie. In juli 1994 behaalde hij zijn doctoraal examen, na een onderzoeksstage bij de capaciteitsgroep Humane Biologie onder leiding van dr. M. van Baak. In augustus 1994 startte hij als assistent-in-opleiding (AIO) bij de capaciteitsgroep Humane Biologie van de Universiteit Maastricht onder leiding van dr. W.D. van Marken Lichtenbelt, prof. dr. ir. W.H.M. Saris en prof. dr. K.R. Westerterp. In oktober $1997 \mathrm{kreeg}$ hij een reisbeurs van de Nederlands organisatie voor Wetenschappelijk Onderzoek (NWO) voor een werkbezoek aan het National lnstitutes of Health (NIH) te Phoenix, Arizona, USA. Hier werd gedurende 7 maanden onderzoek verricht naar de genetische determinanten van obesitas en werden moleculair biologische technieken aangeleerd. Vanaf 1 augustus 1998 tot heden is hij als universitair docent werkzaam bij de capaciteitsgroep Humane Biologie te Maastricht. 



\section{List of publications}

\section{Articles}

- Schrauwen, P., van Baak, M.A. The effect of beta-adrenergic blockade on non-esterified fatry acid uptake of exercising skeletal muscle during arm cranking. Int I Sporis Med. 16: $439-444,1995$.

- Jeukendrup, A.E., Saris, W.H.M., Schrauwen, P., Brouns, F., Wagenmakers, A.J.M. Metabolic availability of medium chain triglycerides co-ingested with carbohydrates during prolonged exercise. J Appl Physiol. 79: 756-762, 1995.

- Schrauwen, P., Marken Lichtenbelt, W.D. van, Westerterp, K.R., Saris, W.H.M. The effect of diet composition on leptin concentration in lean subjects. Metabolism. 46:420-424, 1997.

- Schrauwen, P., Marken Lichtenbelt, W.D. van., Saris, W.H.M., Westerterp, K.R. The adaptation of nutrient oxidation to nutrient intake on a high-fat diet. Zeitung fir Ernahrungswissenschaft. 36: 306-309, 1997.

- Schrauwen, P., Marken Lichtenbelt, W.D. van., Saris, W.H.M., Westerterp, K.R. Changes in fat oxidation in response to a high-fat diet. Am J Clin Nutr. 66: 276-282, 1997.

- Schrauwen, P., Marken Lichtenbelt, W.D. van., Saris, W.H.M., Westerterp, K.R. Role of glycogen-lowering exercise in the change of fat oxidation in response to a high-fat diet. Am J Physial. 273: E623-E629, 1997.

- Schrauwen, P., Marken Lichtenbelt, W.D. van., Westerterp, K.R. Energy balance in th respiration chamber: individual adjustment of energy intake to energy expenditure. Int $J$ Obesiny. 21: $769-774,1997$.

Schrauwen, P., Marken Lichtenbelt, W.D. van, Saris, W.H.M., Westerterp, K.R. Aanpassing vetwerbranding aan vetinname: Rol van de glycogeenwoorrad. Woeding. 58: 28, 1997.

Schrauwen, P., Marken Lichtenbelt, W.D. wan., Saris, W.H.M., Westerterp, K. R. Fat balance in obese subjects: role of glycogen stores. Am J Physiol. 274: E1027-E1033, 1998.

Schrauwen, P., Leijssen, D.P.C., Marken Lichtenbelt, W.D. van., Baak, M.A. vain., Gijsen, A.P., Wagenmakers, A.J.M. Validation of the $[1,2-13 \mathrm{C}]$-acetate recovery factor for correction of $[\mathrm{U}-13 \mathrm{C}]$-palmitate oxidation rates. Journal of Physology. in press, 1998.

Schrauwen, P., Xia, J., Bogardus, C., Pratley, R., Ravussin, E. Skelletal muscle UCP3 expression is a determinant of energy expenditure in Pima Indians. Diabetes, in press, 1998. 
- Schrauwen, P., Troost, F.J., Xia, J., Ravussin, E., Saris, W.H.M. Skeletal muscle UCP2 and UCP3 expression in trained and untrained male subjects. Am I Physiol submitted, 1998.

- Schrauwen, P., Walder, K., Ravussin, E. Human uncoupling proteins and obesity. Obesity Research. submitted 1998.

- Walder, K., Norman, R.A., Hanson, R.L., Schrauwen, P., Neverova, M., Jenkinson, C.P., Easlick, J., Warden, C.H., Pecqueur, C., Raimbault, S., Riquier, D., Silver, M.H.K., Shuldiner, A.R., Solanes, G., Lowell, B.B., Chung, W.K., Leibel, R.L., Pratley, R., Ravussin, E. Association between uncoupling protein polymorphisms (UCP2-UCP3) and energy metabolism/obesity in Pima Indians. Hum Mol Genetics. 7: 1431-1435, 1998.

\section{Book chapters}

- Schrauwen, P., Walder, K., Ravussin, E. The role of UCPs in energy balance. In: WesterterpPlantega. M.S. Steffens, A.B., Tremblay, A. (eds). Regulation of food intake and energy expenditure. EDRA, Milan, Italy. in press, 1998.

\section{Abstracts}

- Schrauwen, L.P.A.J, Marken Lichtenbelt, W.D. van, Thimister, E.J.E.M., Westerterp, K.R. Feeding subjects at energy balance in a respiration chamber. Int $J$ Obesity. 19 (suppl 2): $\mathrm{S} 82,1995$.

- Schrauwen, P., Jeukendrup, A.E., Brouns, F., Wagenmakers, A.J.M., Saris, W.H.M. Metabolic response to carbohydrate-fat supplementation during prolonged exercise. Med Sci Sports Exerc, 27 (suppl): $\$ 213,1995$.

- Jeukendrup, A.E., Saris, W.H.M., Schrauwen, P., Brouns, F., Wagenmakers, A.J.M. Oxidation of orilly ingested medium chain triglycerides (MCT) during prolonged exercise. Med Sci Sports Exerc. 27 (suppl): S101, 1995.

- Schrauwen, P., Marken lichtenbelt, W.D. van, Saris, W.H.M., Westerterp, K.R. Adaptation to a high-fat diet. Int J Obesity. 20 (suppl 4): S81, 1996.

- Schrauwen, P., Marken Lichtenbelt, W.D. van, Saris, W.H.M., Westerterp, K.R. The effect of glycogen lowering exercise and diet composition on fat oxidation. Med Sci Sports Exerc. 29 (suppl 5): S199, 1997.

- Schrauwen, P., Marken Lichtenbelt, W.D. van, Saris, W.H.M., Westerterp, K.R. The role of glycogen in the adaptation of lat oxidation to a high-fat diet. Int J Obesity. 21 (suppl 2): S74, 1997 . 
- Saris, W.H.M., Schrauwen, L.P.A.J., van Vught, S., van Galen, M.M. The effect of exercise intensity on 24-h substrate metabolism in obese men. Int J Obesity. 21 (suppl 2): $575,1997$.

- Schrauwen, P., Troost, F.J., Xia, J., Ravussin, E., Saris, W.H.M. Effect of acute exercise and endurance training on skeletal muscle UCP2 and UCP3 mRNA expression. Int J Obesity. 22 (suppl), 1998.

- Schrauwen, P., Marken Lichtembelt, W.D. van, Saris, W.H.M., Westerterp, K.R. Increase in whole-body fat oxidation on a high-fat diet is not accompanied by an increase in plasma derived fatty acid oxidation. Int J Obesity. 22 (suppl 3): S182, 1998. 